FHWA/IN/JTRP-2008/2

Final Report

CLASSIFICATION OF ORGANIC SOILS

\author{
Pao-Tsung Huang \\ Mital Patel \\ Maria Caterina Santagata \\ Antonio Bobet
}

September 2009 
Final Report

\title{
FHWA/IN/JTRP-2008/2 CLASSIFICATION OF ORGANIC SOILS
}

\author{
by \\ Pao-Tsung Huang \\ Graduate Research Assistant \\ Mital Patel \\ Graduate Research Assistant \\ Maria Caterina Santagata \\ Assistant Professor \\ and \\ Antonio Bobet \\ Associate Professor \\ School of Civil Engineering \\ Purdue University \\ Joint Transportation Research Program \\ Project No. C-36-36TT \\ File No. 6-14-45 \\ SPR-3005

\begin{abstract}
Conducted in Cooperation with the Indiana Department of Transportation and the U.S. Department of Transportation

Federal Highway Administration
\end{abstract}

The contents of this report reflect the views of the authors who are responsible for the facts and the accuracy of the data presented herein. The contents do not necessarily reflect the official views or policies of the Indiana Department of Transportation or the Federal Highway Administration at the time of publication. This report does not constitute a standard, specification, or regulation.

School of Civil Engineering

Purdue University

September 2009 
TECHNICAL REPORT STANDARD TITLE PAGE

\begin{tabular}{|c|c|c|}
\hline $\begin{array}{l}\text { 1. Report No. } \\
\text { FHWA/IN/JTRP-2008/2 }\end{array}$ & 2. Government Accession No. & 3. Recipient's Catalog No. \\
\hline \multirow{2}{*}{\multicolumn{2}{|c|}{$\begin{array}{l}\text { 4. Title and Subtitle } \\
\text { Classification of Organic Soils }\end{array}$}} & $\begin{array}{l}\text { 5. } \quad \text { Report Date } \\
\text { September } 2009\end{array}$ \\
\hline & & 6. Performing Organization Code \\
\hline \multicolumn{2}{|c|}{$\begin{array}{l}\text { 7. Author(s) } \\
\text { Pao-Tsung Huang, Mital Patel, Maria Caterina Santagata, and Antonio Bobet }\end{array}$} & $\begin{array}{l}\text { 8. Performing Organization Report No. } \\
\text { FHWA/IN/JTRP-2008/2 }\end{array}$ \\
\hline \multicolumn{2}{|l|}{$\begin{array}{l}\text { 9. Performing Organization Name and Address } \\
\text { Joint Transportation Research Program } \\
1284 \text { Civil Engineering Building } \\
\text { Purdue University } \\
\text { West Lafayette, IN 47907-1284 }\end{array}$} & 10. Work Unit No. \\
\hline \multicolumn{2}{|l|}{$\begin{array}{l}\text { 12. Sponsoring Agency Name and Address } \\
\text { Indiana Department of Transportation } \\
\text { State Office Building } \\
100 \text { North Senate Avenue } \\
\text { Indianapolis, IN } 46204\end{array}$} & 14. Sponsoring Agency Code \\
\hline \multicolumn{3}{|l|}{ 15. Supplementary Notes } \\
\hline
\end{tabular}

\section{Abstract}

The presence of organics in soils is generally associated with high compressibility, significant secondary compression, often unsatisfactory strength characteristics, and low unit weight. As a result of the above, many state DOTs (Departments of Transportation) in the United States have strict limits on the maximum value of the organic content (2-7\%) that can be present in soils to be used as subgrades and backfills. The loss on ignition test is the most widely used technique for measuring organic content. However, especially for low organic content soils, this method can lead to significantly overestimate the true organic content. As a result, certain soils may be incorrectly classified and erroneously considered unviable for certain applications; in other cases unnecessary costly treatments may be requested, even if not required. These are the issues motivating the research presented in this report, which addressed the classification of organic soils and the quantification of organic matter in soils.

The research reviewed existing classification systems for organic soils, the effects of organic matter on the geotechnical properties of soils, and the methods for determination of organic content. In addition to the review of the existing literature, this research also included experimental work conducted on natural soils with varying organic content, as well as on laboratory prepared (“artificial”) organic soils. The experiments performed included loss on ignition tests, Atterberg limits, colorimetric tests, dry combustion tests, thermal analyses, and X-ray diffraction analyses.

The work led to propose a system for classifying organic soils which is based on the percentage of organic matter present: soils with organic content $<3 \%$ are termed mineral soils; if the organic content is $>3 \%$ and $<15 \%$, soils are classified as mineral soils with organics; when the organic content exceeds $15 \%$ but is $<30 \%$, the term organic soil is employed. Finally, soils with organic content higher than $30 \%$ are termed highly organic soils or peats. Given the potential errors associated with measuring organic content using the LOI method, this research proposes an approach based on the combined use of the LOI test, the liquid limit test conducted both before.

\author{
17. Key Words \\ Organic soils, classification, LOI, Atterberg limits, liquid limit \\ ratio, colorimetric test.
}

\section{Distribution Statement}

No restrictions. This document is available to the public through the National Technical Information Service, Springfield, VA 22161

\section{Security Classif. (of this report) Unclassified}

\author{
20. Security Classif. (of this page) \\ Unclassified
}

\begin{tabular}{|c|c|}
\hline 21. No. of Pages & 22. Price \\
180 & \\
\hline
\end{tabular}




\section{TABLE OF CONTENTS}

Page

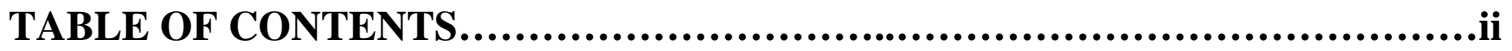

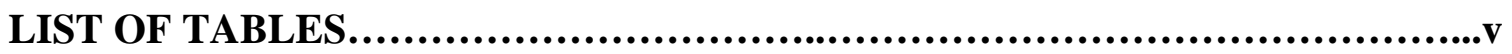

LIST OF FIGURES..........................................................vii

CHAPTER 1: INTRODUCTION..............................................1

1.1 STATEMENT OF PROBLEM.............................................

1.2 OBJECTIVES..........................................................4

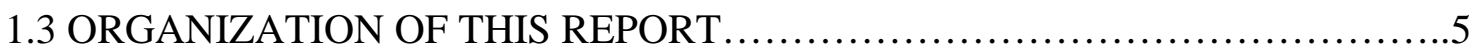

CHAPTER 2: CLASSIFICATION OF ORGANICS................................7

2.1 INTRODUCTION ..........................................................

2.2 CHARACTERISTICS OF SOIL ORGANIC MATTER...........................7

2.3 AGRICULTURAL CLASSIFICATION.................................11

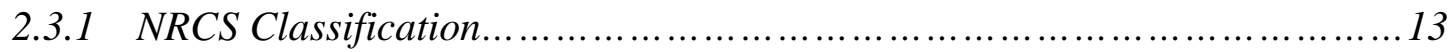

2.3.2 Canadian System of Soil Classification........................................21

2.3.3 Australian Soil Classification system......................................24

2.3.4 New Zealand Soil Classification system...................................28

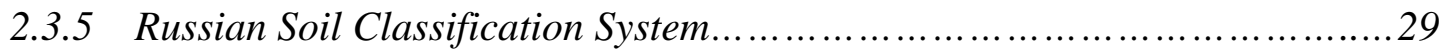

2.3.6 Danish Soil Classification System........................................33

2.3.7 The Soil Classification System in England and Wales...........................34

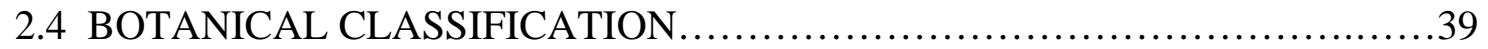

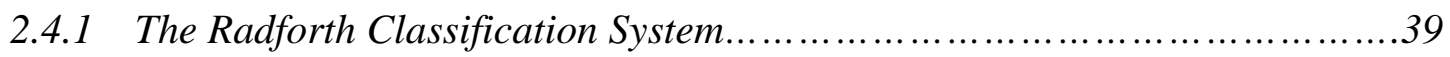

2.4.2 The Modified Von Post Classification System.................................43

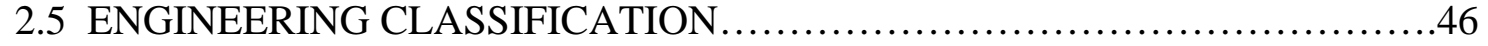

2.5.1 Engineering Classification Systems in the United States ......................46

2.5.2 Engineering Classification of the International Organization for

Standardization (ISO) ...................................................52

2.5.3 Classification by Indiana Department of Transportation (INDOT).............54

2.6 OTHER CLASSIFICATION SYSTEMS ...................................55

2.6.1 Classification Systems Reviewed by Myslinska (2003) ...........................55

2.6.2 Classification Systems Reviewed by Landva et al. (1980) .......................60 


\section{CHAPTER 3: EFFECTS OF ORGANIC MATTER ON GEOTECHNICAL}

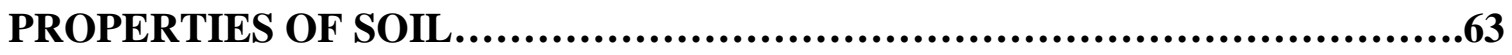

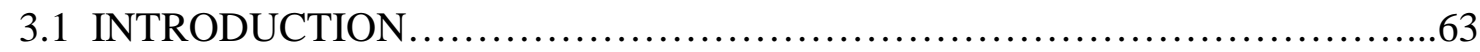

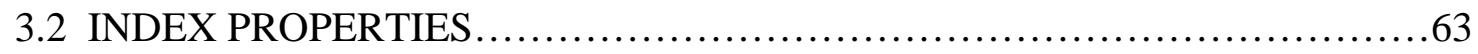

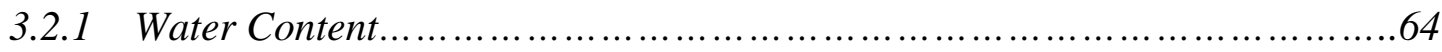

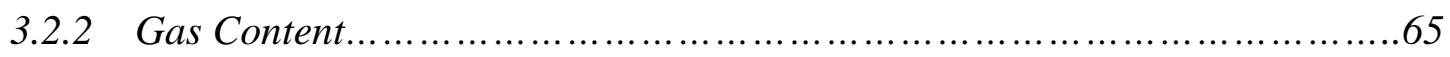

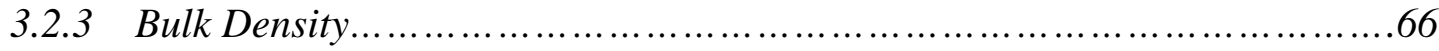

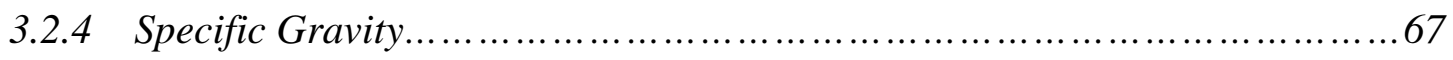

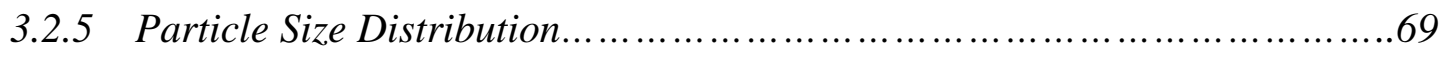

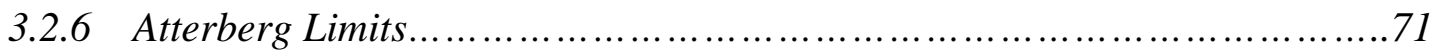

3.2.7 Shrinkage Potential..............................................................

3.2.8 Cation Exchange Capacity and Acidity ............................................74

3.3 ENGINEERING PROPERTIES..........................................75

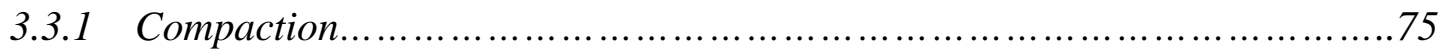

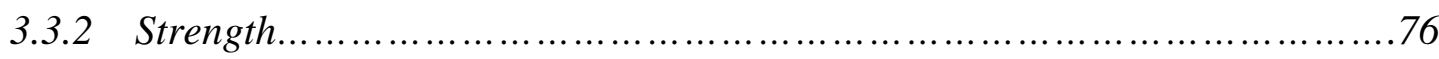

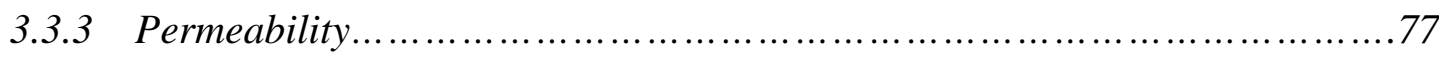

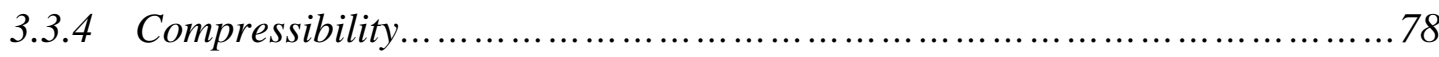

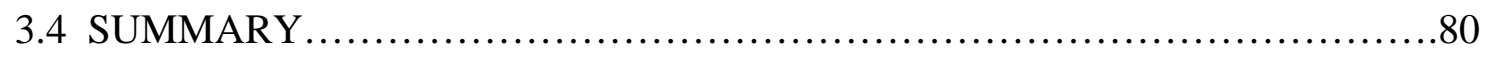

\section{CHAPTER 4: METHODS FOR DETERMINATION OF ORGANIC CONTENT.82}

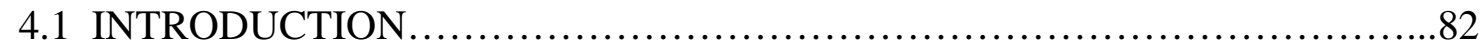

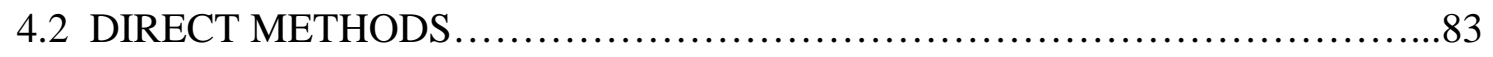

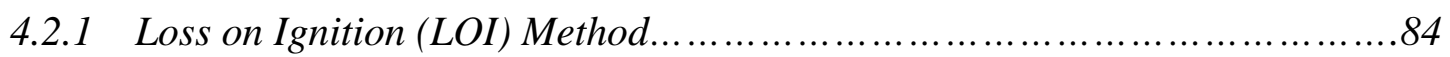

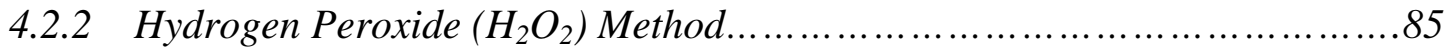

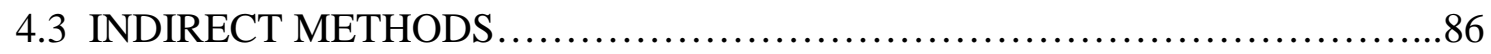

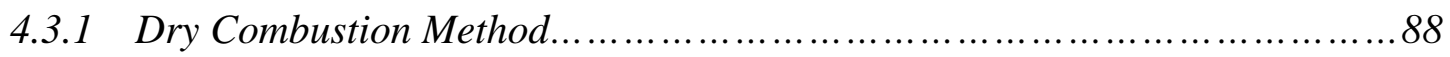

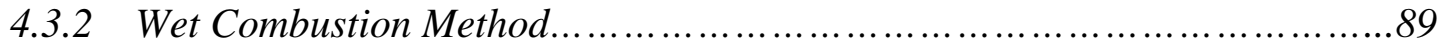

4.3.3 Dichromate Oxidation Method...................................................91

4.3.4 Methods of Removing Inorganic Carbon.........................................92

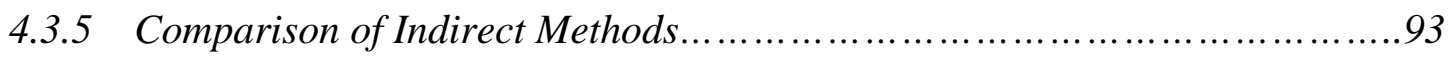

4.4 LIMITATIONS OF LOSS ON IGNITION TEST ...............................95 


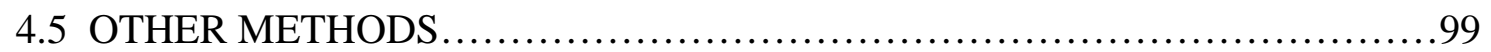

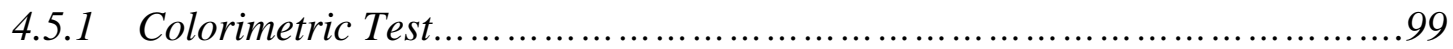

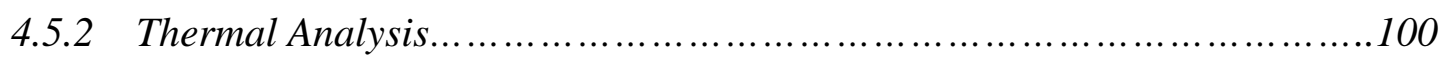

CHAPTER 5: EXPERIMENTAL WORK........................................106

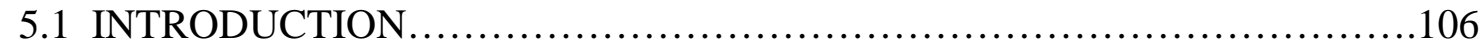

5.2 OVERVIEW OF EXPERIMENTAL WORK.....................................108

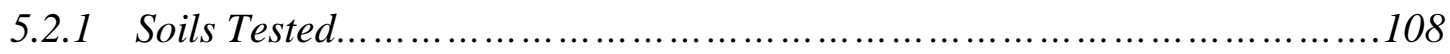

5.2.2 Test Methods and Procedures....................................................112

5.2.2.1 Loss on ignition test (LOI) ......................................................114

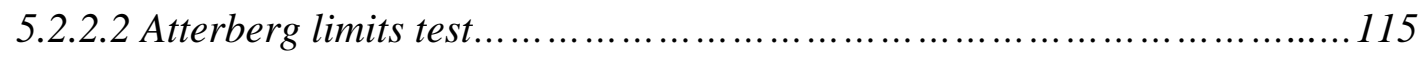

5.2.2.3 Colorimetric test.........................................................116

5.2.2.4 Dry combustion test $\left(\right.$ LECO ${ }^{\circledR}$ Analysis).......................................118

5.2.2.5 Loss of carbon dioxide test (Gravimetric method)...........................118

5.2.2.6 Thermogravimetric Analysis (TG)..........................................119

5.2.2.7 Differential scanning calorimetry (DSC)..................................119

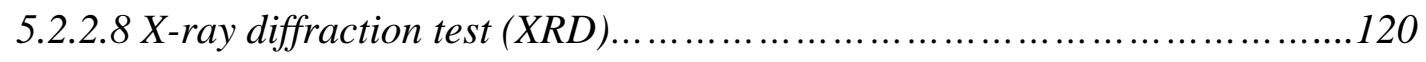

5.3 RESULTS AND DISCUSSIONS.........................................120

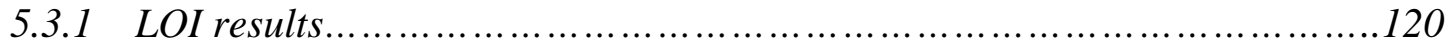

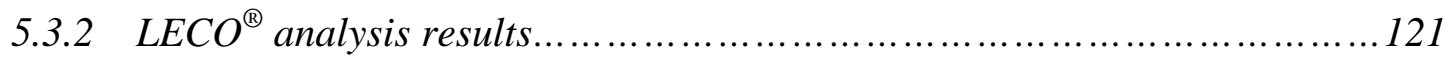

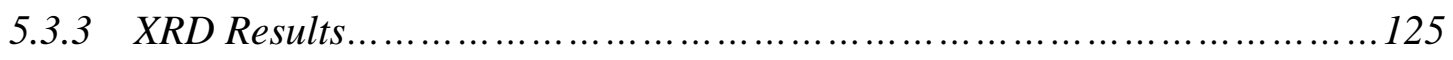

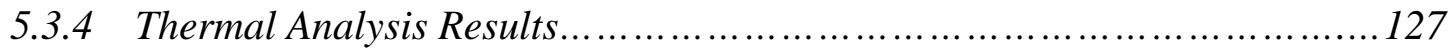

5.3.5 Atterberg Limits Results........................................................130

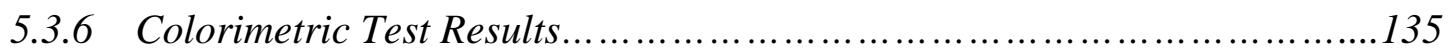

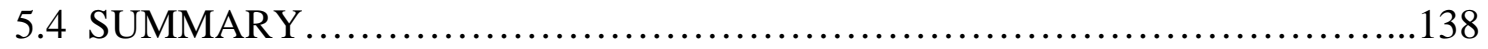

CHAPTER 6: PROPOSED CLASSIFICATION.................................140

6.1 INTRODUCTION...................................................... 140

6.2 CLASSIFICATION SYSTEM..........................................

6.3 SCREENING APPROACH.............................................147

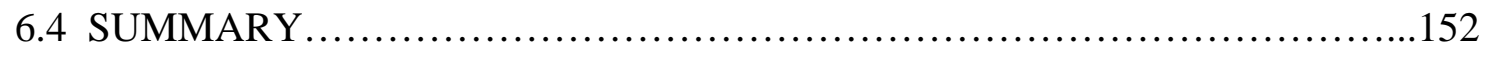

CHAPTER 7: CONCLUSIONS AND RECOMMENDATIONS ...................153

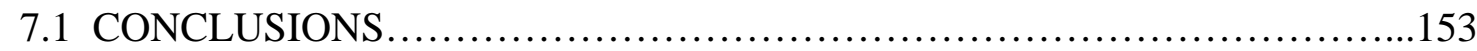




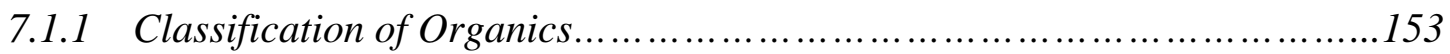

7.1.2 Effects of Organic Matter on Geotechnical Properties of Soils................154

7.1.3 Methods for Determination of Organic Matters...............................155

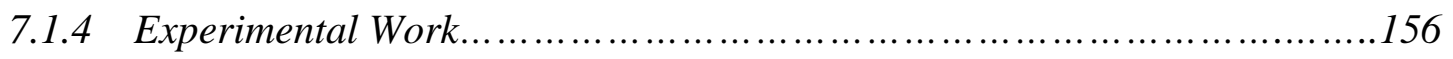

7.1.5 Proposed Classification...................................................158

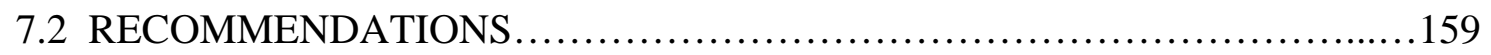

LIST OF REFERENCES................................................162

APPENDIX A: CLASSIFICATION EXAMPLES...................................A-1 


\section{LIST OF TABLES}

Page

Table 2.1: Elemental composition of humic acids extracted from soils from widely different climates (Schnitzer and Khan, 1978).........................10

Table 2.2: List of orders of New Zealand soil classification (NZSC) and their correlation with soil taxonomy (Hewitt, 2003)............................29

Table 2.3: Soil classification in Denmark (Greve and Madsen, 1999)........................33

Table 2.4: Structural typification of peat (MacFarlane, 1969).............................40

Table 2.5: Typification of peat cover (MacFarlane, 1969).............................41

Table 2.6: Engineering significance of typification of peat cover (MacFarlane, 1969)...42

Table 2.7: Explanation of symbols indicating water content of organic soil .43

Table 2.8: Explanation of symbols indicating degree of decomposition of

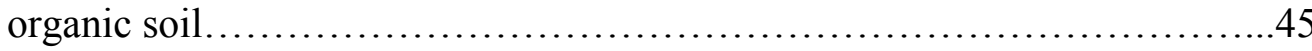

Table 2.9: Unified Soil Classification System (ASTM D2487).....................48

Table 2.10: Classification of soil (AASHTO M 145) ................................ 52

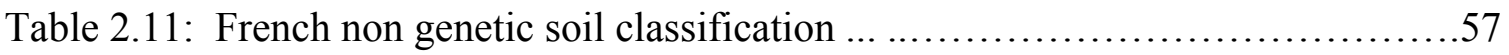

Table 2.12: Non genetic soil classification system in The Netherlands.................57

Table 3.1: Values of $\mathrm{C}_{\alpha} / \mathrm{C}_{\mathrm{c}}$ for various types of geotechnical materials (Terzaghi et al, 1996).............................................. 80

Table 3.2: Values of natural water content (wo), initial vertical hydraulic conductivity (kvo), and $\mathrm{C} \alpha / \mathrm{Cc}$ for peat deposits (Mesri et al, 1997)....................80

Table 4.1: Summary of recommended temperature and duration of LOI test............85

Table 4.2: Summary of advantages and disadvantages of indirect methods of determining organic carbon (Nelson and Sommer, 1996)...........................95

Table 4.3: Summary of relationship between soil organic matter content and loss on ignition at different temperature and duration (Nelson and Sommer, 1996)...97

Table 4.4: Results of TG analysis (Velde, 1992)................................ 103

Table 5.1: Summary of tested soils.........................................110

Table 5.2: Water and organic content of parent soils and organic source used to

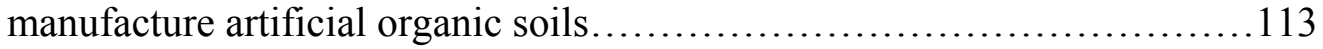

Table 5.3: Overview of testing program......................................... 114 
Table 5.4: Summary of test results of natural soils.

Table 5.5: Mineral composition of three size fractions of the organic source

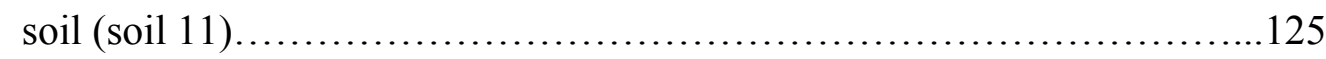

Table 5.6: Summary of test results of artificial organic soils .......................132

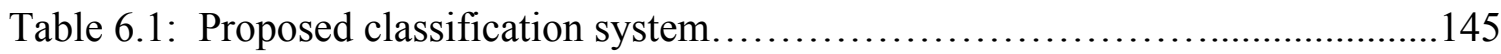

Table 6.2: Criteria of organic soil classification by INDOT (section 903.05)..........146

Table 6.3: Summary of some engineering classification systems...................146 


\section{LIST OF FIGURES}

Page

Figure 1.1: DOT's organic content threshold for subgrade or backfill..................1

Figure 2.1: Classification of soil organic matter................................

Figure 2.2: Property variations for three fractions of humic substance (Swift, 1996)....11

Figure 2.3: Soil profile showing Horizons...................................13

Figure 2.4: Classification of soil in Australia (From Australian Collaborative Land

Evaluation Program (Isbell, 2002)....................................28

Figure 2.5: Development of different approaches to soil classification in Russia

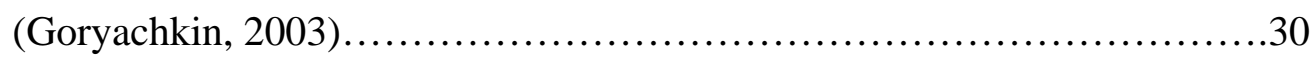

Figure 2.6: Classification of Fine Grained Soil (ASTM D2487)......................50

Figure 2.7: Classification of Organic Fine Grained Soil (ASTM D2487)..............50

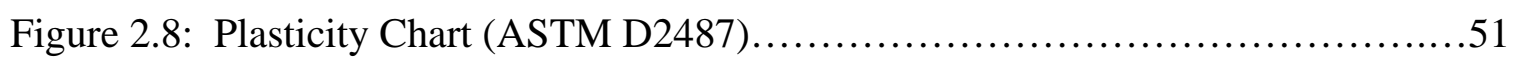

Figure 2.9: Classification of soil according to INDOT.............................54

Figure 2.10: Proposed Soil Classification System (Myslinska, 2003)..................60

Figure 2.11: Divisions used for classifying peats and organic soils

(Landva et al. 1980) ..............................................62

Figure 3.1: Relationship between ash content and water content (P.M. Jarrett (Ed.), 1983)

Figure 3.2: Dependence of total water content on the degree of peat decomposition

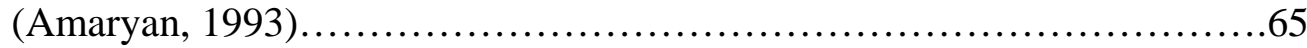

Figure 3.3: Volume of gas in a laboratory sample of peat (after Moran et al. 1958).....66

Figure 3.4: Bulk density and degree of decomposition (Radforth etal, 1996)...........67

Figure 3.5: Specific gravity and organic content (Radforth et al, 1996)...............68

Figure 3.6: Specific gravity and fiber content (Radforth et al, 1996)..................69

Figure 3.7: Particle size distribution of illitic soils with 0\% organic content (Abdallah, 1999).

Figure 3.8: Particle size distribution of illitic soils with 5.5\% organic content (Abdallah, 1999) .71

Figure 3.9: Particle size distribution of illitic soils with 29.6\% organic content (Abdallah, 1999) 
Figure 3.10: Atterberg Limits change with organic content (Abdallah, 1999)............72

Figure 3.11: The effect of bulk density on shrinkage and volume recovery on rewetting

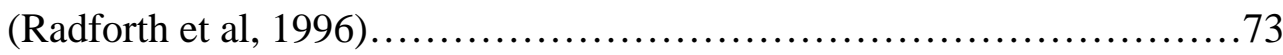

Figure 3.12: Organic content and $\mathrm{pH}$ (Radforth et al, 1996).......................74

Figure 3.13: Cation exchange capacity with organic content (Radforth et al, 1996)......75

Figure 3.14: Compaction curves for illitic soil-organic matter mixtures.

(Abdallah, 1999)..............................................

Figure 3.15: Unconfined compressive strength vs. organic content for an illitic soil (Abdallah, 1999)....................................................

Figure 3.16: Natural water content (wo) and compression index for peats as compared to those of soft clay and silt deposits (Mesri et al, 1997)....................79

Figure 4.1: Two approaches to determine the quantity of organic content in soils......83

Figure 4.2: Diagram of apparatus used to determine C by wet combustion method (Nelson and Sommers, 1996)....................................90

Figure 4.3: Relationships between soil organic matter content and loss on ignition at different temperature and duration.

Figure 4.4: Relationships between soil organic matter content and loss on ignition at $450^{\circ} \mathrm{C}$ .98

Figure 4.5: TGA curve for Halloysite (Bish and Duffy 1963)....................103

Figure 4.6: TGA curve for Gypsum heated at $2^{\circ} \mathrm{C} / \mathrm{min}$ (Bish and Duffy 1963).......104

Figure 4.7: TGA curve for Gypsum heated at $10^{\circ} \mathrm{C} / \mathrm{min}$ (Bish and Duffy 1963).......104

Figure 4.8: Simplified diagram of DTA and DSC analyzer .......................105

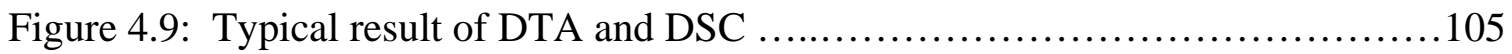

Figure 5.1: Pictures of tested soils including 21 natural soils and 3 clay minerals.....112

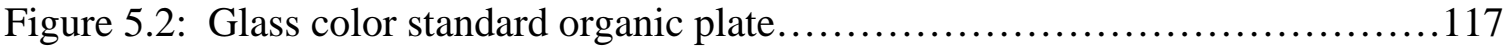

Figure 5.3: Plot of loss on ignition and organic content..........................123

Figure 5.4: XRD spectrum for soil 9......................................126

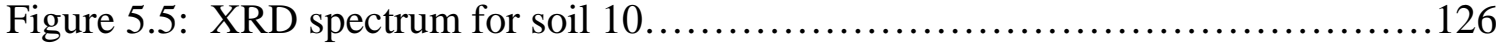

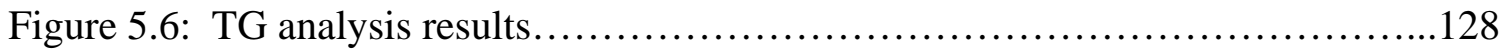

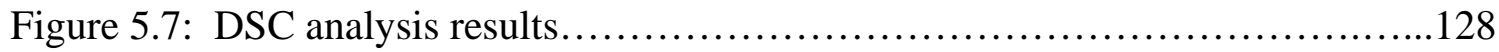

Figure 5.8: $\mathrm{TG}$ analysis results at Temperature from $120^{\circ} \mathrm{C}$ to $400^{\circ} \mathrm{C} \ldots \ldots \ldots \ldots \ldots \ldots . .129$ 
Figure 5.9: Relationship between organic content and liquid limit ratio..............133

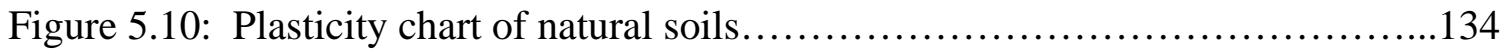

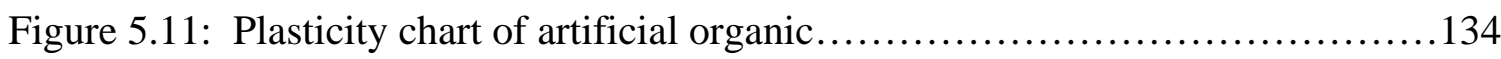

Figure 5.12: Colorimetric results for tests conducted on artificial organic soils........138

Figure 6.1: Flow chart of classification for organic soils...........................148

Figure 6.2: Screening approach for the classification of soils with organic content on the border between mineral soil and mineral soils with organic matter .....149

Figure 6.3: Approach for establishing whether a soil may be accepted in an application for which there is a maximum threshold organic content. 


\section{CHAPTER 1}

\section{Introduction}

\subsection{Statement of problem}

Organic deposits are commonly encountered in the Midwest region of the United States, including in the State of Indiana. As for other "problem" soils, the behavior of organic soils often does not follow traditional rules of soil behavior, thus posing significant challenges to the design profession. The presence of organics in soils is, in fact, generally associated with high compressibility, significant secondary compression, often unsatisfactory strength characteristics, and low unit weight. The high compressibility and creep often increase the risks of inadmissible settlements and/or foundation failure. The unsatisfactory strength characteristics associated with the low values of the maximum dry density are a main concern in road construction.

As a result of the above, the construction of foundations, embankments, excavations, and other ground works often becomes very difficult in presence of soils with organic matter. For this reason, many state DOTs (Departments of Transportation) in the United States have strict limits on the maximum value of the organic content that can be present in soils to be used as subgrades and backfills. A study performed by Chau (1999) on behalf of the Mississippi Department of Transportation indicates that 17 states in the United States and one province in Canada have specific guidelines on this matter, either requiring that the organic matter of the soil be below 2-7\% (depending on the state) or relying on the engineer's judgment in the field (Figure 1.1). The MSDOT report also indicated that most DOTs rely on either the loss on ignition (ASTM D2974) or manualvisual classification procedures (ASTM D2488) to identify organic soils. This raises two 
concerns. One is the reliability of the techniques employed to identify and classify organic soils; the other is the uncertainty and subjectivity associated with engineering judgment.

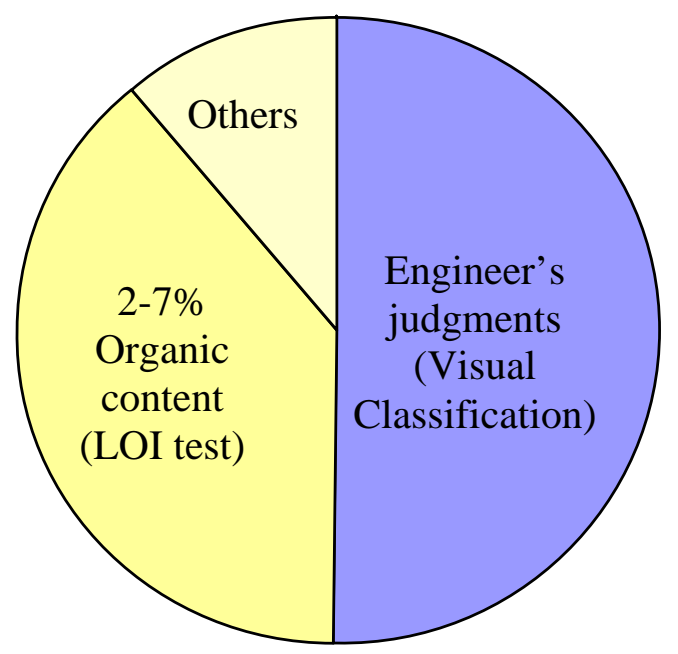

FIG. 1.1 DOT's organic content threshold for subgrade or backfill

A variety of methods are available to identify organic matter in soils. In general, these methods can be divided into two categories: qualitative assessments and quantitative measurements. In civil engineering practice, a commonly used qualitative approach to determine whether a soil can be considered organic is the use of the Atterberg limits tests. As outlined in ASTM D2487, the Unified Soil Classification System (USCS) classifies silts and clays as organic based on the difference in the liquid limit measured before and after oven drying the soil. If $L L_{\text {oven dried }} / L_{\text {non dried }}<0.75$, it is expected that the engineering properties will be affected by the organic content; thus, clays and silts in this category are termed organic (and denoted as OL or OH depending on whether the LL is smaller or greater than 50). While there is no doubt that the 
presence of organic matters markedly affects the LL (in a recent study conducted at Purdue (Zhang 2002) the addition of only 5\% of organic matter to an inorganic clay led to an increase in $L L$ from $49 \%$ to $\left.72 \%\left[L L_{\text {oven dried }} / L L_{\text {non dried }}=0.68\right]\right)$ this type of criterion in its present form does not discriminate between soils containing different amounts of organic matter.

The loss on ignition is the most common quantitative measurement of organic matter content used in engineering practice. However, potential errors associated with this technique have been pointed out by many researchers. The heating temperature and heating duration can significantly affect the results, and the presence of select inorganic constitutes (e.g. hydrated alluminosilicates, carbonate minerals) can also lead to overestimate the organic content. These errors can have significant impact in the case of soils containing low amounts of organic matter (Christensen and Malmros, 1982; Howard and Hward. 1990), leading to greatly overestimate the true organic matter content

Existing classification systems for organic soils are quite diverse and based on different purposes and criteria. Soil classification systems can be grouped in three categories: agricultural classification systems, botanical classification systems, and engineering classification systems. Agricultural classification systems give organic soils different names based on the degree of decomposition of the organic matter. The von Post classification system, one of the more commonly used botanical classification systems, uses seven parameters to group organic soils: depth of sample, peat type, degree of humification, moisture content, fiber content, presence of woody remnants and other information as pertinent and presence of charcoal and plant remnants. Another botanical classification system, Radforth's Classification system, classifies both the underlying 
organic soil ("peat structure”) and the soil cover ("peat cover”). Engineering classification systems such as the ASTM, AASHTO, ISO and Canadian system classify organic soils either by the organic content or by visual observation. A review of these classification systems indicates that there are many inconsistencies in the criteria used to classify organic soils as well as in the distinction between organic soils and peats. As a result, there is no consensus on a generally accepted classification system and classification procedures. This appears to be a very significant void that needs to be addressed.

\subsection{Objectives}

The overall scope of the research is to investigate methods for the characterization of organic soils and develop guidelines for their classification.

The specific objectives of the report are to:

- $\quad$ propose a new approach for classifying organic soils that has significance from an engineering perspective;

- develop clear and simple definitions for different types of organic soils;

- provide recommendations for simple methods for performing characterization tests on organic soils that can best capture differences in content and nature of the organic matter. 
In the research performed these objectives were pursued through:

- a state of the art review of the methods and procedures used both in the US and abroad to characterize and classify organic soils;

- an in depth characterization study using a variety of techniques of a number of organic soils sampled throughout the state of Indiana and artificial organic soils prepared in the laboratory.

\subsection{Organization of this report}

This report is organized in seven chapters. Chapter 1 provides a brief introduction of the problem investigated and summarizes the objectives of the research conducted to address it. Chapter 2 reviews existing classification systems for organic soils used in the US and abroad, explaining in some detail the criteria and philosophy of each system. The effects of organic matter on the index and engineering properties of soils are discussed in Chapter 3, while Chapter 4 addresses the methods available for determining organic matter content.

In addition to the careful review of the existing literature summarized in Chapter 2-4, this research also included experimental work. This work was conducted on natural soils with varying organic matter, as well as on laboratory prepared (“artificial”) organic soils, and included loss on ignition tests, Atterberg limits, colorimetric tests, dry combustion tests, thermal analysis, and X-ray diffraction analyses. Chapter 5 presents the experimental program and discusses the test results. The literature review and the experimental work served to draw conclusions and recommendations for the classification of organic soils from an engineering perspective. The proposed approach is 
presented in Chapter 6. Finally, Chapter 7 summarizes the conclusions of this research and provides recommendations for future work. An appendix provides examples of the application of the classification system proposed to a number of natural soils. 


\section{CHAPTER 2}

\section{Classification of Organic Soils}

\subsection{Introduction}

This chapter reviews methods used for classifying organic soils. As indicated by Cline (1949), "classifications are contrivances made by humans to suit their purposes. They are not themselves truths that can be discovered". A perfect classification would have no drawbacks when used for the purpose intended. Each distinctly different purpose, to be served best, demands a different classification. Indeed, organic soils have been classified not only by engineers but also by agronomists and botanologists.

After presenting a brief review of soil organic matter in Section 2.2, the chapter presents an overview of soil classification systems, focusing on the classification of organic soils, and highlighting the characteristics/properties of these soils which are exploited for classification purposes. Sections 2.3, 2.4 and 2.5 summarize more commonly used agricultural, botanical and engineering classification systems. Additional classification systems also presented in the literature are discussed in Section 2.6.

\subsection{Characteristics of soil organic matter}

The presence of soil organic matter, a complex mixture of organic compounds, differentiates organic soils from inorganic soils. The amount of soil organic matter significantly affects index, physico-chemical and engineering properties of soils, including specific gravity, water content, liquid limit, plastic limit, density, cation exchange capacity, hydraulic conductivity, compressibility and strength.

The Soil Science Society of America has defined soil organic matter as "the organic fraction of soil, including plant, animal, and microbial residues, fresh and at all stages of 
decomposition, and relatively resistant soil humus" (SSSA, 1979). As stated by Stevenson (1994), soil organic matter includes "the total organic material in soils, including litter, light fraction, microbial biomass, water-soluble organics, and stabilized organic matter" Given the complexity of soil organic matter, it can be normally classified into two major categories: living organic matter and non-living organic matter. Living organic matter, the minor fraction of soil organic matter, consists of soil biota such as bacteria, fungi, and algae, and fresh and un-decomposed animal or plant debris. Non-living organic matter, which is the plant or animal debris at different stages of decomposition and transformation, is the major portion of the total organic components in soils. Because of the various chemical components, non-living organic matter is usually divided into humic and non-humic substances (Hayes and Swift, 1978). Non-humic substances refer to all recognizable plant or animal debris plus all of the identifiable classes of organic compounds in their original or transformed stages. The organic compounds are amino acids (including polypeptides), carbohydrates (including monosaccharide, oligosaccharide, and polysaccharide), and lipids (including fats, waxes, resins, and so on) (Schnitzer and Kahn, 1972). Humic substances refer to "a general category of naturally occurring, biogenetic, heterogeneous organic substances that can generally be characterized as being yellow to black in color, of high molecular weight, and refractory" (Sparks, 2003). These materials cannot be identified as belonging to an established group of organic compounds. They are further classified as fulvic acid, humic acid, and humin.

Non-humic substances are easily attacked by soil micro-organisms and exist in the soil for a relatively short period of time (Schnitzer and Kahn, 1972, Sparks, 2003). Therefore, the term 'soil organic matter' is usually used as a synonym of humus. Strictly speaking, 
soil organic matter refers to only those organic materials that accompany soil particles which are smaller than 2-mm (SSSA, 1996).

Figure 2-1 summarizes the classification of soil organic matter outlined above.

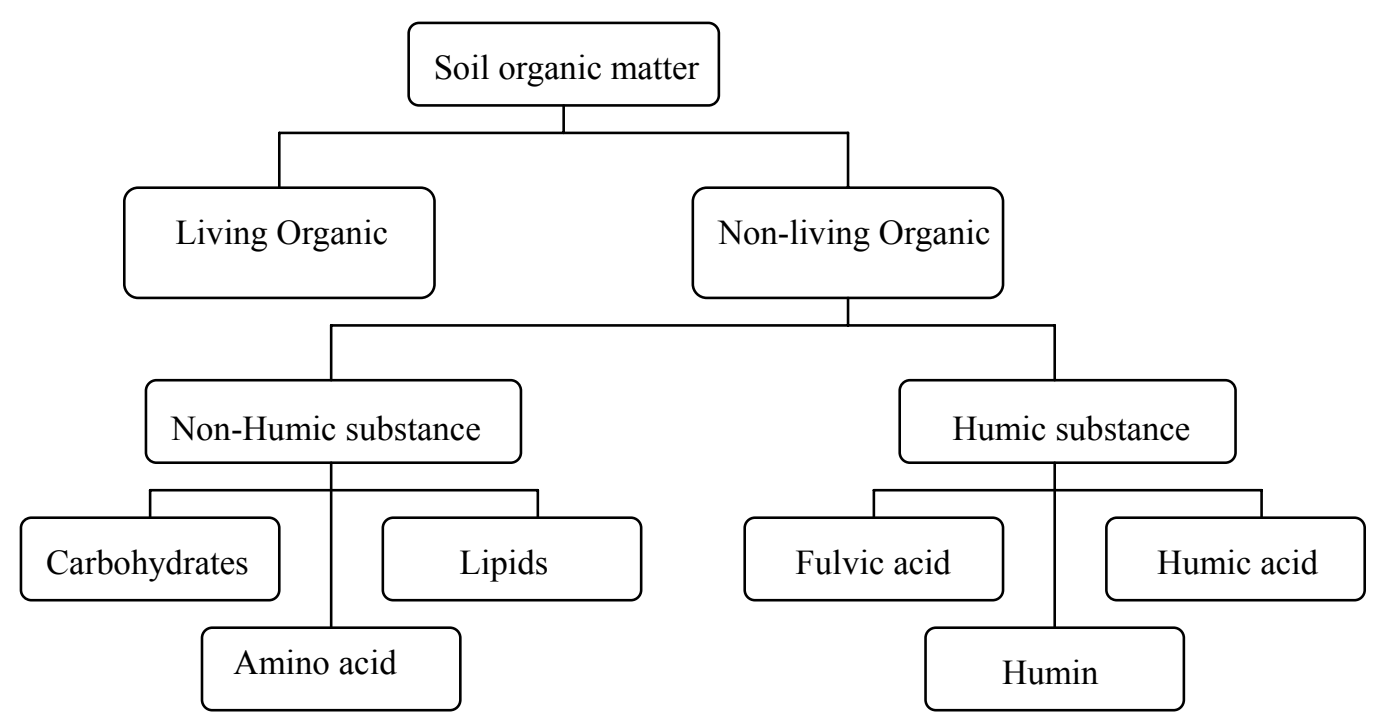

FIG 2.1- Classification of soil organic matter

Humic substances consist of fulvic acid, humic acid, and humin. Fulvic acid is the colored soil organic matter that is soluble in both alkali and dilute acid. Humic acid is the dark-colored organic matter which is only soluble in alkali. Humin is the soil organic matter fraction that is insoluble in alkali and remains after extraction of the humic and fulvic acids with dilute alkali. The distribution of these three fractions of soil organic matter varies with soil types and depth; however, the elemental compositions are very similar in these three fractions of soil organic matter. Generally, the element compositions include carbon $(\mathrm{C})$, hydrogen $(\mathrm{H})$, Nitrogen $(\mathrm{N})$, oxygen $(\mathrm{O})$, and Sulfur $(\mathrm{S})$. For humic acid, the typical rage of its elemental composition is about $54-59 \% \mathrm{C}, 3-6 \% \mathrm{H}, 1-6 \% \mathrm{~N}$, 
$33-38 \% \mathrm{O}$, and $0.1-1.5 \% \mathrm{~S}$. For fulvic acid, the typical rage of elemental composition is about $41-51 \% \mathrm{C}, 4-7 \% \mathrm{H}, 1-3 \% \mathrm{~N}, 40-50 \% \mathrm{O}$, and $0.1-3.5 \% \mathrm{~S}$. For humin, the range is very close to that of humic acid (Schnitzer and Kahn, 1978). Table 2-1 presents the range of element composition for humic acids from soils from widely different climates. Figure 2-2 shows fractions of soil humic substances and properties varying with fractions. These properties include molecular weight, carbon content, oxygen content, acidity, cation exchange capacity, nitrogen content, and resemblance to lignin.

TABLE 2.1 - Elemental composition of humic acids extracted from soils from widely different climates: $C=$ carbon, $H=$ hydrogen, $N=$ nitrogen, $S=$ sulfur, and $O=$ oxygen

\begin{tabular}{|c|c|c|c|c|c|}
\hline \multirow{2}{*}{$\begin{array}{l}\text { Element } \\
(\%)\end{array}$} & \multirow[t]{2}{*}{ Arctic } & \multicolumn{2}{|c|}{ Cool, temperate } & \multirow[t]{2}{*}{ Subtropical } & \multirow[t]{2}{*}{ Tropical } \\
\hline & & acid soils & neutral soils & & \\
\hline $\mathrm{C}$ & 56.2 & $53.8-58.7$ & $55.7-56.7$ & $53.6-55.0$ & $54.4-54.9$ \\
\hline $\mathrm{H}$ & 6.2 & $3.2-5.8$ & $4.4-5.5$ & $4.4-5.0$ & $4.8-5.6$ \\
\hline $\mathrm{N}$ & 4.3 & $0.8-2.4$ & $4.5-5.0$ & $3.3-4.6$ & $4.1-5.5$ \\
\hline $\mathrm{S}$ & 0.5 & $0.1-0.5$ & $0.6-0.9$ & $0.8-1.5$ & $0.6-0.8$ \\
\hline 0 & 32.8 & $35.4-38.3$ & $32.7-34.7$ & $34.8-36.3$ & $34.1-35.2$ \\
\hline
\end{tabular}

(Schnitzer and Khan, 1978) 


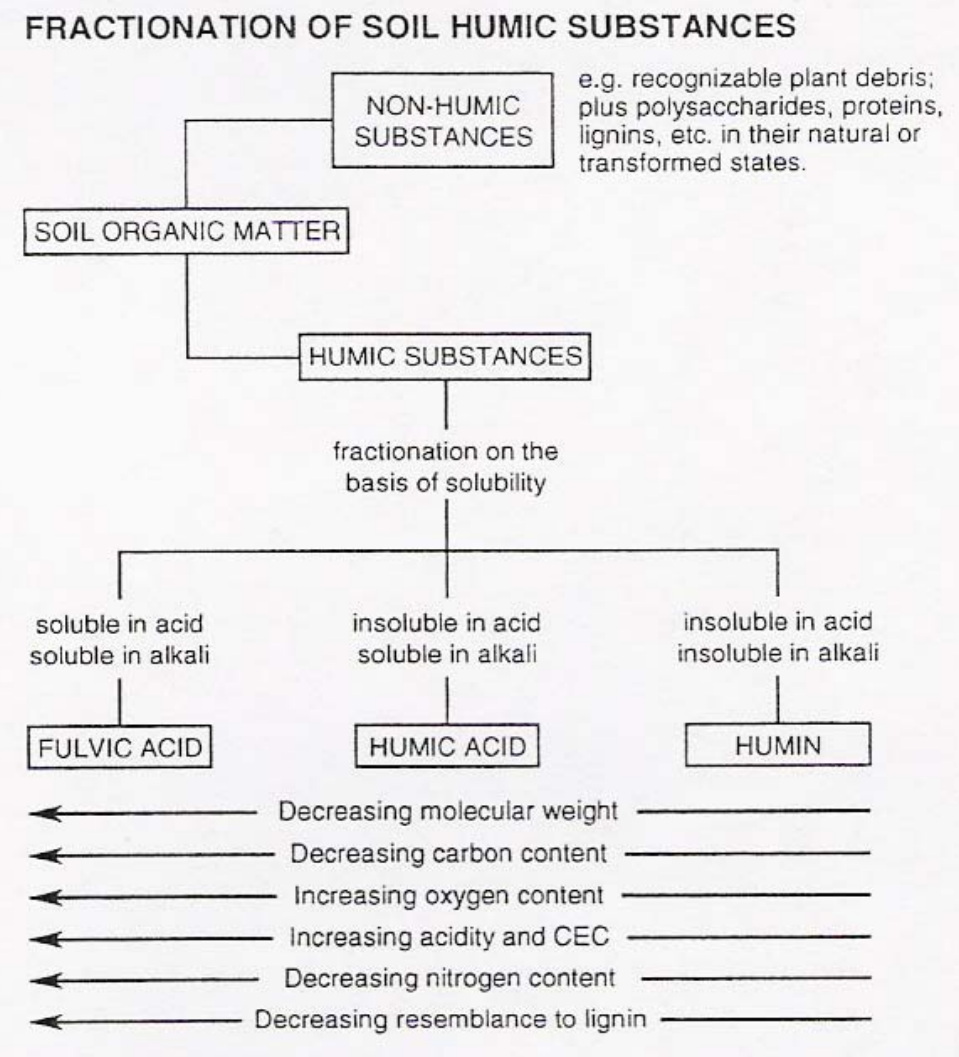

FIG 2.2 - Property variations for three fractions of humic substance (Swift, 1996)

\subsection{Agricultural Classification}

The agricultural classification of soils is based on a taxonomy which divides the soil into categories. It also considers the soil horizons while classifying the soil. Horizons are layers of soil, approximately parallel to the surface, having distinct characteristics produced by soil forming processes. These horizons are useful in classifying the soils and making interpretations regarding soil formation. Master horizons are designated with the letters $\mathrm{O}, \mathrm{A}, \mathrm{B}$ and $\mathrm{C}$. The O-horizon is an organic horizon formed from the accumulation of organic material deposited on the surface that is not saturated with water for more than few days a year and contains 35 percent or more organic matter. The H-Horizon is similar to the O-Horizon but is characteristic of a deposit which is 
saturated with water for prolonged periods and contains $30 \%$ or more organic matter if the mineral fraction contains more than $60 \%$ of clay and $20 \%$ or more organic matter if the mineral fraction contains no clay or intermediate proportions or organic matter for intermediate contents of clay. The A-Horizon is the mineral horizon formed or forming at or adjacent to the surface that either shows an accumulation of humidified organic matter intimately associated with the mineral fraction, or has a morphology acquired by soil formation but lacks the properties of the $\mathrm{E}$ and $\mathrm{B}$ horizons (see below). The B-Horizon is a mineral horizon in which the rock structure is somewhat evident. The C-Horizon is a mineral horizon of unconsolidated material from which the solum is presumed to have formed and which does not show properties typical of any other master horizon. There are other horizons, as described further. The E-Horizon is a mineral horizon showing a concentration of sand and silt fractions high in resistant minerals, resulting from a loss of silicate clay, iron or aluminum or some combination of them. The R-Horizon is a layer of continuous indurated rock. Apart from the master horizon designations, there are suffix letters which indicate the properties which can occur concurrently in the same master horizon.

Figure 2.3 depicts the various master horizons in the soil 


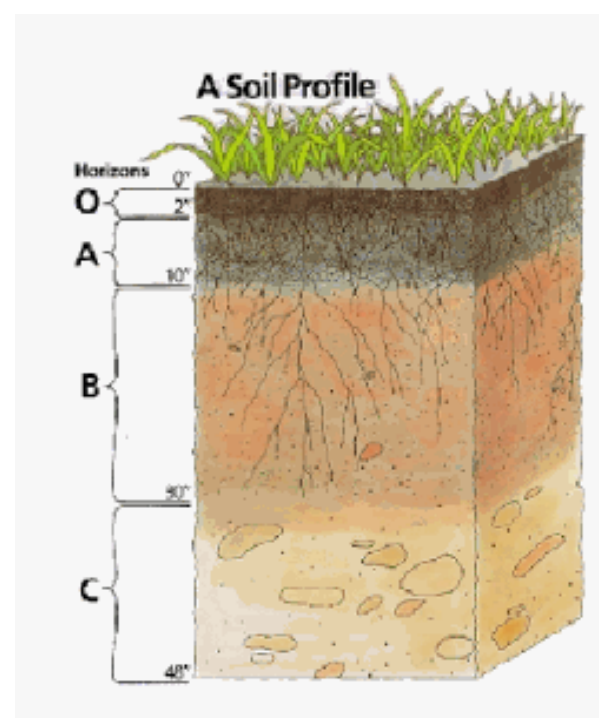

FIG 2.3 - Soil profile showing Horizons

The Natural Resources Conservation Service (NRCS) is the institute that classifies the soil agriculturally in the United States while in Canada this is done by the Canadian Soil Classification System. Apart from these, the soils in Australia, New Zealand, Russia, Denmark and England are also classified agriculturally as described below.

\subsubsection{NRCS Classification}

The NRCS soil classification (USDA $1999^{1}$ ) classifies the soil into six categories: orders, suborders, great groups, subgroups, families and series. This hierarchical scheme permits classification of soils from general to specific. "Orders are differentiated by the presence or absence of diagnostic horizons or features that reflect soil forming processes". The differentiae used in defining the suborders vary from order to order. They include properties that influence genesis and that are relevant to plant growth.

The differentiae in the great groups separate soils that have "close similarities in

\footnotetext{
${ }^{1}$ Text included in quotes is extracted from this reference
} 
kind, arrangement and degree of expression of horizons" and also have a "similar base status". Subgroups allow consideration of properties that are not used above the subgroup level as well as of certain features which, while not dominant are "still markers of important sets of processes". Note that, as stated by the USDA (1999), some of these features may be dominant in some other great group, suborder, or order.

The subgroups can be of 3 types; (a) Typic subgroups- "these are not necessarily extensive but in some taxa they simply represent the soils that do not have characteristics defined for other subgroups"; (b) Intergrades (Transitional) subgroups - these have "properties that may be a result of processes that cause one kind of soil to develop from or toward another kind of soil;" and (c) Extragrades - "these subgroups have some properties that are not representative of the great group but that do not indicate transitions to any other known kind of a soil." Going further we have families in which, the soils within the subgroup are grouped based on similarities in "physical and chemical properties that affect their responses to management and manipulation for use". The series is the lowest category of classification. "The differentiae used for series generally are the same as those used for classes in other categories, but the range permitted for one or more properties is narrower than the range permitted in a family or some other higher category."

There are 12 orders: Alfisols, Andisols, Aridosols, Entisols, Gelisols, Histosols, Inceptisols, Mollisols, Oxisols, Spondosols, Ultisols and Vertisols. They are divided into 64 suborders which are further divided into more than 300 great 
groups. The great groups are divided in to more than 2400 subgroups, which are further divided into families, which further are separated into more than 19000 recognized series. At the level of each category the heterogeneity reduces and the soil becomes clearly identifiable. Of the 12 orders, Histosols are characterized by the presence of organic matter and are most relevant to the work presented in this report. Hence they are discussed in some detail below.

Prior to discussing histosols it is useful to review (a) how the US soil taxonomy (USDA 1999) differentiates between mineral soil material and organic soil material. With regard to this point Chapter 3 of USDA (1999) provides the following definitions for mineral and organic soil material:

"Mineral soil material (less than $2.0 \mathrm{~mm}$ in diameter) either:

1. Is saturated with water for less than 30 days (cumulative) per year in normal years and contains less than 20 percent (by weight) organic carbon; or

2. Is saturated with water for 30 days or more cumulative in normal years (or is artificially drained) and, excluding live roots, has an organic carbon content (by weight) of:

a. Less than 18 percent if the mineral fraction contains 60 percent or more clay; or

b. Less than 12 percent if the mineral fraction contains no clay; or

c. Less than $12+$ (clay percentage multiplied by 0.1 ) percent if the mineral fraction contains less than 60 percent clay."

In contrast, "Soil material that contains more than the amounts of organic carbon described above for mineral soil material is considered organic soil material." In this chapter of USDA (1999) it is also stated that "nearly all soils contain more 
than traces of both mineral and organic components in some horizons, but most soils are dominantly one or the other" and it is suggested that "the horizons that are less than about 20 to 35 percent organic matter, by weight, have properties that are more nearly those of mineral than of organic soils.

\section{Histosols}

According to USDA's general rule a soil without permafrost can be classified as a Histosol "if half or more of the upper $80 \mathrm{~cm}$ is organic". Additionally, a soil also classified as a Histosol "if the organic material rests on the rock or fills voids in fragmental, cindery, or pumiceous materials. If the bulk density of the soil is less than 0.1 , then three fourths or more of the upper $80 \mathrm{~cm}$ of that soil must be organic". The NRCS soil taxonomy also states that Histosols must "not have Andic soil properties ${ }^{2}$ in 60 percent or more of the thickness between the soil surface and either a depth of $60 \mathrm{~cm}$ or a densic, lithic, or paralithic contact" which means a contact between the soil and a densic material ${ }^{3}$, lithic material ${ }^{4}$ or a paralithic material ${ }^{5}$. Finally, certain requirements on the organic material are set.

Histosols are further divided in to 4 suborders depending on presence of water, presence of mineral layer and the presence of horizons. These suborders are: Folists, which are the Histosols that are saturated with water for less than 30

\footnotetext{
2 Andic Soil Properties- the Andic Soils have a dominance of short-range-order minerals or Al-humus complexes that result from weathering and mineral transform with a minimum of translocation.

${ }^{3}$ Densic Material- This is a relatively unaltered material that has a non-cemented rupture resistance class.

${ }^{4}$ Lithic Material- This consists of a rock or a stone material.

${ }^{5}$ Paralithic Material- It is similar to Lithic Material except that it is softer.
} 
cumulative days during normal years and not drained artificially; Fibrists, which consist of slightly decomposed organic materials and are artificially drained at times; Saprists, which are wet Histosols with highly decomposed organic materials; and Hemists, which are Histosols with moderately decomposed organic materials.

\section{Folists:}

According to the NRCS classification (USDA 1999), these are "mostly freely drained Histosols that consist primarily of O-Horizons derived from leaf litter, twigs and branches resting on the rock or on fragmental materials such as gravel, stones, and boulders in which the interstices are filled or partly filled with organic material". Folist soils are saturated with water for less than 30 cumulative days during normal years and are not artificially drained. Folists are common in humid climates and high elevations. In the US most of the Folists are found in Hawaii and Alaska, although they can also be found in the western part of the US, in the northern Lake states and in the Northeast.

The Folist suborder is further divided in to 4 great groups namely Cryofolists, Torrifolists, Ustifolists and Udifolists. This division is based on the type of temperature and moisture regime in the soil: folists with a cryic ${ }^{6}$ temperature regime are cryofolists; the ones with a torric ${ }^{7}$ (or aridic) moisture regime are the torrifolists; the ustifolists are the ones with an ustic or xeric soil moisture regime and the remaining folists are classified as udifolists. Folists are futher divided into

\footnotetext{
${ }^{6}$ Cryic Temperature Regime - Soils with annual temperature greater than 0 deg and less than 8 degrees.

${ }^{7}$ Torric Moisture Regime - Dry regime
} 
8 subgroups namely Lithic Cryofolists, Typic Cryofolists, Lithic Torrifolists, Typic Torrifolists, Lithic Ustifolists, Typic Ustifolists, Lithic Udifolists and Typic Udifolists. This distinction is based on the presence (Lithic) or not (Typic) of a lithic contact within $50 \mathrm{~cm}$ of the surface.

\section{Fibrists:}

According to the NRCS classification, these are wet Histosols, saturated with water for 30 or more cumulative days (or artificially drained) with very slight decomposition of the organic material so that the botanic origin of the materials can be readily determined.. Under tactile observations, more than $3 / 4$ of then soil consist of fibers that remain after rubbing between the thumb and the finger. Fibrists have a bulk density $<0.1 \mathrm{~g} / \mathrm{cc}$ and most of the time the water level is near the surface. The NRCS classification also states that Fibrists lack a sulphuric horizon within the top $50 \mathrm{~cm}$ and do not have sulphidic materials ${ }^{8}$ within $100 \mathrm{~cm}$ of the soil surface. Fibrists occur from the Equator to latitudes with a cryic temperature regime, in particular in large flat areas such as coastal plains.

Fibrists are further divided in to three great groups: Cryofibrists, Haplofibrists and, Sphagnofibrists, based on temperature regime. Cryofibrists, which are fibrists which have a cryic soil temperature regime, are divided in to six sub groups: Hydric which have a water layer below the surface tier; Lithic, which have a lithic section within the section; Terric, which have a mineral layer with thickness $30 \mathrm{~cm}$ or more within the control section, below the surface tier; Fluvaquentic, which

\footnotetext{
${ }^{8}$ Sulfidic Material - Materials which contain oxidizable sulfur compounds.
} 
have mineral layers within organic materials; Sphagnic, which have $3 / 4$ th fiber volume due to presence of sphagnum; and Typic, which include all other Cryofibrists.

Haplofibrists are the fibrists which have a soil temperature warmer than the cryic and have less than $3 / 4^{\text {th }}$ fiber volume due to sphagnum. They are divided into seven sub groups: five already outlined above (Hydric, Lithic, Terric, Fluvaquentic and Typic) and two additional sub groups: Limnic Haplofibrists, which have one or more limnic ${ }^{9}$ layers within the control section and Hemic Haplofibrists, which have one or more layers of hemic or sapric materials.

Finally, Sphagnofibrists are fibrists derived mainly from the various species of Sphagnum ( $>34^{\text {th }}$ of their fiber volume must come from Sphagnum). Most of these soils have a frigid temperature regime. As in the case of Haplofibrists, Sphagnofibrists are further divided into: Hydric, Lithic, Limnic, Terric, Fluvaquentic, Hemic and Typic.

\section{Hemists:}

Hemists are wet Histosols in which the organic material is moderately decomposed so that its botanic origin cannot be easily determimed. These soils are characterized by: fiber content of the organic material between $1 / 6$ to $2 / 3$; bulk density between $0.1 \mathrm{~g} / \mathrm{cc}$ to $0.2 \mathrm{~g} / \mathrm{cc}$; and a very high ground water level (except in the case of artificial drainage). They occur from the Equator to latitudes with a cryic temperature regime. Hemists are divided in to five great groups: Sulfohemists, which have a sulfuric horizon in the upper $50 \mathrm{~cm}$ of the soil;

\footnotetext{
${ }^{9}$ Limnic Material - Material related to lakes and ponds.
} 
Sulfihemists, which have sulfidic materials in the upper $100 \mathrm{~cm}$ of the soil surface; Luvihemists, which have a horizon which has humilluvic ${ }^{10}$ material which constitutes a volume of one-half or more; Cryohemists, which are characterized by a cryic temperature regime; and Haplohemists, which include all other Hemists. These great groups are all further divided into subgroups.

\section{Saprists:}

Saprists are wet Histosols in which the organic material is well decomposed, so that its origin is difficult to determine. For saprists the fiber content is $<1 / 6$ after rubbing, and the bulk density is greater than $0.2 \mathrm{~g} / \mathrm{cc}$. These soils typically occur in areas where the ground water table fluctuates within the soils, or in areas where the soils have undergone periods of aerobic conditions. When drained, fibric and hemic materials typically decompose under eaerobic conditions to form sapric materials.

Saprists are further classified in to four great groups: Sulfosaprists, having a sulfuric horizon within $50 \mathrm{~cm}$ of the surface; Sulfisaprists, having sulfidic materials within $100 \mathrm{~cm}$ of the surface; Cryosaprists, having a cryic temperature regime and Haplosaprists, which include Saprists that do not fall in the above great groups..

In summary, the NCRS classifies the soil into 12 orders, of which Histosols

\footnotetext{
${ }^{10}$ Humilluvic Material - Illuvial humus that accumulates after prolonged cultivation of some acid organic soils.
} 
represent the soils characterized by the presence of organic matter. Histosols are further classified into four suborders: Folists, Fibrists, Hemists and Saprists based on the degree of decomposition (increasing going from Folists to Saprists). These suborders are further classified into great groups, subgroups, families and series..

\subsubsection{Canadian System of Soil Classification}

The Canadian System of Soil Classification (Soil Classification Working Group 1998) differentiates soil types on the basis of measured properties of the soil profile and uses a hierarchical scheme to classify soils based largely on geological material and texture. The major categories in this system are: orders, great groups, subgroups, families, and series. These categories are defined in a manner similar to that employed in the US soil classification system. However unlike the US soil Classification system, the Canadian soil classification system does not include suborders. At its most general level, the Canadian System recognizes nine different soil orders based on the horizons present in the soil. These horizons are of two kinds: (a) Mineral Horizons containing 17\% or less organic carbon by weight (corresponding to about $30 \%$ organic matter) and (b) Organic Horizons-containing more than $17 \%$ organic carbon by weight. According to the Canadian Soil Classification System the horizons A, B, C, R and W are Mineral Horizons. Horizon A is a mineral horizon that "forms at or near the surface in the zone of leaching or eluviation of materials in solution or suspension, or of maximum in situ accumulation of organic matter or both. The accumulated organic matter is usually expressed morphologically by a darkening of the surface soil". Horizon B "is characterized by enrichment in organic matter, sesquioxides, or clay; or by the 
development of soil structure; or by a change of color denoting hydrolysis, reduction, or oxidation. In B horizons, accumulated organic matter is evidenced usually by dark colors relative to the $\mathrm{C}$ horizon". Horizon $C$ "is comparatively unaffected by the pedogenic processes operating in A and B horizons". Horizon $R$ "is a layer of consolidated bedrock too hard to break with hand or dig with a spade when moist". Finally, Horizon $W$ is a layer of water which occurs only in some soils (Cryosolic, Gleysolic or Organic soils).

Organic Horizons "occur in Organic soils and commonly at the surface of mineral soils. They may occur at any depth beneath the surface in buried soils or overlying geologic deposits." They are divided into 2 groups: O-Horizon, which is "mainly peat material developed from mosses and wood materials and $L, F$ and $H$ - Horizon which are folic materials (with increased degree of decomposition going from $\mathrm{L}$ to $\mathrm{F}$ to $\mathrm{H}$ ) which develop primarily from the accumulation of leaves, twigs, and woody materials with or without a minor component of mosses".

The O-Horizon is divided into the following subhorizons: Of, Oh, Om based on the presence of fibers which reflect the degree of decomposition (as measured by the von Post scale - see Section 2.4.2) which ncreases going from fibric, to mesic, to humic.

The Canadian Soil Classification System classifies the soil into 9 general orders namely Brunisols, Chernozem, Cryosol, Gleysol, Luvisol, Organic, Podzol, Regosol and Solonetzic. These orders of soil are defined and differentiated from one and other based on the regime temperature, presence of minerals and mineral layers, presence of organic materials and presence of water layers in the soil. 
Amongst these, Organic Soils are mainly composed of organic matter in various stages of decomposition. Fens and Bogs are commonly seen organic soils and these soils lack the presence of mineral soil particles.

According to the Canadian System of Soil Classification, Organic Soils:

1. "Have organic horizons (more than $17 \%$ organic $\mathrm{C}$ by weight) that extend from the surface to one of the following:

a. A depth of $60 \mathrm{~cm}$ or more if the surface layer is fibric material (Of) having a bulk density of $<0.075 \mathrm{~g} \mathrm{~cm}^{-3}$.

b. A depth of $40 \mathrm{~cm}$ or more if the surface layer consists of mesic or humic material (Om or Oh) having a bulk density $\geq 0.075 \mathrm{~g} \mathrm{~cm}^{-3}$.

c. A depth of more than $40 \mathrm{~cm}$ if composed of folic materials (L, F, and $\mathrm{H})$, or at least $10 \mathrm{~cm}$ if a lithic contact or fragmental materials are present. Folic materials must be more than twice the thickness of a mineral soil layer if the mineral layer is less than $20 \mathrm{~cm}$ thick. "

or

2. "Have one or more mineral horizons or layers within $40 \mathrm{~cm}$ of the surface in addition to the organic horizons $(\mathrm{O})$ as follows:

a. If a mineral horizon or layer thinner than $40 \mathrm{~cm}$ occurs at the surface, the underlying organic horizon or horizons must have a total thickness of at least $40 \mathrm{~cm}$. 
b. If one or more mineral horizons or layers occur within $40 \mathrm{~cm}$ of the surface, the organic material must occupy more than $40 \mathrm{~cm}$ of the upper $80 \mathrm{~cm}$ of the control section."

Organic soils are divided into four great groups: Fibrisols, Mesisols, Humisols and Folisols. The first three represent soils formed in hydrophytic vegetation, and are separated based on the degree of decomposition of the organic material, which is measured using the von Post scale (see Section 2.4.2), and which increases going from fibrisols to mesisols to humisols. They are commonly saturated with water throughout the year. Folisosl are organic soils formed in upland (folic) organic materials and are soils that are only briefly saturated with water. These great groups are further classified into subgroups based on the sequence of the existing horizons.

\subsubsection{Australian Soil Classification System}

The Australian agricultural soil classification (Isbell 2002) is similar to that used in the US and Canada. It classifies the soil into 14 orders which are further separated in suborders, great groups and subgroups. . Figure 2.4 shows a schematic diagram of the 14 orders. The order that is of interest in the context of discussing the classification of organic soils is that of Organosols, which are soils "dominated by organic materials". The Australian classification system provides its own definition of organic materials, which are "plant-derived organic accumulations that are either:

a. saturated with water for long periods or are artificially drained and, excluding live plant tissue, (i) have $18 \%$ or more organic carbon if the mineral fraction is 
$60 \%$ or more clay, (ii) have $12 \%$ or more organic carbon if the mineral fraction has no clay, or (iii) have a proportional content of organic carbon between 12 and $18 \%$ if the clay content of the mineral fraction is between zero and $60 \%$;

or

b. saturated with water for no more than a few days and have $20 \%$ or more organic carbon."

It is also noted that loss-on-ignition (LOI) may be used as an estimate of organic carbon, and that for non-calcareous soils the relationship between organic carbon and LOI will be influenced by clay content. Recommendations for relating LOI to organic carbon content as a function of clay content are also provided (for clay< $20 \% \mathrm{LOI}=2 \mathrm{OC}$; for clay $=20-60 \% \mathrm{LOI}=2.3 \mathrm{OC}$; for clay $>60 \% \mathrm{LOI}=2.7 \mathrm{OC}$ ).

Organosols are defined as soils that are not regularly inundated by saline tidal waters and either:

i. "Have more than $0.4 \mathrm{~m}$ of organic materials within the upper $0.8 \mathrm{~m} . "$

or

ii. "Have organic materials extending from the surface to a minimum depth of $0.1 \mathrm{~m}$; these either directly overlie rock or other hard layers,partially weathered or decomposed rock or saprolite, or overlie fragmental material 
such as gravel, cobbles or stones in which the interstices are filled or partially filled with organic material."

Similarly to what was discussed for the Canadian and US taxonomy, based on the degree of decomposition of the organic matter, this order is further divided into 3 suborders: Fibric, Hemic and Sapric.

The Fibric suborder is dominated by fibric peat which is undecomposed to weakly decomposed organic material. The Hemic and the Sapric suborders are dominated respectively by hemic peat, which is formed by moderately to well decomposed organic material, and by sapric peat which is formed by strongly to completely decomposed organic materials.

The suborders are further classified into the following great groups (note that not all great groups are applicable to all the suborders):

- Folic: "soils that are more or less freely drained and are never saturated for more than several days unless rain is falling and contain organic materials";

- Sulfuric: "soils in which sulfuric materials occur within the upper $1.5 \mathrm{~m}$ of the profile";

- Sulfidic: "soils in which sulfidic materials occur within the upper $1.5 \mathrm{~m}$ of the profile";

- Calcareous: "soils in which the major part of the organic materials is calcareous";

- Basic: "soils in which the major part of the organic materials is not calcareous but is not strongly acid"; 
- Acidic: "soils in which the major part of the organic materials is strongly acid."

The great groups are further classified into subgroups based on the layers overlying and underlying the layer of organic soils. These subgroups are Lithic, in which the organic layer directly overlies hard rock; Paralithic, in which the organic materials directly overlie partially weathered or weathered rock; Marly in which a marl layer exists either within or immediately below the organic materials; Rudaceous, in which the organic materials directly overlie fragmental materials such as cobbles, gravels or interstices; Modic in which layers of humose material underlie the organic materials; Placic in which a thin iron pan underlies the organic material; Ashy in which the organic material shows traces of burnt peat; Terric in which a layer of unconsolidated mineral material exists within or below the organic material but within $0.8 \mathrm{~m}$ of the surface; Regolithic, in which a layer (or layers) of unconsolidated mineral material occurs below $0.8 \mathrm{~m}$ of the surface. 


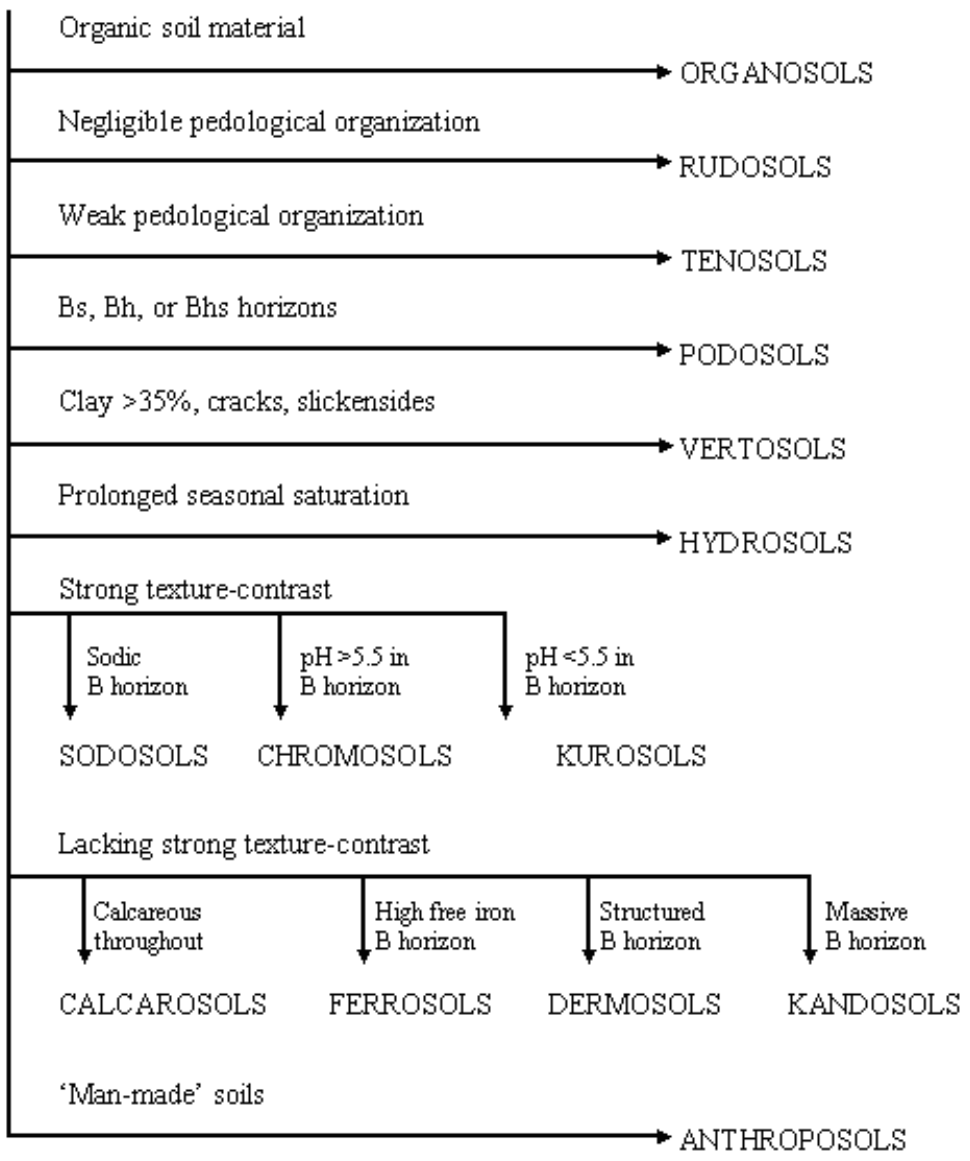

FIG 2.4 - Classification of soil in Australia (Isbell 2002)

\subsubsection{New Zealand Soil Classification System}

According to Hewitt (2003), soils in New Zealand are classified hierarchically into four categories: orders, groups, subgroups and soil forms. The 15 orders used in the New Zealand Soil Classification System are summarized in Table 2.2, which also provides the correlation with the US soil taxonomy. As shown in Table 2.2, the term "organic soils" is used in this classification system to refer to soils that would be termed Histosols in the US soil Taxonomy.

The orders are divided in to 73 soil groups based on factors such as drainage, parent material, chemical and physical properties. The groups further break into 
253 subgroups which are further divided into soil forms that provide more details about the soil parent material, texture and permeability.

TABLE 2.2 - List of Orders of New Zealand Soil Classification (NZSC) and their Correlation with US Soil Taxonomy (Hewitt 2003)

Table 14.1 List of Orders of the New Zealand Soil Classification (NZSC) and Their Correlation with Soil Taxonomy

\begin{tabular}{ll}
\hline \multicolumn{1}{c}{ NZSC order } & \multicolumn{1}{c}{ Correlation with Soil Taxonomy } \\
\hline Allophanic Soils & $\begin{array}{l}\text { Andisols excluding vitric soils } \\
\text { Drastically disturbed, mixed, or truncated soils, or soils made from human- } \\
\text { deposited material. Mostly correlated with the Arents } \\
\text { Dystrudepts and Dystrustepts }\end{array}$ \\
Brown Soils & Aquents, Aquepts, and Aquox \\
Gley Soils & Aquults, Humults and Udalfs, in basic igneous parent materials \\
Granular Soils & Ustolls, Aquolls, Rendolls, Vertisols \\
Melanic Soils & Histosols \\
Organic Soils & Oxisols \\
Oxidic Soils & Aquepts, Aqualfs, Fragiaquepts, Dystrustepts \\
Pallic Soils & Aquods, Orthods \\
Podzols & Vitraquands, Vitrands, Vitricryands \\
Pumice Soils & Entisols or not-soil \\
Raw Soils & Aquents, Orthents, Psamments, Fluvents \\
Recent Soils & Aridisols (mainly Xeric subgroups) \\
Semiarid Soils & Aquults, Humults, Udults \\
Ultic Soils &
\end{tabular}

\subsubsection{Russian Soil Classification System}

Soil classification has evolved greatly in Russia, as shown in Figure 2.5 (Goryachkin et al. 2003), which summarizes its evolution from the late 1800's until 2000. The review by Goryachkin et al. (2003) highlights the different approaches to soil classification employed in Russia over this period: a "geological" approach based on "mineralogical, physical and chemical characteristics of substrates;" a "factor-genetic" approach based "mainly on linkages of soil with climatic zones and other soil forming factors, such as topography and parent materials;" an "evolutionary' that "takes into account the development of soils in time;" a "profile-genetic" approach which is "based on soil characteristics (horizons, 
features) formed by pedogenesis." The latter approach was the basis for the most recent developments in soil classification

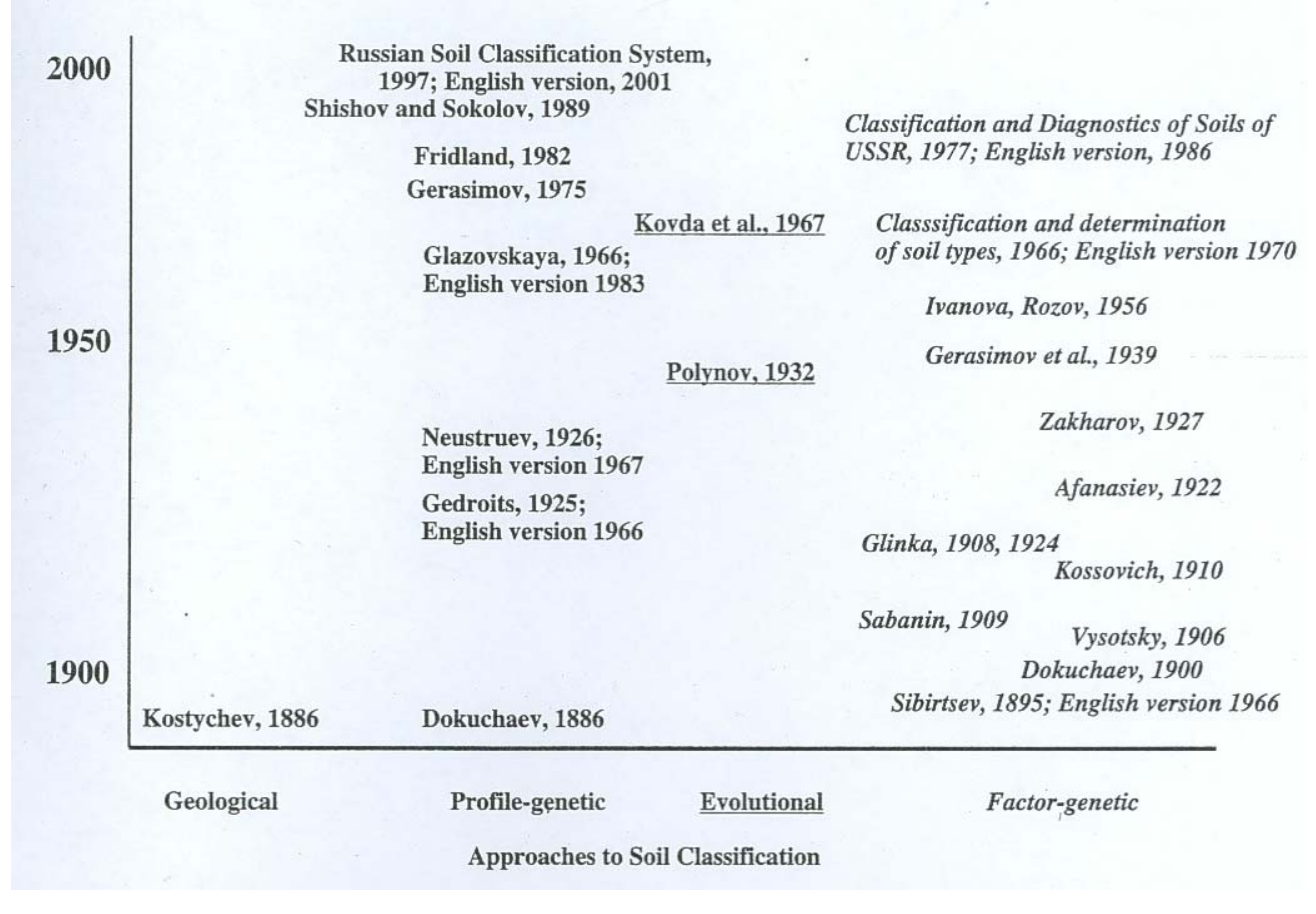

FIG 2.5 - Development of different approaches to soil classification in Russia (Goryachkin, 2003)

According to this system, soils are classified into 19 orders namely Fulvisols, Gleysols, Regosols, Leptosols, Andosols, Arenosols, Vertisols, Cambisols, Calcisols, Solonetz, Solonchaks, Kastanozema, Chernozems, Phaeozems, Gleyzems, Planosols, Podzoluvisola, Podzols and Histosols. The order of interest for this research is that of Histosols.

\section{Histosols}

Histosols are soils dominated by fresh or partly decomposed organic material. Such soils have $40 \mathrm{~cm}$ or more of organic soil materials either extending down from the surface or taken cumulatively within the upper $80 \mathrm{~cm}$ of the soil; the 
thickness of the $\mathrm{H}$ horizon may be less when it rests on rock or on fragmental material in which the interstices are filled with organic matter.

Histosols are further classified as Terric, Fibric, Gelic.

\section{Terric}

"These soils have highly decomposed organic materials with strongly reduced amounts of visible plant fibers and a very dark grey to black color to a depth of 35 $\mathrm{cm}$ or more from the surface. They have imperfect to very poor drainage and lack a sulfuric horizon or sulfidic materials within $125 \mathrm{~cm}$ of the surface. They also lack permafrost within $200 \mathrm{~cm}$ of the surface".

Histosols Terric are further divided into (a) Peat-ashes banded boggycharacterized by layers of volcanic sands and ash in the peat horizon, (b) Peats low moor- characterized by the peaty $(\mathrm{O})$ horizon, which is more than $50 \mathrm{~cm}$ thick. They are light-brownish in color and acid in reaction. The mineral ash content is less than $6.5 \%$, and the organic material is not decomposed or only slightly decomposed and (c) Peats Boggy Solonchakous- characterized by the presence of soluble salts.

\section{Fibric}

"These soils have raw or weakly decomposed organic materials and a fiber content which is dominant to a depth of $35 \mathrm{~cm}$ or more from the surface. They have very poor drainage or are undrained, and do not have a sulfuric or sulfidic 
horizon within $125 \mathrm{~cm}$ of the surface. Like the Terric Histosols the Fibric Histosols do not have permafrost within $200 \mathrm{~cm}$ of the surface."

Fibric Histosols are further divided into (a) Peats transitional moor: compared to low moor soils they are characterized by darker color, higher degree of decomposition of the organics, and higher ash content (6.5- 10.0\%), (b) Peats high moor, which have a dark colored peat horizon, and ash content less than 10\% and (c) Peats boggy (without subdivision) soils, which correspond to generally recognized Histosols with no clearly defined, or not well-known, characteristics. The group can be correlated with combined peat and boggy soils, including soils with hydromorphic ${ }^{11}$ organic properties, formed under the influence of stagnating or moving ground or surface water (fresh or saline) and the associated hydrophilous vegetation.

\section{Gelic}

"The soils which have permafrost within the top $200 \mathrm{~mm}$ thickness of the soil are Gelic Histosols. Peats boggy degrading (mineralizing) soils are a component of patterned soils covering the tundra zone. They have features of pedoturbation ${ }^{12}$ and have permafrost within 100-200 cm from the soil surface."

\footnotetext{
${ }^{11}$ Hydromorphic Soil - Soils that develop under conditions of poor drainage in marshes, swamps, seepage areas, or flats.

${ }^{12}$ Pedoturbation - destruction of the features of illuviation
} 


\subsubsection{Danish Soil Classification System}

The soil classification system employed in Denmark, as reported by Greve and Madsen (1999), is summarized in Table 2.3. Soils are divided into 8 types depending on the soil texture down to a depth of $20 \mathrm{~cm}$. Further the soil is divided into 12 classes based on the percentage by weight of the various soil fractions. Depending on the presence of organic matter and lime (as shown in the Table 2.3) the soils are classified as organic and calcareous soils. Organic soils have an organic matter content exceeding $10 \%$ by weight and a lime content between 0 and $90 \%$; calcareous soils have less than $10 \%$ by weight organic content and more than $10 \%$ by weight lime content.

TABLE 2.3 - Soil Classification in Denmark (Greve and Madsen 1999)

\begin{tabular}{|c|c|c|c|c|c|c|c|c|}
\hline \multirow[b]{2}{*}{$\begin{array}{l}\text { Color } \\
\text { Code }\end{array}$} & \multirow[b]{2}{*}{ Soil Type } & \multirow{2}{*}{$\begin{array}{l}\text { JB- } \\
\text { nr. }\end{array}$} & \multicolumn{6}{|c|}{ Percentage by Weiglt } \\
\hline & & & $\begin{array}{c}\text { Clay } \\
<2 \mu \mathrm{m}\end{array}$ & $\begin{array}{c}\text { Silt } \\
2-20 \mu \mathrm{m}\end{array}$ & $\begin{array}{l}\text { Fine Sand } \\
20-200 \mu \mathrm{m}\end{array}$ & $\begin{array}{l}\text { Total Sand } \\
2-2000 \mathrm{~m}\end{array}$ & \begin{tabular}{|l|} 
Org. Mat. \\
$\mathbf{5 8 . 7} \%$ C
\end{tabular} & $\begin{array}{l}\text { Lime } \\
\mathrm{CaCO}_{3}\end{array}$ \\
\hline 1 & Coarse Sandy Soil. & 1 & \multirow{2}{*}{0.5} & \multirow{2}{*}{$0-20$} & $0-50$ & \multirow{2}{*}{$75-100$} & \multirow{10}{*}{$\leq 10$} & \multirow{10}{*}{$\leq 10$} \\
\hline 2 & Fine Sandy Sol. & 2 & & & $50-100$ & & & \\
\hline \multirow{2}{*}{3} & \multirow{2}{*}{ Clayey Sandy Soll. } & 3 & \multirow{2}{*}{ 5-10 } & \multirow{2}{*}{$0-25$} & $0-40$ & \multirow{2}{*}{$65-95$} & & \\
\hline & & 4 & & & $40-95$ & & & \\
\hline \multirow{2}{*}{4} & \multirow{2}{*}{ Sandy Clayey Soil. } & 5 & \multirow{2}{*}{$10-15$} & \multirow{2}{*}{$0-30$} & $0-40$ & \multirow{2}{*}{ 55-90 } & & \\
\hline & & 6 & & & $40-90$ & & & \\
\hline 5 & Clayey Soil. & 7 & $15-25$ & 0.35 & & $40-85$ & & \\
\hline \multirow{3}{*}{6} & \multirow{3}{*}{$\begin{array}{l}\text { Heavy Clayey Soil } \\
\text { or Silty Soil. }\end{array}$} & 8 & $25-45$ & $0-45$ & & 10.75 & & \\
\hline & & 9 & $45-100$ & 0.50 & & $0-55$ & & \\
\hline & & 10 & 0.50 & $20-100$ & & 0.80 & & \\
\hline 7 & Organic Soil. & 11 & & & & & $>10$ & $0-90$ \\
\hline 8 & Calcareous Soil & 12 & & & & & $\leq 10$ & $>10$ \\
\hline
\end{tabular}




\subsubsection{Soil Classification in England and Wales}

This section reviews the soil classification employed in England and Wales as reported by Avery (1980) and by the web site developed by the National Soil Resources Institute of Cranfield University in the UK (www.soilsworldwide.net). According to these references this classification system is organized in classes (or major groups), groups, subgroups and series (or types). The distinction in ten classes is based on characteristics of the soil profile (the soil thickness extending from the ground surface to about $1.50 \mathrm{~m}$, and formed by several soil horizons). As stated by Avery (1980), the ten classes are "differentiated primarily by the composition of the soil material [....] and the presence or absence of diagnostic horizons $[\ldots]$ and the hydrologic conditions governing their development." within specified depths

With regard to composition the classification system gives primary consideration to organic content. Soils are classified either as organic soils, humose mineral soils or non-humose mineral soils based on threshold values of the $\%$ of organic carbon content $(\mathrm{OC} \%)$. These threshold values depend on the clay content. Specifically:

- the transition between humose mineral soil and organic soil is $15 \%$ OC $(\sim 20 \%$ organic matter) with no clay present and $18 \%$ ( $\sim 30 \%$ organic matter) for $50 \%$ clay. For intermediate values of the clay content $(1-49 \%)$, the threshold is calculated by linearly interpolating the threshold values above. 
- the transition between non-humose mineral soil and humose mineral soil is $\sim 4.5 \%$ OC with no clay present and $7 \%$ for $50 \%$ clay. For intermediate values of the clay content $(1-49 \%)$, the threshold is calculated by linearly interpolating these threshold values

As stated by Avery (1980), "the variable limits accord with field experience that a given proportion of organic matter modifies the physical properties of a sand more than it does those of a clay."

Particle size classes (sand, silt and clay) are used to further differentiate non organic soils materials, which are classified based on the proportions of sand, silt and clay sized particle. These soils can also be called Humose if they contain $>8$-12 percent organic matter (depending on clay content) and very stony if they contain $>35$ percent stones.

Consideration is also given to the calcium carbonate content. Soils are divided into three groups as follows: non-calcareous: if $\mathrm{CaCO}_{3}<1 \%$; calcareous: if $\mathrm{CaCO}_{3}=1$ to $40 \%$; extremely calcareous (Carbonatic): if $\mathrm{CaCO}_{3}>40 \%$.

Horizons are designated using the following notation: $L$ for superficial fresh litter; $F, H$ and $O$ for other organic horizons; $A, E, B$, or $C$ for unconsolidated mineral horizons; and $R$ for hard rock (a few other distinctions are also possible). 
Of relevance to this report are the organic horizons which are described by Avery (1980) as follows:

$F, H$ "Organic horizons originating as litter deposited or accumulated at the surface, and seldom saturated with water for more than one month at a time;"

F "Partly decomposed or comminuted litter [...], in which the original plant structures are visible to the naked eyes;"

$H \quad$ "Well decomposed often mixed with mineral matter, in which the original plant structures cannot be seen;"

$O \quad$ "Peaty horizons accumulated under wet conditions. They are saturated with water for at least 30 consecutive days in most years or have been artificially drained." For this horizon a further differentiation is based on the degree of humification of the peat ( $\mathrm{Of}^{*}$ for fibrous peat, $\mathrm{Om} *$ for semi-fibrous peat, $\mathrm{Oh}^{*}$ for humified peat) based on the von Post scale of decomposition.

As mentionaed above, these soil profile characteristics are used to classify soils in a hierarchical system, which includes four levels: major groups (or classes), groups, subgroups and series or types). The 10 classes are the following: Terrestrial raw soil, Raw gley soils, Lithomorphic soils, Pelosols, Brown soils, Podzolic soils, Surface-water gley soils, Ground-water gley soils, Man made soils and Peat soils. Most of these classes can contain organic materials (in some cases the further subdivision of the class includes a "humic" subgroup). The tenth class, that of Peat Soils corresponds to "predominantly organic soils originated from partially 
decomposed plant remains that accumulated under waterlogged conditions". According to the classification system peats must have $40 \mathrm{~cm}$ of organic material within the upper $80 \mathrm{~cm}$, excluding the fresh litter and living moss. Alternatively, they must have more than $30 \mathrm{~cm}$ of organic material resting directly on the bedrock or on stony material.

Peat soils are further subdivided into 2 groups: Raw Peat Soils and Earthy ${ }^{13}$ Peat Soils.

Raw Peat Soils are peat soils that "lack an earthy topsoil or ripened mineral surface layer of equivalent thickness. They are located in undrained sites under semi-natural bog or fen vegetation where peat is still accumulating. Raw Peat Soils are further subdivided into 4 sub groups: (a) Raw oligo-fibrous peat soils, which "consist of predominantly fibrous or semi fibrous peat that contains remains of Sphagnum, Eriphorum, Calluna or Trichophorum; and have a $\mathrm{pH}$ less than 4.0 throughout the layer"; (b) Raw eu-fibrous peat soils are soils, which "consist of predominantly fibrous or semi fibrous peat that does not contain remains of Sphagnum or other mosses and has a $\mathrm{pH}$ more than 4.0 in at least some part of the layer"; (c) Raw oligo-amorphous peat soils, i.e. "humified peat with $\mathrm{pH}$ less than 4.0 throughout the layer"; and (d) Raw eutro-amorphous peat soils, i.e. "humified peat with $\mathrm{pH}$ more than 4.0 in at least some part of the layer".

${ }^{13}$ Earthy - Like the earth; here decomposed to an extent that they appear as earth. 
Earthy Peat Soils are organic soils are "organic soils, normally drained, with a well aerated and structured, relatively firm surface horizon containing few or no recognizable plant remains.". They are found in drained peat lands used for agriculture and under semi-natural vegetation, particularly where the upper horizons are relatively well aerated or rich in calcium. They are further classified into the following 5 subgroups: (a) Earthy oligo fibrous peat soils, which "lack a sulphuric horizon and consist of fibrous and semi fibrous peat that does not have remains of sphagnum and a $\mathrm{pH}$ less than 4.0 throughout the layer"; (b) Earthy eu-fibrous peat soils that "lack a sulphuric horizon and consist of fibrous and semi fibrous peat that do not have remains of sphagnum and a $\mathrm{pH}$ more than 4.0 in at least some part of the layer"; (c) Earthy oligo-amorphous peat soils, which "lack a sulphuric horizon within $80 \mathrm{~cm}$ of depth of the layer and consist of humified peat with a pH of 4.0 throughout the layer"; (d) Earthy eutro-amorphous peat soils, which "lack a sulphuric horizon within $80 \mathrm{~cm}$ of depth and consist of humidified peat with $\mathrm{pH}$ of 4.0 in at least some part of the layer"; and (e) Earthy sulphuric peat soils, which have a sulphuric horizon within a depth of $80 \mathrm{~cm} "$ 


\subsection{Botanical Classification}

The foundation of botanical classification is the division of peat based on two types of structure: fibrous and granular, and the identification of the floristic terms. The most established botanical classification systems are: (a) the Radforth Classification System and (b) the Von Post Classification System. Landva et al. (1983) note that one key difference between these two classification systems is that the von Post system is intended to be applicable to "all organic soils that support plant growth", while then the Radforth system "includes only wholly organic deposits, that is peat". They also note that the Radforth classification system "was developed for use by engineers, and therefore little botanical knowledge is involved". However, given that it is not based on geotechnical tests/properties, it is discussed here.

\subsubsection{Radforth Classification System}

The Radforth Classification System (Radforth 1969) classifies both peat structure and peat cover. With regards to Peat Structure, the Radforth classification system classifies peats (materials with organic content $>80 \%$ ) into three main groups (see Table 2.4): (1) amorphous granular peats, (2) fine fibrous peats, and (3) coarse fibrous peats, based on the fiber content (MacFarlane and Williams, 1974). Amorphous-granular peats have the lowest shear strength and tensile strength, while coarse-fibrous peats have the highest natural void ratio and compressibility among the three types of peats. The peat is then classified into 17 categories based on the presence of wood remnants.

The Peat Cover classification, which is shown in Table 2.5, provides a description of the basic structure of the soil above the organic soil deposit. According to Table 2.5 there are 


\section{9 classes of vegetal cover from A to I.}

While the Radforth classification system is not based on geotechnical properties, and hence cannot alone be relied on for engineering purposes, it provides a description of the soil which can be of significance to engineers. Table 2.6 shows how some inferences on the general engineering properties of organic soils can be drawn based on the type of peat cover.

TABLE 2.4 - Structural Typification of Peat (MacFarlane 1969)

\begin{tabular}{|c|c|c|}
\hline $\begin{array}{l}\text { Predominant } \\
\text { characteristic }\end{array}$ & Category & Name \\
\hline \multirow[t]{4}{*}{ Amorphous-granular } & $\begin{array}{l}1 \\
2 \\
3\end{array}$ & $\begin{array}{l}\text { Amorphous-granular peat } \\
\text { Non-woody, fine-fibrous peat } \\
\text { Amorphous-granular peat containing non-woody fine } \\
\text { fibres }\end{array}$ \\
\hline & $\begin{array}{l}4 \\
5\end{array}$ & $\begin{array}{l}\text { Amorphous-granular peat containing woody fine fibres } \\
\text { Peat, predominantly amorphous-granular, containing } \\
\text { non-woody fine fibres, held in a woody, fine-fibrous } \\
\text { framework }\end{array}$ \\
\hline & 6 & $\begin{array}{l}\text { Peat, predominantly amorphous-granular containing } \\
\text { woody fine fibres, held in a woody, coarse-fibrous } \\
\text { framework }\end{array}$ \\
\hline & 7 & $\begin{array}{l}\text { Alternate layering of non-woody, fine-fibrous peat and } \\
\text { amorphous-granular peat containing non-woody fine } \\
\text { fibres }\end{array}$ \\
\hline \multirow[t]{3}{*}{ Fine-fibrous } & 8 & $\begin{array}{l}\text { Non-woody, fine-fibrous peat containing a mound of } \\
\text { coarse fibres }\end{array}$ \\
\hline & 9 & $\begin{array}{l}\text { Woody, fine-fibrous peat held in a woody, coarse-fibrous } \\
\text { framework }\end{array}$ \\
\hline & $\begin{array}{l}10 \\
11\end{array}$ & $\begin{array}{l}\text { Woody particles held in non-woody, fine-fibrous peat } \\
\text { Woody and non-woody particles held in fine-fibrous peat }\end{array}$ \\
\hline \multirow[t]{4}{*}{ Coarse-fibrous } & $\begin{array}{l}12 \\
13 \\
14\end{array}$ & $\begin{array}{l}\text { Woody, coarse-fibrous peat } \\
\text { Coarse fibres criss-crossing fine-fibrous peat } \\
\text { Non-woody and woody fine-fibrous peat held in a coarse- } \\
\text { fibrous framework }\end{array}$ \\
\hline & 15 & $\begin{array}{l}\text { Woody mesh of fibres and particles enclosing amorphous- } \\
\text { granular peat containing fine fibres }\end{array}$ \\
\hline & 16 & $\begin{array}{l}\text { Woody, coarse-fibrous peat containing scattered woody } \\
\text { chunks }\end{array}$ \\
\hline & 17 & $\begin{array}{l}\text { Mesh of closely applied logs and roots enclosing woody } \\
\text { coarse-fibrous peat with-woody chunks }\end{array}$ \\
\hline
\end{tabular}


TABLE 2.5 - Typification of Peat Cover (MacFarlane 1969)

\begin{tabular}{|c|c|c|c|c|}
\hline $\begin{array}{l}\text { Coverage } \\
\text { type } \\
\text { (class) }\end{array}$ & $\begin{array}{l}\text { Woodiness } \\
\text { vs. non- } \\
\text { woodiness }\end{array}$ & $\begin{array}{c}\text { Stature } \\
\text { (approximate } \\
\text { height) }\end{array}$ & $\begin{array}{l}\text { Texture } \\
\text { (where } \\
\text { required) }\end{array}$ & $\begin{array}{l}\text { Growth } \\
\text { habit }\end{array}$ \\
\hline A & Woody & $15 \mathrm{ft}$ or over & - & Tree form \\
\hline B & Woody & $5-15 \mathrm{ft}$ & - & $\begin{array}{l}\text { Young or dwarfed tree or } \\
\text { bush }\end{array}$ \\
\hline C & Non-woody & $2-5 \mathrm{ft}$ & - & Tall, grasslike \\
\hline D & Woody & $2-5 \mathrm{ft}$ & - & Tall shrub or very \\
\hline $\mathrm{E}$ & Woody & $\mathrm{Up}$ to $2 \mathrm{ft}$ & - & Low shrub \\
\hline $\mathrm{F}$ & Non-woody & $\mathrm{Up}$ to $2 \mathrm{ft}$ & - & Mats, clumps, or patches \\
\hline G & Non-woody & Up to $2 \mathrm{ft}$ & - & Singly or loose \\
\hline $\mathrm{H}$ & Non-woody & Up to 4 in. & $\begin{array}{l}\text { Leathery } \\
\text { to crisn }\end{array}$ & $\begin{array}{l}\text { association } \\
\text { Mostly continuous mats }\end{array}$ \\
\hline I & Non-woody & Up to $4 \mathrm{in.}$ & $\begin{array}{l}\text { Soft or } \\
\text { velvety }\end{array}$ & $\begin{array}{l}\text { Often continuous mats, } \\
\text { sometimes in } \\
\text { hummocks }\end{array}$ \\
\hline
\end{tabular}




\section{TABLE 2.6 - Engineering Significance of Typification of Peat Cover (MacFarlane 1969)}

\begin{tabular}{|c|c|}
\hline $\begin{array}{l}\text { Predominant class } \\
\text { in formula }\end{array}$ & Engincering significance \\
\hline A & $\begin{array}{l}\text { (1) Presence of large woody erraties in the peat } \\
\text { (2) The position of relatively stallow depths of peat for the landscape as a } \\
\text { whole } \\
\text { (3) Location of best drained peat (qualified by itemis (a) and (b) in text) } \\
\text { (4) Location of best drained mineral soil sublayer } \\
\text { (5) Presence of highly permeable peat } \\
\text { (6) Vicinity of lowest summer temperatures in the peat } \\
\text { (7) Location of the coarsest, most durable peat } \\
\text { (8) Best conditions for static load (sec, however, item (c) in text) and } \\
\text { dynamic loading }\end{array}$ \\
\hline B & Same as for $A$ above, but less intensively represented \\
\hline$c$ & $\begin{array}{l}\text { Predominance rare, except in tropical and subtropical locations (for } \\
\text { example, Guyana, Brazil, Paraguay and Uruguay, and possibly } \\
\text { Southern Rhodesia, Nigeria, Isaci, Mataysia, ete.) }\end{array}$ \\
\hline D & $\begin{array}{l}\text { (1) Linear drainage, often an open water course } \\
\text { (2) Lage condition around a confined muskeg (bog) } \\
\text { (3) Traps present } \\
\text { (4) Good, but highly elastic, bearing conditions; difficult to consolidate } \\
\text { and with marked patterned local differentials as to rate of consolidation } \\
\text { (5) Features highly conducive to spring flooding } \\
\text { (6) Sit in the mineral soil sublayers with highly mixed aggregate from } \\
\text { outwash } \\
\text { (7) Features conducive to differential settlement (often abrupt) under load }\end{array}$ \\
\hline $\mathrm{E}$ & $\begin{array}{l}\text { Equally important as o above and is very common in temperate, arctic, } \\
\text { and subarctic zones } \\
\text { (1) High order of homogeneity in peat, even in relation to micro- } \\
\text { topography in which mounds, ridges, and ice knolls are imporiant } \\
\text { (2) Peat difficult to re-wet once drained of gravitational water } \\
\text { (3) Conditions accommodating to certuin articulated whecled vehictes } \\
\text { (Enright } 1962 \text { ) } \\
\text { (4) Good cohesion and tensility, moderate elasticity even when water } \\
\text { shows at the sarface in the field } \\
\text { (5) Fasily drainahle conditions (for free water) }\end{array}$ \\
\hline $\mathrm{F}$ & $\begin{array}{l}\text { Presence of highly critical conditions when prominent in the formula: } \\
\text { (1) Low points on drainage gradients } \\
\text { (2) Muskeg with ecntres of extremely low bearing potential whether wet } \\
\text { ar relatively dry } \\
\text { (3) Peat of low tensile strength and showing little elasticity unless the local } \\
\text { water table is consistently high (small open pools the year round) } \\
\text { (4) Sites where shear strength is lowest in meskeg at frequent intervals: } \\
\text { water is not excessive }\end{array}$ \\
\hline G & $\begin{array}{l}\text { Rarely predominates in the formula, is indicative of a highly fluctuating } \\
\text { water table }\end{array}$ \\
\hline $\mathrm{H}$ & $\begin{array}{l}\text { When predominant indicates presence of: } \\
\text { (1) Permalrost and late seasonal subsurface ice conditions of uneven } \\
\text { contour } \\
\text { (2) Maximum range of microtopographic amplitude (often abropt) for all } \\
\text { moskeg. } \\
\text { (3) Local imponding and highly irregular, dissected drainage gradienis } \\
\text { (4) Reiatively focally degraded peat (structurally and mechanically dis- } \\
\text { rupicd (Eydt 1962)) }\end{array}$ \\
\hline 1 & $\begin{array}{l}\text { Unless Class } 1 \text { is the only component comprising the cover formula (which } \\
\text { is rare), it lacks prominence. When it is a single coniributing factor in } \\
\text { cover it is very local, usually no more than } 4 \text { or } 5 \mathrm{~m} \text { in area of coverage, } \\
\text { and the following occur: } \\
\text { (1) Vehicle immobilization on the second pass for amphibious vehicles } \\
\text { (2) The base of minor or major drainage gradients }\end{array}$ \\
\hline
\end{tabular}




\subsubsection{Modified Von Post Classification System}

This classification system uses seven parameters to group organic soils. The Von Post system (Landva and Pheeney, 1980) was originally designed to describe the degree of humification of peat. Later, it was modified to include other properties of peat as well as surface characteristics of peat deposits as discussed below. According to the modified Von Post Classification System seven parameters need to be known to classify peat. These parameters include: depth of sample extraction, peat type, moisture content, degree of humification, fiber content, presence of woody remnants and other information as pertinent (e.g. presence of charcoal and plant remnants). Each of these parameters appears in the designation of the soil, as detailed below.

(1) Depth of sample (in $\mathrm{cm}$ )

(2) Peat type based on recognizable features from the original plants; (S) S phagnum, (C) Carex, (Er) Eriophorum, (Eq) Equisetum, (Ph) Phragmites, (S ch) Scheuchzeria, (N) Shrubs, (L) Wood

(3) Moisture content - see Table 2.7 (Note: $\mathrm{B}_{1}$ indicates a dry soil)

TABLE 2.7 - Explanation of symbols indicating water content of organic soil

\begin{tabular}{lc}
\hline \multicolumn{2}{c}{ Mass based water content } \\
\hline $\mathrm{w}<500 \%$ & $\mathrm{~B}_{2}$ \\
$500 \%<\mathrm{w}<1000 \%$ & $\mathrm{~B}_{3}$ \\
$1000 \%<\mathrm{w}<2000 \%$ & $\mathrm{~B}_{4}$ \\
$\mathrm{w}>2000 \%$ & $\mathrm{~B}_{5}$ \\
\hline
\end{tabular}

0-30 CS H $\mathrm{H}_{1-2} \mathrm{~B}_{3} \mathrm{~F}_{0} \mathrm{R}_{2} \mathrm{~W}_{0}$ (seeds; Pot. palustr.) 
(4) Fiber content

Both the presence of fine fibers $(F)$ and coarse fibers is noted $(\mathrm{R})$. The former are mainly due to the presence of Eriphorum, while the term coarse fiber refers to fibers with diameter greater than $1 \mathrm{~mm}$. For both a subscript (0-3) serves to quantify the amount present (see below).

$\mathrm{F}_{0}\left(\mathrm{R}_{0}\right)-\mathrm{Nil}$

$\mathrm{F}_{1}\left(\mathrm{R}_{1}\right)$-Low content

$\mathrm{F}_{2}\left(\mathrm{R}_{2}\right)$-Moderate content

$\mathrm{F}_{3}\left(\mathrm{R}_{3}\right)$-High content

(5) Degree of Humification: the letter $\mathrm{H}$ with a numeric subscript (1 to 10) serves to describe the degree of humification (e.g. H1 = completely decomposed peat) see Table 2.8.

(6) Presence of woody remnants: this is indicated with the letter W with a numeric subscript (0 to 3 ): the greater the content of woody remnants, the greater the subscript. Specifically:

$\mathrm{W}_{0}$-Nil

$\mathrm{W}_{1}$-Low content

$\mathrm{W}_{2}$-Moderate content

$\mathrm{W}_{3}$-High content

(7) Other information as pertinent is added to the end using suitable symbols and abbreviations. Thus layers of charcoal indicating old fires, seeds, and other 
recognizable plant remnants may be noted.

\section{TABLE 2.8 - Explanation of symbols indicating degree of decomposition of organic}

soil

Symbol Description

$\overline{\mathrm{H}_{1}} \quad$ Completely undecomposed peat, which when squeezed, releases almost clear water. Plant remains easily identifiable. No amorphous material present.

$\mathrm{H}_{2} \quad$ Almost completely undecomposed peat which, when squeezed, releases clear or yellowish water. Plant remains still easily identifiable. No amorphous material present.

$\mathrm{H}_{3} \quad$ Very slightly decomposed peat which, when squeezed, releases muddy brown water, but for which no peat passes between the fingers. Plant remains still identifiable and no amorphous material present.

$\mathrm{H}_{4} \quad$ Slightly decomposed peat which, when squeezed, releases very muddy dark water. No peat is passed between the fingers but the plant remains slightly pasty and has lost some of the identifiable features.

$\mathrm{H}_{5} \quad$ Moderately decomposed peat which, when squeezed, releases very muddy water with a very small amount of amorphous granular peat escaping between the fingers. The structure of plant remains is quite indistinct although it is still possible to recognize certain features. The residue is strongly pasty.

$\mathrm{H}_{6} \quad$ Moderately strongly decomposed peat with a very indistinct plant structure. When squeezed, about one-third of the peat escapes between fingers. The residue is strongly pasty but shows the plant structure more distinctly than before squeezing

$\mathrm{H}_{7} \quad$ Strongly decomposed peat. Contains a lot of amorphous material with very faintly recognizable plant structure. When squeezed, about one-half of the peat escapes between fingers. The water, if any is released, is very dark and almost pasty

$\mathrm{H}_{8} \quad$ Very strongly decomposed peat with a large quantity of amorphous material and very indistinct plant structure. When squeezed, about two-thirds of the peat escapes between the fingers. Small quantity of pasty water may be released. The plant materials remaining in the hand consist of residues such as roots and fibers that resist decomposition.

$\mathrm{H}_{9} \quad$ Practically fully decomposed peat in which there is hardly any recognizable plant structure. When squeezed, almost all the peat escapes between the fingers as a fairly uniform paste.

$\mathrm{H}_{10} \quad$ Completely decomposed peat with no discernible plant structure. When squeezed, all the wet peat escapes between the fingers 
The following is an example of the designation for a particular soil:

$$
\text { 0-30 CS H-2 } \mathrm{B}_{3} \mathrm{~F}_{0} \mathrm{R}_{2} \mathrm{~W}_{0} \text { (seeds; Pot. palustr.) }
$$

This indicates that the peat is taken from the surface at a depth between 0 and 30 centimeters; that it is composed of Carex-Spaghnum remnants; that the decomposition varies from nil to very slight; that the quantity of fine fibers is nil and that of coarse fibers is low; no woody material is present; the presence of Pontentilla palustris seeds is noted.

\subsection{Engineering Classification}

Various organizations around the world are responsible for soil classification systems intended to be used by civil engineers. The goal of all these calssification systems is to provide the means to describe soils through a recognized system grouping them in cathegories, such the that the soils within a given cathegory may be expected to exhibit similar engineering behavior. Soil classification generally relies on the performance of index tests (most commonly limits and particle size analysis). The sections below review selected engineering classification systems with particular attention placed to those more commonly employed in the United States.

\subsubsection{Engineering Classification Systems in The United States}

In the United States the American Society for Testing Materials (ASTM) and the American Association of State Highway and Transportation Officials (AASHTO) are the major organizations that classify soils. Additional classification systems have been developed by other organization such as some state DOTs. 
(a) American Society for Testing Materials (ASTM)

The American Society for Testing Materials (ASTM D2487) classifies soils according to the Unified Soil Classification System based on particle size distribution and the Atterberg limits (Liquid Limit, LL; Plastic Limit, PL, and Plasticity Index, PI=LL-PL). This classification system distinguishes between two main soil types - fine and coarse grained soils - based on whether the \% finer than $0.075 \mathrm{~mm}$ (\# 200 sieve) is greater or equal than $50 \%$ (fine grained soils), or smaller than $50 \%$ (coarse grained soils). It considers organic soils as a subgroup of fine grained soils. Specifically, a soil is termed organic if the ratio of the liquid limit of the sample after oven drying to the preoven drying liquid limit is less than 0.75 . Otherwise, the fine grained soil is termed inorganic, and is classified as either a clay or a silt, based on where its liquid limit and plasticity index plots on the plasticity chart contained in the standard (Fig. 2.8).

The ASTM classification system also considers highly organic soils, which it terms peats. Soils are classified as highly organic based on the prevalence of organic matter, their dark color and organic odor (i.e. not making use of any particular test/measurement).

ASTM D2487 assigns both group symbols and group names to soils as shown in Table 2.9 and Figures 2.7 and 2.8. In the case of organic soils the symbol is formed by two letters: the first is always "O", while the second depends on whether the LL is smaller than $50 \%$ ("L" for low plasticity) or equal or greater than $50 \%$ (" $\mathrm{H}$ " for high plasticity). Note that the symbol does not reflect whether the soil would have been classified as a clay or a silt (i.e. where the 
pre-oven drying LL and PI would have plotted on the plasticity chart). As shown in Table 2.9, this is instead reflected in the group name.

In the case of highly organic soils ASTM employs the group symbol "Pt" and the group name "Peat".

TABLE 2.9 - Unified Soil Classification System (ASTM D2487)

TABLE 1 Soll Classification Chart

\begin{tabular}{|c|c|c|c|c|c|c|c|}
\hline \multirow{2}{*}{\multicolumn{6}{|c|}{ Criteria for Assigning Group Symbols and Group Names Using Laboratory Tests A }} & \multicolumn{2}{|r|}{ Soll Classification } \\
\hline & & & & & & $\begin{array}{l}\text { Group } \\
\text { Symbol }\end{array}$ & Group Name \\
\hline \multirow{8}{*}{$\begin{array}{l}\text { COARSE-GRAINED SOILS } \\
\text { More than } 50 \times \text { retained on No. } \\
200 \text { sieve }\end{array}$} & \multirow{4}{*}{\multicolumn{2}{|c|}{$\begin{array}{l}\text { Gravels } \\
\text { More than } 50 \times \text { of coarse } \\
\text { fraction retained on No. } 4 \\
\text { sieve }\end{array}$}} & \multirow{2}{*}{$\begin{array}{l}\text { Clean Gravels } \\
\text { Less than } 5 \times \text { fines } \\
\end{array}$} & \multicolumn{2}{|c|}{$\mathrm{Cu} \geq 4$ and $1 \leq \mathrm{Ce} \leq 3^{E}$} & GW & Well-graded gravel" \\
\hline & & & & \multicolumn{2}{|c|}{$\mathrm{Cu}<4$ and/or $1>\mathrm{Ce}>3^{E}$} & GP & Poorly graded gravel" \\
\hline & & & \multirow{2}{*}{$\begin{array}{l}\text { Gravels with Fines } \\
\text { More than } 12 \times \text { fines }\end{array}$} & \multicolumn{2}{|c|}{ Fines classify as ML $\propto$ o MH } & GM & Silty gravel $5,0, M$ \\
\hline & & & & \multicolumn{2}{|c|}{ Fines classify as $\mathrm{CL}$ or $\mathrm{CH}$} & GC & Clayey graved $\mathbf{0 , H}$ \\
\hline & \multirow{4}{*}{\multicolumn{2}{|c|}{$\begin{array}{l}\text { Sands } \\
50 x \text { or more of coarse } \\
\text { fraction passes No. } 4 \text { sieve }\end{array}$}} & \multirow{2}{*}{$\begin{array}{l}\text { Clean Sands } \\
\text { Less than } 5 \times \text { fines } 0\end{array}$} & \multicolumn{2}{|c|}{$\mathrm{Cu} \geq 6$ and $1 \leq \mathrm{Cc} \leq 3^{E}$} & sw & Well-graded sand' \\
\hline & & & & \multicolumn{2}{|c|}{$\mathrm{Cu}<6$ and $/$ or $1>\mathrm{Cc}>3^{E}$} & SP & Poorty graded san \\
\hline & & & Sands with Fines & \multicolumn{2}{|c|}{ Fines classify as ML or MH } & SM & Silty sand $0, H$, \\
\hline & & & & \multicolumn{2}{|c|}{ Fines classify as $\mathrm{CL}$ or $\mathrm{CH}$} & SC & Clayey sand $0, \mathrm{H}, \mathrm{I}$ \\
\hline \multirow{6}{*}{$\begin{array}{l}\text { FINE-GRAINED SOILS } \\
50 \% \text { or more passes the No. } \\
200 \text { sieve }\end{array}$} & \multirow{3}{*}{\multicolumn{2}{|c|}{$\begin{array}{l}\text { Silts and Clays } \\
\text { Liquid limit less than } 50\end{array}$}} & inorganic & \multicolumn{2}{|c|}{$\mathrm{PI}>7$ and plots on or above $" \mathrm{~A}^{*}$ line } & $\mathrm{CL}$ & Lean clay KL,M \\
\hline & & & & \multicolumn{2}{|c|}{$\mathrm{PI}<4$ or plots below " $\mathrm{A}$ " line } & ML & Silt $K, L, M$ \\
\hline & & & organic & \multicolumn{2}{|c|}{$\frac{\text { Liquid limit }- \text { oven dried }}{\text { Liquid limit }- \text { not dried }}<0.75$} & $\mathrm{OL}$ & $\frac{\text { Organic clay }{ }^{K}, L, M, N}{\text { Organic silf }{ }^{X, L, M, O}}$ \\
\hline & Silts and Clays & & inorganic & \multicolumn{2}{|c|}{ P1 plots on or above ${ }^{-} A{ }^{*}$ line } & $\mathrm{CH}$ & Fat clay $\times, 2,0$ \\
\hline & & & & \multicolumn{2}{|l|}{ PI plots below "A* line } & $\mathrm{MH}$ & Elastic silt $K L, M$ \\
\hline & & & organic & \multicolumn{2}{|c|}{$\begin{array}{l}\text { Uquid limit - oven dried } \\
\text { Liquid limit - not dried }\end{array}$} & $\mathrm{OH}$ & $\frac{\text { Organic clay }{ }^{K, L, M, P}}{\text { Organic silK,L,M,O }}$ \\
\hline \multicolumn{2}{|l|}{ HIGHLY ORGANIC SOILS } & \multicolumn{4}{|c|}{ Primarily organic matter, dark in cotor, and organic odor } & PT & Peat \\
\hline \multicolumn{2}{|c|}{$\begin{array}{l}\text { 1 Based on the material passing the 3-in. (75-mm) } \\
\text { sieve. } \\
\text { 'If field sample contained cobbles or boulders, or } \\
\text { both, add "with cobbles or boulders, or both" to } \\
\text { group name. } \\
\text { 'Gravels with } 5 \text { to } 12 \times \text { fines require dual } \\
\text { symbols: } \\
\text { GW-GM well-graded gravel with sitt } \\
\text { GW-GC well-graded gravel with clay } \\
\text { GP-GM poorly graded gravel with sitt } \\
\text { GP-GC poorty graded gravel with clay } \\
\text { - Sands with } 5 \text { to } 12 \times \text { fines require dual } \\
\text { symbols: } \\
\text { SW-SM wel-graded sand with silt } \\
\text { SW-SC well-graded sand with clay } \\
\text { SP-SM poorly graded sand with silt } \\
\text { SP-SC poorly graded sand with clay }\end{array}$} & \multicolumn{3}{|c|}{ 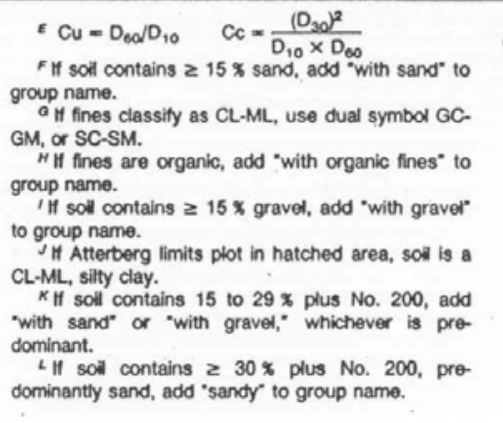 } & \multicolumn{3}{|c|}{ 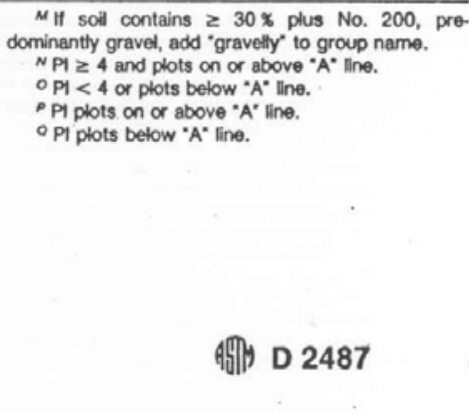 } \\
\hline
\end{tabular}

A separate ASTM standard (ASTM D 4427) provides a more detailed classification of peats, which it defines as "naturally-occurring highly organic substance derived primarily from plant materials" and distinguishes from other organic soil materials by the "lower ash content (less than $25 \%$ ash by dry weight (based on test methods contained in D 2974)). 
In ASTM D 4427 peats are classified on the basis of fiber content, ash content, acidity, absorbency and botanical composition.

Based on fiber content peats are classified either as fibric (more than $67 \%$ fibers), hemic ( $33 \%$ to $67 \%$ fiber content), and sapric (less than $33 \%$ fibers). The standard notes that the fiber content may be related to the degree of humification (H) developed by Von Post (fibric corresponds approximately to $\mathrm{H}_{1}-\mathrm{H}_{3}$; hemic corresponds to $\mathrm{H}_{4}-\mathrm{H}_{6}$; and sapric corresponds to $\mathrm{H}_{7}-\mathrm{H}_{10}$ ).

Peats are divided into 3 categories based on the ash content (i.e. the material remaining after drying in a furnace): low ash (less than $5 \%$ ash), medium ash (5\% to $15 \%$ ash), and high ash (ash content greater than $15 \%$ ).

Peats can also be classified based on the acidity, as measured by the $\mathrm{pH}$,. There are 4 categories: highly acidic ( $\mathrm{pH}$ less than 4.5 ); moderately acidic ( $\mathrm{pH}$ between 4.5 and 5.5); slightly acidic ( $\mathrm{pH}$ between 5.5 and 7.0), and finally basic $(\mathrm{pH}$ greater than or equal to 7.0 ).

Classification of the peat based on the absorbency relies on the water holding capacity of the peat as measured by Test Methods D 2980. The peat can be extremely absorbent (water holding capacity greater than 1500\%); highly absorbent (water holding capacity between 800 and 1500\%); moderately absorbent (water holding capacity greater between $300 \%$ and $800 \%$ ); and slightly absorbent (water holding capacity less than or equal to $300 \%$ ).

Finally, the botanical composition is based on the dominant plant genus, genera, or informal plant group identified by visual inspection. Peats are classified with single or double botanical names, with the only requirement that the peat should have at least $75 \%$ of fiber content from the designated type of plant. 


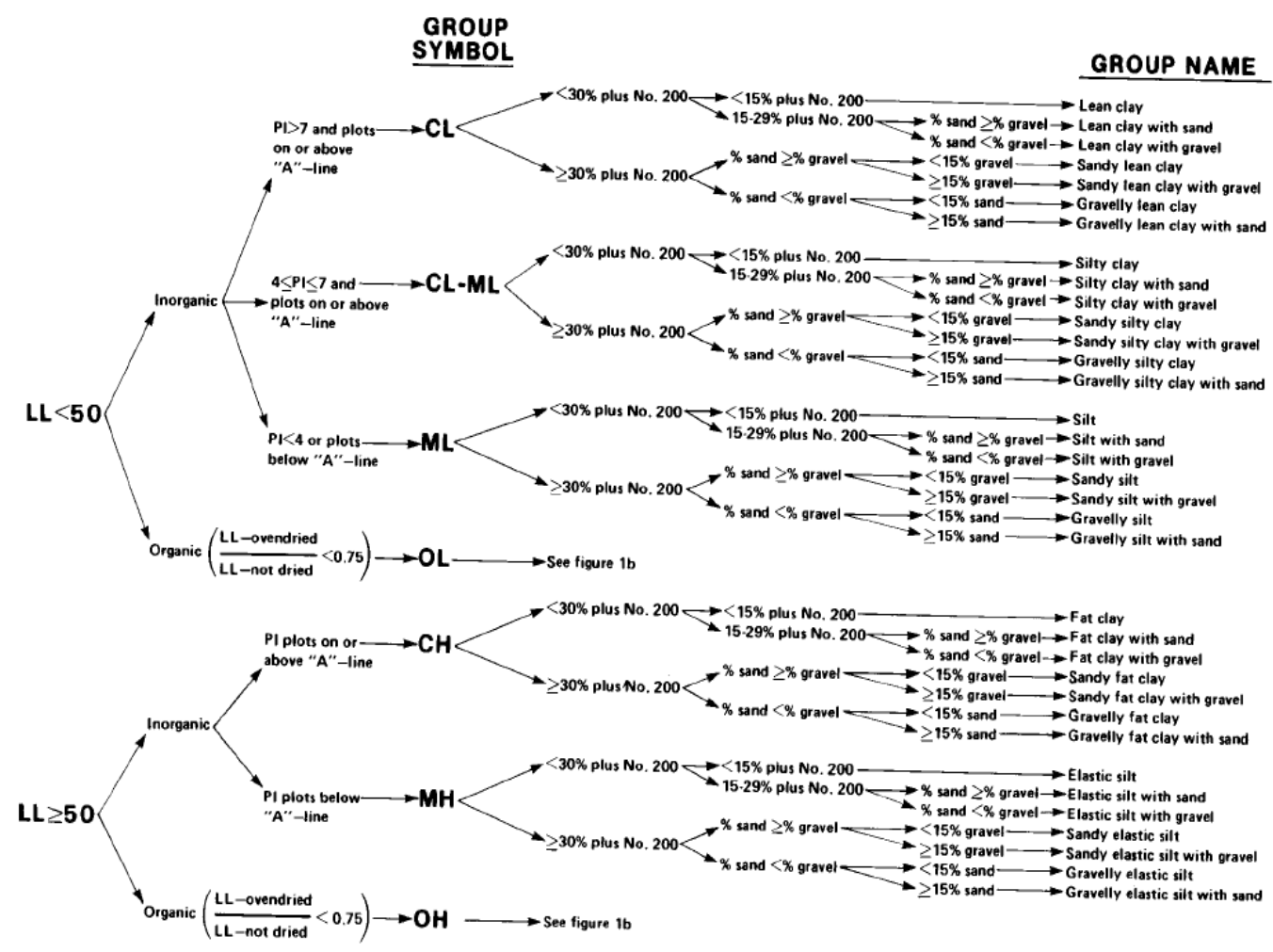

FIG. 2.6 - Classification of Fine Grained Soil (ASTM D2487)

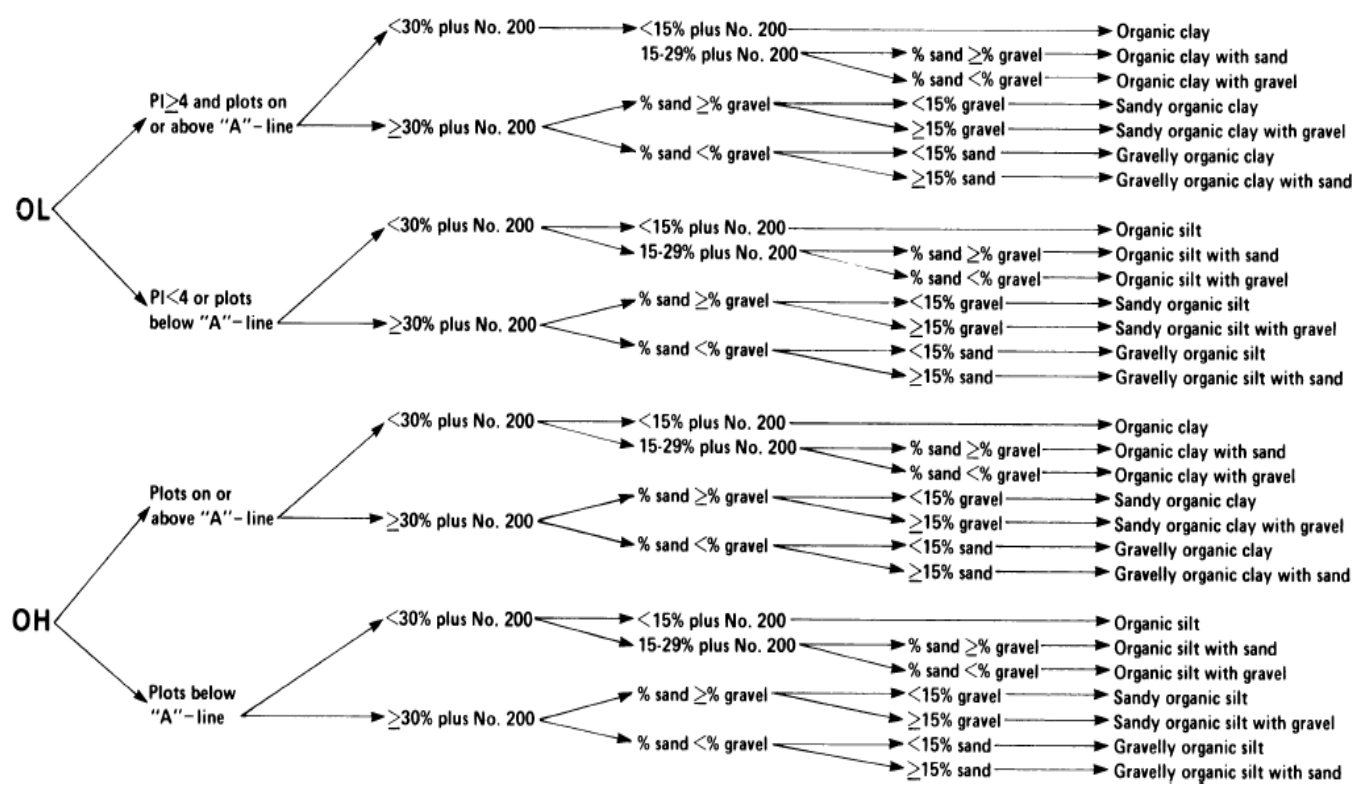

FIG. 2.7 - Classification of Organic Fine Grained Soil (ASTM D2487) 


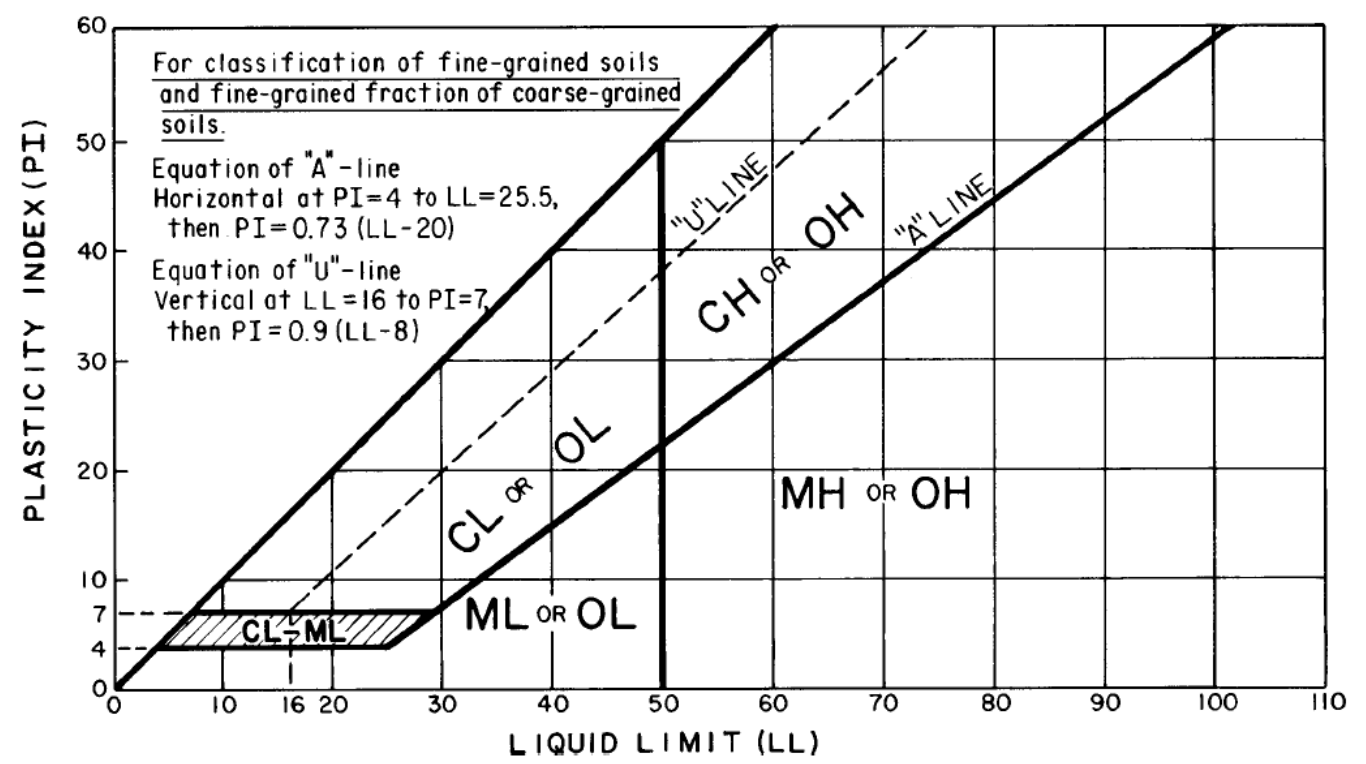

FIG. 2.8 - Plasticity Chart (From ASTM D2487)

(b) American Association of State Highway and Transportation Officials (AASHTO):

AASHTO is the association that represents the transportation departments of 50 states in the US. It represents all five transportation modes: air, highways, public transportation, rail and water. AASHTO's classification of soils is based on construction requirements related to each mode of transportation. AASHTO M-145 classifies the soil into 7 groups, from A-1 to A-7, based on particle size analysis and Atterberg limits (as shown in Table 2.10). The eighth group - A-8 - consists of Highly Organic Soils (peat or muck). The classification of this soil is based on visual inspection, and is not dependent on the results of particle size analysis or Atterberg limits. The soil is composed primarily of partially decayed organic matter which generally has fibrous texture, a dark brown or black color, and an odor of decay. 
TABLE 2.10 - Classification of soil (AASHTO M 145)

Table 1-Classification of Soils and Soil-Aggregate Mixtures

\begin{tabular}{|c|c|c|c|c|c|c|c|}
\hline \multirow{2}{*}{$\begin{array}{c}\text { General Classification } \\
\text { Group Classification }\end{array}$} & \multicolumn{3}{|c|}{$\begin{array}{c}\text { Granular Materials } \\
\text { (35 Percent or Less Passing } 75 \mu \mathrm{m} \text { ) }\end{array}$} & \multicolumn{4}{|c|}{$\begin{array}{c}\text { Silt-Clay Materials } \\
\text { (More Than } 35 \text { Percent Passing } 75 \mu \mathrm{m} \text { ) }\end{array}$} \\
\hline & A-1 & $\mathrm{A}-3^{a}$ & A-2 & A-4 & A-5 & A-6 & A-7 \\
\hline $\begin{array}{l}\text { Sieve analysis, percent passing: } \\
2.00 \mathrm{~mm} \text { (No. 10) } \\
0.425 \mathrm{~mm} \text { (No. 40) } \\
75 \mu \mathrm{m} \text { (No. 200) }\end{array}$ & $\begin{array}{c}- \\
50 \max \\
25 \max \end{array}$ & $\begin{array}{l}- \\
51 \min \\
10 \max \end{array}$ & $\begin{array}{c}- \\
- \\
35 \max \end{array}$ & $\begin{array}{c}- \\
- \\
36 \min \end{array}$ & $\begin{array}{c}- \\
- \\
36 \min \end{array}$ & $\begin{array}{c}- \\
- \\
36 \min \end{array}$ & $\begin{array}{c}- \\
- \\
36 \min \end{array}$ \\
\hline $\begin{array}{l}\text { Characteristics of fraction passing } 0.425 \mathrm{~mm} \text { (No. } 4 \\
\text { Liquid limit } \\
\text { Plasticity index }\end{array}$ & $6 \max$ & $\mathrm{NP}$ & ${ }^{b}$ & $\begin{array}{l}40 \max \\
10 \max \end{array}$ & $\begin{array}{l}41 \min \\
10 \max \end{array}$ & $\begin{array}{l}40 \max \\
11 \min \\
\end{array}$ & $\begin{array}{l}41 \mathrm{~min} \\
11 \mathrm{~min}\end{array}$ \\
\hline General rating as subgrade & \multicolumn{3}{|c|}{ Excellent to Good } & \multicolumn{4}{|c|}{ Fair to Poor } \\
\hline
\end{tabular}

a The placing of A-3 before A-2 is necessary in the "left to right elimination process" and does not indicate superionity of A-3 over A-2.

- See Table 2 for values.

Table 2-Classification of Soils and Soil-Aggregate Mixtures

\begin{tabular}{|c|c|c|c|c|c|c|c|c|c|c|c|}
\hline General Classification & \multicolumn{7}{|c|}{$\begin{array}{c}\text { Granular Materials } \\
\text { (35 Percent or Less Passing } 75 \mu \mathrm{m})\end{array}$} & \multicolumn{4}{|c|}{$\begin{array}{c}\text { Silt-Clay Materials } \\
\text { (More Than } 35 \text { Percent Passing } 75 \\
\mu \mathrm{m})\end{array}$} \\
\hline \multirow[b]{2}{*}{ Group Classification } & \multicolumn{2}{|c|}{ A-1 } & \multirow[b]{2}{*}{ A-3 } & \multicolumn{4}{|c|}{ A-2 } & \multirow[b]{2}{*}{ A-4 } & \multirow[b]{2}{*}{ A-5 } & \multirow[b]{2}{*}{ A-6 } & A-7 \\
\hline & A-1-a & $A-1-b$ & & A-2-4 & A-2-5 & A-2-6 & A-2-7 & & & & $\begin{array}{l}\text { A-7-5, } \\
\text { A-7-6 }\end{array}$ \\
\hline \multicolumn{12}{|l|}{ Sieve analysis, percent passing: } \\
\hline $2.00 \mathrm{~mm}$ (No. 10) & $50 \max$ & - & - & - & - & - & - & - & - & - & - \\
\hline $0.425 \mathrm{~mm}$ (No. 40$)$ & $30 \max$ & $50 \max$ & $51 \mathrm{~min}$ & - & - & - & - & - & - & - & - \\
\hline $75 \mu \mathrm{m}$ (No. 200) & $15 \max$ & $25 \max$ & $10 \max$ & $35 \max$ & $35 \max$ & $35 \max$ & $35 \max$ & $36 \min$ & $36 \mathrm{~min}$ & $36 \min$ & $36 \min$ \\
\hline \multicolumn{12}{|l|}{ Characteristics of fraction passing $0.425 \mathrm{~mm}$ (No. 40 ) } \\
\hline Liquid limit & \multicolumn{2}{|c|}{-} & - & $40 \max$ & $41 \mathrm{~min}$ & $40 \max$ & $41 \mathrm{~min}$ & $40 \max$ & $41 \mathrm{~min}$ & $40 \max$ & $41 \min$ \\
\hline Plasticity index & \multicolumn{2}{|c|}{$6 \max$} & NP & $10 \max$ & $10 \max$ & $11 \mathrm{~min}$ & $11 \mathrm{~min}$ & $10 \max$ & $10 \max$ & $11 \mathrm{~min}$ & $11 \min ^{a}$ \\
\hline Usual types of significant constituent materials & \multicolumn{2}{|c|}{$\begin{array}{l}\text { Stone fragments, } \\
\text { gravel and sand }\end{array}$} & $\begin{array}{l}\text { Fine } \\
\text { sand }\end{array}$ & \multicolumn{4}{|c|}{ Silty or clayey gravel and sand } & \multicolumn{2}{|c|}{ Silty soils } & \multicolumn{2}{|c|}{ Clayey soils } \\
\hline General rating as subgrade & \multicolumn{7}{|c|}{ Excellent to Good } & \multicolumn{4}{|c|}{ Fair to Poor } \\
\hline
\end{tabular}

- Plasticity index of A-7.5 subgroup is equal to or less than LL minus 30. Plasticity index of A-7.6 subgroup is greater than LL minus 30. (See Figure 2.)

\subsubsection{Engineering Classification of The International Organization for}

\section{Standardization (ISO)}

A soil classification system is also provided by The International Organization for Standardization in ISO 14688-1 (2002) and ISO 14688-2 (2004). Similarly to what was described above for the ASTM and AASHTO classification systems, ISO 14688-2, which address the classification principles, indicates that this system utilizes particle size distribution and plasticity to identify boulders, cobbles, gravels, sands, silts and clays. However, this system also includes 
organic content as a key characteristic used in classifying soils. Specifically, a distinction is made between low organic content (organic content between 2 and $6 \%$ - by dry mass), medium organic content (organic content between 6 and 20\%); and high organic content (organic content greater than 20\%) soils. The presence of organics is recognized in the denomination proposed by the standard through the use of the symbol "Or" when the organic material represents the "principal" component of the soil (e.g. saOr to refer to a sandy organic soil), and by the symbol "or" when it is the secondary or tertiary component (e.g. orSa ro refer to a organic sand). ISO 14688-2 also states that classification of in situ organic soils should be "based on the type of organic matter, [...], on the genetic origin and the degree of decomposition of the organic constituents." Additional guidance on this matter is provided in Part 1 of ISO 14688, which is devoted to " identification and description of soils [.... by visual and manual techniques." Here organic matter is defined as "matter consisting of plant and/or animal organic materials, and the conversion products of those materials, e.g. humus." The standard suggests that "small quantities of dispersed organic matter in a soil can produce a distinctive odour and colours" and it is recommended that both odor and color be described as their intensity "indicates the proportion of organic matter." For soils consisting principally of organic matter, ISO 14688-1 provides the following designation based on degree of decomposition (determined in the wet state by squeezing), and fiber content:

- Fibrous peat - which is characterized by a fibrous structure, with easily recognizable plant remains, and retains some strength. 
— Pseudo fibrous peat - which has an easily recognizable plant structure but a diminution in strength.

- Amorphous peat - which has no visible plant structure and mushy consistency.

— Gyttja - which is formed by decomposed plant and animal remains and may contain inorganic constituents.

- Humic soils - which contain plant remains and living organisms, as well as a large content of inorganic constituents.

\subsubsection{Classification by Indiana Department of Transport (INDOT)}

INDOT has adopted the AASHTO soil classification system. However, with regards to organic soils, INDOT utilizes its own classification system summarized in Figure 2.9: soils with an organic content greater than 30\% are classified as peats; soils with organic content greater than $19 \%$ but less than $30 \%$ as organic soils; soils with organic content between 13 and $19 \%$ are said to have "some organic matter"; soils with organic content between 7 and $13 \%$ aresaid to have "little organic matter"; and finally, soils with organic content between 1 and 7\% are referred to as having traces of organic matter.

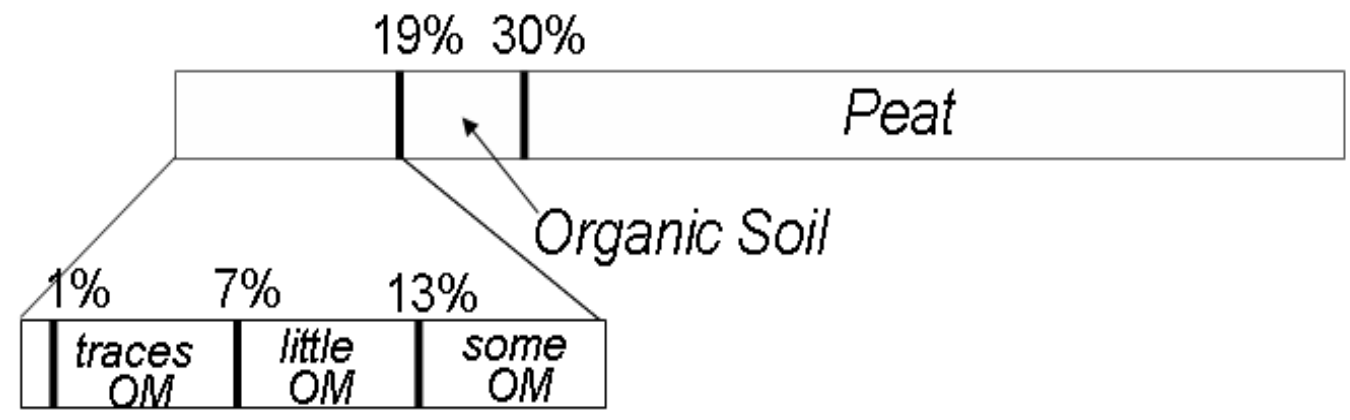

FIG 2.9 - Classification of soil according to INDOT 


\subsection{Other Classification Systems}

This section discusses the information contained in the paper "Classification of organic soil for engineering geology" published in the Geological Quarterly (Myslinska 2003) (section 2.6.1) and briefly reviews some of the classification systems summarized in the paper "Geotechnical Classification of Peats and Organic Soils" (Landva et al. 1983) published in a ASTM special technical publication devoted to testing of peats and organic sols (section 2.6.2).

\subsubsection{Classification Systems Reviewed by Myslinska (2003)}

The author reviews approaches to the classification of organic soils as applied in different countries (with particular attention to European norms) and then proposes a classification system

According to the studies carried out by the author the approaches to classifying organic soils used in various countries can be organized in 3 classes: (a) Genetic Classification (b) Non Genetic (Descriptive) Classification and (c) Descriptive-Genetic Classification.

(a) Genetic Classification :

Genetic classification systems classify organic soils depending on the environment in which they are present. For example, a fluvial environment leads to the formation of Gyttja soil; a fluvial - terrestrial environment leads to Fen Peat ${ }^{14}$; while a terrestrial environment leads to Bog Peat ${ }^{15}$ and

\footnotetext{
${ }^{14}$ Fen Peat - Peat that forms as plants such as sedges, reeds and herbs die and accumulate at the bottom of the lake.
} 
Transition Peat soils.

(b) Non Genetic Classification:

Non genetic classification systems classify organic soils based on the organic matter content. An example of this type of classification is that used in France, which is summarized in Table 2.11. In The Netherlands, a country where these soils are dominant, organic soils are classified based on the percentage of three components: organic matter, clay fraction (fi) and the sum of the sand and silt fraction (fp). According to this subdivision, two groups of organic soils are distinguished: peats (15-100\% organic matter; $0-70 \%$ clay and other fractions) and other organic soils-humus (0-15\% organic matter; $70-100 \%$ clay and other fractions). As shown in Table 2.12, peats are subdivided into poorly clayey, strongly clayey, poorly sandy and strongly sandy, and humic soils are further subdivided into poorly and strongly humic.

Also the German norm DIN 18196 utilizes threshold values of the organic content to classify a soil as organic. Specifically, a sand is classified as organic if the organic content is greater than 3\%; for a finer soil the threshold value increases to $5 \%$.

${ }^{15}$ Bog Peat - This is acidic peat formed as a result of a deposit of dead plant material. 
TABLE 2.11 French Non Genetic Classification of Organic Soils

\begin{tabular}{cc}
\hline Classification & \% Organic Content \\
\hline Poorly Organic Soil & $<10 \%$ \\
Medium Organic Soil & 10 to $30 \%$ \\
Highly Organic Soil & $>30 \%$ \\
\hline
\end{tabular}

TABLE 2.12 Non Genetic Soil Classification System in The Netherlands

\begin{tabular}{llc}
\hline & Classification & $\%[\mathrm{OM}], \%[\mathrm{fi}], \%[\mathrm{fp}]$ \\
\hline \multirow{4}{*}{ Peat } & Poorly Clayey & $30-55 \% \mathrm{fi}$ \\
& Strongly Clayey & $55-70 \% \mathrm{fi}$ \\
& Poorly Sandy & $22.5-35 \% \mathrm{OM} ; 30-55 \% \mathrm{fi}, 0-8 \% \mathrm{fp}$ \\
& Strongly Sandy & $15-22.5 \% \mathrm{OM} ;>8 \% \mathrm{fp}$ \\
\hline \multirow{2}{*}{ Humus } & Poorly Humic & $0-2.2 \% \mathrm{OM}$ \\
& Strongly Humic & $2.2-15 \% \mathrm{OM}$ \\
\hline
\end{tabular}

$\mathrm{OM}=$ organic matter; $\mathrm{fi}=$ clay fraction; $\mathrm{fp}=$ sand and silt fraction

(c) Descriptive-Genetic Classification:

According to Myslinska (20030 classification systems belonging to this third category are based on threshold values of the organic content as well as consideration of the origin of the soil. As an example of a classification system falling in this category, Myslinska cites the ISO classification system discussed above (Section 2.5.3).

Myslinska (2003) also discusses various classification systems utilized in Poland. The current Polish norm (PN-86/B-0248) classifies organic soils in the following 4 classes, based on the origin of the organic soil:.

- Humic soils (non-rocky soils containing over $2 \%$ of organic particles of 
plant origin, microflora and microfauna);

- Warps (sandy or clayey soils developed during accumulation of mineral and organic particles in an aqueous environment);

— Gyttja (muds with a calcium carbonate content exceeding 5\%, which form the soil skeleton, resulting in a rocky soil with a low value of shear strength)

- Peats (soils developed from decayed plant remains, undergoing carbonization, with organic matter content usually over $30 \%$ ).

Note that a previous version of the norm included further subdivision of the classes based on organic matter content.

Other standards and norms used in Poland are also reported, including one given by Wolski (1996), that contains contains descriptive as well as genetic elements. Specifically, this classification system distinguishes the following soils:

— low ash peats, containing $0-25 \%$ ash;

— medium ash peaty soils, containing $25-50 \%$ ash;

— high ash muds, containing 50-80\% ash;

— organic silts and clays (mineral-organic soils), containing

80-98\% ash;

— gyttja and lake marl (organic-calcareous soils, which are considered as a separate group, irrespective of ash content).

The last Polish classification system reviewed by Myslinska (2003) - also 
falling in the third cathegory identified above- is that provided by another Polish researcher (Borys 1996 - in Polish), who subdivides organic soils into:

— warps (ash content (Ac) 80-98\%);

- muds (Ac 25-80\%);

— muddy peats (Ac 25-80\%);

non-muddy peats (Ac 0-25\%) (amorphous, amorphous-fibrous, fibrous);

— mucks (Ac 20-98\%).

- gyttja, which is further subdivide in : organic (Ac <65\%; $\mathrm{CaCO} 3$ 0-20\%); carbonate (Ac $<60 \%$; $\mathrm{CaCO} 320-90 \%$ ); and mineral (Ac $>65 \% ; \mathrm{CaCO}<20 \%)$.

Following the review of existing classification systems, Myslinska (2003) proposes a new classification system, which considers both the origin of the organic soil and the organic matter content (and hence falls in the third of the categories identified above). This classification system, which is summarized in Figure 2.10 starts from a genetic subdivision of organic soils, as the environment of deposition and the post-depositional transformations are known to affect chemical, physico-chemical and mechcanical properties). Hence, a distinction is made, for example, between fen peats and bog peats; mucks (formed from peats after watering) and gyttja are considered separately; and muds, which are alluvial deposits are treated differently from mineral soils. In the chart shown in Figure 2.10, the various subdivisions are plotted in correspondence to different 
ranges of ash content $\left(A_{c}\right.$ - determined by the loss on ignition method) or the organic matter content $\left(\mathrm{I}_{\mathrm{om}}\right)$. An additional subdivision is based on $\mathrm{I}_{\mathrm{om}}$ (or $A_{c}$ ), which influences most of the physico-mechanical properties; for example see the distinction between organic $\left(\mathrm{I}_{\mathrm{om}}=25-80 \%\right)$, mineral-organic $\left(\mathrm{I}_{\mathrm{om}}=10-30 \%\right)$, and mineral $\left(\mathrm{I}_{\mathrm{om}}=2-10 \%\right)$ gyttja. (Note the slight overlap in these subdivisions, which finds no clear explanation in the paper.

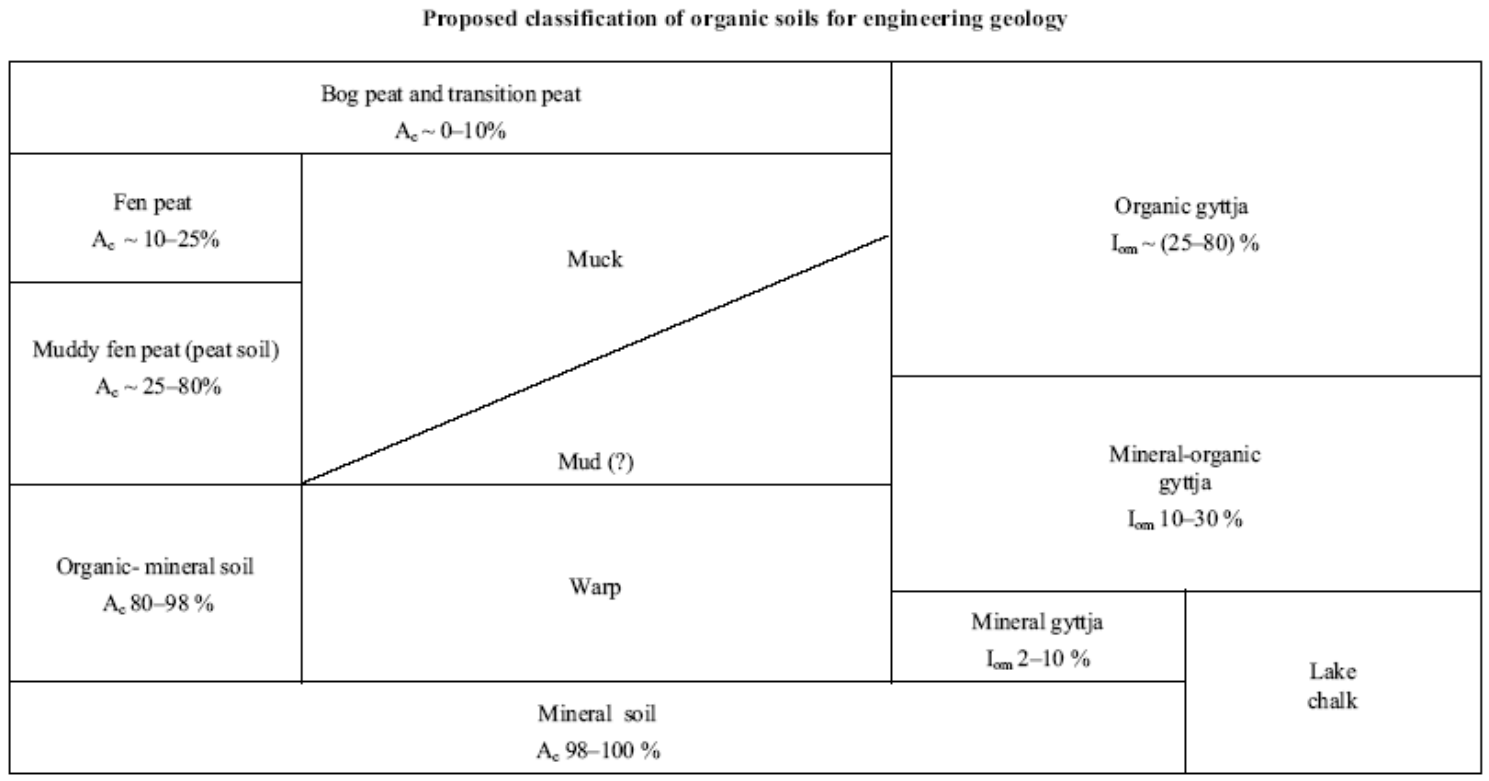

Figure 2.10 - Soil Classification System Proposed by Myslinska (2003)

\subsubsection{Classification Systems Reviewed by Landva et al. (1980)}

The authors of this publication review different systems used to classify organic soils and peats with the goal of indentifying the approaches more relevant to geotechnical engineers. Of particular relevance to this research is the summary data reported in Figure 2.11 below, which 
summarizes the threshold ash content values used by various classification systems to distinguish between mineral soils, organic soils and peats (note that if the loss on ignition can be ascribed solely to the combustion of organic matter [this is not necessarily the case, as will be discussed in Chapter 4], the organic content can be calculated as $100 \%$ - ash content(\%)). In the figure IPS refers to the International Peat Society and CSSC to the Canada Soil Survey Committee. The other references pertain to studies by individual researchers, while the last reference is the classification system proposed by Landva et al. (1980) as a result of their review and research work. Figure 2.10 indicates significant variation in the terminology used to denote these soils, as well as in the threshold ash content values used to identify the transition between organic soils and peats. Finally, note that only the bottom three studies recognize the potential impact of the presence of less than $5-10 \%$ organic matter. 


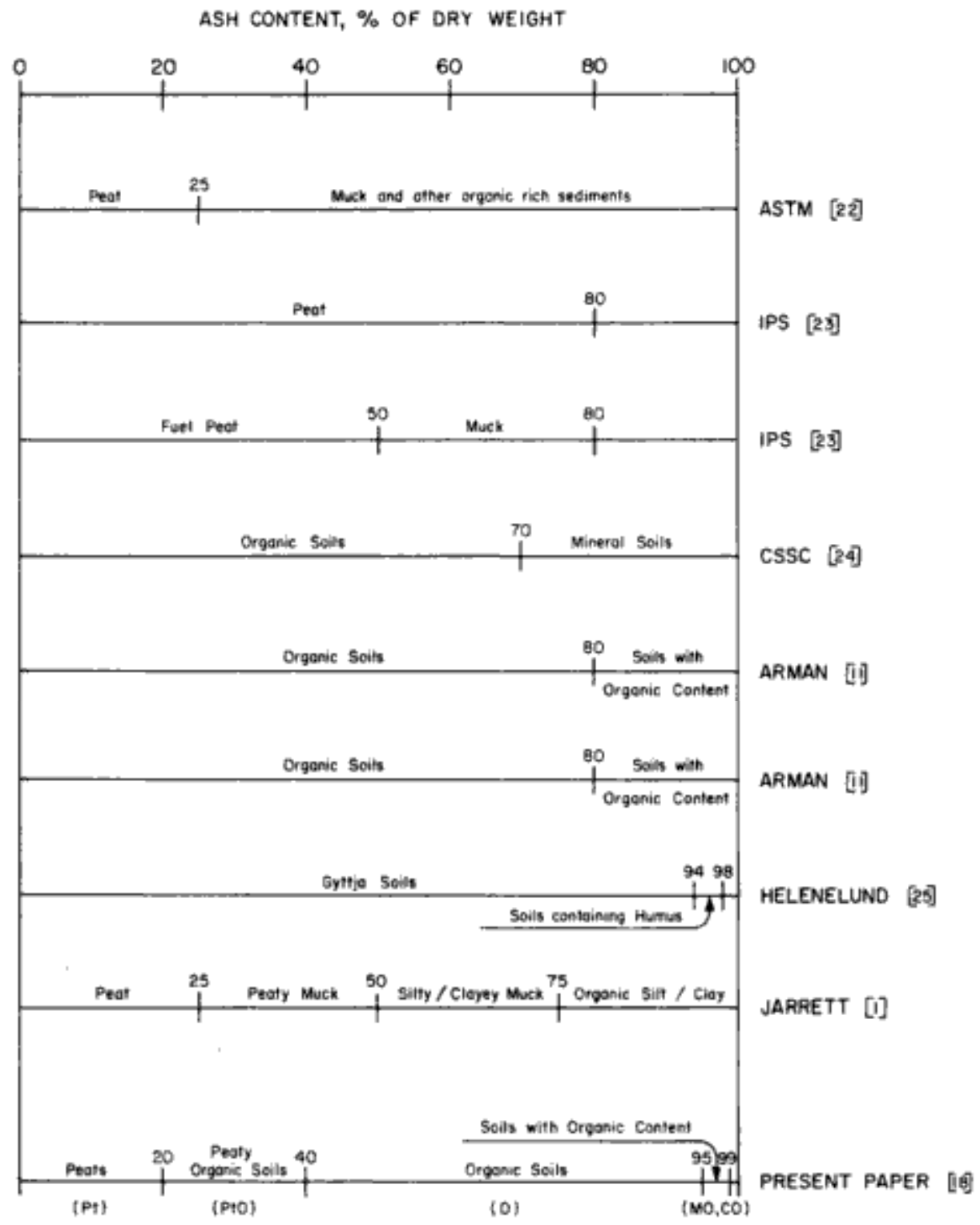

FIG 2.11 - Divisions used for classifying peats and organic soils (Landva et al. 1980) 


\section{CHAPTER 3}

\section{Effects of Organic Matter on Geotechnical Properties of Soil}

\subsection{Introduction}

The effects of organic matter on soil properties have been extensively investigated in the technical literature, particularly in the soil science and agronomy fields, due to the important role played by organic matter in fertilizers, soil-applied pesticides, and the carbon cycle. In civil engineering, however, organic matter has not received the same attention, even though it is recognized that organic matter plays a critical role in engineering practice. The presence of organic matter in soils is associated with lower specific gravity, higher compressibility, larger creep coefficients, as well as unsatisfactory strength characteristics. These properties are the reason why soils with significant organic matter are perceived by civil engineers as "problem soils".

This chapter provides a summary of the effects of organic matter on the geotechnical properties of soils. The first section addresses index properties while the second section discusses engineering properties.

\subsection{Index Properties}

The basic soil indices include water content, gas content, bulk density, specific gravity, particle size distribution, Atterberg limits, shrinkage potential, and two chemical indices: cation exchange capacity and acidity. The following sections discuss the influence of organic matter on the above indices. 


\subsubsection{Water Content}

Organic soils usually have very high water content. The fibrous structure of the soils results in large voids and the high cation exchange capacity of organic matter increase the attraction of water molecules; both properties result in high water content.

Figure 3.1 presents the range of water content with ash content (the organic content is calculated as $100 \%$ minus the ash content (\%)). Figure 3.1 shows that the average water content significantly increases with organic content, especially for organic content less than $80 \%$. The water content of organic soils can be three orders of magnitude larger than inorganic soils. For example, for peats, with an organic content larger than $75 \%$, the water content ranges from $600 \%$ to $1600 \%$ or higher.

Figure 3.2 illustrates the influence of the "nature" of the organic matter. The more humified (decomposed) the organic soil is, the smaller the water content. This is related with the decomposition of the plant matter of the soil (fibric) into amorphous (sapric) material. In other words, for a soil with the same organic matter content, the water content decreases with the degree of humification.

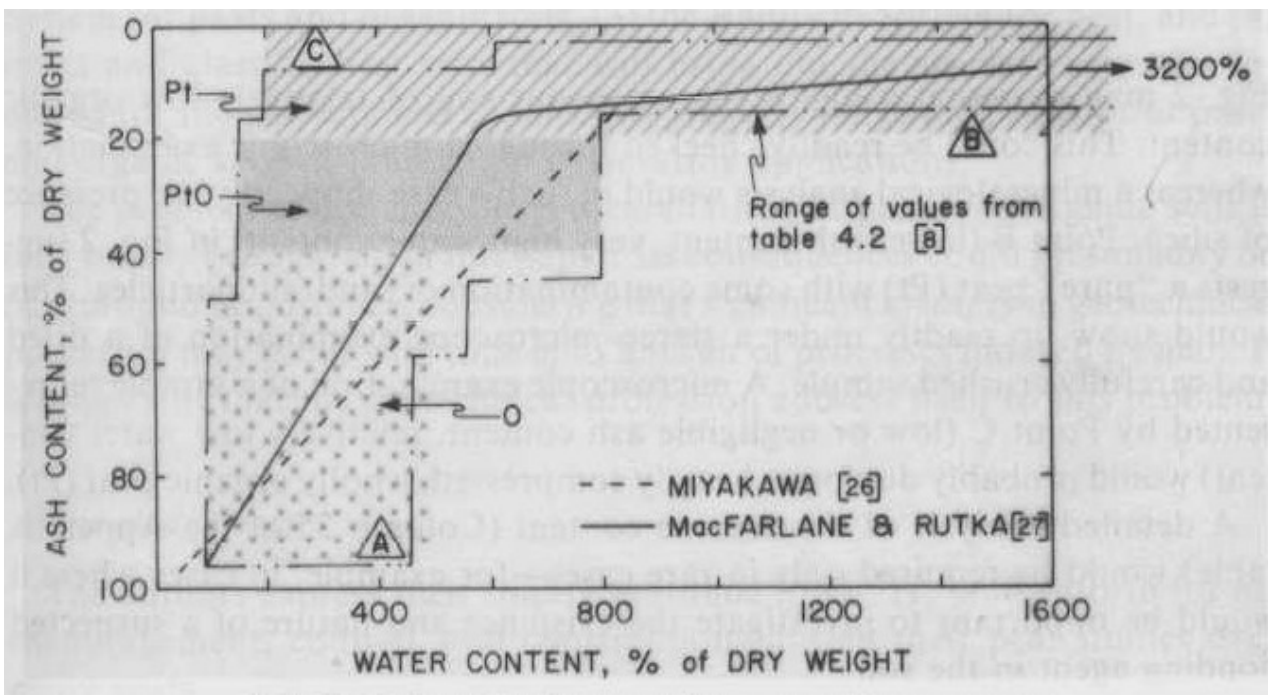

FIG 3.1- Relationship between ash content and water content (P.M. Jarrett (Ed.), 1983) 


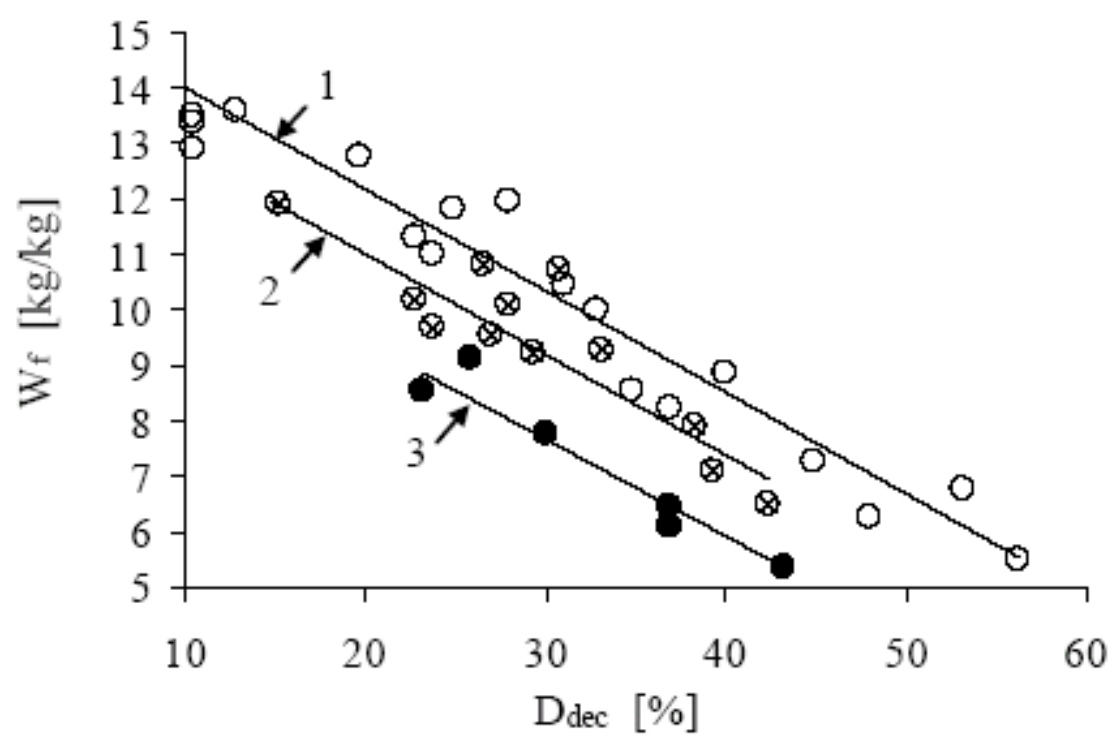

FIG 3.2-Dependence of total water content on the degree of peat decomposition (Amaryan, 1993)

\subsubsection{Gas Content}

The gas content of a soil is a very important parameter, which can change with time. The gas content influences permeability, consolidation rate, and pore pressure generation (Lea and Brawner, 1963). In organic soils there are two types of pores: macro and micro pores (additional comments are provided in the discussion about permeability). The gas in the macro pores is free gas while the gas in the micro voids is entrapped. The macro pores can be reduced by confining pressure but the micro pores cannot. Thus permeability, deformability, and pore pressure generation, are strongly linked with the size of the macro pores and the nature of their fluid.

The organic matter may undergo chemical decomposition which is accompanied by the production of marsh gas with small amounts of nitrogen and carbon dioxide. This is a concern for buildings and other facilities built on a highly organic soil (MacFarlane 
(Ed), 1969) since marsh gas can be released through fissures and holes and cause burning (Moran, 1958).

The gas content in organic soil cannot be easily measured. Moran et al. 1958, used consolidation tests to determine the volume of free gas in highly organic soils. Figure 3.3 shows the results obtained from the consolidation tests. The curves represent the volume of free gas and total gas against the void ratio at different degrees of saturation. The difference between total gas and free gas is the gas entrapped in the micro voids. The figure shows that for lower degrees of saturation the entrapped gas decreases with decreasing void ratio. This is because of the diffusion of entrapped gas into unsaturated pores.

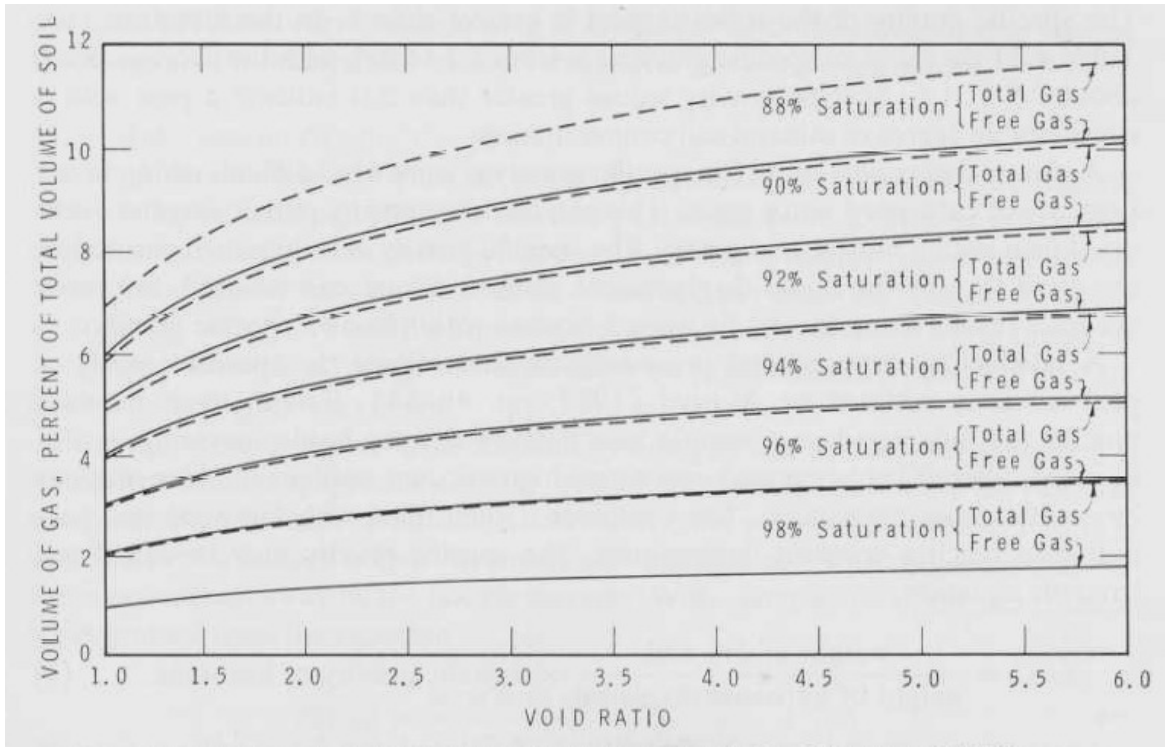

FIG 3.3-Volume of gas in a laboratory sample of peat (after Moran et al. 1958)

\subsubsection{Bulk Density}

Bulk density is defined as the ratio of the dry weight of soil to its total volume. Bulk density is a function of void ratio, organic content, and specific gravity. Typically, soils with higher organic content have low bulk density, especially when the fiber content 
is high (i.e. low degree of decomposition). Figure 3.4 presents a relationship between bulk density and degree of decomposition. The fibers in the organic soil create a more open structure which results in more voids. The reduction of bulk density with fiber content is substantial. For example, for a soil with over $80 \%$ fiber content, the bulk density can be as low as $0.05 \mathrm{~g} / \mathrm{cc}$.

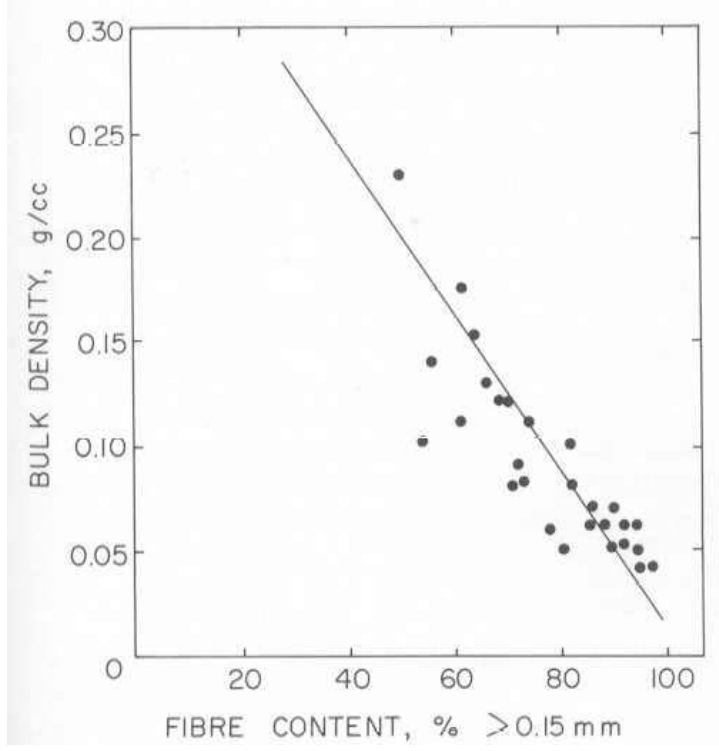

FIG 3.4- Bulk density and degree of decomposition (Radforth et al, 1996)

\subsubsection{Specific Gravity}

The specific gravity of soils with high organic content is generally in the range of 1.0 to 2.0. For soils with high organic content, a typical value is 1.5 . The mineral content increases the specific gravity; thus specific gravities greater than 2.0 are an indication of a soil with high mineral content (i.e. low organic content) (MacFarlane (Ed.), 1969).

Figure 3.5 shows a relationship between specific gravity and organic content. The specific gravity tends to decrease as the organic content increases. There is substantial 
scatter in the figure, in particular in soils with $80 \%$ and larger organic content; however there is a clear trend of increasing specific gravity with decreasing organic content. The scatter is due to the presence of entrapped air or gas, which makes measurements difficult especially in high-organic content soils (MacFarlane (Ed.), 1969).

As with bulk density, the specific gravity also degreases as the fiber content increases. Figure 3.6 gives a relation between specific gravity and fiber content.

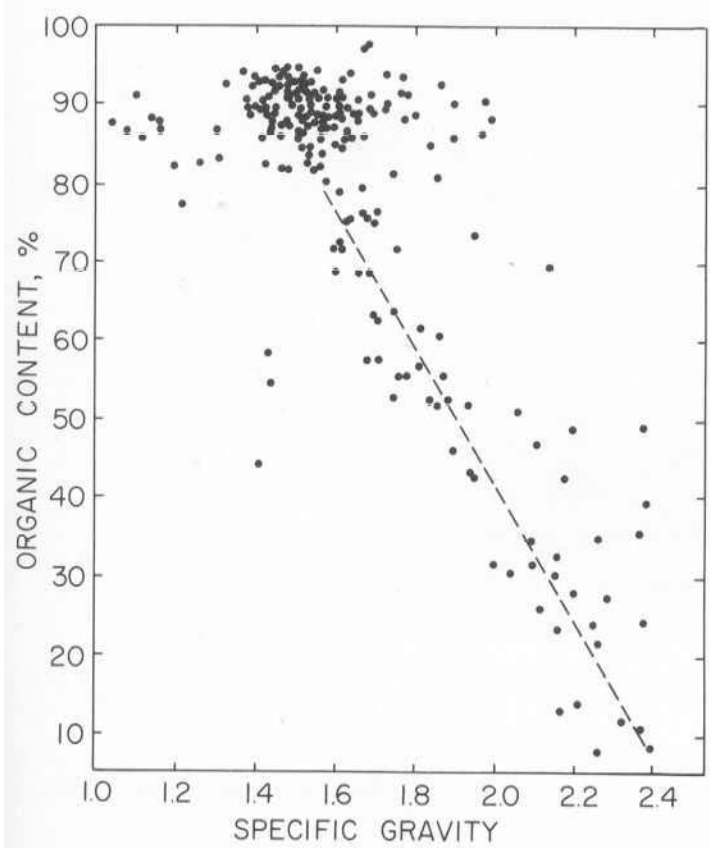

FIG 3.5- Specific gravity and organic content (Radforth et al, 1996) 


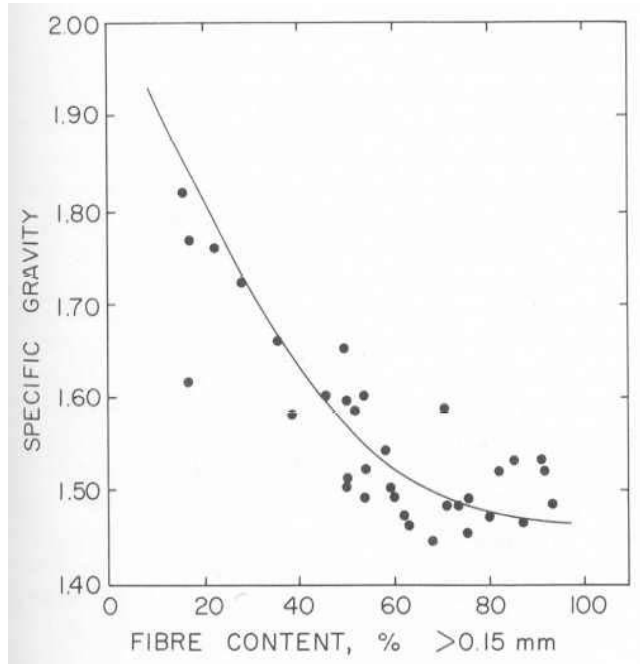

FIG 3.6- Specific gravity and fiber content (Radforth et al, 1996)

\subsubsection{Particle Size Distribution}

Particle size distribution is an index that represents the state of soil aggregation. Typically $50-80 \%$ of organic matter is absorbed on the clay surface; the rest is relatively un-decomposed, for example plant roots (Abdallah, 1999). Particle size distribution is affected by two mechanisms: aggregation and dispersion. Organic matter influences aggregation in three ways.

(1) Organic substances may behave as binding agents of clay particles. Binding may occur through H-bonding and coordination with polyvalent cation, which neutralizes the negative charge of the clay surface by the acidic functional group of organic matter (i.e. $\mathrm{COO}^{-}$) which reduces the repulsion between clay particles.

(2) Organic matter surrounding clay particles provides cementation and encapsulation of the particles which hold them together.

(3) Soil particles can also be held together by fungal hyphen and microscopic plant roots. 
Dispersion reduces aggregation of soil particles. There are three possible mechanisms for dispersion (Abdallah, 1999):

(1) Saturation of the surface adsorption sites of the particles

(2) Reversal of surface charge (Weber, 1972)

(3) Intermolecular competition for bonding site

Figures 3.7 to 3.9 illustrate the aggregation and dispersion mechanisms. The figures represent the size distribution of an illitic soil with different organic content. Figure 3.7 presents the particle size distribution with the illitic soil with no organic matter; Figure 3.8 with $5.5 \%$ organic and Figure 3.9 with $29.6 \%$ organic. Small amounts of organic matter (Figure 3.8) cause aggregation, while larger amounts (Figure 3.9) cause dispersion.

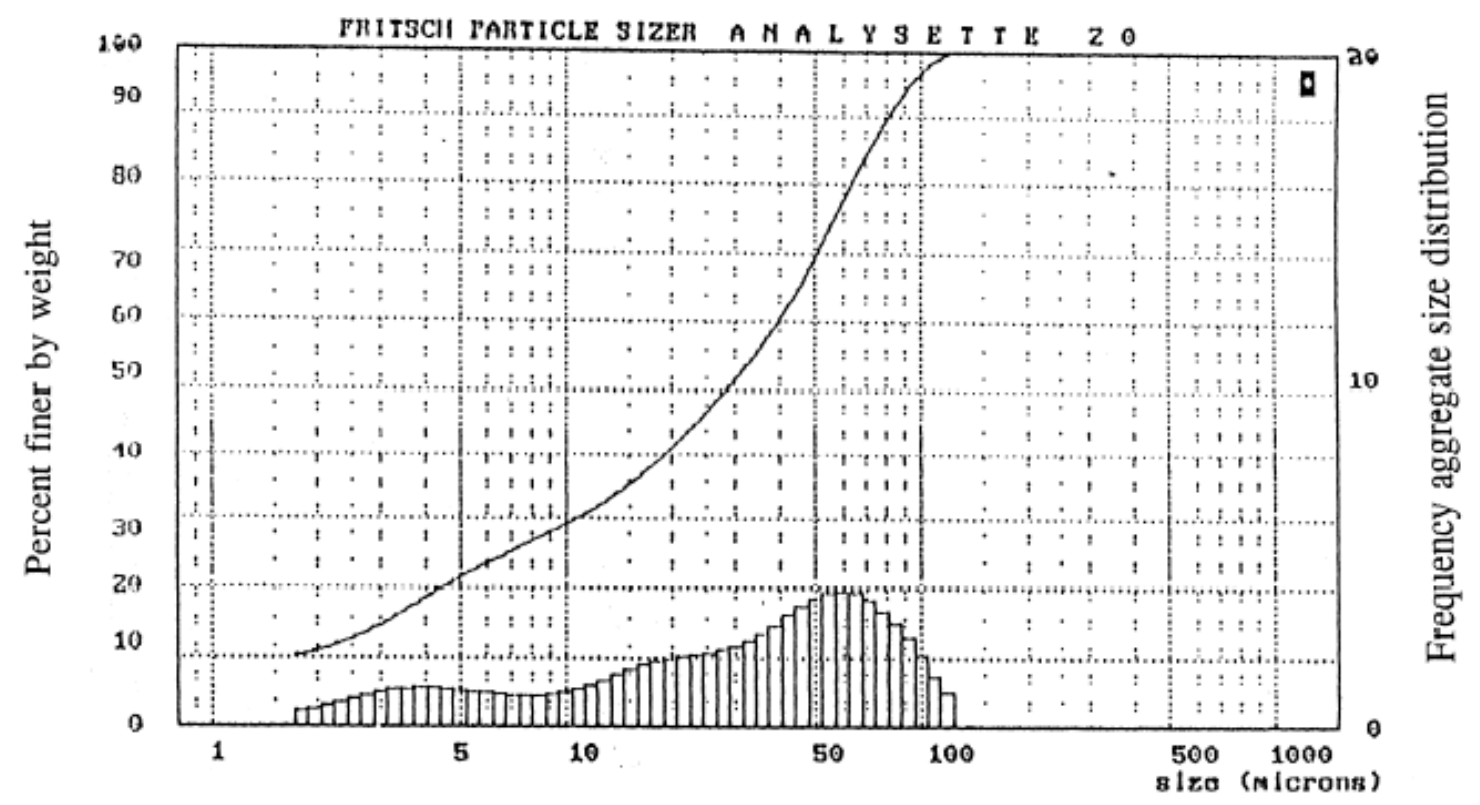

FIG 3.7- Particle size distribution of illitic soils with 0\% organic content (Abdallah, 1999) 


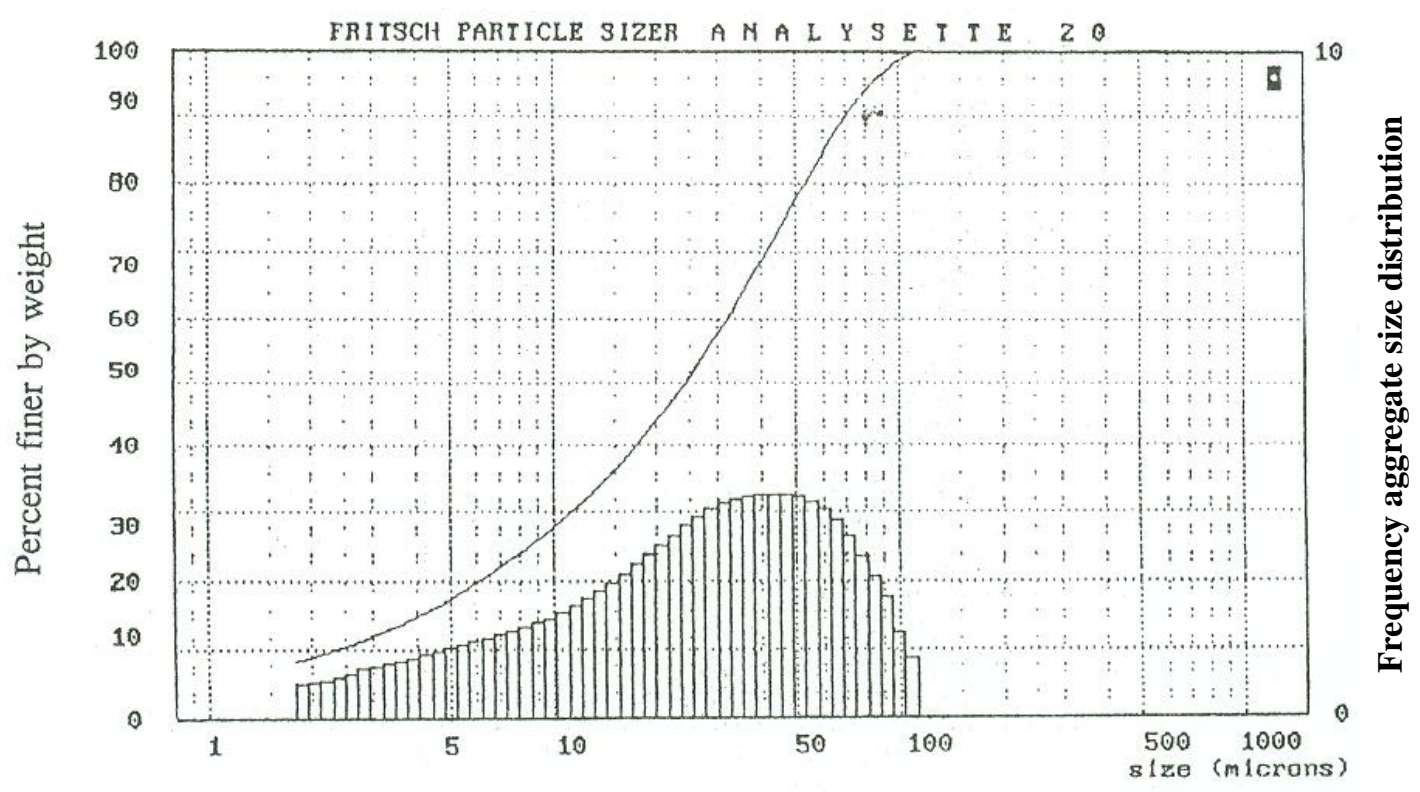

FIG 3.8- Particle size distribution of illitic soils with 5.5\% organic content (Abdallah, 1999)

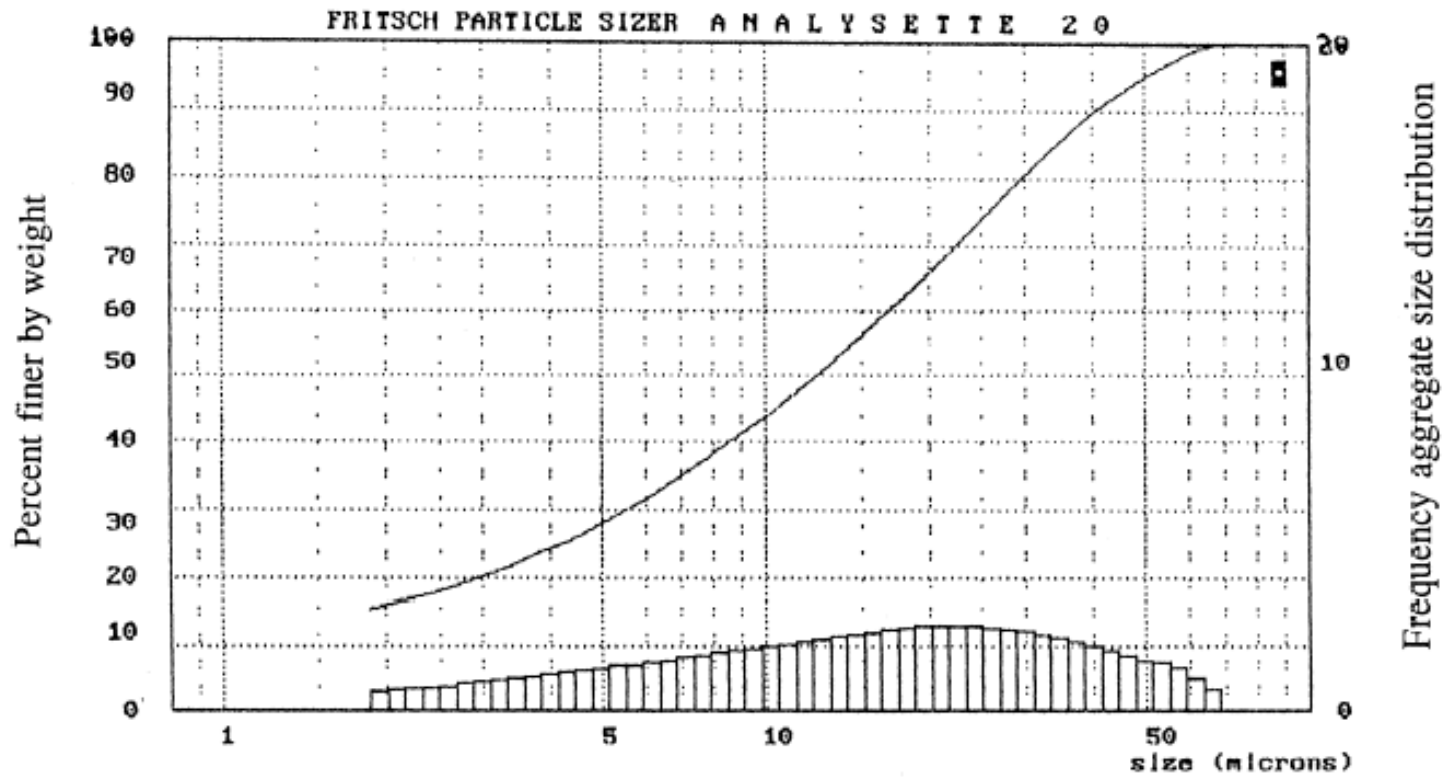

FIG 3.9- Particle size distribution of illitic soils with 29.6\% organic content (Abdallah, 1999)

\subsubsection{Atterberg Limits}

Atterberg limits comprise liquid limit (LL) and plastic limit (PL). The Atterberg limits of an organic soil depend on two opposing characteristics: higher water adsorption 
capacity of organic matter, and particle aggregation from organic substances. The higher water adsorption of the organic matter increases the limits, but the tendency of organic matter to aggregate the soil mineral fraction tends to reduce the limits. In general both liquid and plastic limits increase with organic content. This is so because the water adsorption capacity of the organic matter usually exceeds the reduction caused by organic matter induced aggregation. Figure 3.10 gives the trend of liquid and plastic limits with organic content. The limits were conducted drying the soil at two different temperatures. The results indicate that the limits depend on the drying method. This is expected because the higher temperature usually removes more free water than lower temperature does during the same period.
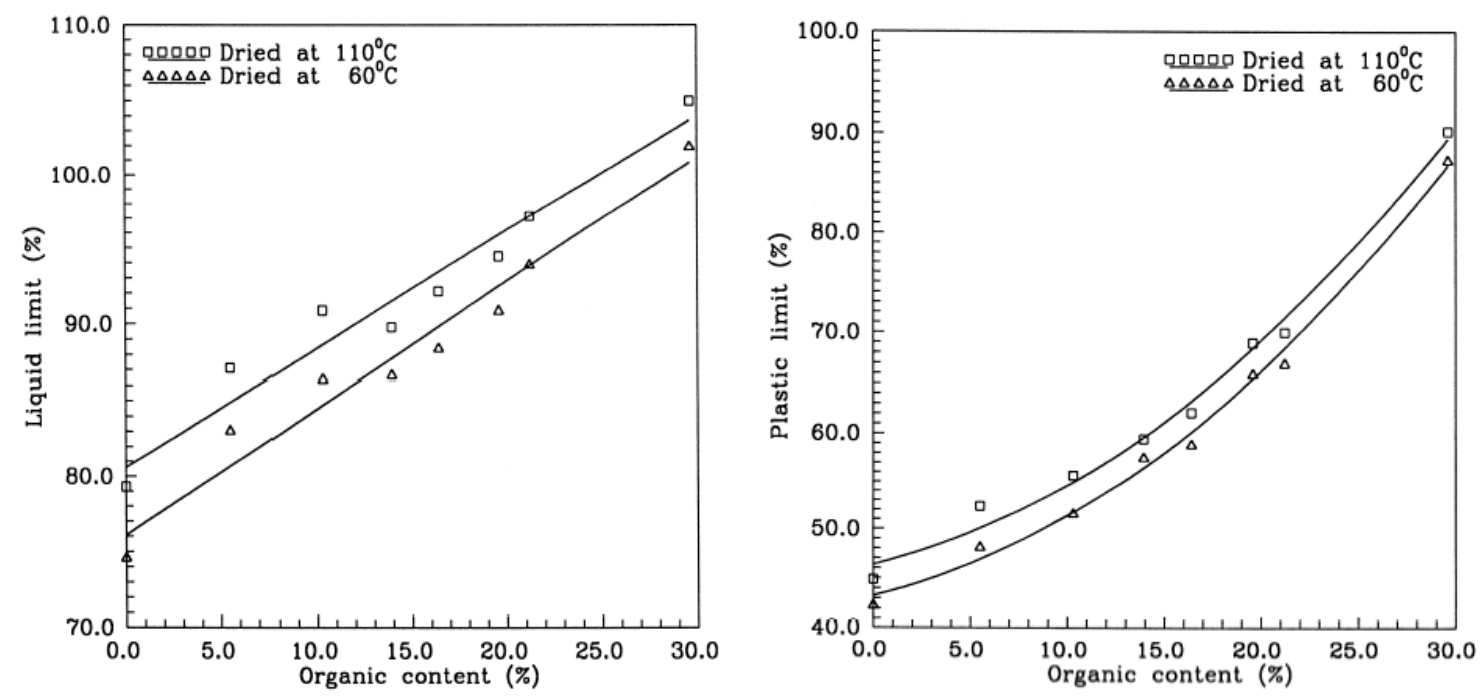

FIG 3.10- Atterberg Limits change with organic content (Abdallah, 1999)

\subsubsection{Shrinkage Potential}

Shrinkage can be significant in soils with high organic content. For loose high organic soils, the volume change can reach $70 \%$ of their initial volume upon drying. Figure 3.11 shows the volume changes experienced by an organic soil with wetting and 
drying. The results are given as a function of the bulk density, which reflects the organic content of the soil, as lower bulk densities are associated with larger organic content. The results indicate that shrinkage increases as the organic content increases. The different paths observed in the Figure as the soil is dried and wetted are an indication of the hysteretic response of the soil at changes in water content. Such behavior is also dependent on the type of soil; for example Feustel and Byers (1930) observed that, on average, "the amount of water that is taken up again after air drying varies from 55 percent of that capable of being held in a sphagnum peat to 33 percent of that capable of being held in a heath peat."

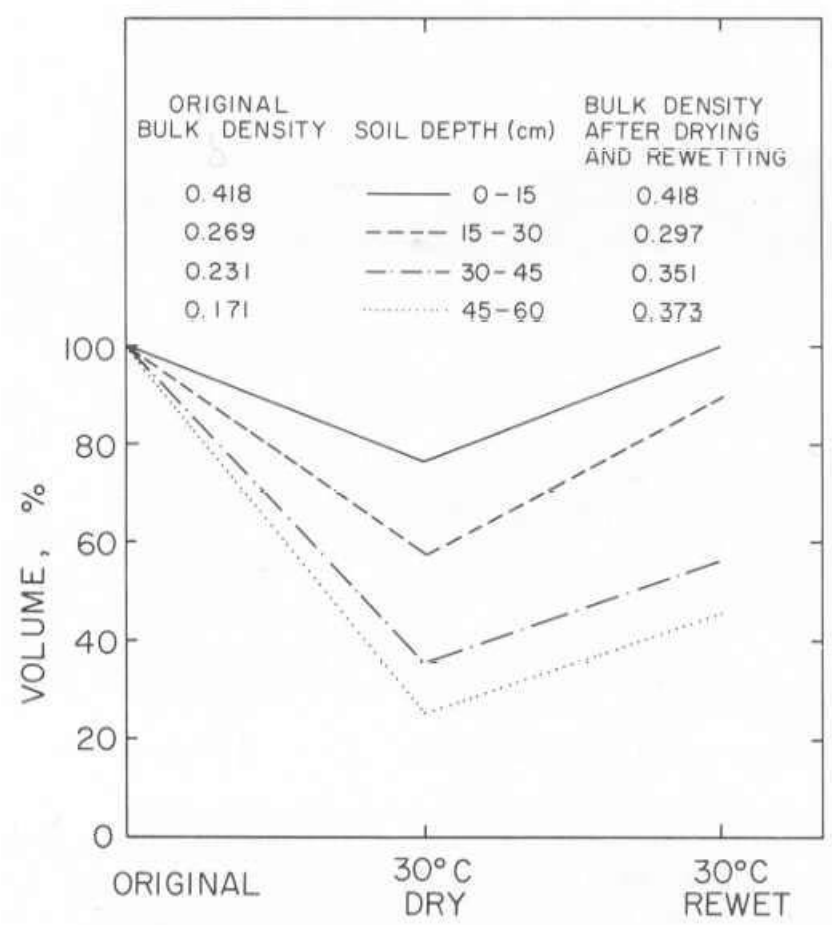

FIG 3.11- The effect of bulk density on shrinkage and volume recovery on rewetting (Radforth et al, 1996) 


\subsubsection{Cation Exchange Capacity and Acidity}

The cation exchange capacity of a soil is the ability of the soil to absorb and exchange cations, which are attracted to the surface of the soil particles. The acidity affects the magnitude of cation exchange capacity. In clay minerals, the cation exchange capacity attains its maximum value at $\mathrm{pH}$ 8.2. Stevenson (1994) pointed out that the cation exchange capacity of organic matter increases significantly with $\mathrm{pH}$. Humic substances consist of two major chemical groups: carboxyl and phenolic-OH groups. The carboxyl group can lose its proton at $\mathrm{pH} 3.0$, and the phenolic-OH group is ionized at $\mathrm{pH}$ 9.0. The cation exchange capacity cannot increase indefinitely with $\mathrm{pH}$ since at very high pH some organic substance is dissolved and brakes down by hydrolysis (Tan, 2005). The $\mathrm{pH}$ of organic soils is typically around 4-7. Figure 3.12 shows the $\mathrm{pH}$ of typical organic soils with organic content. As the organic content increases, the $\mathrm{pH}$ of the soil increases. Figure 3.13 shows the trend of cation exchange capacity with organic content. As the organic content increases the cation exchange capacity increases.

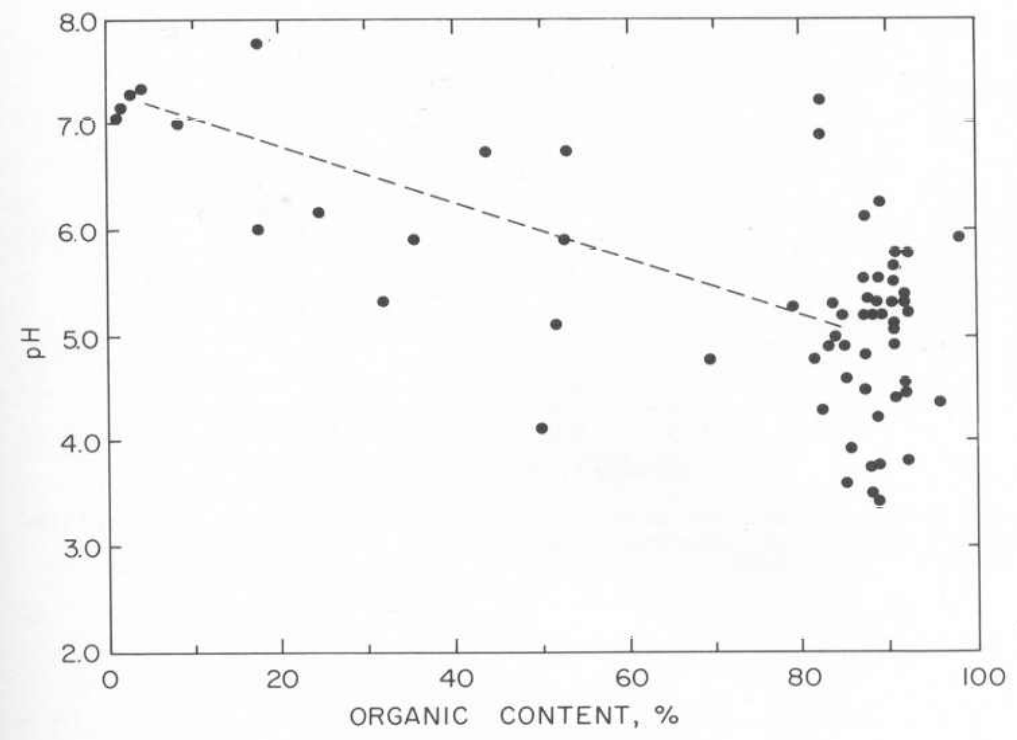

FIG 3.12- Organic content and $p H$ (Radforth et al, 1996) 


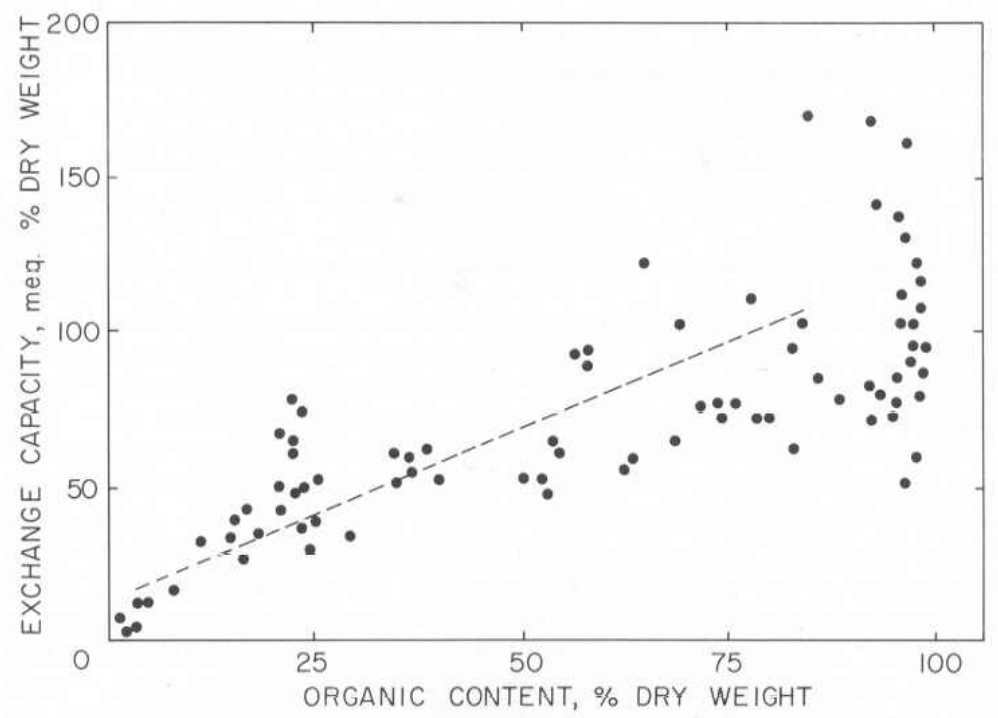

FIG 3.13- Cation exchange capacity with organic content (Radforth et al, 1996)

\subsection{Engineering Properties}

The previous section has discussed fundamental characteristics of organic soils. This section attempts to address the engineering properties of organic soils, including compaction behavior, strength, permeability and compressibility.

\subsubsection{Compaction Behavior}

Figure 3.14 shows the compaction curves of an illitic soil with different organic content. The maximum dry density decreases with organic content and the optimum moisture content increases as the organic content increases. The trend shown in the figure compares well with the tendency of organic matter to adsorb water and with the reduction of specific gravity with increasing organic content. 


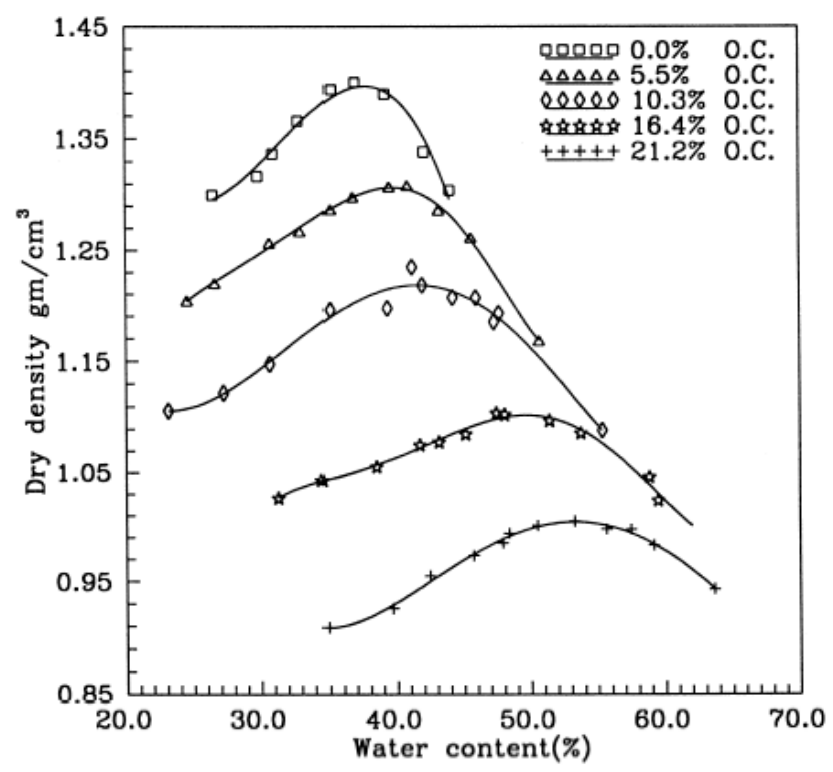

FIG 3.14- Compaction curves for illitic soil-organic matter mixtures. (Abdallah, 1999)

\subsubsection{Strength}

The strength of organic soils strongly depends on the organic content. Figure 3.15 shows the unconfined compression strength of an illitic soil with different percentages of organic matter. The plot clearly shows that as the organic content increases, the strength quickly decreases. This is an expected result since the strength of soils is highly dependent on water content and the water content of a soil generally increases with organic content. In addition, due to the high deformability of organic matter the maximum strength is reached at higher deformations with increasing organic matter. Also the depositional process of the organic soil results in strengths that can be quite different in the direction perpendicular or parallel to the direction of deposition. Finally the fiber content, which is related to the degree of humification, influences the shear strength. The fibers in the soil may produce a reinforcing effect on the soil matrix increasing the shear strength of the soil (Landva et al, 1980); such an increase may be scale dependent, where 
the length of the fibers should be compared with the volume of the soil tested. Thus it is expected that fiber content may have a more substantial effect on specimens at the laboratory scale than on large volumes of soil loaded by, for example, a road embankment.

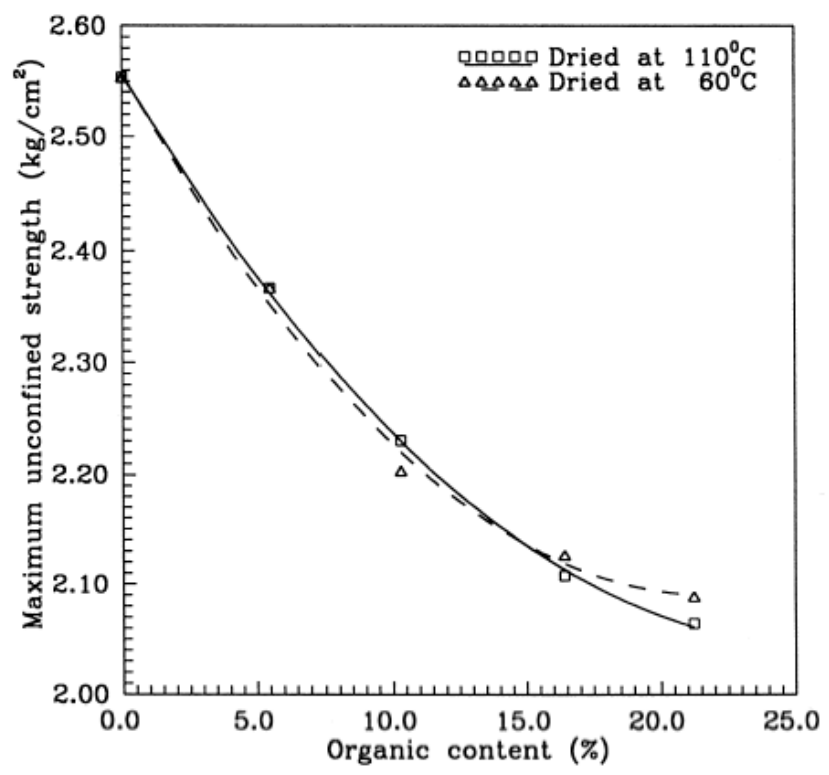

FIG 3.15- Unconfined compressive strength vs. organic content for an illitic soil (Abdallah, 1999)

\subsubsection{Permeability}

Permeability is affected by the size and continuity of soil pores. Given the large water content of organic soils (Sections 3.3.1) and the discussion regarding gas content (Section 3.3.2), it is expected that the permeability of organic soils is much higher than that of inorganic soils. For example, the permeability of an organic soil with more than $75 \%$ organic content is 100 to 1000 times larger than that of inorganic clay. The degree of decomposition of the organic matter and the degree of aggregation of organic soil particles determine the permeability of organic soils. The organic matter-induced 
aggregation of soil particles tends to increase the permeability (Stevenson, 1994). With increasing degree of decomposition, "there is a small decrease in porosity and a considerable decrease in the effective diameter of pores" Walmsley (1973). MacFarlane (1969) pointed out that "the highly colloidal, amorphous peats tend to discourage permeability by water whereas the open-meshed fibrous peats are initially quite permeable". Because of the deposition process of the soil matter, the permeability in vertical direction is much smaller than in the horizontal direction. Permeability may be also changing with time. Organic soils exhibit large deformations induced by creep. As a result the pore space in the soil may be drastically reduced with time, resulting in a dramatic decrease of permeability.

\subsubsection{Compressibility}

Peats and organic soils exhibit a much higher compressibility than other geotechnical materials (Mesri et al, 1997). First, organic soils have much higher natural water content and void ratio than inorganic soils; and second, organic soils have the highest values of $\mathrm{C} \alpha / \mathrm{Cc}$ (Mesri and Godlewiski, 1977; Mesri at al, 1994).

Because of the large water content of organic soils which, given the low specific gravity of organic matter, is associated with large void ratios, their compression index is very high. Figure 3.16 provides a summary of natural water content and compression index for peats and a comparison with soft clays and silt deposits. As one can see, the compressibility of organic soils can be over one order of magnitude larger than that of inorganic soils.

Laboratory experiments on organic and inorganic soils show that the ratio $\mathrm{C} \alpha / \mathrm{Cc}$ is a material property (Mesri and Godlewiski, 1977), i.e. it remains essentially constant 
for a given soil. In other words, as the $\mathrm{C}_{\mathrm{c}}$ of a soil increases, $\mathrm{C}_{\alpha}$ also increases. Table 3.1 provides a summary of average values of $\mathrm{C} \alpha / \mathrm{Cc}$ found for different soils. For an inorganic clay the ratio is 0.04 and for a peat 0.06 , a $50 \%$ increase. The trend is confirmed by the observations from Mesri et al (1997), as shown in Table 3.2, with ratios from $0.04-0.06$ up to 0.1 .

The secondary consolidation behavior of organic soils is strongly dependent on the nature of the organic matter. For amorphous peat secondary compression originates from the "gradual adjustment of the soil grains into a more stable configuration following the rupture of the soil structure that occurs during the primary stage" (Berry and Poskitt, 1972), which indicates that amorphous peats behave similar to clay soils (Berry and Poskitt, 1972). For fibrous peats, it is suggested (Berry and Poskitt, 1972) that secondary compression is due to the drainage of water form micropores. It is this process that determines the rate of creep (Landva, 1983).

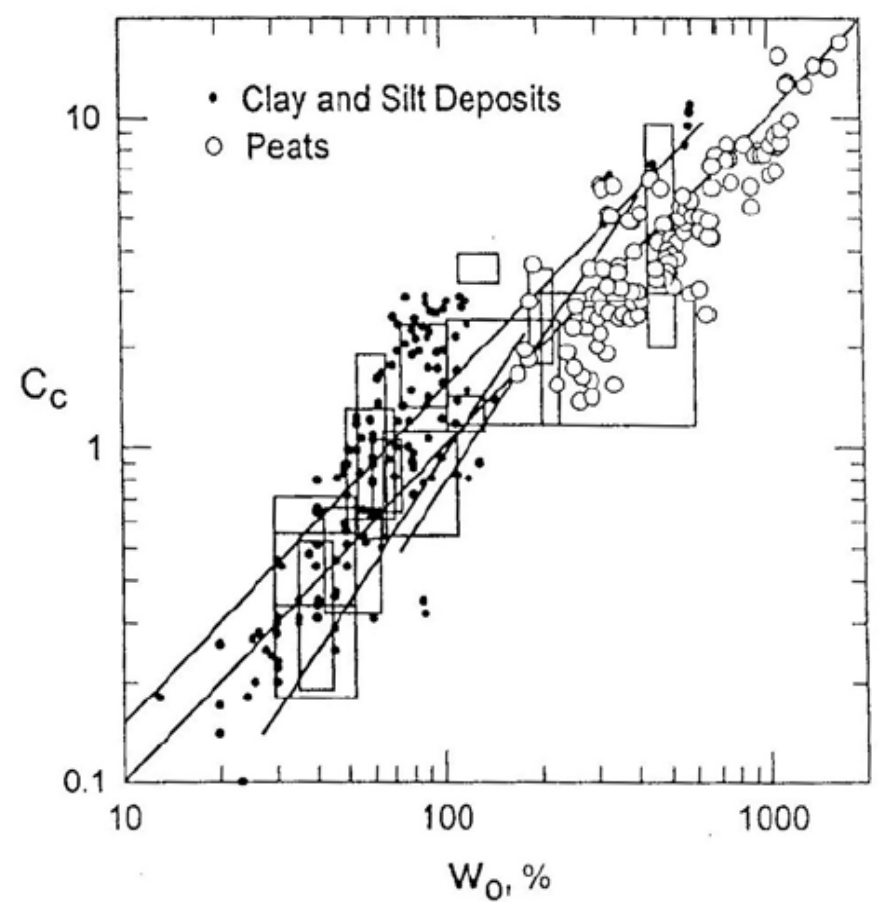

FIG 3.16- Natural water content (Wo) and compression index for peats as compared to those of soft clay and silt deposits (Mesri et al, 1997) 
Table 3.1- Values of $C_{a} / C_{c}$ for various types of geotechnical materials (Terzaghi et al, 1996)

\begin{tabular}{|c|c|}
\hline Material & $\mathrm{C}_{\alpha} / \mathrm{C}_{\mathrm{c}}$ \\
\hline Granular soils including rockfill & $0.02 \pm 0.01$ \\
\hline Shale ad mudstone & $0.03 \pm 0.01$ \\
\hline Inorganic clays and silts & $0.04 \pm 0.01$ \\
\hline Organic clays and silts & $0.05 \pm 0.01$ \\
\hline Peat and muskeg & $0.06 \pm 0.01$ \\
\hline
\end{tabular}

Table 3.2- Values of natural water content (wo), initial vertical hydraulic conductivity $\left(k_{v o}\right)$, and $\mathrm{C} \alpha / C \mathrm{C}$ for peat deposits (Mesri et al, 1997)

\begin{tabular}{|c|c|c|c|c|}
\hline $\begin{array}{l}\text { Peat } \\
\text { (1) }\end{array}$ & $\begin{array}{l}w_{0} \\
\% \\
(2)\end{array}$ & $\begin{array}{l}k_{\infty} \\
\mathrm{m} / \mathrm{s} \\
(3)\end{array}$ & $\begin{array}{c}C_{a} / C_{c} \\
(4)\end{array}$ & $\begin{array}{l}\text { Reference } \\
\text { (5) }\end{array}$ \\
\hline $\begin{array}{l}\text { Fibrous peat } \\
\text { Peat } \\
\text { Amorphous and fibrous peat } \\
\text { Canadian muskeg } \\
\text { Amorphous to fibrous peat } \\
\text { Peat } \\
\text { Fibrous peat } \\
\text { Fibrous peat } \\
\text { Amorphous to fibrous peat } \\
\text { Fibrous peat } \\
\text { Dutch peat } \\
\text { Fibrous peat }\end{array}$ & $\begin{array}{c}850 \\
520 \\
500-1,500 \\
200-600 \\
705 \\
400-750 \\
605-1,290 \\
613-886 \\
600 \\
660-1,590 \\
370 \\
610-850 \\
\end{array}$ & $\begin{array}{c}4 \times 10^{-6} \\
- \\
10^{-7}-10^{-6} \\
10^{-5} \\
- \\
10^{-9} \\
10^{-6} \\
10^{-6}-10^{-3} \\
10^{-6} \\
5 \times 10^{-7}-5 \times 10^{-5} \\
6 \times 10^{-8}-10^{-7}\end{array}$ & $\begin{array}{c}0.06-0.10 \\
0.061-0.078 \\
0.035-0.083 \\
0.09-0.10 \\
0.073-0.091 \\
0.075-0.085 \\
0.052-0.072 \\
0.06-0.085 \\
0.042-0.083 \\
0.06 \\
0.06 \\
0.052\end{array}$ & $\begin{array}{l}\text { Hanrahan (1954) } \\
\text { Lewis (1956) } \\
\text { Lea and Brawner (1963) } \\
\text { Adams (1965) } \\
\text { Keene and Zawodniak (1968) } \\
\text { Weber (1969) } \\
\text { Samson and LaRochell (1972) } \\
\text { Berry and Vickers (1975) } \\
\text { Dhowian and Edil (1981) } \\
\text { Lefebvre et al. (1984) } \\
\text { Den Haan (1994) } \\
\text { Present study (1997) }\end{array}$ \\
\hline
\end{tabular}

\subsection{Summary}

The geotechnical properties of organic soils depend on the following factors: (1) organic content; (2) type of organic matter; (3) degree of decomposition of the organic matter; and (4) void ratio. In general, as the organic content increases, water content, Atterberg limits, cation exchange capacity, and acidity all increase, whereas specific density, bulk density, plastic index, and efficiency of compaction decrease. In addition to organic content, the type of organic matter and the degree of decomposition of organic 
matter are two critical factors affecting the strength, permeability, and compressibility of organic soils. A more fibrous structure and the less degree of decomposition usually lead to higher permeability and compressibility. The strength of organic soil is reduced with the presence of organic matter; however, the fibrous structure, if present, may increase the strength and some tensile strength is expected. Void ratio is the result of organic content, type of organic matter and degree of decomposition: a more fibrous structure, a higher organic content, and a lower degree of decomposition all lead to a more open structure, i.e. an increased void ratio. Void ratio controls the major properties of organic soils, especially the compressibility. Compressibility is the key characteristic of organic soils in construction. The short primary consolidation and the large secondary consolidation (creep) always create problems in civil engineering practice when organic soils are present. 


\section{CHAPTER 4}

\section{Methods for the Determination of Organic Content}

\subsection{Introduction}

Different classification systems employ various criteria or parameters for the identification and classification of organic soils. These include botanical composition, degree of humification, water content, bulk density, specific mass, fiber content, shrinkage potential, $\mathrm{pH}$, Atterberg limits, and even the composition of organic matter (e.g. humin, humic acid, and fulvic acid content). This results in that a variety of methods are required to use for well classifying organic soils. In engineering practice organic content is the parameter most commonly employed to identify and classify organic soils. As discussed in Chapter 3, most soil index properties and engineering properties of organic soils are related to organic content.

A review of the existing literature shows, however, that there no universally accepted method to determine the organic content in soils. This report will provide and overview of the most common tests used.

The general idea of measuring organic content is to remove the organic matter from the soil and quantify it. Many methods have been proposed to perform this measurement. This report classifies these methods into two major groups: direct methods and indirect methods; see Figure 4.1. In the direct methods, the organic content of a soil is directly measured. Loss on ignition and hydrogen peroxide $\left(\mathrm{H}_{2} \mathrm{O}_{2}\right)$ digestion are the two primary methods belonging to this category. In the indirect methods, the concentration of organic carbon is measured by chemical methods. The quantity of organic matter is then determined by multiplying the concentration of organic carbon by a factor which varies with soil type and depth. This factor has a typical range of 1.7 2.1 
(Nelson and Sommers, 1996), and is based the assumption that organic matter contains approximately $58 \%$ organic carbon.

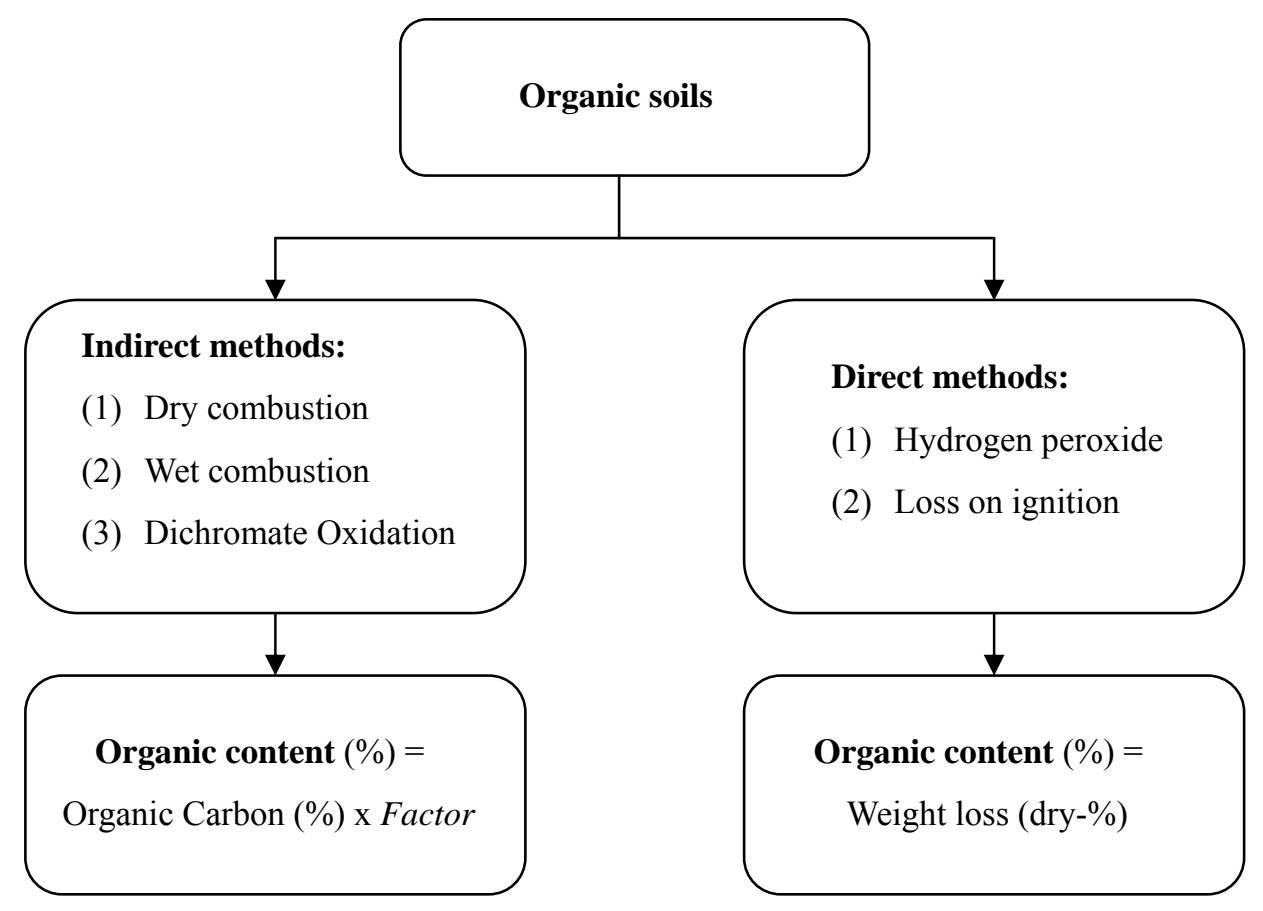

FIG 4.1- Indirect versus direct approaches for determining the organic content in soils

\subsection{Direct Methods}

The methods of direct estimation of organic content in soils include loss on ignition (LOI) and hydrogen peroxide $\left(\mathrm{H}_{2} \mathrm{O}_{2}\right)$ digestion. In both methods the soil organic matter is measured from the quantity of organic matter removed. The percentage of weight loss in dry condition represents the organic content.

\subsubsection{Loss on Ignition (LOI) Method}

The loss on ignition is a method based on the thermal decomposition of organic matter. High temperature heating is used to remove organic matter. An oven dried soil sample (typically about $10 \mathrm{~g}$ in mass and entirely passing the No.10 sieve) is placed in a 
crucible and set in a well-temperature-control furnace. The weight loss of the soil sample due to the oxidation of the organic matter, termed the loss on ignition (LOI (\%)) is obtained from the following:

$$
\operatorname{SOM}(\%)=\operatorname{LOI}(\%)=\frac{\text { Weight }_{105}-\text { Weight }_{440}}{\text { Weight }_{105}} \times 100
$$

where $\operatorname{SOM}(\%)$ stands for the soil organic matter content; Weight 105 is the weight of the soil after oven-drying to $105^{\circ} \mathrm{C}$ for 24 hours and Weight 440 is the weight of the soil after ignition at $440^{\circ} \mathrm{C}$ for a given period of time. The temperature of $440^{\circ} \mathrm{C}$ used in this equation is based on ASTM D 2974 Method C.

The results of the loss on ignition test are sensitive to the heating temperature and duration. The major reason for this is that heating to $440^{\circ} \mathrm{C}$ leads not only to decomposition of the organic matter but also to the loss of the structural water present in some clay minerals. An example of such a mineral is gypsum $\left(\mathrm{CaSO}_{4} \cdot 2 \mathrm{H}_{2} \mathrm{O}\right)$, a common mineral in soils from arid regions. At different temperatures gypsum releases different amounts of water, e.g. $1.5 \mathrm{H}_{2} \mathrm{O}$ at $128^{\circ} \mathrm{C}$ and the remaining $\mathrm{H}_{2} \mathrm{O}$ at $163^{\circ} \mathrm{C}$ (Lide, 1993). Additionally, de-hydroxylation of aluminosilicates and decomposition of inorganic carbonates may also take place during heating in the furnace. This additional weight loss further affects the results leading to overestimate the organic content of the soil. Preventing de-hydroxylation of aluminosilicates and decomposition of inorganic carbonates in organic soils is a critical issue for reducing the errors in the LOI test. Pretreatment with $\mathrm{HCl}$ and $\mathrm{HF}$ can be used to remove mineral matters (Rather 1917) to eliminate de-hydroxylation of aluminosilicate and decomposition of inorganic carbonates. However, it is known that the pretreatment with $\mathrm{HCl}$ and $\mathrm{HF}$ may also dissolve part of the organic matter, resulting in an underestimation of the organic content. 
Oven-drying the soil sample before ignition is another factor which can affect the results. While oven drying is intended to remove the gravity water in the soil, in the case of highly organic soils, the regular drying temperature $\left(105^{\circ} \mathrm{C}\right)$ can partially oxidize organic matter. The LOI test conducted on the oven-dried soil would then underestimate the true organic matter content. For highly organic soils, it is recommended that the oven drying temperature be decreased to $90^{\circ} \mathrm{C}$ (Landva et. al, 1983).

A range of ignition temperatures and duration for the LOI test have been proposed in the literature. Table 4.1 summarizes the recommendation contained in current test standards. Further discussion of the influence of ignition temperature and duration on the LOI results is presented in Section 4.4.

TABLE 4.1- Summary of recommended temperature and duration of LOI test

\begin{tabular}{lccc}
\hline \multicolumn{1}{c}{ Methods } & Oven-Dry Temp. & Ignition Temp. & Duration \\
\hline ASTM D2974 Method C & $105^{\circ} \mathrm{C}_{ \pm} 5^{\circ} \mathrm{C}$ & $440^{\circ} \mathrm{C}$ & Until weight loss contsant \\
ASTM D2975 Method D & $105^{\circ} \mathrm{C} \pm 5^{\circ} \mathrm{C}$ & $750^{\circ} \mathrm{C}$ & Until weight loss contsant \\
AASHTO T267 & $110^{\circ} \mathrm{C} \pm 5^{\circ} \mathrm{C}$ & $455^{\circ} \mathrm{C} \pm 10^{\circ} \mathrm{C}$ & 6 hours \\
$\begin{array}{l}\text { Muskege Engineering } \\
\text { Handbook }\end{array}$ & $\mathrm{n} / \mathrm{a}$ & $880-900^{\circ} \mathrm{C}$ & 3 hours \\
\hline
\end{tabular}

\subsubsection{Hydrogen Peroxide $\left(\mathrm{H}_{2} \mathrm{O}_{2}\right)$ Method}

The hydrogen peroxide $\left(\mathrm{H}_{2} \mathrm{O}_{2}\right)$ method is based on the digestion of organic matter by an alkaline solution. The soil sample is tested with $10 \mathrm{ml}$ of a $30 \%$ or $50 \%$ hydrogen peroxide $\left(\mathrm{H}_{2} \mathrm{O}_{2}\right)$ solution at a temperature below $110^{\circ} \mathrm{C}$ to oxidize organic matter. $\mathrm{H}_{2} \mathrm{O}_{2}$ is continually added to the sample until bubbling ceases, at which point the digestion is considered to be complete. The sample is then oven-dried at $105^{\circ} \mathrm{C}$, and the total 
organic matter estimated gravimetrically by the loss of weight.

$$
\operatorname{SOM}(\%)=\frac{\text { Weight }_{\text {Loss }}}{\text { Weight }_{\text {Original }}}
$$

Hydrogen peroxide digestion is a quick and easy method to determine the quantity of organic content in soils; however, the oxidation of organic soil may be incomplete. The oxidation process varies markedly with soils. In addition, the volatile organic compounds may be lost if samples are air or oven dried prior to digestion. Ideally this method is not appropriate to quantify the organic matter in soils but it is a means which can be employed to compare the readily oxidizable material in different soils (Nelson and Sommers, 1996). Also, it is a technique commonly used to pre-treat soils prior to determining the particle-size distribution of the inorganic fraction (Schumacher, 2002).

\subsection{Indirect Methods}

Indirect methods measure the concentration of total organic carbon (TOC) in soils instead of the total quantity of soil organic matter. Natural organic carbon is widely found in soils because it is the product of decomposition of plant and animal debris. Organic carbon is, therefore, the major element in organic soils. Typically, organic carbon accounts for $48 \%-58 \%$ of the total weight of organic soils.

The total quantity of soil organic matter can be determined by multiplying the concentration of organic carbon by a factor. This factor, which represents the ratio of the total weight of organic soil to the weight of the organic carbon, varies with soil type and depth. There is no universal value of this factor. Because of the complications associated with total soil organic matter determination, soil scientists (Nelson and Sommers 1996) recommend using the concentration of total organic carbon to represent the degree of 
organic content.

There are two basic methodologies to determine the quantity of organic carbon in soils. Both methodologies are based on chemical oxidation techniques, where total organic carbon can be obtained as follows:

Methodology I: Total carbon and inorganic carbon are measured separately, and the organic carbon is then measured from the difference between these two values.

Methodology II: The inorganic carbon is removed prior to measuring the total carbon content. The total organic carbon can be then assumed to be equal to the total carbon content.

Generally, in soils, it is not recommended to measure the total organic carbon by the difference between total carbon and inorganic carbon. This method requires in fact that two different tests be conducted on two separate soil samples. One sample is needed for the total carbon determination and the other one is required for determining the inorganic carbon. This can lead to some inaccuracies as the organic matter may not be evenly distributed in the two samples. Therefore, it is generally recommended that the organic carbon be determined by Methodology II and that the soil be first pre-treated to remove the inorganic carbon. Note, however, that the solutions added to a soil sample to remove the inorganic carbon may affect the results in the subsequent test and that sometimes inorganic carbon is not completely removed.

There are three major methods employed to determine the organic carbon content: dry combustion, wet combustion, and the dichromate oxidation method. All of them 
require pre-treatment of the sample if inorganic carbon sources such as dolomite and calcite are present in the soil. Dry and wet combustion require a special combustion train to combust the organic carbon. Dichromate oxidation method is a more rapid test and requires less equipment, although external heating is an additional option to promote better results.

\subsubsection{Dry Combustion Method}

Dry combustion is a method based on the principle of oxidizing organic carbon and thermally decomposing other carbonate minerals. As discussed above, soils are generally pretreated to remove inorganic carbon prior to dry combustion. $\mathrm{CO}_{2}$ is collected after combustion to obtain the organic carbon content. In this method, soil is placed in a furnace at a very high temperature $\left(>1000^{\circ} \mathrm{C}\right)$ and purified oxygen is supplied. The high temperature converts the organic carbon into $\mathrm{CO}_{2}$. The amount of $\mathrm{CO}_{2}$ is absorbed by a suitable absorbent in an effluent gas stream and quantified by titration, gravimetric, and manometric techniques.

There are three types of furnace used for dry combustion: resistance, induction, and automated furnaces. In a resistance furnace, the sample is placed in a tube and the heating elements made of high resistance materials surround the tube. The sample is heated by radiation, conduction, and convection.. In an induction furnace the heating element is powered by the high frequency electromagnetic radiation. The soil samples are indirectly heated by radiation, conduction, and convection from the heating element in induction field because only ferrous metals and some materials can be heated by high frequency electromagnetic radiation. The automated furnace is based on either the resistance method or the induction method. The only difference is that the automated 
furnace is a commercial instrument for automatically determining the organic carbon.

Different furnaces are suitable for different temperatures and require special accelerators for combustion. Generally, resistance based furnaces provide medium temperatures and employ cupric oxide $(\mathrm{CuO})$ mixed with soil as an accelerator. Induction furnaces offer higher temperature and use $\mathrm{Fe}, \mathrm{Sn}$, and tin-coated copper accelerators.

Nowadays the most common way to conduct dry combustion test is using an automated furnace technique such as the LECO ${ }^{\circledR}$ analyzer. In such a system a soil sample of about $0.2 \mathrm{~g}$ is placed in a tin capsule and then combusted in the resistance furnace of the analyzer. An operating temperature of $950^{\circ} \mathrm{C}$ is typical and ultra high purity $\mathrm{O}_{2}$ is commonly used as a carrier gas. The elemental analyzer not only gives the carbon content but also provides the hydrogen and nitrogen content simultaneously.

\subsubsection{Wet Combustion Method}

Wet combustion is a method based on chromic acid digestion. In this method a soil pretreated to remove inorganic carbon is digested in a 60:40 mixture of $\mathrm{H}_{2} \mathrm{SO}_{4}-\mathrm{H}_{3} \mathrm{PO}_{4}$ containing $\mathrm{K}_{2} \mathrm{Cr}_{2} \mathrm{O} 7$ in a $\mathrm{CO}_{2}$ free air stream at a temperature of $210^{\circ} \mathrm{C}$ to convert organic carbon to $\mathrm{CO}_{2}$. The temperature of heating is intended to be high enough to assist the complete oxidation of carbon, but also low enough to avoid excessive fuming during the test. The amount of $\mathrm{CO}_{2}$ is collected and quantified by titration, and gravimetric techniques. The amount of $\mathrm{CO}_{2}$ released is then adsorbed by an absorbent and weighed to determine the quantity of organic carbon. Figure 4.2 presents a schematic diagram of the apparatus used for wet combustion. The advantage of this method is that the cost is less compared to the equipment required for dry combustion; however, it is quite time-consuming to assemble and disassemble the equipment which is very large and 
occupies considerable space.

Note that if the soil contain a considerable amount of $\mathrm{Cl}^{-}$(such soils are termed "salt affected"), the errors associated with this method ca be substantial. In order to prevent this, the purifying train shall include two traps (see Figure 4.2, traps $F$ and $G$ ). One has potassium iodide (KI) and one contains silver sulfate $\left(\mathrm{Ag}_{2} \mathrm{SO}_{4}\right)$ (Nelson and Sommers, 1996). These two traps will absorb the released free $\mathrm{Cl}_{2}$ to eliminate the $\mathrm{Cl}_{2}$ interference.

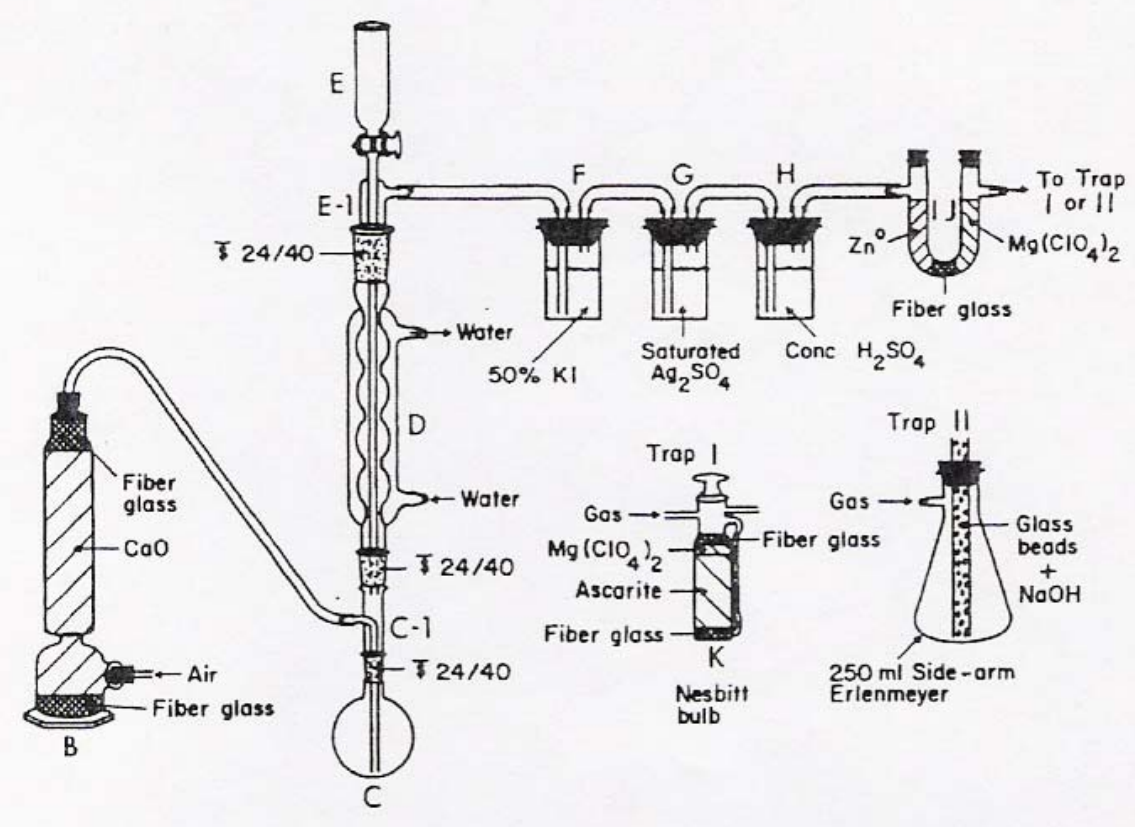

FIG 4.2- Diagram of apparatus used to determine C by wet combustion (Nelson and Sommers, 1996) 


\subsubsection{Dichromate Oxidation Method}

Dichromate oxidation is a wet combustion-based method. Both wet combustion and dichromate oxidation treat soils with potassium dichromate and sulfuric acid. After oxidation with potassium dichromate, the organic carbon is converted to $\mathrm{CO}_{2}$. The following equation shows the process of dichromate digestion. Note that the method is based on the assumption that the average valence of carbon in organic matter is zero.

$$
2 \mathrm{Cr}_{2} \mathrm{O}_{7}^{-2}+3 \mathrm{C}^{0}+16 \mathrm{H}^{+}=4 \mathrm{Cr}^{3+}+3 \mathrm{CO}_{2}+8 \mathrm{H}_{2} \mathrm{O}
$$

During the process of dichromate digestion, there are three main measured products: the excess/ unused $\mathrm{Cr}_{2} \mathrm{O}_{7}^{-2}, \mathrm{Cr}^{3+}$, and $\mathrm{CO}_{2}$. In common wet combustion, the $\mathrm{CO}_{2}$ is collected for determining the quantity of organic carbon. In dichromate oxidation,

the excess/ unused $\mathrm{Cr}_{2} \mathrm{O}_{7}^{-2}$, and $\mathrm{Cr}^{3+}$ will remain in the solution after oxidation. They are measured by titration or colorimetric methods to determine the quantity of organic carbon.

In the dichromate oxidation method, also referred to as the Walkley-Black procedure, organic carbon may not be oxidized completely. The recovery of organic carbon using the Walkley-Black procedure is about $60 \% \sim 86 \%$ with a mean recovery of $76 \%$ (Walkley and Black, 1934). A correction factor of 1.33 is commonly employed to the results to adjust the recovery of organic carbon.

In order to improve the recovery of organic carbon, a modified Walkley-Black procedure has been proposed. This modified method includes heating of the sample at $140-150^{\circ} \mathrm{C}$ for 30 minutes during the dichromate digestion (Mebius, 1960). Note that control of the temperature is critical in this procedure because the dichromate solution decomposes at temperatures above $150^{\circ} \mathrm{C}$. 
Generally, dichromate oxidation is a very simple and rapid method which does not require special equipment. However, the measurements are subject to interference by certain soil constituents, leading to spurious results with some soils (Walkley, 1947). In particular, chloride, ferrous iron and higher oxides of Mn have been shown to undergo oxidation-reduction reactions in chromic acid mixtures leading to incorrect values for organic carbon (Nelson and Sommer, 1996). Specifically, the presence of chloride and ferrous iron can generate a positive error and the presence of higher oxides of Mn can produce a negative error.

\subsubsection{Methods of Removing Inorganic Carbon}

If inorganic carbon in the form, for example, of calcite $(\mathrm{CaCO} 3)$ or dolomite $\left(\mathrm{CaMg}\left(\mathrm{CO}_{3}\right) 2\right)$, is present, pretreatment of the soil sample is required prior to conduct dry or wet combustion tests when the total carbon content is determined as the organic carbon content. Before doing any pretreatment, the sample shall be tested by adding drops of $3 \mathrm{M}$ Hydrochloric acid $(\mathrm{HCl})$ to a small soil sub-sample. If there is strong froth, the soil is then considered to require pre-treatment.

For wet combustion, the most common procedure is to treat the soil with acid. A combination of $\mathrm{HCl}$ and $\mathrm{H}_{2} \mathrm{SO}_{4}$ is used to remove inorganic carbon; however, the $\mathrm{HCl}$ may oxidize some organic carbon compounds leading to a carbon loss and $\mathrm{Cl}^{-}$interferes with the wet oxidation method. To prevent this effect, a combination of $\mathrm{H}_{2} \mathrm{SO}_{4}$ and $\mathrm{FeSO}_{4}$ is used. $\mathrm{H}_{2} \mathrm{SO}_{4}$ destroys the inorganic carbon, while $\mathrm{FeSO}_{4}$ minimizes oxidation and decarboxylation of organic carbon (Nelson and Sommers, 1996, Schumacher, 2002).

For dry combustion, the soil is typically pre-treated with sulfurous acid $\left(\mathrm{H}_{2} \mathrm{SO}_{3}\right)$ at room temperature and then heated to remove the excess $\mathrm{H}_{2} \mathrm{SO}_{3}$. However, when organic 
soil is treated with $\mathrm{H}_{2} \mathrm{SO}_{3}$, some organic matter is destroyed and some decarboxylation is produced. Also there is no clear indication of whether the inorganic carbon is clearly removed or not (Allison, 1965). Generally speaking, the pretreatment prior to dry combustion is more difficult than the pretreatment for wet combustion (Nelson and Sommers, 1996).

If the organic carbon content is determined by the difference between total carbon and inorganic carbon, it is not necessary to remove inorganic carbon in advance. One soil sample can be tested by dry or wet combustion for total carbon content and the other sample can be used for the "loss of carbon dioxide test". This test determines the inorganic carbon content of a soil by adding hydrochloric acid $(\mathrm{HCl})$. The acid leads to decomposition of the carbonate and $\mathrm{CO}_{2}$ is released to the atmosphere. The decrease in weight resulting from the production of $\mathrm{CO}_{2}$ is proportional to the carbonate content of the soil (Loeppert and Suarez, 1996). Generally, a soil sample of about $1 \mathrm{~g}$ is placed in a flask with $10 \mathrm{ml} \mathrm{3M}$ Hydrochloric acid $(\mathrm{HCl})$. The weight of the flask containing the soil sample and the hydrochloric acid are then monitored overtime (e.g. every 15 minutes) until the change in weight is less than 1-2 mg. The carbon content is then calculated by

$$
\mathrm{CO}_{3}-\mathrm{C}, \%=\left(\frac{\mathrm{g}, \mathrm{CO}_{2} \text { lost }}{\mathrm{g}, \text { soil }}\right)(0.2727)(100)
$$

\subsubsection{Comparison of Indirect Methods}

As summarized in Table 4.2, each of the three indirect methods described above: dry combustion, wet combustion, and dichromate oxidation, has advantages and disadvantages, From an engineering point of view, selecting a method to determine the total organic carbon depends on time constraints, equipment availability, and cost. The 
report, "Method for the determination of total organic carbon (TOC) in soils and sediments" by Schumacher, USEPA, 2002, recommends using a high temperature-automated-dry combustion technique after the soil is pretreated to remove inorganic carbon. This recommendation is based on the following (Schumacher, USEPA, 2002):

(1) Minimal sample preparation is required other than drying the sample. The removal of water from the sample is essential during the determination of total organic carbon in dry combustion. The automated technique results in less sample preparation.

(2) Destruction of all carbon form is ensured at temperatures in excess of $1350^{\circ} \mathrm{C}$.

(3) The actual sample analysis time is short.

(4) The automated system has been shown to be more precise than manually operated systems.

(5) The high temperature, automated, dry combustion technique has been shown to produce comparable TOC concentration when compared to standard wet chemistry techniques (i.e. Walkley-Black technique).

(6) The automated system is capable of determining total $\mathrm{H}, \mathrm{S}$, and $\mathrm{N}$ simultaneously with TOC, thus providing additional information about the characteristics of the organic matter.

(7) The newer automated systems can be purchased with a simple autoloader allowing the analyst to load batches. 
TABLE 4.2- Summary of advantages and disadvantages of indirect methods of determining organic carbon (Nelson and Sommer, 1996)

\begin{tabular}{|c|c|c|}
\hline Method & Advantages & Disadvantages \\
\hline $\begin{array}{l}\text { Dry combustion (Resistance } \\
\text { furnace) }\end{array}$ & $\begin{array}{l}\text { Method widely used in other disciplines, } \\
\text { variable sample size }\end{array}$ & $\begin{array}{l}\text { Time consuming, leak free } \mathrm{O}_{2} \text { sweep train is required. } \\
\text { Slow release of } \mathrm{CO}_{2} \text { from alkaline earth carbonate }\end{array}$ \\
\hline $\begin{array}{l}\text { Dry combustion (Induction } \\
\text { furnace) }\end{array}$ & $\begin{array}{l}\text { Rapid combustion, high temperature ensure } \\
\text { conversion of all } \mathrm{C} \text { to } \mathrm{CO}_{2}\end{array}$ & $\begin{array}{l}\text { Leak free } \mathrm{O}_{2} \text { sweep train is required. Induction furnace } \\
\text { is expensive }\end{array}$ \\
\hline $\begin{array}{l}\text { Dry combustion } \\
\text { (Automated) }\end{array}$ & Rapid and simple, good accuracy and precision. & $\begin{array}{l}\text { Expensive equipment. Slow release of } \mathrm{CO}_{2} \text { from } \\
\text { alkaline earth carbonate with resistance furnace }\end{array}$ \\
\hline Wet combustion & $\begin{array}{l}\text { Equipment readily available, good accuracy, } \\
\text { easily adapted to analysis of solutions, } \\
\text { titrimetric analysis of } \mathrm{CO}_{2} \text { less subject to } \\
\text { operator error }\end{array}$ & $\begin{array}{l}\text { Time consuming, gravimetric determination of } \mathrm{CO}_{2} \\
\text { requires careful analytical techniques, titrimetric } \\
\text { determination of } \mathrm{CO}_{2} \text { is less expensive }\end{array}$ \\
\hline $\begin{array}{l}\text { Dichromate Oxidation } \\
\text { without external heat }\end{array}$ & $\begin{array}{l}\text { Very rapid and simple. No special equipment } \\
\text { needed }\end{array}$ & $\begin{array}{l}\text { Incomplete oxidation of organic } \mathrm{C} \text { necessitates use of a } \\
\text { correction factor, which often results in erroneous } \\
\text { values; chloride, } \mathrm{Fe}^{2+} \text { and } \mathrm{MnO}_{2} \text { interfere with method; } \\
\text { it assumes soil organic } \mathrm{C} \text { has an average valence of } 0 \text {; } \\
\text { variable recovery of } \mathrm{C} \text { from carbonized materials. }\end{array}$ \\
\hline $\begin{array}{l}\text { Dichromate Oxidation with } \\
\text { external heat }\end{array}$ & $\begin{array}{l}\text { Rapid and simple, complete oxidation of } \\
\text { organic C }\end{array}$ & $\begin{array}{l}\text { Chloride, } \mathrm{Fe}^{2+} \text { and } \mathrm{MnO}_{2} \text { with method; some specialized } \\
\text { equipment is needed; it assumes soil organic } \mathrm{C} \text { has an } \\
\text { average valence of } 0 \text {; variable recovery of } \mathrm{C} \text { from } \\
\text { carbonized materials. }\end{array}$ \\
\hline
\end{tabular}

\subsection{Limitations of the Loss on Ignition Test}

As mentioned in Section 4.2.1, the result of the loss on ignition test is significantly influenced by ignition temperature and duration. The effects of ignition temperature and duration on the LOI results have been widely investigated for many years. Table 4.3 summarizes some of the key studies on this topic, which have produced relationships between LOI (\%) and true organic content (\%) as measured by the Walkley-Black method using a factor of 2. Specifically, the table includes: the reference, 
the number of soils examined in each of the studies, the ignition conditions (temperature and duration), and the range in organic content of the soils studied (last column). From a regression through the experimental data, each of the studies produced a linear relationship between LOI and organic content of the type: $\mathrm{SOM}=\mathrm{a}+\mathrm{b}$ LOI. The values of coefficients $\mathrm{a}$ and $\mathrm{b}$ as well as the $\mathrm{r}^{2}$ for the regression are also included in Table 4.3. Figure 4.3 presents the regression lines for all the proposed relationships. The significant range in the correlations between LOI (\%) and organic content reflects the impact of temperature and duration and points to the great uncertainty in predicting organic content from the LOI test. Figure 4.4 shows only the data from three of the studies which employed the same ignition temperature of $440^{\circ} \mathrm{C}$, with ignition duration ranging from 6 hours to 16 hours. Even for the same ignition temperature there remains a great uncertainty in the relationship between soil organic matter and LOI (by almost a factor of 2 as indicated by the red arrows). Additionally, it is found that there is no consistent trend in the change in LOI with increasing duration of the ignition process. This implies that the presence of unknown minerals in the soil samples plays a critical role in the outcome of the LOI test. This effect is likely to be especially significant in the case of clayey soils containing low amounts of organic matter such as subsoils (Christensen and Malmros, 1982; Howard and Hward. 1990). 
TABLE 4.3- Summary of relationship between soil organic matter content and loss on ignition at different temperature and duration (Nelson and Sommer, 1996)

\begin{tabular}{|c|c|c|c|c|c|c|c|}
\hline & \multirow{2}{*}{$\begin{array}{l}\# \text { of } \\
\text { soils }\end{array}$} & \multicolumn{2}{|c|}{ Ignition condition } & \multicolumn{3}{|c|}{ Regression coefficients } & \multirow{2}{*}{$\begin{array}{c}\text { Range of } \\
\text { organic matter } \\
\text { content }\end{array}$} \\
\hline & & $\begin{array}{c}\text { Temperature } \\
\left({ }^{\circ} \mathrm{C}\right) \\
\end{array}$ & Time (Hr) & $\mathrm{b}$ & $\mathrm{a}$ & $r^{2}$ & \\
\hline Ball (1964) & 65 & 375 & 16 & 0.916 & -0.8 & -- & $1 \%-70 \%$ \\
\hline Howard (1965) & 36 & 550 & $\begin{array}{l}\text { To constant } \\
\text { weight }\end{array}$ & 0.94 & -0.96 & 0.99 & -- \\
\hline Ramney (1969) & 48 & 375 & 28 & 1.11 & 0.35 & 0.99 & -- \\
\hline Davies (1974) & 17 & 430 & 24 & 0.983 & -0.64 & 0.99 & N/A \\
\hline $\begin{array}{l}\text { Christensen \& } \\
\text { Malmros (1982) }\end{array}$ & 85 & 550 & 4 & 0.985 & -0.23 & 0.99 & -- \\
\hline $\begin{array}{l}\text { Spain et al. } \\
\text { (1982) }\end{array}$ & 766 & 950 & 0.5 & 0.796 & -0.6 & -- & $0.2 \%-28 \%$ \\
\hline Storer (1984) & 215 & 500 & 4 & 0.937 & -1.7 & 0.96 & $0.64 \%-52.4 \%$ \\
\hline Goldin (1987) & 60 & 600 & 6 & 0.81 & -1.42 & 0.86 & $>40 \%$ \\
\hline David (1988) & 174 & 450 & 12 & 1.04 & -0.03 & 0.92 & $1 \%-20 \%$ \\
\hline $\begin{array}{l}\text { Ben-Dor \& Banin } \\
\text { (1989) }\end{array}$ & 91 & 400 & 8 & 0.972 & -0.37 & 0.97 & $0.09 \%-13.32 \%$ \\
\hline $\begin{array}{l}\text { Howard \& } \\
\text { Howard (1990) }\end{array}$ & 564 & 550 & 3 & 0.84 & -1.68 & 0.98 & -- \\
\hline $\begin{array}{l}\text { Lowther et al. } \\
\text { (1990) }\end{array}$ & 38 & 450 & 16 & 0.914 & 0 & 0.99 & $0.5 \%-10 \%$ \\
\hline Donkin (1991) & 45 & 450 & 6 & 0.568 & 0 & 0.98 & $<10 \%$ \\
\hline $\begin{array}{l}\text { Schulte et al. } \\
\text { (1991) }\end{array}$ & 316 & 360 & 2 & 1.126 & 0.38 & 0.9 & $0.1 \%-54.4 \%$ \\
\hline
\end{tabular}




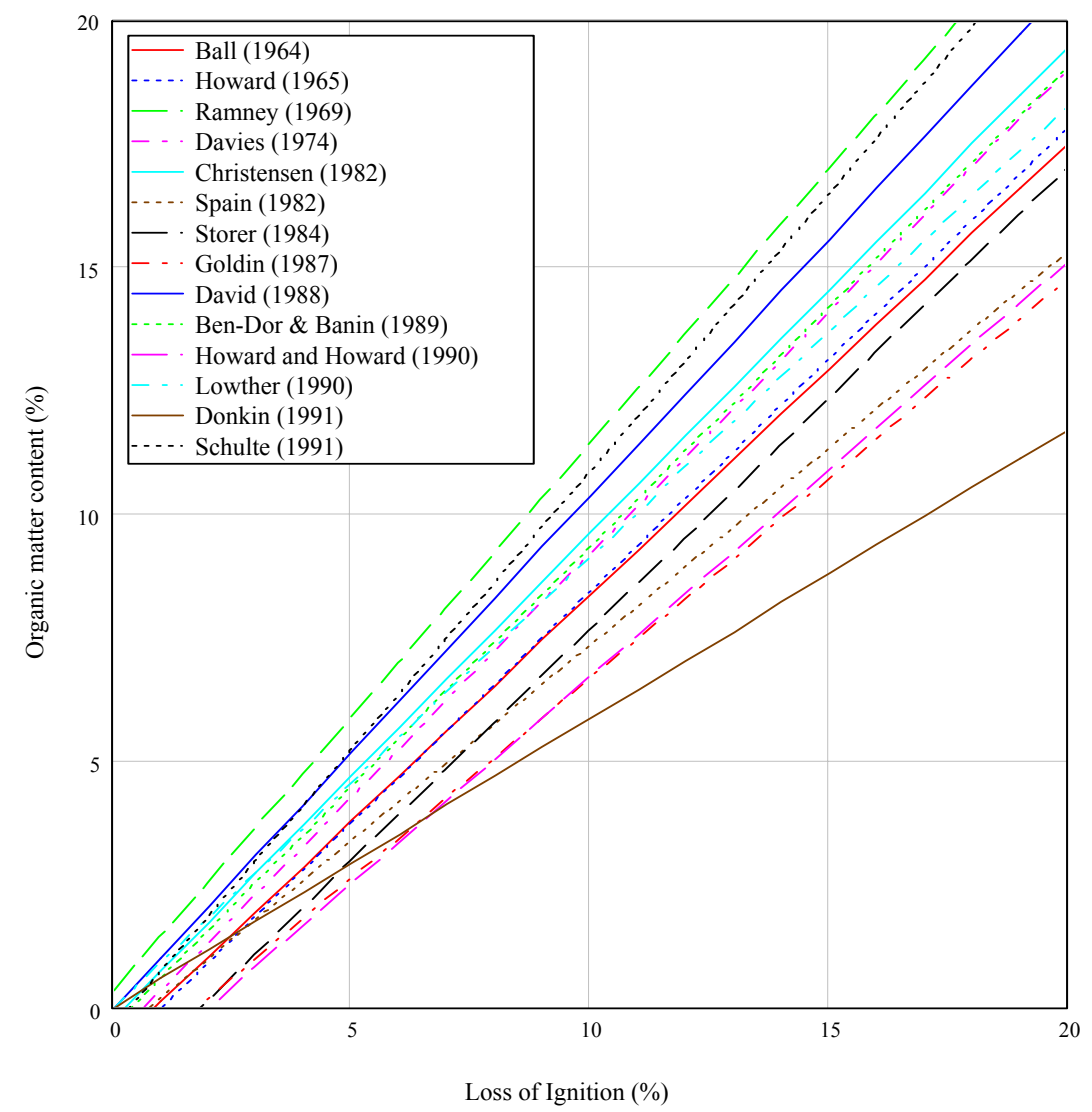

FIG 4.3-Relationships between soil organic matter content and LOI (various ignition temperatures and ignition duration)

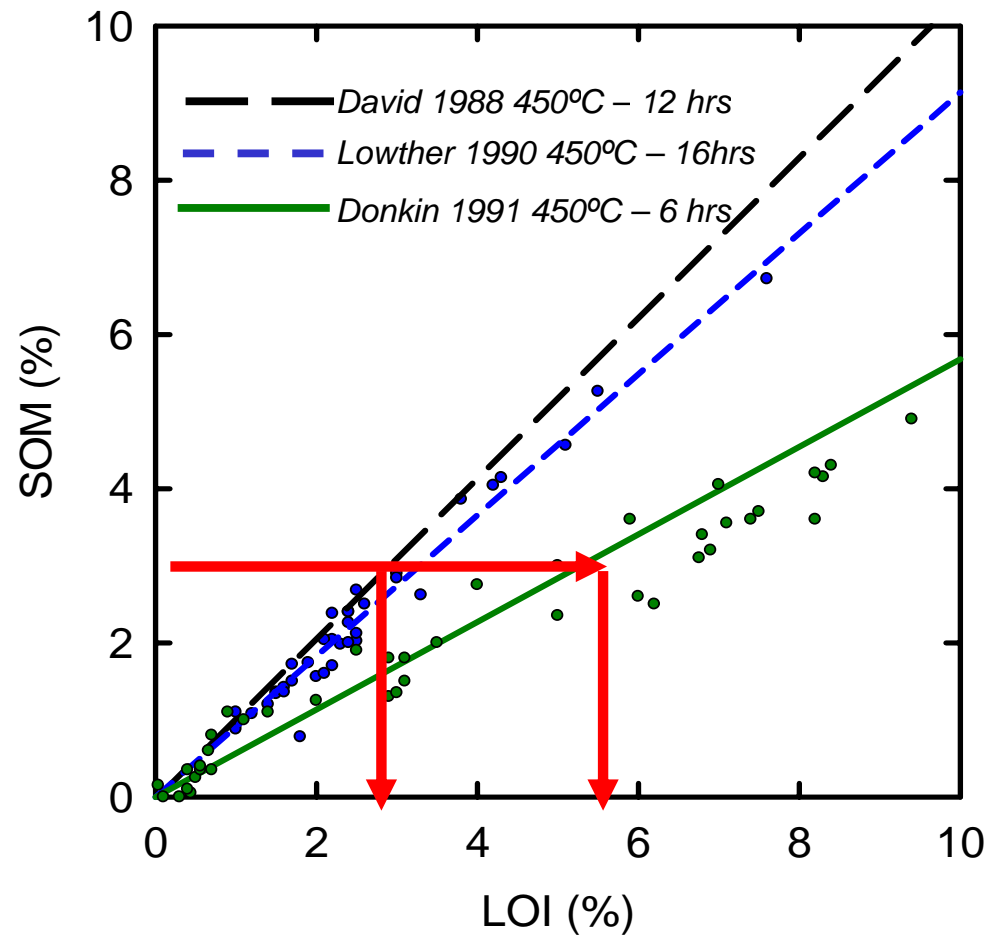

FIG 4.4- Relationship between soil organic matter content and LOI at $450{ }^{\circ} \mathrm{C}$ 


\subsection{Other Methods}

The direct methods (loss on ignition test and hydrogen peroxide test) and the indirect methods (dry/wet combustion and dichromate oxidation method) discussed above are widely employed to determine the organic content of soils. In addition to these methods, there are other techniques that can be used to derive information on the presence of organic matter (without necessarily providing a measure of the organic content) and/or complement the results of the already discussed methods. The following sections briefly review two of these methods: the colorimetric test and thermal analysis. In geotechnical engineering yet another approach, based on performing the liquid limit before and after oven drying the soil, is used to establish whether a soil is to be termed organic. This approach is discussed in more detail in the following chapter (Section $5.2 .3 .2)$

\subsubsection{Colorimetric Test}

The colorimetric test (AASHTO T 21-05; ASTM C 40-04) is the test used to detect the presence of organic impurities in fine aggregates used for concrete. The principle of this test is to extract humic substances, which represent a major portion of soil organic matter, from soils using sodium hydroxide $(\mathrm{NaOH})$ as the extractant.

In this test, the entire tested sample is air-dried and when necessary crushed to pass the \#10 sieve. The opening size of No. 10 sieve is the definition of fine aggregate by AASHTO M-147. A glass bottle is then filled to the $130 \mathrm{~mL}$ level with the dry sample. A $3 \%(0.75 \mathrm{M}) \mathrm{NaOH}$ solution is used to fill the bottle to $200 \mathrm{~mL}$. The bottle is then capped and shaken vigorously, and allowed to stand for 24 hours. The color of the supernatant liquid in the bottle after 24 hours is related to the presence of organic matter. 
According to the standard, "if the color of the supernatant liquid is darker than that of the standard color of solution or the glass color standard organic plate No. 3 (Gardner Color Standard No.11), the fine aggregate under test shall be considered to possibly contain injurious organic compounds, and further tests should be made before approving the fine aggregates for use in concrete". In this study the glass color standard is employed instead of using standard color solutions. The glass color standard, which is described in ASTM standard D1544, is an easy, rapid, and portable way to check the color.

The colorimetric test is a very easy, economic, and less time consuming method (the color of the supernatant usually changes within 2 hours if organic matter is present in the soil). Additionally, the color change is sensitive to small amounts of organic matter. However, the test has some disadvantages. The biggest one is that while the colorimetric test is sensitive to the presence of organic matter, there is no clear correspondence between color and quantity of organic matter, i.e. the organic content cannot be inferred from the color results. A second disadvantage is that the method can lead to false positives, i.e. the supernatant can turn dark even if no organic matter is present). False positives appear to be associated with the presence, for example, of ferrous ions.

\subsubsection{Thermal Analysis}

Thermal analysis includes different types of tests such as Thermogravimetric Analysis (TGA), Differential Thermal Analysis (DTA), and Differential Scanning Calorimetry (DSC). Generally, these tests aim to understand how a soil reacts to the input of thermal energy in terms of weight loss, temperature changes, and energy absorption, respectively. 
In the context of this research, the results of thermal analyses are useful to show how processes other than oxidation of organic matter can lead to weight loss as a result of heating. More importantly, thermal analysis shows that the thermal reactions of organic matter and minerals upon heating to high temperature are opposite (one exothermic, the other endothermic), and thus this technique can be used to assess whether weight loss (as observed in the LOI tests) results from organic matter oxidation or de-hydroxylation of minerals.

In Thermogravimetric Analysis (TGA), a soil sample typically 40mg in mass is placed in a chamber, which, starting from room temperature is heated to the desired temperature, which depends on the capacity of analyzer. The rate at which temperature is increased is typically $10-20^{\circ} \mathrm{C} / \mathrm{min}$, and pure Nitrogen is supplied at a rate of $50 \mathrm{ml} / \mathrm{min}$. Figure 4.5 shows an example of a TGA curve obtained from a test conducted on halloysite, a mineral of the kaolinite group, employing a heating rate of $10^{\circ} \mathrm{C} / \mathrm{min}$. It is shown that significant weight loss $(\sim 14-15 \%)$ occurs between $400^{\circ} \mathrm{C}$ and $500^{\circ} \mathrm{C}$. The results of TG analyses conducted on various swelling and non-swelling clay minerals are summarized in Table 4.4, which shows the percentage weight loss of the minerals in different temperature ranges. It can be assumed that the weight loss between $10^{\circ} \mathrm{C}$ and $20^{\circ} \mathrm{C}$ is due to the loss of the adsorbed water; that the weight loss between $200^{\circ} \mathrm{C}$ and $300^{\circ} \mathrm{C}$ is due to the removal of bound water and it takes a temperature beyond $500^{\circ} \mathrm{C}$ to get rid of the crystalline water.

From Table 4.4 it is observed that, kaolinite, for example, can loose significant weight (about $14 \%$ ) when heated to $500-600^{\circ} \mathrm{C}$. Weight loss in this temperature range can occur also for illite which can also show approximately $2 \%$ weight loss in the $200-300^{\circ} \mathrm{C}$ 
range. The rate of weight loss markedly depends on the time of heating and the rate at which the material is heated. This is illustrated in Figures 4.6 and 4.7, which show the TGA curves for gypsum heated at $2^{\circ} \mathrm{C} / \mathrm{min}$ and $10^{\circ} \mathrm{C} / \mathrm{min}$, respectively.

Overall, the data above provide clear evidence that heating to $440^{\circ} \mathrm{C}$, as is typically done in a LOI tests can lead to weight loss not associated with organic matter oxidation, and that particularly for low values of organic content, the LOI can be inaccurate.

Differential Thermal Analysis (DTA), and Differential Scanning Calorimetry (DSC) are other two thermal analysis methods used for the study of soils. Figure 4.8 provides a simplified diagram of a DTA or DSC analyzer. In the analyzer, a soil sample is placed on one plate, while a second plate is used as reference. The principle of DTA is to apply the same amount of thermal energy to the two plates and measure the difference of temperature arising. The principle of DSC is to keep the temperature of the two plates the same and measure the difference of energy absorbed by plates. Figure 4.9 shows a typical result of a DTA and DSC analysis. In this graph temperature increasing with time is represented on the $\mathrm{X}$-axis, while the $\mathrm{Y}$-axis plots either the difference in temperature (DTA) or the difference in thermal energy (DSC). The figure shows that that the dehydroxylation of minerals and the evaporation of water are endothermic reactions which are represented by convex curves. The oxidation of organic matter is, instead an exothermic reaction, which appears as a concave curve on the graph. Thus, through DTA or DSC it is possible to differentiate between these two reactions. 


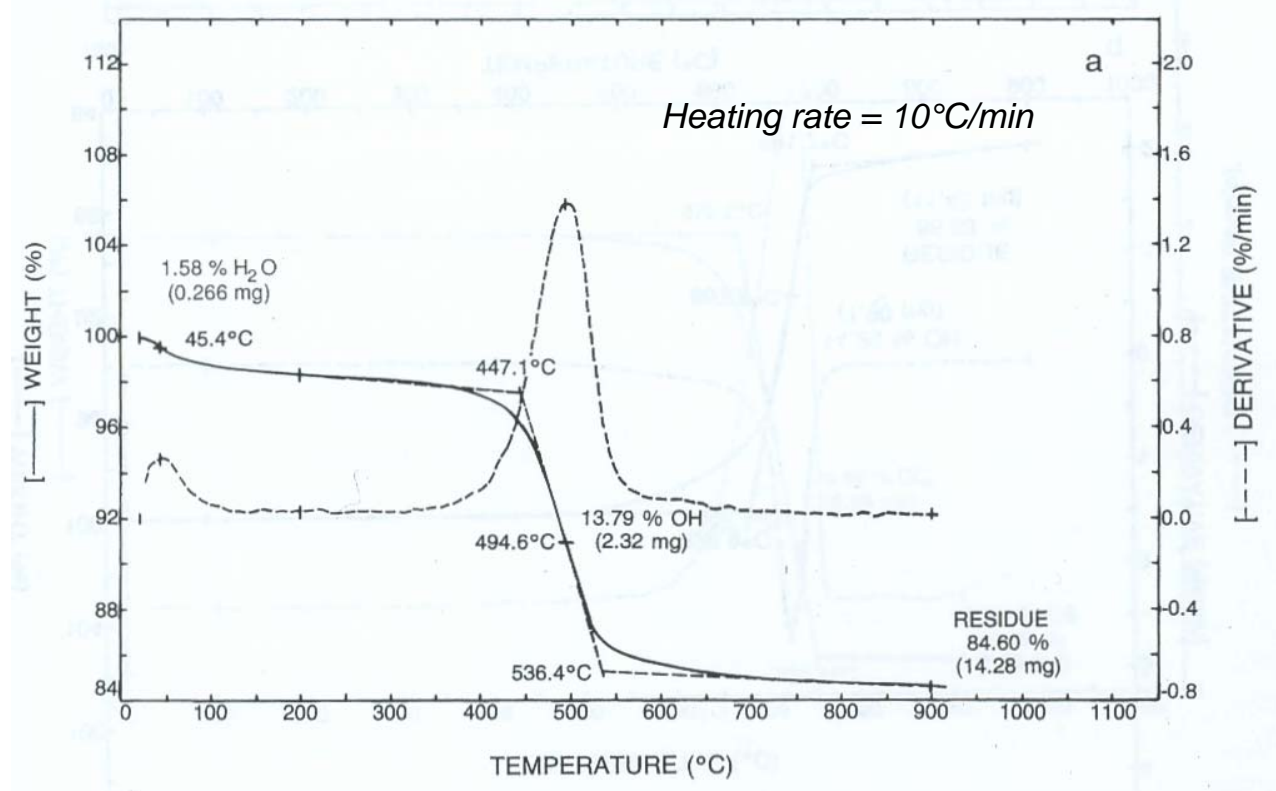

FIG 4.5- TGA curve for Halloysite (Bish and Duffy, 1990)

TABLE 4.4- Results of TG analysis (Velde, 1992)

\begin{tabular}{|c|c|c|c|c|}
\hline & \multicolumn{4}{|c|}{ Weight loss $(\%)$} \\
\hline & $10-20^{\circ} \mathrm{C}$ & $200-300^{\circ} \mathrm{C}$ & $500-600^{\circ} \mathrm{C}$ & $>600^{\circ} \mathrm{C}$ \\
\hline \multicolumn{5}{|l|}{ Smectites } \\
\hline \multicolumn{5}{|c|}{ Montmorillonite } \\
\hline Beidellite & 12 & 3 & 4 & - \\
\hline Nontronite & & & & \\
\hline \multicolumn{5}{|l|}{ Saponite } \\
\hline \multicolumn{5}{|l|}{ Stevensite } \\
\hline Vermiculite & 6 & 2 & 4 & - \\
\hline Sepiolite & 10 & $2 \sim 4$ & $2 \sim 3$ & \\
\hline Palygorskite & 10 & $2 \sim 4$ & $2 \sim 3$ & - \\
\hline \multicolumn{5}{|l|}{ Mica-like } \\
\hline Illite & 1 & 2 & 5 & - \\
\hline Glauconite & 2 & 3 & 12 & - \\
\hline \multicolumn{5}{|l|}{ Kaolinite } \\
\hline Kaolinite & 1 & - & 14 & - \\
\hline Halloysite & 7 & - & 13 & - \\
\hline $2: 1+1$ chlorite & - & - & - & $8 \sim 12$ \\
\hline $\begin{array}{l}\text { Berthierine } \\
\text { Chamosite }\end{array}$ & $1 \sim 2$ & - & - & $8 \sim 12$ \\
\hline Talc & - & - & - & 6 \\
\hline Pyrophyllite & - & - & 5 & - \\
\hline
\end{tabular}




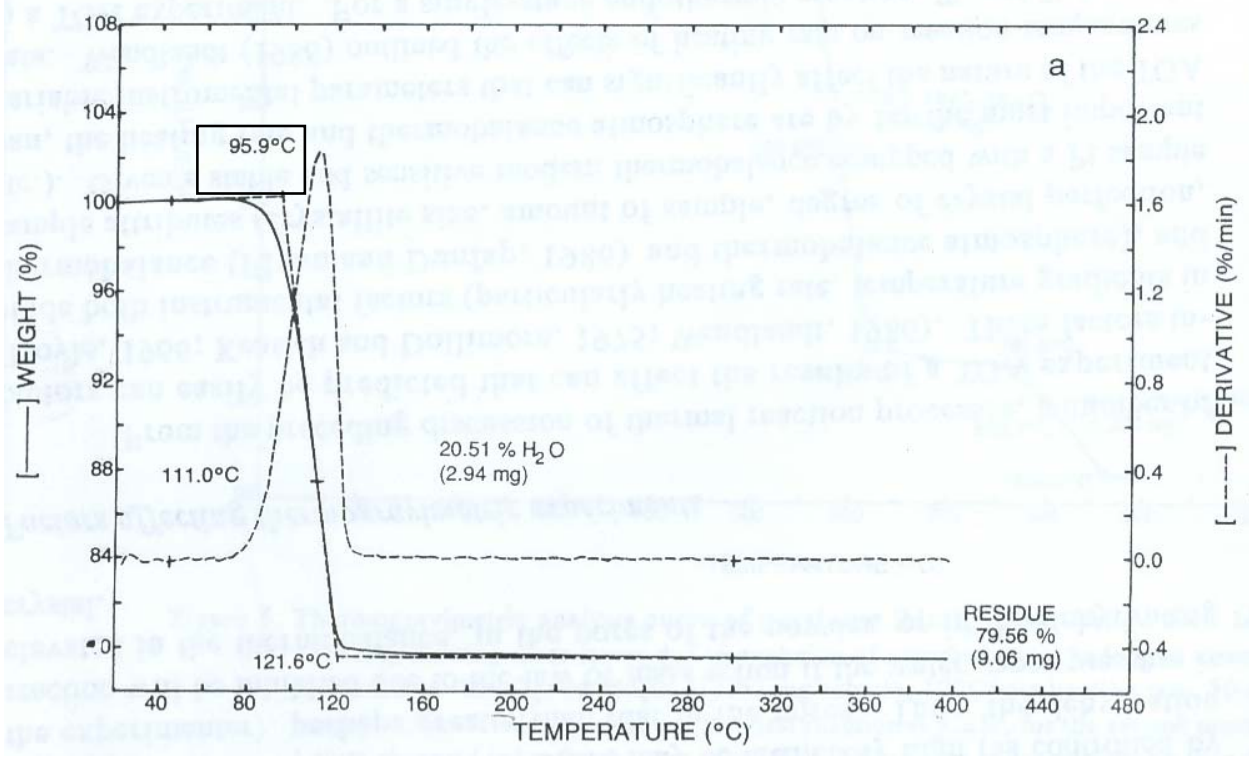

FIG 4.6- TGA curve for Gypsum heated at $2^{\circ} \mathrm{C} / \mathrm{min}$ (Bish and Duffy, 1990)

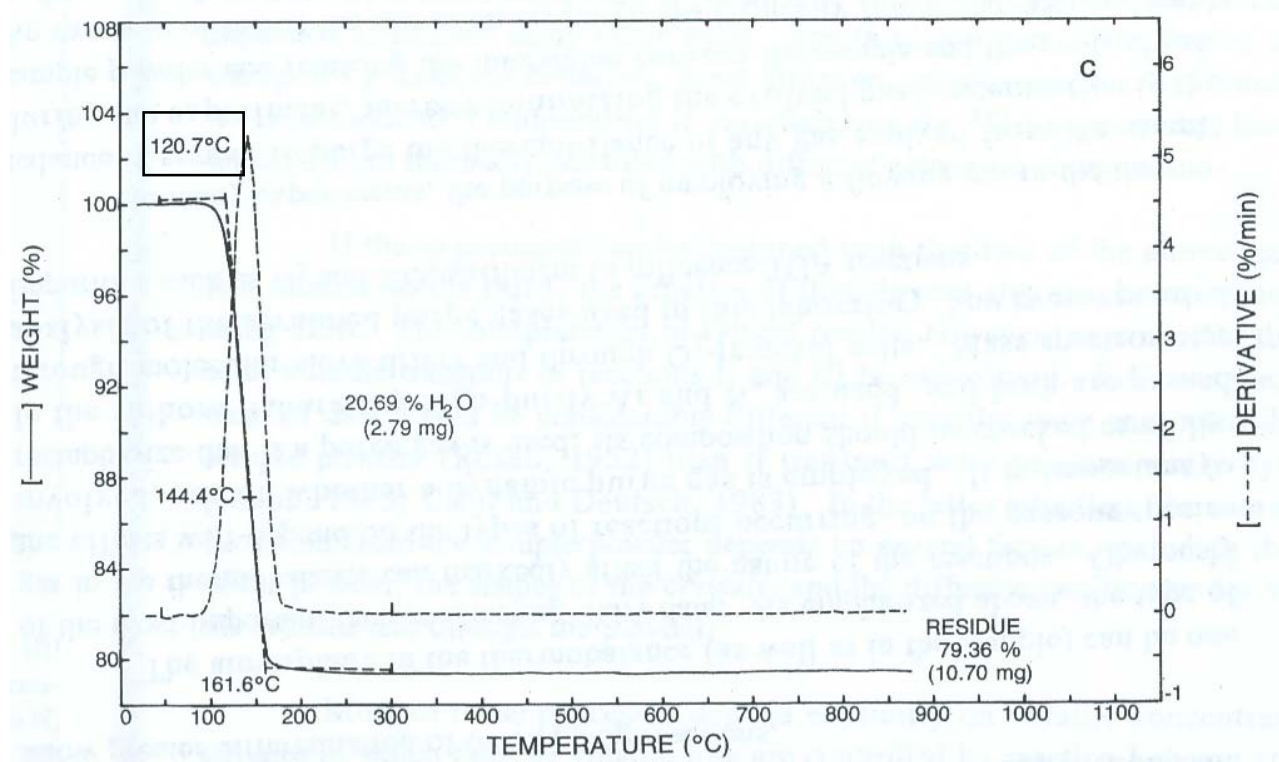

FIG 4.7- TGA curve for Gypsum heated at $10^{\circ} \mathrm{C} / \mathrm{min}$ (Bish and Duffy, 1990) 


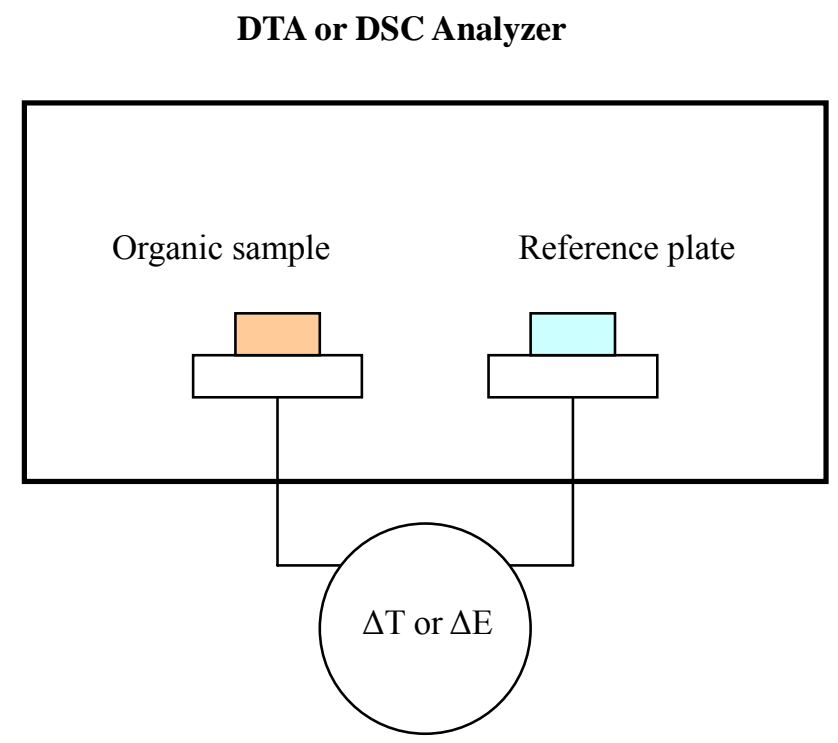

FIG 4.8- Simplified diagram of DTA and DSC analyzer

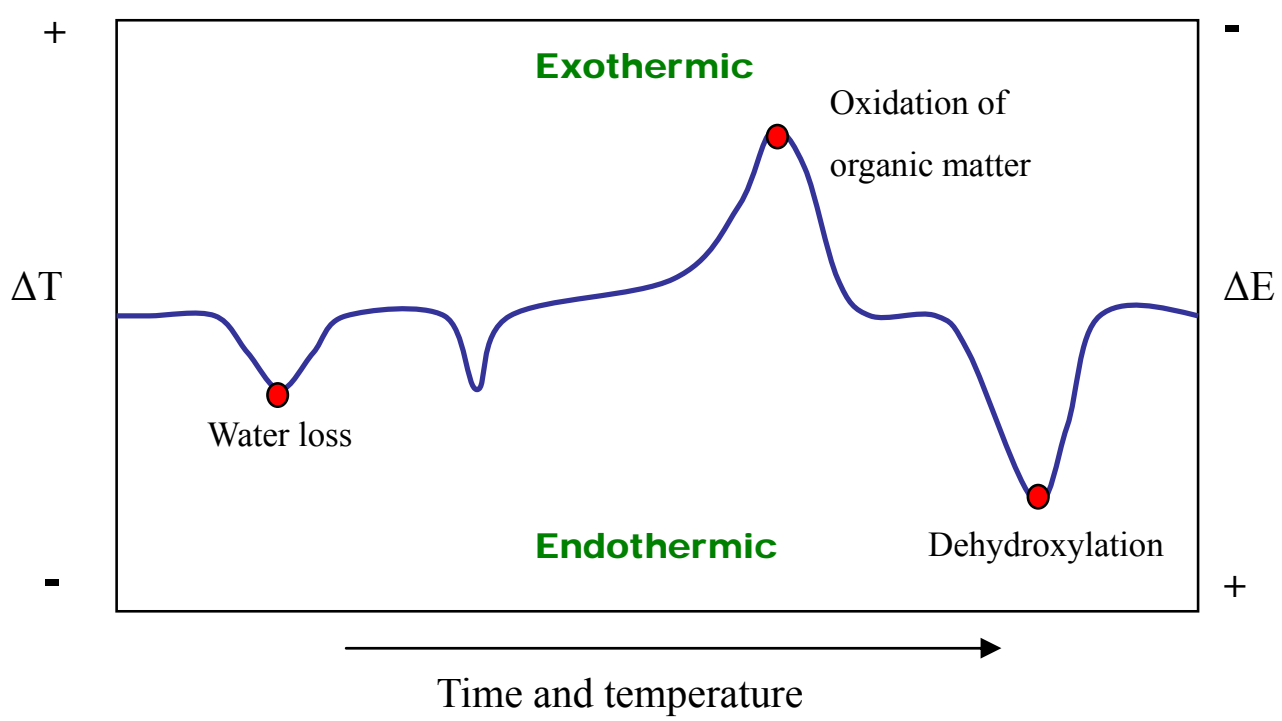

FIG 4.9- Typical result of DTA and DSC 


\section{CHAPTER 5 \\ Experimental Work}

\subsection{Introduction}

Identification of organic matter in soils is important for construction projects and requires adequate means. As discussed in Chapter 3, the presence of organic matter has significant effects on many geotechnical properties, including water content, gas content, bulk density, specific gravity, efficiency of compaction, permeability, strength, compressibility and creep.

In light of the above, many state DOTs in the United States have strict thresholds for the maximum organic matter content allowed in soils to be used as subgrades and backfills. According to a report prepared by the Mississippi Department of Transportation (Zia,2006), these threshold values are typically quite small, in the $2 \%-7 \%$ range, making it critical that the organic matter content be accurately determined.

A variety of means is available to determine organic matter, and was briefly reviewed in Chapter 4. The commonly employed methods are based on either direct determination of the organic content (e.g. loss on ignition (LOI) and hydrogen peroxide $\left(\mathrm{H}_{2} \mathrm{O}_{2}\right)$ digestion), or on indirect determination (e.g. dry/wet combustion and dichromate

oxidation). Other techniques such as the colorimetric test can be used to assess whether a soils is likely to contain some organic matter, without, however, quantifying the amount present.

From an engineering perspective, the most common approach to identify organic soils is based on conducting Atterberg limits tests (i.e. determining the reduction in the liquid limit after oven drying at $105^{\circ} \mathrm{C}$ ) and/or loss on ignition tests. The liquid limit test is an easy, rapid test required for classifying fine grained soils. While it represents a 
useful means for determining whether a soil is to be classified as organic, the criterion of $25 \%$ reduction in liquid limit does not translate into a value of the organic content.

The loss on ignition method is a very simple test, although it requires the availability of a furnace that can reach temperatures of $440^{\circ}-500^{\circ} \mathrm{C}$. The potential errors associated with this method were reviewed in Chapter 4. Specifically, it was pointed out that heating temperature and heating duration can significantly affect the results and that select inorganic constitutes (e.g. hydrated alluminosilicates, carbonate minerals) often present in soils can burn at temperatures equal to or below that employed in the test, causing an overestimation of the true organic matter of the soil.

Given the shortcomings associated with the various methods discussed above, the experimental program conducted for this research was designed with the following objectives:

(1) Assess the error associated with the use of the LOI test for quantifying organic matter content.

(2) Gain an improved understanding of the thermal behavior of soils at the temperatures used to conduct the loss on ignition test.

(3) Study the relationship between organic content and the reduction of liquid limit.

(4) Examine the sensitivity of the colorimetric method for screening soils for organic content.

(5) Explore the combined use of different testing methods to increase the precision of screening organic soils. 


\subsection{Overview of Experimental Work}

\subsubsection{Soils tested}

Three major types of soil samples were tested: natural soils, clay minerals, and laboratory prepared "artificial" organic soils. Table 5.1 lists the soils tested while photos of most of the natural soils samples and the clay minerals are provided in Figure 5.1.

As shown in Table 5.1, based on visual classification (ASTM D2487), most natural soils were classified as clays (C) or silts (M) with low (L) or high $(\mathrm{H})$ plasticity, except soil 11 and soil 14. The first is a black soil with visible organic matter (40 $-60 \%$ based on work conducted by Hwang (2006)), which can be termed a peat (Pt). Soil 14 is a well graded and clean sand (SW) used for the backfill of mechanically stabilized earth walls. The majority of the natural soils were collected from the state of Indiana. The only exceptions are represented by soil 6 which is the silt size fraction of the standard Ottawa sand; and soils 9 and 10, which are the two ASTM reference clays, CL clay and CH clay, respectively.

The clay minerals tested in this study included two kaolinites from different sources (the first from Feldspar Co., the second from Ward's Natural Science Establishment Inc), a commercial Wyoming bentonite product (from VolClay Industries), a montmorillonite (from Ward's Natural Science Establishment Inc) and grundite, an illitic clay extensively used for geotechnical research. All of these clay minerals were purchased from commercial companies. Kaolinite is a clay mineral with 1:1 elemental silica-gibbsite sheet. Montmorillonite is a 2:1 phyllosilicate clay mineral consisting of a gibbsite sheet with two silica sheets. Bentonite is the clay consisting of mostly montmorillonite. Grundite is clay made of kaolinite, illite/mixed layers, quartz, feldspar and gypsum. 
The artificial organic soils were manufactured by mixing three different clays (parent soils) with one highly organic soil (organic source). Three types of artificial organic soils, herein referred to as AOS-1, AOS-2 and AOS-3, were prepared in this study. AOS-1 was made using soil 9 (ASTM clay-CL) and soil 11. AOS-2 was made of soil 10 (ASTM clay-CH) and soil 11. AOS-3 consisted of grundite and soil 11. Note that three different samples of soil 11 the organic source material, with slightly different values of organic content, were used to prepare the AOS-1, AOS-2 and AOS-3 soils. All artificial organic soils were mixed targeting different organic contents (expressed as \% of dry mass): $0 \%, 5 \%, 10 \%, 13 \%$, and $23 \%$ for AOS- 1 , and AOS- $2,0 \%, 5 \%$, and $13 \%$ for AOS-3. In the case of AOS-2 additional mixes with lower percentages of organic matter $(1,1.3,1.6,2.2,4.5,5.6 \%)$ were used exclusively for colorimetric tests, as was a $0.3 \%$ organic content mixture of Ottawa sand and the organic source. The results of these tests are discussed in 5.3.5. In order to prepare artificial organic soils with specific values of the organic content, the water content and organic content of the parent soil and the organic source were measured after crushing the soils in a mortar and passing them through No. 40 sieve. Table 5.2 summarizes water content and organic content results for parent soils and organic source. The values of the organic content shown were obtained from the dry combustion test, and, as discussed in more detail in the following, represent the most accurate estimates of the organic content.

The amount of the organic source material required to generate the targeted organic content was then evenly distributed in the parent soil by manually dry mixing in a bowl for 5 minutes employing a spatula. Wet mixing was avoided as initial trials showed that it led to the formation of lumps and uneven distribution of the organic matter within the parent soil. 


\section{TABLE 5.1- Soils tested}

\begin{tabular}{|c|c|c|c|c|}
\hline \multicolumn{2}{|c|}{ Soil name } & $\begin{array}{c}\text { Visual } \\
\text { Classification }\end{array}$ & Color & Remarks \\
\hline \multirow{22}{*}{ 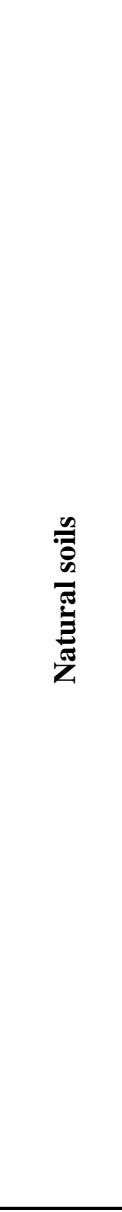 } & Soil 1 & CL & Goldenrod & Lumps \\
\hline & Soil 2 & ML & Goldenrod & Lumps \\
\hline & Soil 3 & CL & Dark goldenrod & Lumps \\
\hline & Soil 4 & ML & Brick red & Presence of dry plant roots and ants \\
\hline & Soil 5 & $\mathrm{CL}$ & Goldenrod & Small lumps \\
\hline & Soil 6 & ML & White & Silt size particle \\
\hline & Soil 7 & ML & Black & Presence of fresh plant roots and seed \\
\hline & Soil 8 & ML & Dark brown & Some dry plant roots \\
\hline & Soil 9 & $\mathrm{CL}$ & Light gray & ASTM CL clay \\
\hline & Soil 10 & $\mathrm{CH}$ & Goldenrod & ASTM CH clay \\
\hline & Soil 11 & $\mathrm{Pt}$ & Black & Lumps \\
\hline & Soil 12 & ML & Brown & Lumps \\
\hline & Soil 13 & $\mathrm{CH}$ & Brown & Lumps \\
\hline & Soil 14 & SW & Varying colors & Backfill material for MSE walls \\
\hline & Soil 15 & ML & Light black & Small, easily broken lumps \\
\hline & Soil 16 & ML & Goldenrod & Small, easily broken lumps \\
\hline & Soil 17 & ML & Black & Small, easily broken lumps \\
\hline & Soil 18 & ML & Light black & Small, easily broken lumps \\
\hline & Soil 19 & ML & Light black & Small, easily broken lumps \\
\hline & Soil 20 & $\mathrm{CL}$ & Dark goldenrod & None \\
\hline & Soil 21 & $\mathrm{CH}$ & Dark goldenrod & None \\
\hline & Soil 22 & - & - & No picture \\
\hline \multirow{5}{*}{ 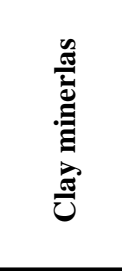 } & Kaolinite-1 & $\mathrm{CH}$ & White & None \\
\hline & Kaolinite-2 & $\mathrm{CH}$ & White & Lumps \\
\hline & Bentonite & $\mathrm{CH}$ & Light gray & No picture \\
\hline & Grundite & $\mathrm{CL}$ & Light gray & None \\
\hline & Montmorilloni & $\mathrm{CH}$ & Light gray & No picture \\
\hline \multirow{3}{*}{ 总 } & AOS-1 & - & - & - \\
\hline & AOS-2 & - & - & - \\
\hline & AOS-3 & - & - & - \\
\hline
\end{tabular}




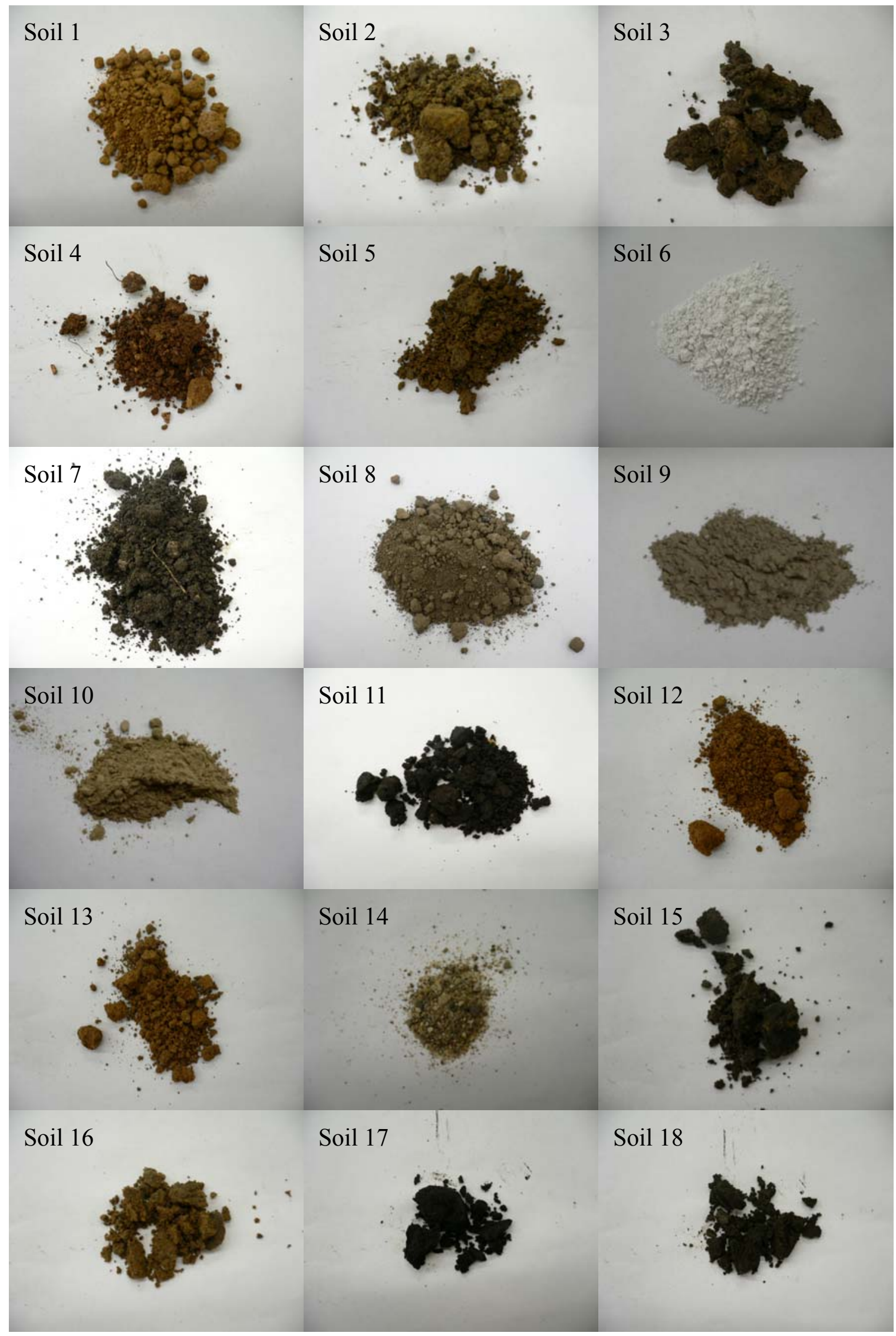




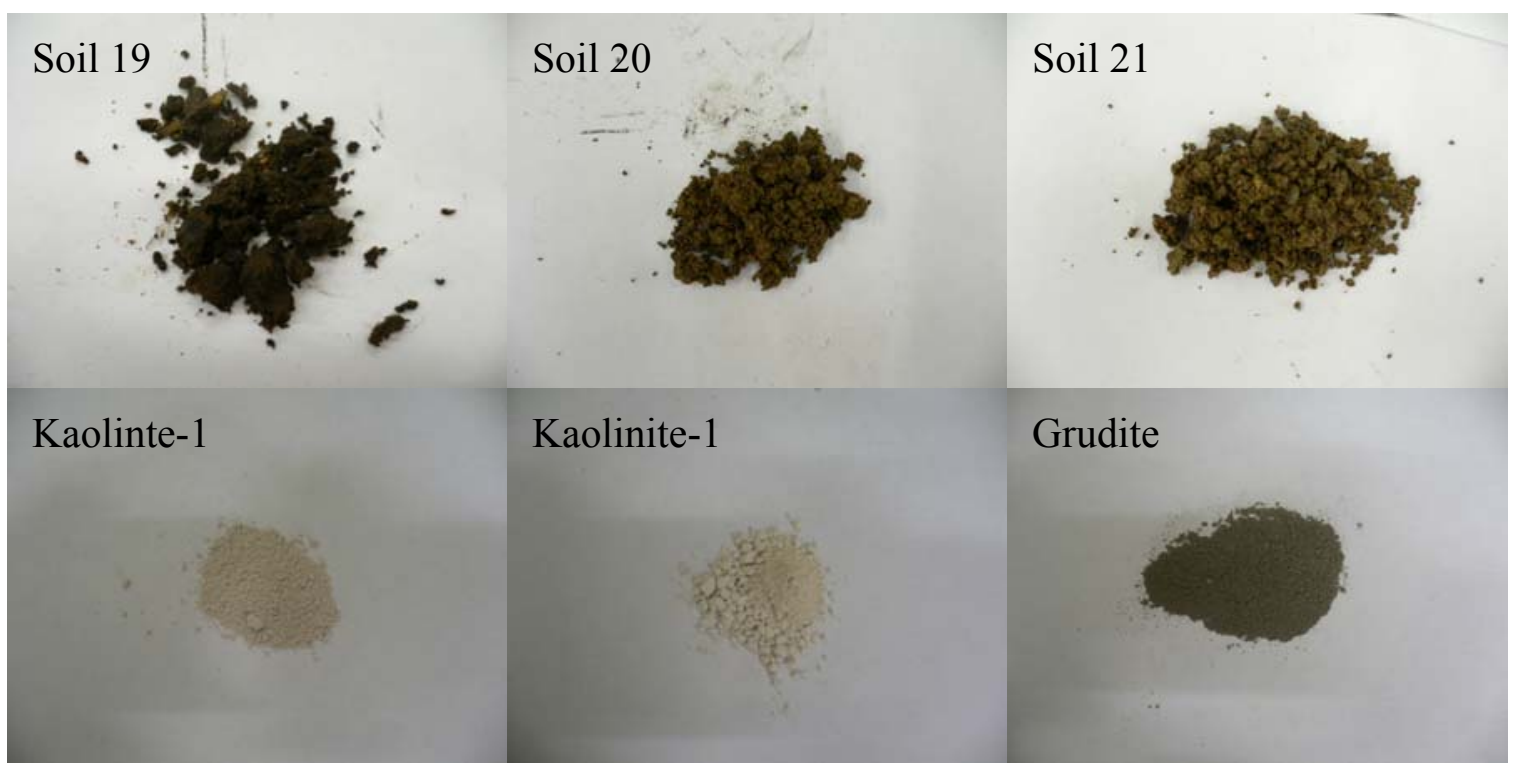

FIG 5.1- Pictures of tested soils including 21 natural soils and 3 clay minerals

\subsubsection{Test methods and procedures}

The experimental work conducted as part of this research included the following tests: a) loss of ignition test (LOI); b) Atterberg limits test; c) colorimetric test; d) dry combustion test (LECO ${ }^{\circledR}$ Analysis); e) loss of carbon dioxide test (gravimetric method); f) thermogravimetric analysis (TG); g) differential scanning calorimetry (DSC); and h) X-ray diffraction analysis (XRD).

The rationale behind the selection of these tests can be summarized as follows: tests a)-c) are potential candidates for use for routine soil classification and thus must be carefully evaluated; tests d) and e) together provide the most accurate estimate of the content of organic matter in soils against which the other methods can be evaluated; tests f)-h) allow an improved scientific understanding of some of the results obtained from the other tests.

The complete testing program is summarized in Table 5.3. Overall, the 22 natural soils and 5 clay minerals were first "screened" conducting several loss on ignition 
tests on each. For those soils with LOI values in the $2 \%-10 \%$ (and for which enough material was available to conduct further tests), the dry combustion technique was employed to measure the organic carbon content and obtain a more reliable estimate of the true organic content. The loss of carbon dioxide test was applied to the soils which contained considerable amount of inorganic carbon. Atterberg limit tests and colorimetric tests were subsequently conducted. Thermal analysis (TG and DSC) was used to study in more depth the thermal reactions of soils 7, 8, 9, 10, Kaolinite-1, and Grundite.

The mineralogy and the organic content of the parent soils and the organic source material used to manufacture the artificial organic soils were characterized by X-ray diffraction (XRD) and dry combustion, respectively. The artificial organic soils were manufactured with different values of the target organic content and then characterized using the Atterberg limits and the colorimetric test.

TABLE 5.2 - Water and organic content of parent soils and organic source used to manufacture artificial organic soils

\begin{tabular}{ccccc}
\hline & & Parent soils & Organic source \\
& Soil $9^{(1)}$ & Soil 10 $10^{(2)}$ & Grundite $^{(3)}$ & Lindberg road soil \\
\hline Water content $(\%)$ & 1.5 & 7.5 & 3.88 & $10.8^{(1)} / 12.13^{(2)} / 12.51^{(3)}$ \\
\hline Organic content $(\%)$ & 1.73 & 1.01 & 2.27 & $36.89^{(1)} / 38.2^{(2)} / 40.34^{(3)}$ \\
\hline
\end{tabular}

(1), (2), and (3) refer to three bin samples of the same soil. 
TABLE 5.3 - Overview of testing program

\begin{tabular}{|c|c|c|c|c|c|c|c|c|c|c|c|}
\hline & Soil name & 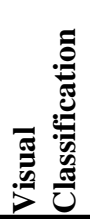 & $\frac{\grave{0}}{0}$ & ఫิ & 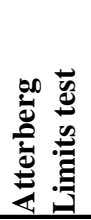 & 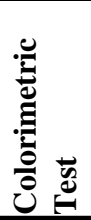 & 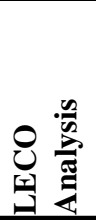 & 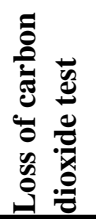 & ڤ & U & $\stackrel{2}{\not z}$ \\
\hline \multirow{22}{*}{ 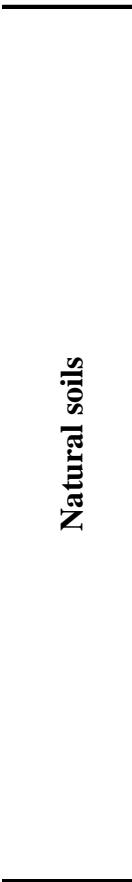 } & Soil 1 & $\mathrm{CL}$ & Goldenrod & $\mathrm{v}$ & $\mathrm{v}$ & $\mathrm{v}$ & $\mathrm{v}$ & & & & \\
\hline & Soil 2 & ML & Goldenrod & $\mathrm{v}$ & $\mathrm{v}$ & $\mathrm{v}$ & $\mathrm{v}$ & & & & \\
\hline & Soil 3 & $\mathrm{CL}$ & Dark goldenrod & $\mathrm{v}$ & $\mathrm{v}$ & $\mathrm{v}$ & $\mathrm{v}$ & $\mathrm{v}$ & & & \\
\hline & Soil 4 & ML & Brick red & $\mathrm{v}$ & $\mathrm{v}$ & $\mathrm{v}$ & $\mathrm{v}$ & $\mathrm{v}$ & & & \\
\hline & Soil 5 & CL & Goldenrod & $\mathrm{v}$ & $\mathrm{v}$ & $\mathrm{v}$ & $\mathrm{v}$ & & & & \\
\hline & Soil 6 & ML & White & $\mathrm{v}$ & $\mathrm{v}$ & $\mathrm{v}$ & $\mathrm{v}$ & & & & \\
\hline & Soil 7 & ML & Black & $\mathrm{v}$ & $\mathrm{v}$ & $\mathrm{v}$ & $\mathrm{v}$ & $\mathrm{v}$ & $\mathrm{v}$ & $\mathrm{v}$ & \\
\hline & Soil 8 & ML & Dark brown & $\mathrm{v}$ & $\mathrm{v}$ & $\mathrm{v}$ & $\mathrm{v}$ & & $\mathrm{v}$ & $\mathrm{v}$ & \\
\hline & Soil 9 & $\mathrm{CL}$ & Light gray & $\mathrm{v}$ & $\mathrm{v}$ & $\mathrm{v}$ & $\mathrm{v}$ & & $\mathrm{v}$ & $\mathrm{v}$ & $\mathrm{V}$ \\
\hline & Soil 10 & $\mathrm{CH}$ & Goldenrod & $\mathrm{v}$ & $\mathrm{v}$ & $\mathrm{v}$ & $\mathrm{v}$ & & $\mathrm{v}$ & $\mathrm{v}$ & $\mathrm{V}$ \\
\hline & Soil 11 & $\mathrm{Pt}$ & Black & $\mathrm{v}$ & $\mathrm{v}$ & & $\mathrm{v}$ & & & & $\mathrm{v}$ \\
\hline & Soil 12 & ML & Brown & $\mathrm{v}$ & & & & & & & \\
\hline & Soil 13 & $\mathrm{CH}$ & Brown & $\mathrm{v}$ & & & & & & & \\
\hline & Soil 14 & SW & Varying colors & $\mathrm{v}$ & & & & & & & \\
\hline & Soil 15 & ML & Light black & $\mathrm{v}$ & & & & & & & \\
\hline & Soil 16 & ML & Goldenrod & $\mathrm{v}$ & & & & & & & \\
\hline & Soil 17 & ML & Black & $\mathrm{v}$ & & & & & & & \\
\hline & Soil 18 & ML & Light black & $\mathrm{v}$ & & & & & & & \\
\hline & Soil 19 & ML & Light black & $\mathrm{v}$ & & & & & & & \\
\hline & Soil 20 & $\mathrm{CL}$ & Dark goldenrod & $\mathrm{v}$ & & & & & & & \\
\hline & Soil 21 & $\mathrm{CH}$ & Dark goldenrod & $\mathrm{v}$ & & & & & & & \\
\hline & Soil 22 & - & - & $\mathrm{v}$ & & & & & & & \\
\hline \multirow{5}{*}{ 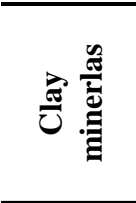 } & Kaolinite-1 & $\mathrm{CH}$ & White & $\mathrm{v}$ & $\overline{\mathrm{v}}$ & $\mathrm{v}$ & $\mathrm{v}$ & & $\mathrm{v}$ & $\mathrm{v}$ & $\mathrm{v}$ \\
\hline & Kaolinite-2 & $\mathrm{CH}$ & White & $\mathrm{v}$ & & $\mathrm{v}$ & $\mathrm{v}$ & & & & \\
\hline & Bentonite & $\mathrm{CH}$ & Light gray & $\mathrm{v}$ & & $\mathrm{v}$ & & & & & \\
\hline & Grundite & CL & Light gray & $\mathrm{v}$ & $\mathrm{v}$ & $\mathrm{v}$ & $\mathrm{v}$ & & $\mathrm{v}$ & $\mathrm{v}$ & $\mathrm{v}$ \\
\hline & Montmorillonite & $\mathrm{CH}$ & Light gray & $\mathrm{v}$ & & $\mathrm{v}$ & & & & & \\
\hline \multirow{3}{*}{ 尝 } & ${ }_{4}$ AOS-1 & - & - & $\mathrm{v}$ & $\mathrm{v}$ & & (1) & & & & \\
\hline & AOS-2 & - & - & $\mathrm{v}$ & $\mathrm{v}$ & & (1) & & & & \\
\hline & $\mathrm{AOS}-3$ & - & - & $\mathrm{v}$ & $\mathrm{v}$ & & (1) & & & & \\
\hline
\end{tabular}

${ }^{(1)}$ true organic content available based on mixing proportions and LECO data for parent soils and organic source material

\subsubsection{Loss on ignition test (LOI)}

The loss on ignition test (LOI) was performed based on ASTM standard D2974 method C. For each soil, an appropriate sample (10-15 g) was placed in a crucible. The water content was measured after oven-drying at $105^{\circ} \mathrm{C} \pm 5^{\circ} \mathrm{C}$ for 24 hours. The crucible with the dry sample was then transferred into the furnace. The furnace used in this study 
is a THERMOLYNE 2000. The sample was kept in the furnace at a temperature of $440^{\circ} \mathrm{C}$ temperature for 16 hours. After ignition, the mass of ash was measured to the nearest $0.01 \mathrm{~g}$, as required by the test. The organic content was then determined as:

$$
\text { O.C.(\%) }=\frac{\operatorname{Mass}_{105^{\circ} \mathrm{C}}-\text { Mass }_{440^{\circ} \mathrm{C}}}{\text { Mass }_{105^{\circ} \mathrm{C}}-\text { Mass }_{\text {crucible }}}
$$

The heating temperature and duration are two critical factors which significantly influence the results. In ASTM D2974, there are two options for the heating temperature: $440^{\circ} \mathrm{C}$ (Method $\mathrm{C}$ ) and $750^{\circ} \mathrm{C}$ (Method D). With regard to the heating duration it is specified that the sample should be held in the furnace until it is completely ashed (i.e., no change of mass occurs with further heating). According to the literature, ignition of soils at 400 to $450^{\circ} \mathrm{C}$ will remove all organic matter and cause minimal dehydroxylation of clay minerals. It is also reported that a heating time of 8 to 16 hours at $400^{\circ} \mathrm{C}$ results in near maximum weight loss (Ben-Dor \& Banin, 1989). For theses reasons, the $440^{\circ} \mathrm{C}$ heating temperature and 16 hours heating time were chosen in this study. 16 hours is also a good testing period in terms of test scheduling, i.e. 5:00 pm to 9:00 am next day.

\subsubsection{Atterberg limit tests}

Atterberg limits tests were performed in accordance with ASTM standard D4318. In the Unified Soil Classification System (USCS), ASTM standard D4318, organic soils are distinguished by the ratio of the oven-dried liquid limit to the non-oven-dried liquid limit (this ratio is referred to in this study as the "liquid limit ratio"). If the ratio is less than 0.75 , the soil is classified as an organic soil with the symbol (O). In this testing program, the determination of the liquid limit was based on the procedures described in the standard. The only difference is in the order of performing the determination of the 
blow counts at various water contents. While the standard suggests a dry (high blow count) to wet (low blow counts) procedure (i.e. water is added to the soil before each blow count determination), a wet to dry procedure was instead used (i.e. a fan is used between each determination to dry the soil). It is acknowledged that the two procedures may cause slight differences in the results of liquid limit; however, the use of the latter procedure is reported to generate more repeatable data. The oven-dried liquid limit was conducted after the sample was oven-dried in the oven at $105^{\circ} \mathrm{C} \pm 5^{\circ} \mathrm{C}$ for 24 hours following identical procedures to those employed for the non-oven dried LL.

Determinations of the plastic limit both before and after oven drying the soil were also conducted.

\subsubsection{Colorimetric test}

The colorimetric test was performed in accordance with the procedures contained in the following standards: ASTM C-40 and AASHTO T 21. The colorimetric test is a standard test mainly used to detect the organic impurities in fine aggregates used in concrete.

In this experimental program the test was conducted using the following procedures: first the entire soil sample was air-dried and, when necessary, crushed so that it passed the No.10 sieve (the opening size of the No.10 sieve corresponds to the definition of fine aggregate according to AASHTO M-147); a glass bottle was then filled to the $130 \mathrm{~mL}$ level with the soil sample to be tested; a 3\% sodium hydroxide solution (0.75M, pH=13.4) was added to the fall to reach the $200 \mathrm{ml}$ level; the bottle was then closed with a stopper and vigorously shaken for a couple of minutes. After 24 hours of standing, the color of supernatant changed was observed. The color depends on the 
presence of organic matter. Specifically, as discussed in Chapter 4, according to the standard, "if the color of the supernatant liquid is darker than that of the standard color of solution or the glass color standard organic plate No. 3 (Gardner Color Standard No.11), the fine aggregate under test shall be considered to possibly contain injurious organic compounds, and further tests should be made before approving the fine aggregates for use in concrete". In this study the glass color standard was employed instead of using standard color solution. The glass color standard, which is described in ASTM standard D1544, is an easy, rapid, and portable way to check the color. Figure 5.2 shows the glass color standard organic plate.

Note that the procedure described implies that it is the bulk volume of the soil sample which is controlled, rather than the mass. Depending on the soil sample, the 130 $\mathrm{ml}$ volume corresponded to a sample mass of $90-130 \mathrm{~g}$, and the solid to liquid ratio also varied.

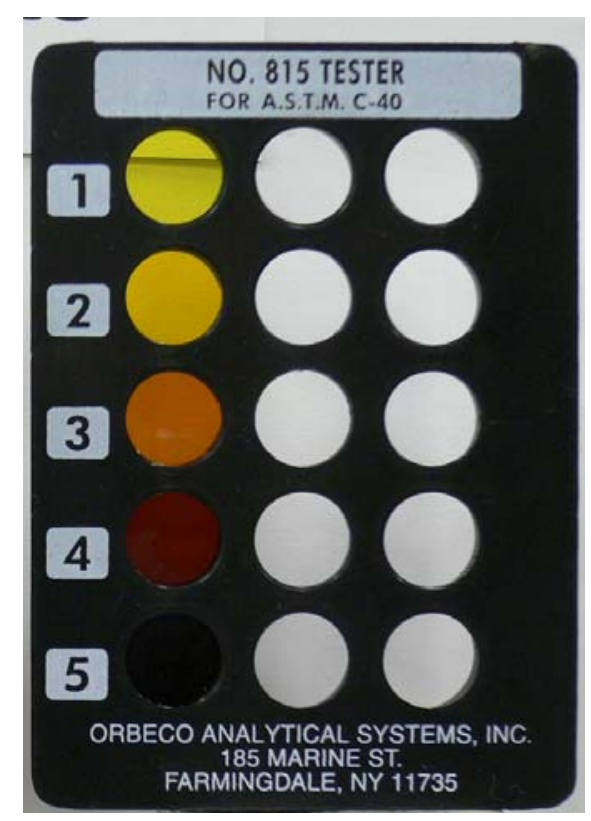

FIG 5.2- Glass color standard organic plate 


\subsubsection{Dry combustion test (LECO ${ }^{\circledR}$ Analysis)}

Dry combustion is a more precise method to estimate the organic content. In this study, a LECO ${ }^{\circledR}$ CHN-2000 elemental analyzer (Schumacher, 2002) was used to conduct this test. The test, which measures the total carbon content of soils, is based on the principle of oxidizing organic carbon and thermally decomposing other carbonate minerals at high temperature. The $\mathrm{CO}_{2}$ released from elemental carbon is then collected and passed through an infrared cell to determine the carbon content. If there is no presence of carbon minerals (i.e. inorganic carbon), the total carbon provided by the dry combustion test corresponds to the total organic carbon (TOC) of the soil. In this study, an assessment of the potential presence of inorganic carbon was made by pre-testing all soil samples by adding drops of $3 \mathrm{M}$ Hydrochloric acid $(\mathrm{HCl})$ to a small soil sub-sample. If strong froth was observed, it was concluded that the soil contained inorganic carbon (e.g. calcite $\left(\mathrm{CaCO}_{3}\right)$ and/or dolomite $\left.\left(\mathrm{CaMg}\left(\mathrm{CO}_{3}\right)_{2}\right)\right)$. In this case, the inorganic carbon content was also separately determined. The total organic carbon content was then determined as the difference between the total carbon content given by the dry combustion test and the inorganic carbon content. In the $\mathrm{LECO}^{\circledR} \mathrm{CHN}-2000$ apparatus a soil sample of about $0.2 \mathrm{~g}$ is placed in a tin capsule and then combusted in the resistance furnace of the analyzer. In this experimental program the operating temperature was selected as $950^{\circ} \mathrm{C}$ and ultra high purity $\mathrm{O}_{2}$ was used as a carrier gas. Note that the LECO ${ }^{\circledR}$ CHN-2000 elemental analyzer not only gives the carbon content but also provides the hydrogen and nitrogen content.

\subsubsection{Loss of carbon dioxide test (Gravimetric method)}

This test was used to determine the inorganic carbon content of soils through the 
addition of hydrochloric acid ( $\mathrm{HCl})$. The addition of acid leads to decomposition of the carbonate and release of $\mathrm{CO}_{2}$ to the atmosphere. The decrease in mass resulting from the release of $\mathrm{CO}_{2}$ is proportional to the carbonate content of the soil (Loeppert and Suarez, 1996). In this study, a soil sample of about $1 \mathrm{~g}$ was placed in a flask with $10 \mathrm{ml} 3 \mathrm{M}$ hydrochloric acid $(\mathrm{HCl})$. The mass of the flask cotaining the soil sample and the acid was then measured every 15 minutes until the change in mass was observed to be less than 1-2 mg. The carbon content was then calculated from the following:

$$
\mathrm{CO}_{3}-\mathrm{C}, \%=\left(\frac{\mathrm{g}, \mathrm{CO}_{2} \text { lost }}{\mathrm{g}, \text { soil }}\right)(0.2727)(100)
$$

\subsubsection{Thermogravimetric Analysis (TG)}

Thermogravimetric analysis is a thermal analysis technique used to quantify the weight loss of materials with increasing temperature. The standard testing procedure for this test is contained in ASTM E1131. In this research a TG analyzer manufactured by TA Instruments $^{\circledR}$ (TG 2050) was used for all the tests. Soil samples of about $40 \mathrm{mg}$ were placed in the chamber of the analyzer and the chamber temperature was gradually increased from the room temperature to $600^{\circ} \mathrm{C}$ at a rate of $10^{\circ} \mathrm{C} / \mathrm{min}$. During the test, pure nitrogen was supplied at a rate of $50 \mathrm{ml} / \mathrm{min}$.

\subsubsection{Differential scanning calorimetry (DSC)}

This analysis aims to understand the thermal behavior of the soils as a function of temperature. Thermal reactions of organic matter and minerals are opposite during thermal digestion (see Chapter 4). For this reason, the results of this test can be used to assess if the loss of ignition is from organic matter combustion or dehydroxylation of 
minerals. The testing procedure for this test is contained in ASTM E794. In this experimental program the DSC 2010 analyzer manufactured by TA Instruments ${ }^{\circledR}$ was used for all the tests. Soil samples approximately $15 \mathrm{mg}$ in mass were placed in the chamber of the analyzer and the temperature was increased at a constant rate of $10^{\circ} \mathrm{C} / \mathrm{min}$ from room temperature to $600^{\circ} \mathrm{C}$. During the test, pure nitrogen was supplied at a rate of $50 \mathrm{ml} / \mathrm{min}$.

\subsubsection{X-ray diffraction (XRD)}

X-ray diffraction is widely used characterize the mineralogy of soils. In this study X-ray diffraction analyses relied on a SIEMENS X-ray diffract meter model D500. All samples were scanned from $3^{\circ}(2 \theta)$ to $65^{\circ}(2 \theta)$ employing $\mathrm{Cu} \mathrm{K} \alpha$ radiation and using a $0.04^{\circ}$ step size. For each step the scanning time was 1 second.

\subsection{Results and Discussion}

\subsubsection{LOI results}

The results of the LOI tests conducted on the natural soils and the clay minerals are summarized in Table 5.4. The table reports LOI data in two separate columns. The first (column 2) presents average values of several LOI measurements conducted on each soil during an early screening process. Early in the testing it was recognized that in many soils the LOI measurements showed significant sample to sample variation. Thus several repeat measurements (see column 3) were performed. The second set of LOI data reported in column 7 represents measurements conducted on the companion samples to those used for the LECO analysis. These data will be discussed in the following section. 
Table 5.4 shows that most soils have LOI values in the $0-10 \%$ range. This is in line with the scope of this research project which intended to focus on soils with small organic matter content. One notable exception is represented by soil 11. This is the organic matter source used to manufacture the artificial organic soils, which was classified as a Peat using visual-manual classification procedures. Note that this is the same soil that has been used in a recently completed JTRP research project (Hwang et al. 2004), and for which there exist ample data on index and one-dimensional compression properties.

In general it is observed that the higher values of LOI reported in Table 5.4 correspond to the soils that during visual classification were found to contain more visible plant debris and were darker in color. There are some important exceptions, including soils 9 and 10 (the two ASTM reference clays), the first Kaolinite, and Grundite, which exhibit unexpectedly high LOI values. More detail on the thermal analysis of these soils is provided in Section 5.3.4 which discusses the results of the TG and DSC analyses

\subsection{2 $\quad$ LECO $^{\circledR}$ analysis results}

As discussed above, in addition to using the LOI method, more precise measurements of the organic matter content were conducted using the dry combustion method (i.e. LECO analysis) in combination, when necessary, with the loss of carbon dioxide method.

As explained in Sections 4.3.1 and 5.2.2.4, the LECO analysis measures the total organic carbon content of a soil, while the loss of carbon dioxide method is used to quantify the inorganic carbon content method. These data are reported in Table 5.4 in columns 4 and 5, respectively. The difference of these two values provides the organic 
carbon content from which the organic matter content can be calculated.

Among the soils tested with this technique only soils 3, 4, and 7 had strong reaction with hydrochloric acid $(\mathrm{HCl})$, indicating that inorganic carbon could be present. For these soils the inorganic carbon content was measured as $3.15 \%, 0.62 \%$, and $1.76 \%$, respectively, and subtracted from the total carbon content to yield the organic carbon content. For all other soils the inorganic carbon content was assumed to be zero. In order to estimate the organic content, a correction factor of 1.724, was applied, i.e. the organic content for each soil was calculated using the following equation:

O.C. $\%=1.724 \times($ Organic_Carbon $\%)=1.724 \times($ Total_Carbon $\%-$ Inorganic_Carbon $\%)$ The data calculated in this manner are summarized in column 6 of Table 5.4.

The estimates of the organic matter content obtained from the results of the LECO analysis can be compared to the LOI data as shown in Figure 5.3. Note that the LECO ${ }^{\circledR}$ analysis requires than only material passing the No.40 sieve $(0.425 \mathrm{~mm})$ be used, which required sieving the soils. After sieving, representative samples were also obtained to perform new LOI tests that could be better compared to the dry oxidation results. These are the values of the LOI reported in column 7 in Table 5.4 and shown in Figure 5.3. The discrepancy between the data in column 2 and column 7 is considered to be a result of sample to sample variability, as well as of the fact that in soil with higher organic content (e.g. soils 11 and 7) it is known that the organic matter is typically more closely attached to smaller size particles (Nelson and Sommers, 1996).

The data presented in Table 5.4 and Figure 5.3 show that for low values of the organic content $(\sim<15 \%)$, the LOI test consistently overestimates the true organic content of the soil. This is clearly an important concern if the loss on ignition method is to be 
used to identify and screen low organic content soils. For example, based on the LOI test, soils 1, 3, 4, and 9 would not be considered adequate for use as subgrade soils in the State of Indiana, which employs a maximum threshold value for the organic content of $3 \%$. The more precise measurement of the organic content using the LECO analysis shows instead that all four are viable subgrade geomaterials. The difference between the estimates of the organic content is especially significant in a few cases, in particular for one of the kaolinite samples (\#1). The effect of high temperature on this soil is further discussed in Section 5.3.4.

The data in Table 5.4 and Figure 5.3 also suggest that for higher values of the organic content ( $>\sim 20 \%)$ the LECO analysis can yield values of the organic content that are greater than those estimated through the LOI. The reason for this discrepancy is likely to be the different sample size used in the LOI (10-15 g) and LECO analysis (0.2 g).

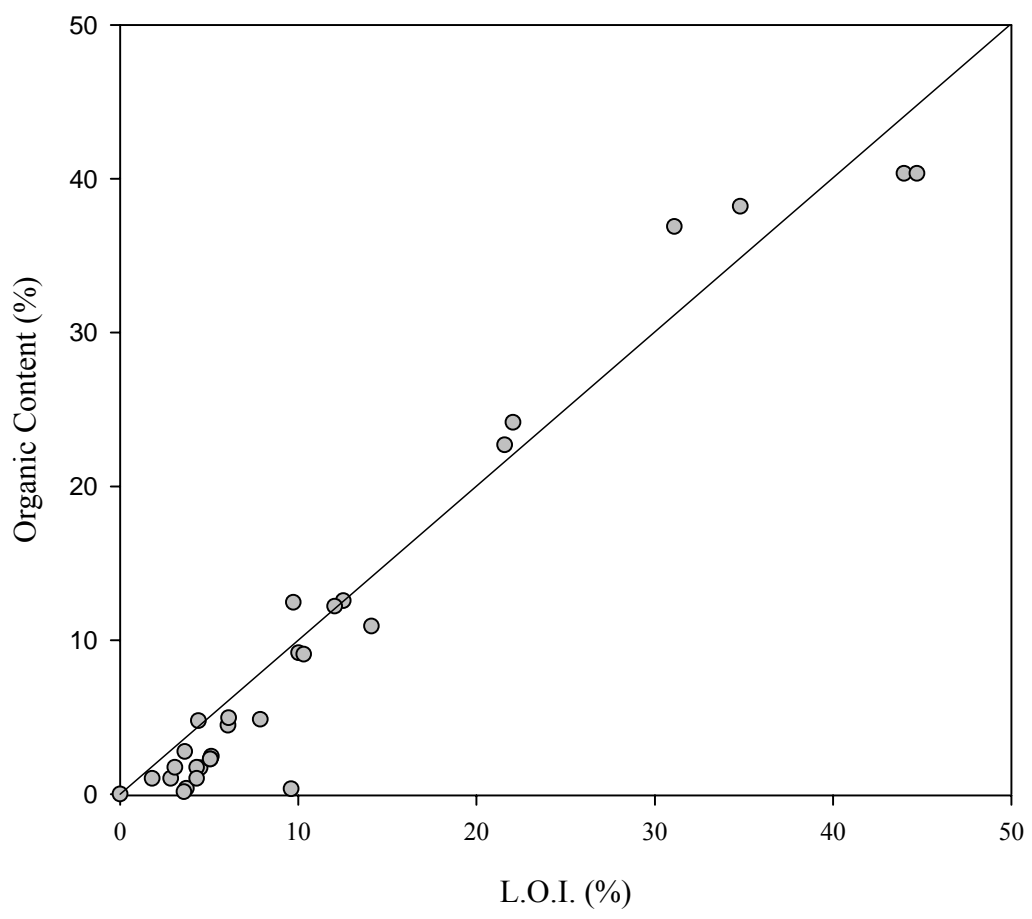

FIG 5.3- Plot of loss on ignition and organic content 
TABLE 5.4 - Summary of test results of natural soils

\begin{tabular}{|c|c|c|c|c|c|c|c|c|c|}
\hline & Soil & Ave. LOI & $\begin{array}{l}\text { LOI } \\
\text { tests }\end{array}$ & $\begin{array}{c}\text { Total } \\
\text { Organic } \\
\text { Carbon } \\
\end{array}$ & $\begin{array}{c}\text { Inorganic } \\
\text { Carbon }\end{array}$ & $\begin{array}{c}\text { Organic } \\
\text { Content }^{(4)} \\
\end{array}$ & $\mathrm{LOI}^{(5)}$ & $\begin{array}{c}\text { Liquid } \\
\text { Limit } \\
\text { Ratio } \\
\end{array}$ & $\begin{array}{c}\text { Colorim. } \\
\text { Test }\end{array}$ \\
\hline & & $\%$ & \# & $\%$ & $\%$ & $\%$ & $\%$ & $\mathrm{n} / \mathrm{a}$ & Color No. \\
\hline \multirow{24}{*}{$\frac{\infty}{\frac{n}{0}}$} & Soil 1 & 3.72 & 5 & 0.21 & - & 0.36 & 3.17 & 0.96 & 1 \\
\hline & Soil 2 & 4.50 & 4 & 0.99 & - & 1.71 & 2.07 & 0.94 & 3 \\
\hline & Soil 3 & 3.63 & 4 & 4.75 & 3.15 & 2.76 & 3.58 & 0.98 & 3 \\
\hline & Soil 4 & 5.13 & 4 & 2.04 & 0.62 & 2.45 & 5.19 & 0.88 & 3 \\
\hline & Soil 5 & 1.80 & 2 & 0.59 & - & 1.01 & 1.24 & 0.98 & $1+$ \\
\hline & Soil 6 & 0.00 & 2 & 0.00 & - & 0.00 & 0.00 & - & $<1^{(6)}$ \\
\hline & Soil 7 & 9.72 & 4 & 8.98 & 1.76 & 12.45 & 10.91 & 0.68 & 5 \\
\hline & Soil 8 & 4.40 & 2 & 2.76 & - & 4.76 & 5.77 & 0.85 & 4 \\
\hline & Soil 9 & 4.30 & 2 & 1.00 & - & 1.73 & 4.55 & 1.00 & 4 \\
\hline & Soil 10 & 2.85 & 2 & 0.59 & - & 1.01 & 2.74 & 0.99 & $1+$ \\
\hline & \multirow{3}{*}{ Soil 11} & $31.10^{(1)}$ & 2 & 21.40 & - & 36.89 & 40.76 & - & \\
\hline & & $34.79^{(2)}$ & 2 & 22.16 & - & 38.20 & 41.98 & - & \\
\hline & & $43.98^{(3)}$ & 2 & 23.40 & - & 40.34 & 46.91 & 0.58 & \\
\hline & Soil 12 & 0.95 & 1 & & & & & & \\
\hline & Soil 13 & 2.50 & 1 & & & & & & \\
\hline & Soil 14 & 0.35 & 1 & & & & & & \\
\hline & Soil 15 & 1.85 & 1 & & & & & & \\
\hline & Soil 16 & 0.95 & 1 & & & & & & \\
\hline & Soil 17 & 8.40 & 1 & & & & & & \\
\hline & Soil 18 & 2.65 & 1 & & & & & & \\
\hline & Soil 19 & 1.65 & 1 & & & & & & \\
\hline & Soil 20 & 2.00 & 1 & & & & & & \\
\hline & Soil 21 & 2.00 & 1 & & & & & & \\
\hline & Soil 22 & 2.00 & 1 & & & & & & \\
\hline \multirow{5}{*}{ 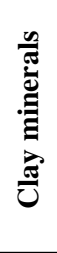 } & Kaolinite-1 & 9.60 & 6 & 0.19 & - & 0.33 & 10.96 & 0.93 & 4 \\
\hline & Kaolinite-2 & 3.59 & 2 & 0.09 & - & 0.15 & 2.37 & & 3 \\
\hline & Bentonite & 0.80 & 1 & & & & & & 2 \\
\hline & Grundite & 5.07 & 3 & 1.32 & - & 2.27 & 3.69 & 0.98 & $2+$ \\
\hline & Montmorillon. & 0.59 & 2 & & & & & & 2 \\
\hline
\end{tabular}

$<$ Notes $>$

(1), (2), (3) refer to different bins in which soil 11 was stored and that were used to manufacture artificial organic soils, AOS-1, AOS-2, AND AOS-3, respectively.

(4) O.C. $\%=1.724 \times($ Organic_Carbon $\%)=1.724 \times($ Total_Carbon $\%-$ Inorganic_Carbon $\%)$

(5) LOI data from companion samples of those used for LECO analysis

(6) The color of supernatant is as lucid as the color of sodium hydroxide solution 


\subsubsection{XRD results}

Characterization of the mineralogy of the parent soils (soils 9, 10, and Grundite) and the organic source material (soil 11) employed to manufacture the laboratory prepared artificial organic soil, was conducted using XRD analysis. Figures 5.4 and 5.5 present the XRD spectra for soils 9 and 10 (ASTM reference clays). The figures show that the two clays have similar mineral composition. The primary components are: Quartz, Illite, Kaolinite, and Goethite $(\mathrm{FeO}(\mathrm{OH}))$. Based on the size of the XRD peaks it appears that all these minerals are more prevalent in soil 9 compared to soil 10 . Additionally, soil 9 appears to also contain some Hematite $\left(\mathrm{Fe}_{2} \mathrm{O}_{3}\right)$.

For Grundite and soil $11 \mathrm{XRD}$ data obtained as part of two recent research projects were available. Specifically, the mineralogy of Grundite was obtained from Kang (2006) based on tests conducted at ETH, in Switzerland. This study showed that the major minerals in Grundite are Quartz, Feldspar, Gypsum, Kaolinite, and illite/mixed layers. The content of each of these mineral was estimated as $19 \%, 5 \%, 3 \%, 10 \%, 63 \%$, respectively. The mineral composition for different size fractions of soil 11 was obtained by Hwang (2006). Table 5.5 summarizes the results of this investigation.

TABLE 5.5 - Mineral composition of three size fractions of the organic source soil (soil 11)

\begin{tabular}{cl}
\hline Fraction size $(\mu \mathrm{m})$ & \multicolumn{1}{c}{ Mineral composition } \\
\hline $5-2$ & quartz, mica (muscovite), kaolinite, gibbsite, rutile, feldspar \\
$2-0.2$ & quartz, kaolinite, vermiculite (dioctahedral), mica (muscovite) \\
$<0.2$ & smectite, mica (muscovite), kaolinite \\
\hline
\end{tabular}




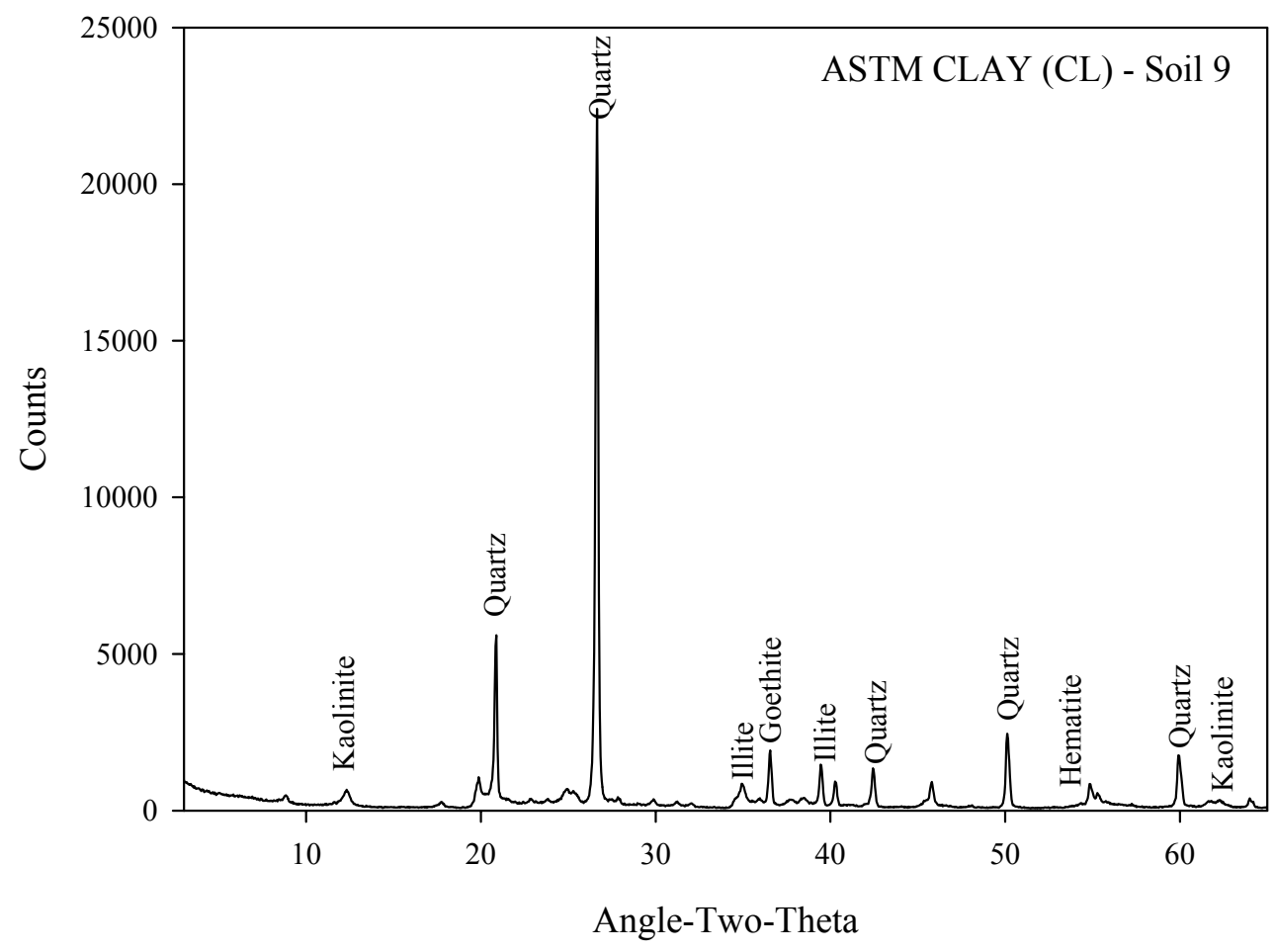

FIG. 5.4 - XRD spectrum for soil 9

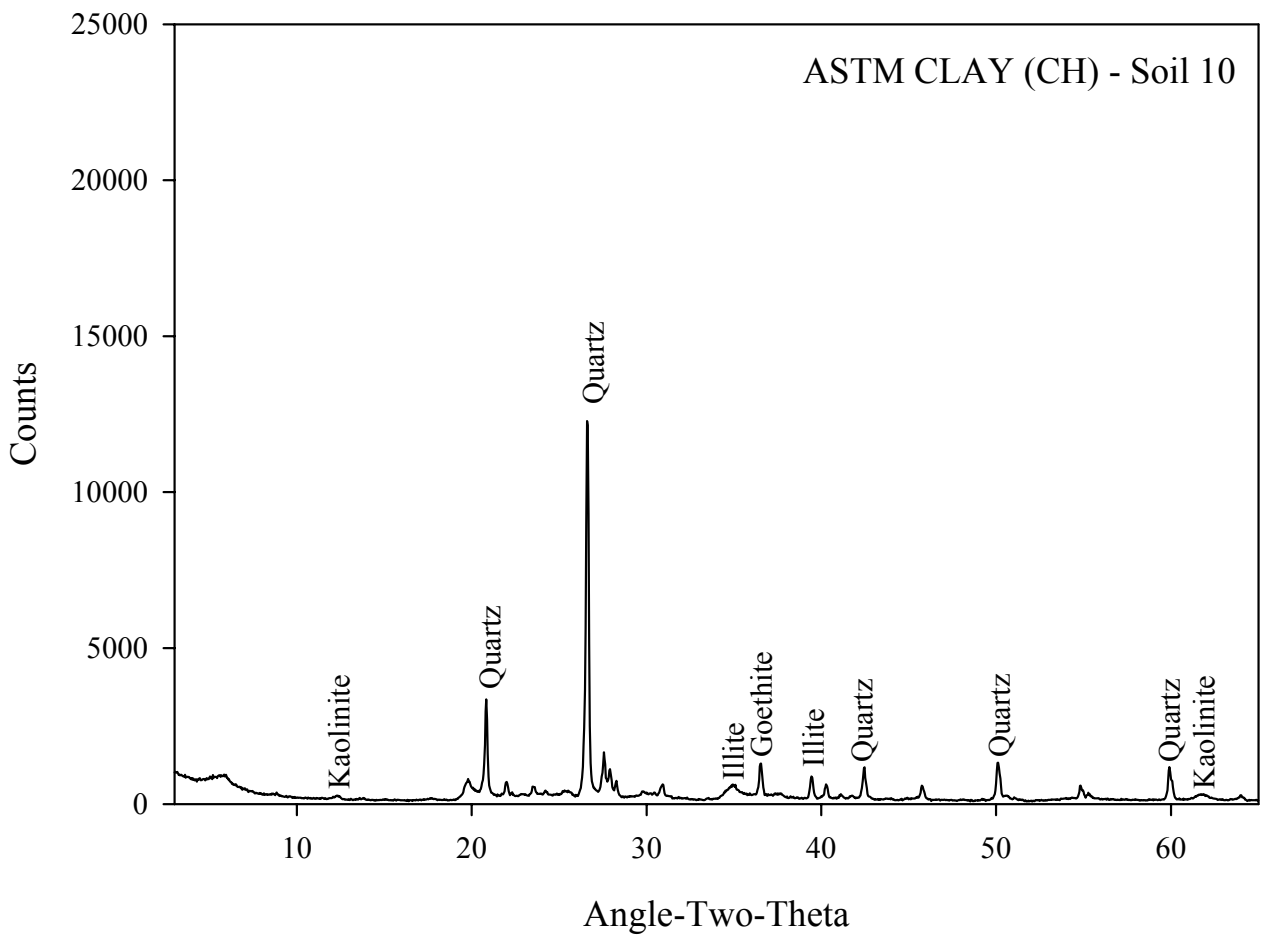

5.3.4 Thermal analysis results FIG. $5.5-X R D$ spectrum for soil 10 
Thermal gravimetry (TG) and direct scanning calorimetry (DSC) were used to analyze the thermal reactions of six of the soils used in this experimental program: soils 7 , $8,9,10$, Grundite and the first of the Kaolinite samples. Note that these were all soils for which significant discrepancy between the LOI and LECO analysis results was observed and thus these tests were intended to shed further insight into the reactions associated with exposure to high temperatures. Figures 5.6 and 5.7 present the TG and DSC results, respectively

As shown in Figure 5.6, the TG results show significant weight loss before the temperature reaches $120^{\circ} \mathrm{C}$. This is also reflected in the DSC curves which show two endothermic peaks before $120^{\circ} \mathrm{C}$. The first endothermic peak $\left(60-70^{\circ} \mathrm{C}\right)$ is associated with evaporation of the surface water while the peak (at $120-150^{\circ} \mathrm{C}$ ) represents the dehydration of the interlayer water which is not so tightly held. Both reactions result in weight loss as indicated by the TG results.

Given that prior to being placed in the furnace the LOI samples are all oven dried, it is the behavior displayed in the TG and DSC tests above $110^{\circ} \mathrm{C}$ that is of greater interest. In the case of soil 9, soil 10, Kaolinite-1 and Grundite, above this temperature, the thermal analysis results all show an endothermic peak around $480-500^{\circ} \mathrm{C}$. This is probably due to the de-hydroxylation of Kaolinite, the presence of which was detected through XRD in all four soils. Baran et al. (2001) showed that the dehydroxilation of Kaolinite occurred at $500-600^{\circ} \mathrm{C}$ (although the heating rate and duration can affect the temperature); and Velde (1992) indicated that the weight loss in correspondence to this temperature was about $14 \%$, consistent with the data shown in Table 4.4. In Figure 5.8, 


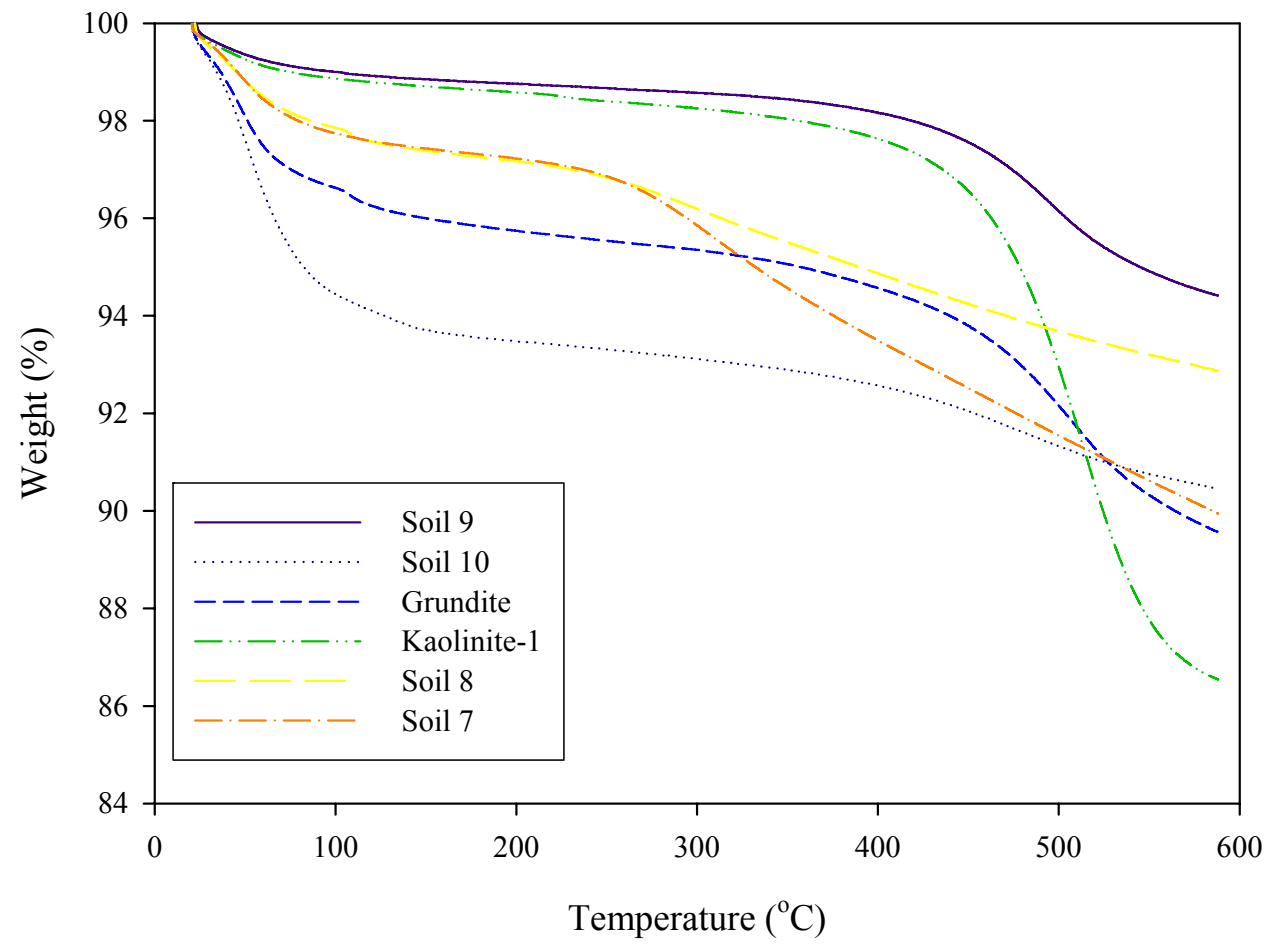

FIG. 5.6 - TG analysis results

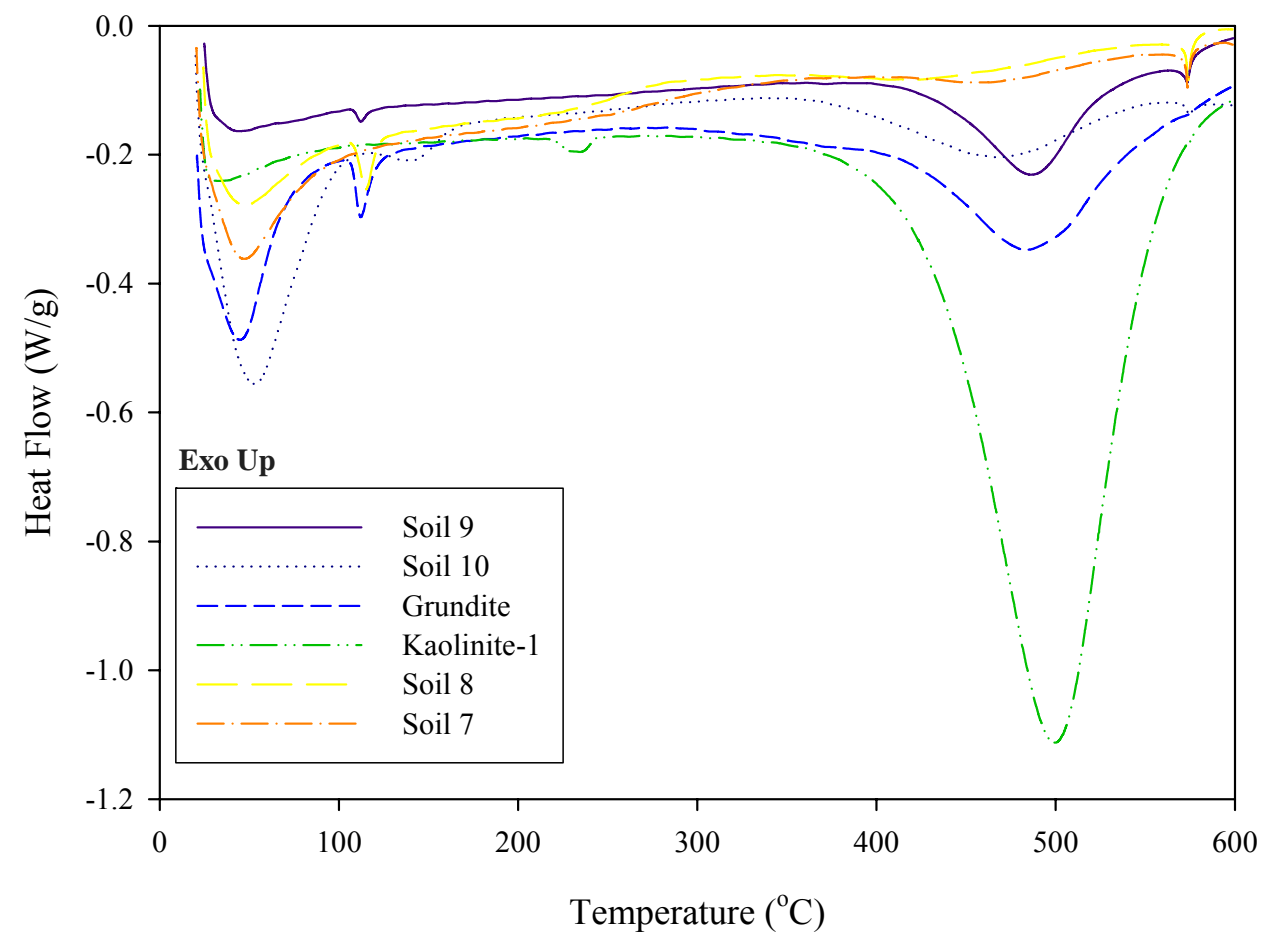

FIG. 5.7 - DSC analysis results 


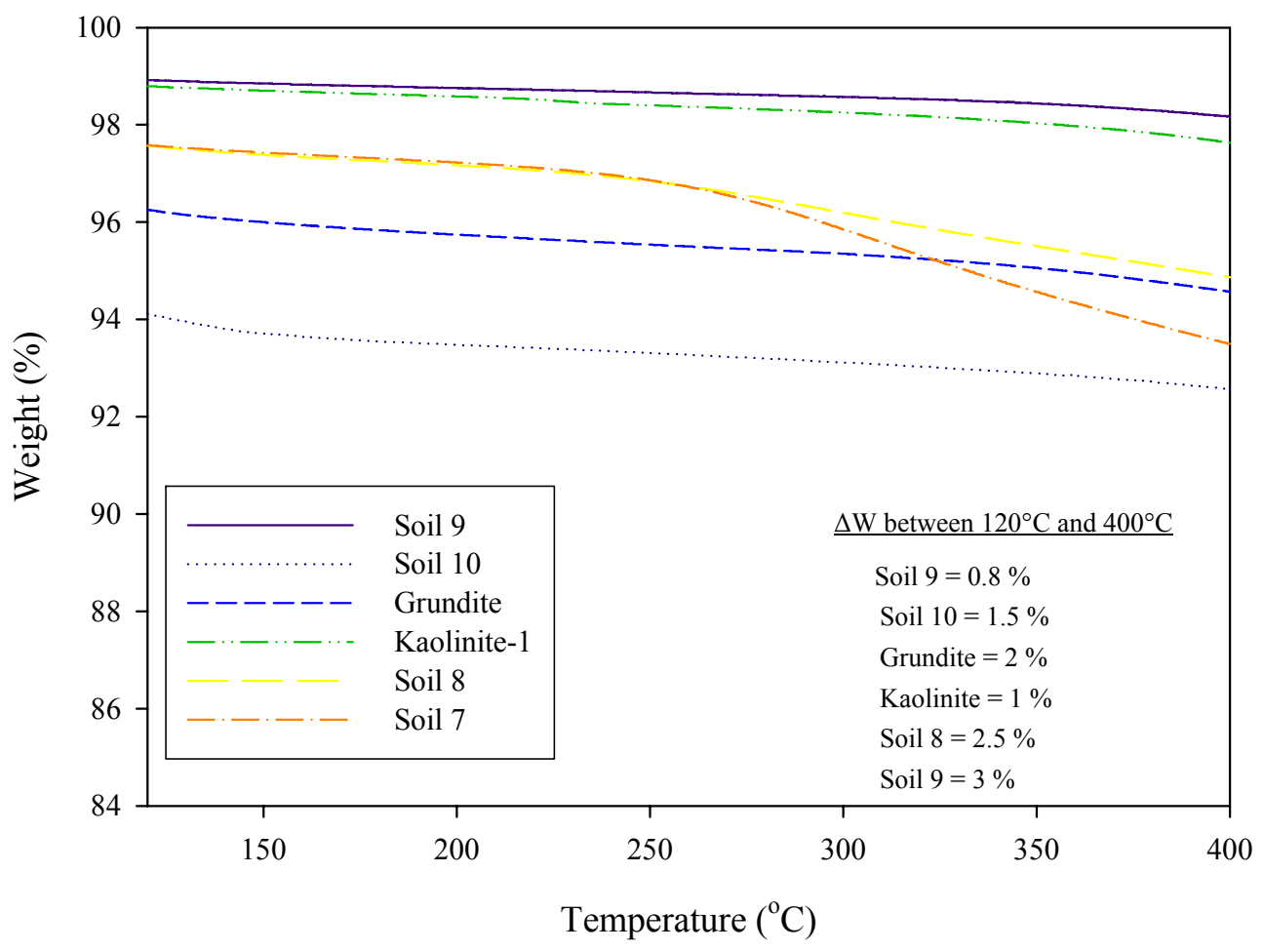

FIG. 5.8 - TG analysis results at Temperature from $120^{\circ} \mathrm{C}$ to $400^{\circ} \mathrm{C}$

only the TG data for temperatures between $120^{\circ} \mathrm{C}$ and $400{ }^{\circ} \mathrm{C}$ is shown (this range should encompass most of the weight loss due to oxidation of the organic matter). The figure also highlights the weight loss associated with heating from $120^{\circ} \mathrm{C}$ to $400{ }^{\circ} \mathrm{C}$ (see bottom right). For soil 9, soil 10, Kaolinite-1 and Grundite the values shown are fairly consistent with the estimates of the true organic content obtained from the LECO $^{\circledR}$ analysis, indicating that the additional weight loss observed in the LOI test is a result of the processes of de-hydroxylation of the clay minerals that under the heating conditions employed in the tests shown occur at slightly higher temperatures.

Soils 7, 8, 9 and 10 also show a small endothermic peak at around $575^{\circ} \mathrm{C}$, which is likely associated with the transition of Quartz. Similar data are shown by Leifeld et al. (2006). Both soil 7 and soil 8 soils showed no major endothermic reaction between $200-500^{\circ} \mathrm{C}$. The DSC curves for these two soils show, instead, evidence of slightly 
exothermic reactions (most likely associated with the oxidation of organic matter.)

\subsubsection{Atterberg limits results}

Atterberg limits tests were conducted on a number of the natural soils, the clay minerals and the artificial organic soils both before and after oven drying. The reduction of the liquid limit (i.e. Liquid limit ratio) was then calculated as $\frac{\text { LLovendried }}{\text { LL }}$. These data are summarized in Table 5.4 (natural soils and minerals) and Table 5.6 (artificial organic soils). This table includes the organic content of each mixture (calculated from the mix proportions and the organic matter content values of parent soil and source material obtained from the LECO analysis), the values of the Atterberg limits (LL and PL) both before and after oven-drying, the values of the Liquid limit and plastic limit raios, and finally the LOI values).

In Figure 5.9 the liquid limit ratios of all soils contained in Tables 5.4 and 5.6 are plotted versus the value of the organic content determined from the LECO analysis. The figure shows that there is a clear relationship between the LL ratio and the organic content suggesting that the LLratio can aid in predicting the organic content. Significant reduction in the LL is observed even for soils with fairly small organic matter content. For example for $5 \%$ organic content the LLratio is already equal to $90 \%$. The following quadratic equation is observed to fit the data quite well: OC $=0.9886-0.018($ LLratio $)+0.0002(\text { LLratio })^{2}$, yielding an $r^{2}$ value of 0.888 .

According to the USCS system, a soil is termed organic soil if the liquid limit ratio is less than 0.75. Using this criterion in Figure 5.9, it is found that the organic content corresponding to a liquid limit ratio of 0.75 of liquid limit ratio is $16.5 \%$. This means that 
soils classified as inorganic based on this criterion actually contain a significant amount of organic matter. Thus this classification criterion is clearly not adequate for evaluating soils for subgrades and backfills for which the organic content must in many cases fall below $3 \%$.

The data presented in Figure 5.9 also indicate that the LL ratio test can aid in interpreting the LOI data. For example, in the case of soil 7 which is characterized by a LOI of about $10 \%$, the LL ratio is 0.68 , indicating that the soil does indeed contain a significant amount of organic matter. This is indeed demonstrated by the results of the LECO analysis. In the case of a soil like the first sample of Kaolinite, despite a similar LOI, the LLratio shows a value fairly close to 1 , pointing to the fact that something other than the presence of organic matter is responsible for the high LOI. This again is confirmed by the results of the LECO analysis which provided an organic content of $0.33 \%$. The above suggests that the LLratio may be used in combination with LOI measurements for classifying organic soils. Further discussion on this point is provided in Chapter 6.

While the USCS classification system requires that only the LL be repeated after oven-drying, for the artificial organic soils the plastic limit was also determined after oven-drying the soil. The values of the PL ratio $\left(=\frac{\text { PLovendried }}{P L}\right)$ are presented in Table 5.6. Overall, the plastic limit ratio shows similar sensitivity as the liquid limit ratio to the presence of organic matter.

The pre-ovendrying values of the PI and the LL of the natural soils and clay minerals are plotted on the Casagrande plasticity chart in Figures 5.10. It is observed that only the soils with organic content less than $1 \%$ (soils 1,5 and 10 - see Table 5.4) 
plot above the A-line, while the rest plot below the A-line. Moreover, it appears that with increasing organic matter the soils tend to plot further below the A-line (e.g. see soils 7, 8 and especially 11, which have the greatest percentage of organic matter based on the data in Table 5.4). This trend is better observed analyzing the LL and PI data for the artificial organic soils (see Table 5.6), which are plotted on the plasticty chart in Figure 5.11. Each of the three data sets (AOS-1, AOS-2 and AOS-3) isolates the effect of organic matter content as degree of humification and mineral substrate remain unchanged.

TABLE 5.6 - Summary of test results of artificial organic soils

\begin{tabular}{|c|c|c|c|c|c|c|c|c|c|}
\hline & \multirow{2}{*}{ Soil } & \multirow{2}{*}{$\begin{array}{c}\begin{array}{c}\text { Organic } \\
\text { Content }^{(1)}\end{array} \\
\%\end{array}$} & \multicolumn{6}{|c|}{ Atterberg Limits } & \multirow{2}{*}{$\frac{\text { LOI }^{(2)}}{\%}$} \\
\hline & & & LL(\%) & $L^{L}(\%)$ & PL(\%) & $\mathrm{PL}_{\mathrm{d}}(\%)$ & LL Ratio & PL Ratio & \\
\hline \multirow{14}{*}{ 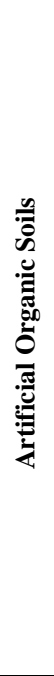 } & AOS- $1-0 \%$ & 1.73 & 55.8 & 55.1 & 26.7 & 25.9 & 0.99 & 0.97 & 3.13 \\
\hline & AOS-1-5\% & 4.47 & 60.8 & 55.5 & 37.1 & 31.9 & 0.91 & 0.86 & 6.27 \\
\hline & AOS-1-10\% & 9.18 & 67.5 & 58.8 & 43.8 & 36.2 & 0.87 & 0.83 & 9.99 \\
\hline & AOS-1-13\% & 12.55 & 71.8 & 59.6 & 45.2 & 36.7 & 0.83 & 0.81 & 12.69 \\
\hline & AOS-1-23\% & 24.16 & 88.1 & 66.9 & 65.6 & 49.0 & 0.76 & 0.75 & 22.23 \\
\hline & AOS-2-None & 1.01 & 34.0 & 33.9 & 25.3 & 26.6 & 1.00 & 1.00 & 4.30 \\
\hline & AOS-2-5\% & 4.95 & 37.4 & 33.2 & 24.3 & 22.6 & 0.89 & 0.93 & 6.29 \\
\hline & AOS-2-10\% & 9.08 & 46.5 & 37.8 & 32.9 & 25.8 & 0.81 & 0.78 & 10.54 \\
\hline & AOS-2-13\% & 12.21 & 53.8 & 41.9 & 38.6 & 29.3 & 0.78 & 0.76 & 11.47 \\
\hline & AOS-2-23\% & 22.69 & 83.0 & 55.7 & 60.7 & 42.6 & 0.67 & 0.70 & 22.11 \\
\hline & AOS-3-None & 2.27 & 42.0 & 41.3 & 28.9 & 32.5 & 0.98 & 1.00 & 5.07 \\
\hline & AOS-3-5\% & 4.84 & 47.4 & 44.2 & 28.7 & 25.9 & 0.93 & 0.90 & 7.68 \\
\hline & AOS-3-10\% & 10.91 & 60.8 & 50.3 & 41.4 & 32.6 & 0.83 & 0.79 & 13.65 \\
\hline & $100 \%$ organic source $e^{(3)}$ & 40.34 & 151.1 & 88.3 & 123.0 & 81.2 & 0.58 & 0.66 & 44.59 \\
\hline
\end{tabular}

$<$ Note $>$

(1) organic content based on mix proportions and LECO measurements on parent soil and organic source

(2) LOI result from test conducted on sample companion to that employed for LECO analysis

(3) from bin used to prepare AOS-3 soils

From the data contained in Tables 5.6 it is found that both the liquid and plastic limit consistently increase with organic content. This is not surprising given the water holding capacity of organic matter. The plasticity index does not however seem to vary 
as significantly with organic content. This is clearly shown in Figure 5.11 in which the position of the soil on the plasticity chart with increasing organic content can be followed. The trend of the points on the plasticity chart is one of divergences from the A-line (Booth and Dahl, 1985).

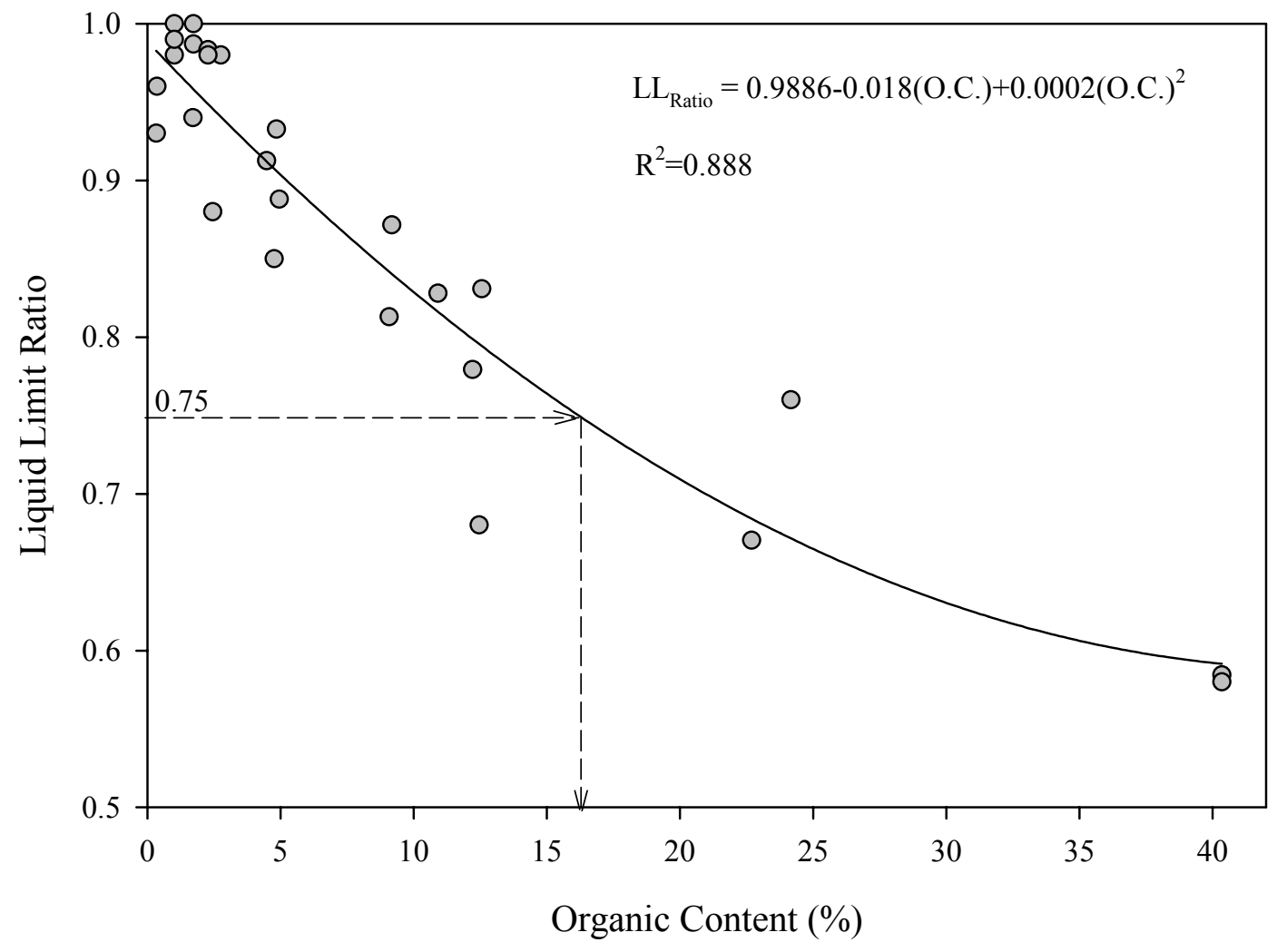

FIG. 5.9 - Relationship between organic content and liquid limit ratio 


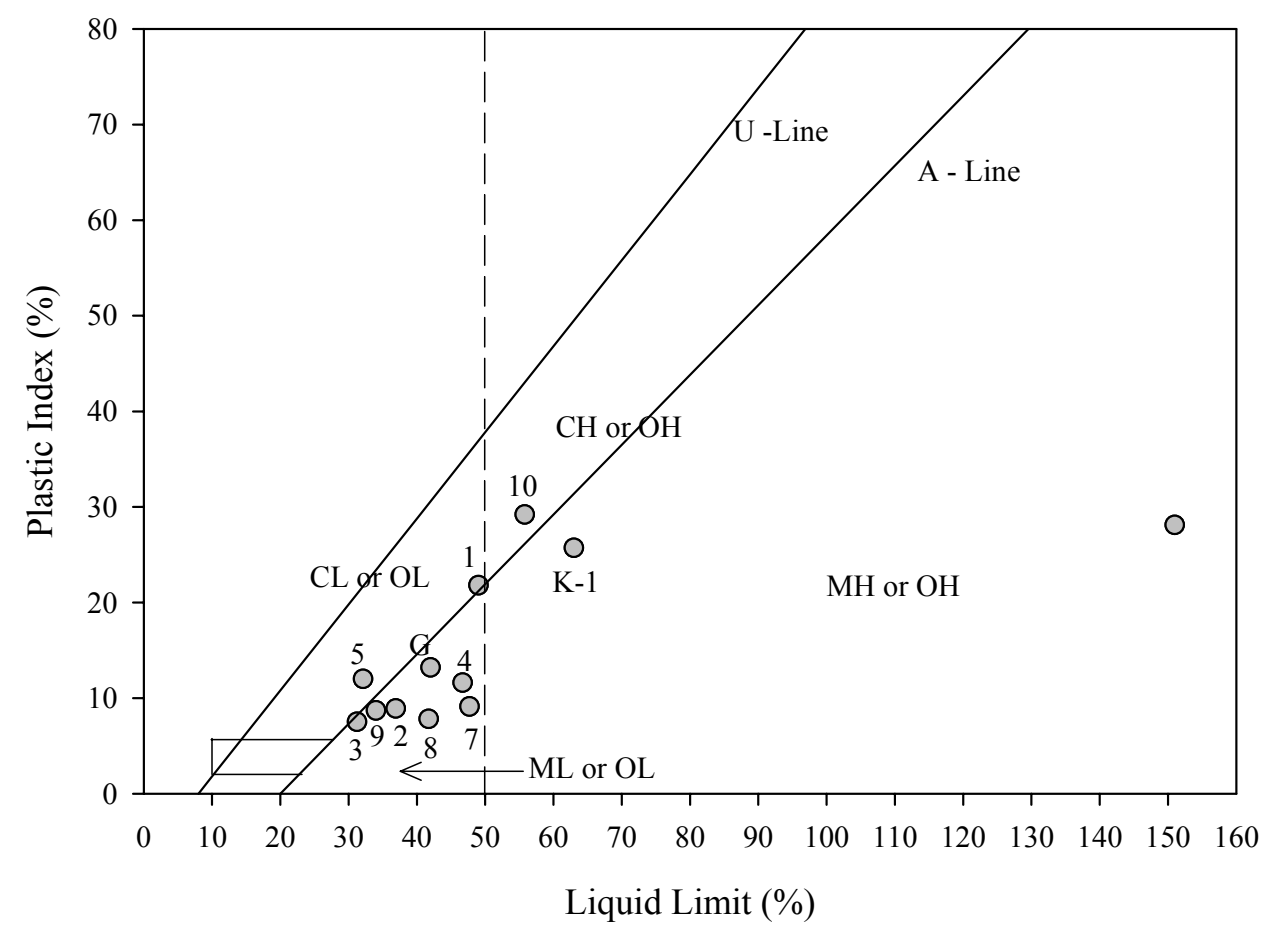

FIG. 5.10- Plasticity chart with data for natural soils

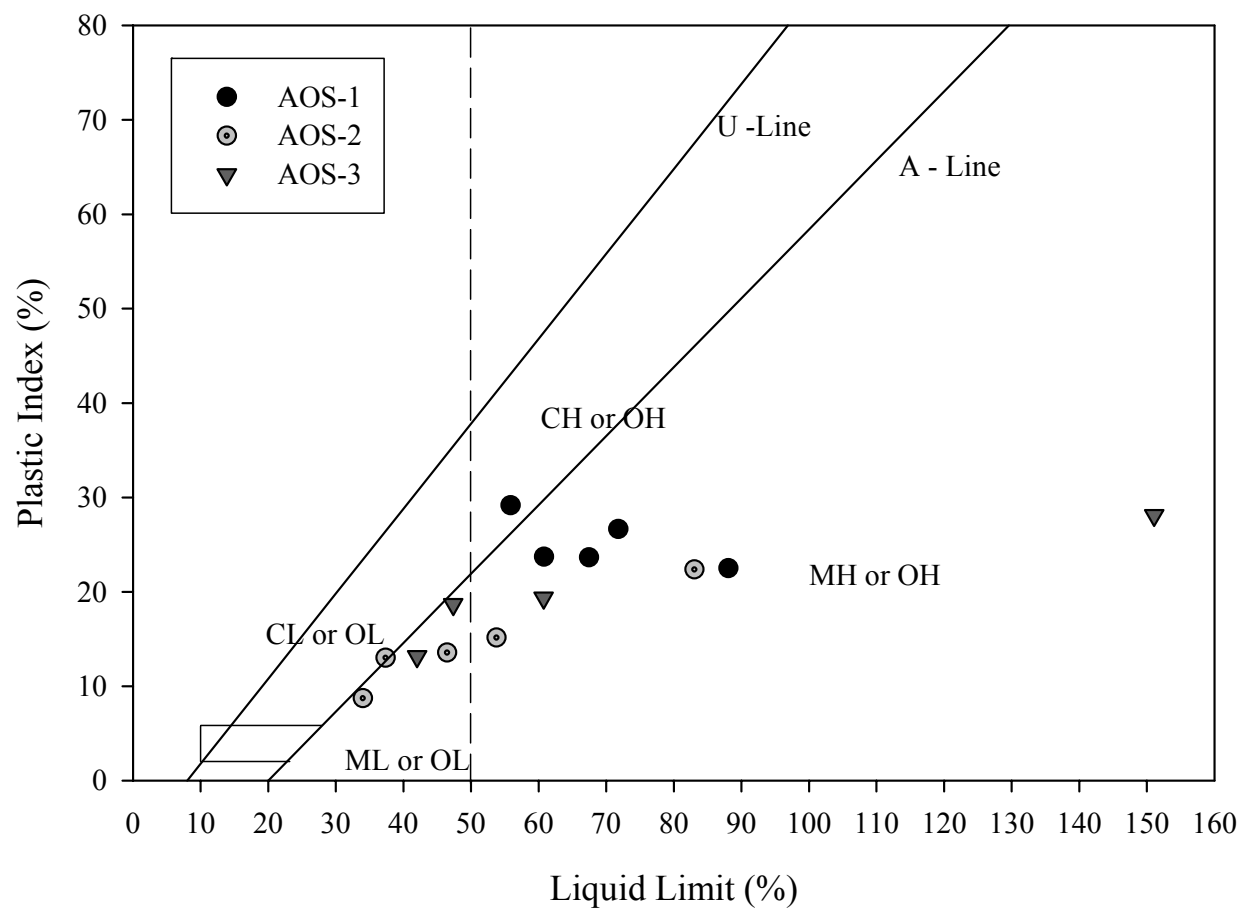

FIG. 5.11- Plasticity chart with data for artificial organic soils 


\subsubsection{Colorimetric test results}

Colorimetric tests were performed on select natural soils and artificial organic soils. For the natural soils the color of the supernatant for each tested soil is shown in Table 5.4. The color number is given from No.1 to No.5. As a reminder, the interpretation of this test assumes the following: if the color of the supernatant is No. 3 or lighter then the soil does not contain any organic matter; if instead the color is darker than No.3, then it is possible that organic matter is present (although false positives are possible). The data for the natural soils and the clay minerals indicate that the color of the supernatant was darker only when the organic content (as measured by the dry oxidation method) was higher than $3 \%$.

Additional tests performed on laboratory prepared artificial organic soils manufactured from the organic source material and either one of the ASTM clays (soil 10) or Ottawa sand showed, instead, a much greater sensitivity to the presence of organic matter. Pictures illustrating the colors of the supernatant solution for these soils are shown in Figure 5.12. In the case of the ASTM clay it is shown that the color of the supernatant fluid reaches No.3 for $1.3 \%$ organic matter. In the case of Ottawa sand, with only $0.3 \%$ organic matter, the color of the supernatant is already darker than No.3.

Overall these results indicate that there is not a direct relationship between the percentage of organic matter and the color of the supernatant solution. This is likely related to the nature of the organics present in the soil, as well as to the type of mineral substrate which may more or less facilitate the extraction by the $\mathrm{NaOH}$ solution. As noted above, for all artificial organic soils the extraction was very effective and the method showed great sensitivity to the presence of organic matter. This may due to the fact that the organic matter contained in the organic source material (soil 11) is especially rich in 
humic acid and fulvic acid which amongst humic substances are those soluble in an alkaline solution. Additionally, the manual mixing of the parent soil and organic source material is likely not to have yielded the same degree of interconnection of organic matter and mineral substrate that characterizes naturally formed soils, thus facilitating the extraction. The effect of the mineral substrate is clearly shown by the result of the text conducted on Ottawa sand with only $0.3 \%$ organic matter. In the case of clays organic substances typically attach to clay mineral surfaces through cation and anion exchange, H-bonding or van der Waals forces, or penetrate into the interlayer spaces of expanding-type clay minerals. These mechanisms clearly do not come into play in the case of sand and thus the extraction process is greatly facilitated.

Overall, while the colorimetric test does not provide a quantitative assessment of the organic content of a soil, it shows great sensitivity to the presence of organic matter in both fine and coarse soils. Thus its use might be considered on conjunction with the LOI test as a means to identify and classify organic soils. This point is further discussed in Chapter 6.

Based on the results of this experimental program, the colorimetric test is always effective in recognizing the presence of organic matter. The data presented in Table 5.4 indicate, however, that under some conditions the test can lead to a "false positive". This is what is observed for the two samples of Kaolinite examined in this study. As shown in Table 5.4, the LECO analysis conducted on these two soils indicates that they contain negligible amount of organic matter $(0.33 \%$ and $0.15 \%$, respectively). Yet, for Kaolinite-1 and Kaolinite-2, the color of the supernatant was observed to correspond to No.3 and No.4, of the glass color standard, respectively. Kaolinite $\left(\mathrm{Al}_{2} \mathrm{Si}_{2} \mathrm{O}_{5}(\mathrm{OH})_{4}\right)$ is a clay mineral with 1:1 elemental silica-gibbsite sheet. Due to isomorphic substitution, the 
$\mathrm{Al}^{3+}$ atoms are commonly replaced by $\mathrm{Fe}^{2+}$ and $\mathrm{Fe}^{3+}$. The latter, which is the most common impurity in the Kaolinite structure (Lombardi et al., 2002), is likely to be responsible for the dark color of the supernatant solution, as, through treatment by sodium hydroxide, the $\mathrm{Fe}^{3+}$ can be dissolved in the solution making it turn a brick red color.

A similar process is likely to have affected the results for soil 9. While the organic content of this soil was only 1.73 , the color of supernatant was No. 4. According to the XRD analysis, soil 9 contains Goethite $(\mathrm{FeO}(\mathrm{OH}))$ and Hematite $\left(\mathrm{Fe}_{2} \mathrm{O}_{3}\right)$ which can also leaed to the dissolution of $\mathrm{Fe}^{3+}$.

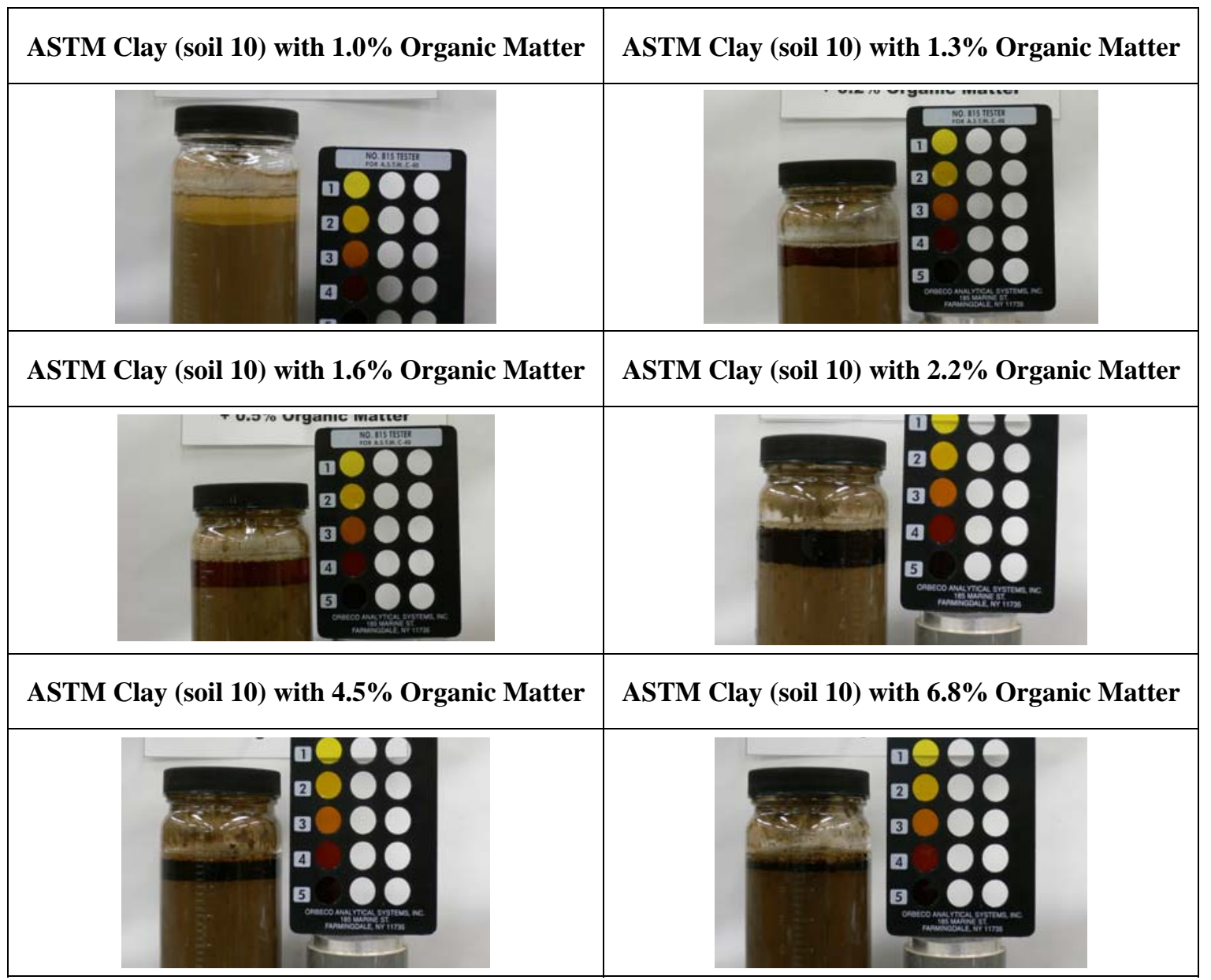




\begin{tabular}{|c|c|c|}
\hline \multicolumn{2}{|c|}{ Ottawa Sand } & Ottawa Sand with 0.3\% Organic Matter \\
\hline & & \\
\hline
\end{tabular}

FIG. 5.12 - Colorimetric results for tests conducted on artificial organic soils

\subsection{Summary}

The main findings of the experimental program can be summarized as follows:

1. The loss on ignition test can lead to overestimate the organic content of soils, as a result of the presence of select clay minerals (such as kaolinite) that de-hydroxilate at temperatures below or equal to the ignition temperature. The impact of these processes on the measured LOI can be very significant in the case of soils with low organic content $(\sim<5-7 \%)$. Thus the loss on ignition method is not an acceptable method to screen soils for the presence of small percentages $(\sim<10 \%)$ of organic matter.

2. Organic soils are characterized by a reduction of liquid limit ratio with increasing organic content. Tests conducted as part of this experimental program indicate that the relationship between LLratio and organic content is rather sensitive, suggesting that it may be possible to use the liquid limit ratio not only to simply identify the presence of organic matter, but possibly as a means to obtain a quantitative measure of the organic content.

3. The $25 \%$ reduction of liquid limit stated in the USCS system represents an organic content in the $15-20 \%$ range. Thus, this criterion may be used 
distinguish between inorganic soils (in which the amount of organic matter does not dominate the behavior of the soil) and organic soils. Other classification systems have similar thresholds including the Canadian system (which sets the distinction between inorganic and organic soils at a organic content of 30\%) and the US Soil Taxonomy and the Malaysian system (which require 20-30\% organic content, depending on the clay content).

4. The colorimetric test is a rapid test, requiring minimal equipment that is very sensitive to the presence of small percentages of organic matter in both coarse and fine grained soils. Its high sensitivity suggests that its use may be of interest for identifying the presence of small amounts of organic matter in soils. The test does appear to generate some false positives in presence of some impurities in the mineral substrate. 


\section{CHAPTER 6 \\ Proposed Classification}

\subsection{Introduction}

A good classification system which provides appropriate expectations of a soil's properties requires well-defined "categories" in which soils can be "grouped" and clear criteria based on straightforward tests for assessing in which "category" any given soil can be placed.

The review of the existing classification systems presented in Chapter 2 highlighted that there are many discrepancies between different classification systems and that there are no generally accepted tests and procedures for classifying organic soils.

In civil engineering practice, the most common criterion used to classify organic soils is the organic content. As mentioned in Chapter 3, organic content is not the only parameter which controls the geotechnical properties of soils. The structure, the degree of humification, and the percentage of fine particles are amongst the other factors that affect the characteristics and behavior of organic soils. As discussed in Chapter 4, a variety of methods can be used for the determination of the organic content of soils. The loss on ignition test remains the most commonly used method in engineering practice. However, the potential errors associated with this method particularly in the case of soils with low $(<\sim 10 \%)$ organic content have to be recognized. For these soils, the loss on ignition alone cannot be used and an approach combining the use of one or more additional tests needs to be considered to increase the precision in determining the organic content.

This chapter proposes an approach for the classification of organic soils that is based on the literature review and the experimental work performed for this research. Sections 6.2 and 6.3 discuss the proposed approach in some detail. Specifically, the first 
section (6.2) presents the classification system itself, while the screening procedures and experimental methods are discussed in Section 6.3.

\subsection{Classification System}

According to the current engineering classification systems and the criteria employed by INDOT, a modified classification system is proposed.

In this proposed classification system, soils with organic content less than or equal to $3 \%$ are termed mineral soils. If the organic content is greater than $3 \%$ and less than or equal to $15 \%$, soils are classified as mineral soils with organics. Once the organic content falls in the $15 \%-30 \%$ range, the term organic soil is employed. Finally, soils with organic content higher than $30 \%$ are termed highly organic soils or peats. Note that the 30\%-100\% organic content range encompasses a wide range of geomaterials. Thus this category should probably include two or more subgroups, maybe in the form of a distinction between highly organic soils and peats. The focus of this research has been on soils at the lower end of organic content values and thus this issue requires further study.

The rationale for the proposed classification system can be summarized as follows:

1. Soils with organic content less than $3 \%$ are usually considered as mineral soils in most existing classification systems, as the presence of $3 \%$ or less organic matter does not significantly change the soil's properties. Also, the Indiana specifications for roadway construction (section 207.03) require that “ soils containing greater than 3\% by dry weight calcium, magnesium carbonate or organic material [as determined based on the loss on ignition test in AAHSTO T 267].......will not be 
permitted within the specified thickness of the subgrade". Therefore, 3\% of organic content is a good boundary for mineral soil.

2. The results of the Atterberg limit tests conducted in this study show that when the liquid limit ratio is smaller than 0.75 , the organic content of the given soil is around $15-18 \%$. Thus, soil with organic content less than $15 \%$ would be classified as inorganic based on the USCS. This is the basis for using a $15 \%$ organic content as a means to distinguish between organic soils and mineral soils with organic matter.

3. $30 \%$ of organic content is adopted to be the boundary of organic soil and highly organic soil (Peat) in many currently existing classification systems such as the CSSC system, as well as in the criteria currently used by INDOT criteria.

The first column in Table 6.1 summarizes the proposed classification, which represents a simplification of the current system used by INDOT. For comparison purposes, Table 6.2 shows the classification system currently used by INDOT, while Table 6.3 summarizes some currently used engineering classification systems

In addition to the four categories listed above, the proposed classification utilizes symbols and names to denote soils. The symbols are intended to be consistent with those used in the AASHTO and/or USCS systems (at least for soils with organic content values up to 30\%) (columns 2 and 4 in Table 6.1). The AASHTO classification system does not include guidelines on names to be assigned to soils. So the names proposed here (column 4 in Table 6.1) are consistent with those used in the USCS system, which, in ASTM D2487 (1999), provides an exhaustive approach for assigning names to soils. Note that, in addition to conducting the tests (see Section 6.3) required for assigning a 
given soil to one of the four groups listed above, definition of a symbol and name would require performing the other tests used to classify soils (sieve analysis and Atterberg limits).

It is proposed that for a "mineral soil" the same symbols used in the AAHSTO or USCS system be used. For example, consider a mineral soil with $20 \%$ sand, $80 \%$ finer than the $\# 200$ sieve, $L L=45$, PI $=20$. According to AASHTO this soil would be classified as an A-7-6 (or a CL according to the USCS). These same symbols with no modification would be used to refer to the soil in the proposed classification, i.e. the presence of the organic matter would be neglected. Similarly the same name used in the USCS would be used ("lean clay with sand” for the example above).

It is suggested that starting with over $3 \%$ organic matter, the symbol and name of the soil should instead recognize the presence of the organic matter. In the case of a soil classified as a "mineral soil with organic matter", it is proposed that the letter "O" follow the AAHSTO (or USCS) symbol. For example, a soil like the one above but having an organic content greater than $3 \%$ would be denoted as A-7-6-O (or CL -O). The same name used in the USCS system would be used with the following addition: "with organic matter" at the end (e.g. "lean clay with sand with organic matter”).

In the case of a soil belonging to the third group listed above ("organic soils"), the letter "O" would go on to precede the AAHSTO (or USCS symbol) reflecting the more dominant role played by organic matter for values of the organic content exceeding $15 \%$. Again referring to the example above, the symbol used would be O-A-7-6 (or O-CL). Note that in the USCS system the presence of approximately $15 \%$ or more organic matter (based on liquid limit ratio) is recognized by replacing the $\mathrm{MH}$ and $\mathrm{CH}$ symbols with $\mathrm{OH}$ and the ML and CL symbols with OL. Unfortunately in this manner information on 
whether the soil in its natural state plots above or below the A-line is lost as both a ML and a CL become OL if the liquid limit ratio is smaller than 0.75. For this reason, for soils in which the inorganic fraction is still very significant (70-85\%), the suggestion to use the letter $\mathrm{O}$ in addition to the original symbol, as here proposed, is preferred. With regard to the name, consistently with what is done in the USCS system for soils with liquid limit ratio below 0.75 , the term "organic" would appear at the beginning of the name (e.g. “organic lean clay with sand”).

The focus of this research effort was on soils with organic content less than $30 \%$ (as indicated by the soils tested in the experimental program). As mentioned above the $15-30 \%$ organic content range encompasses many different geomaterials that should probably not be grouped all together. It is also acknowledged that some of the experimental methods proposed here for classifying soils (e.g. liquid limit) present difficulties in the case of soils with very high organic content, and are not possible in presence of fibers. For these soils engineering judgment comes into play in the selection of the classification system most appropriate for the soil under consideration.

There will be highly organic soils (such as the organic source material - soil 11used in this research) for which it will still be possible to conduct Atterberg limits. For these soils, if using the AASHTO system, visual examination would determine whether the symbol A-8 would be used or if additional tests would be performed to determine the exact grouping. If using the USCS system, given that the liquid limit ratio would undoubtedly be less than 0.75 , the symbol used in this classification system would be used (e.g. OL). The naming system used in the USCS might be adapted to replace the term “organic” with "highly organic” (e.g. "highly organic lean clay with sand”).

There will, however, be soils for which visual examination will indicate that the 
classification based on Atterberg limits is not possible. This would be the case, for example, $\mathrm{i}$ of a fibrous peat with very high LOI (e.g. 80\%). In this case the best approach would be to refer to the soil as an A-8 or a peat and resort to a classification such as the one by Radforth (see Tables 2.5 and 2.6 in Chapter 2) that further classifies the peat according to its cover and structure. In this case it is suggested that the naming system adopted in the Radforth classification be followed (e.g. amorphous granular peat or non-woody-fine fibrous peat). In this study, the Radforth classification system is preferred to others as it $r$ requires less knowledge of horticulture, forestry, and agriculture.

TABLE 6.1- Proposed classification system

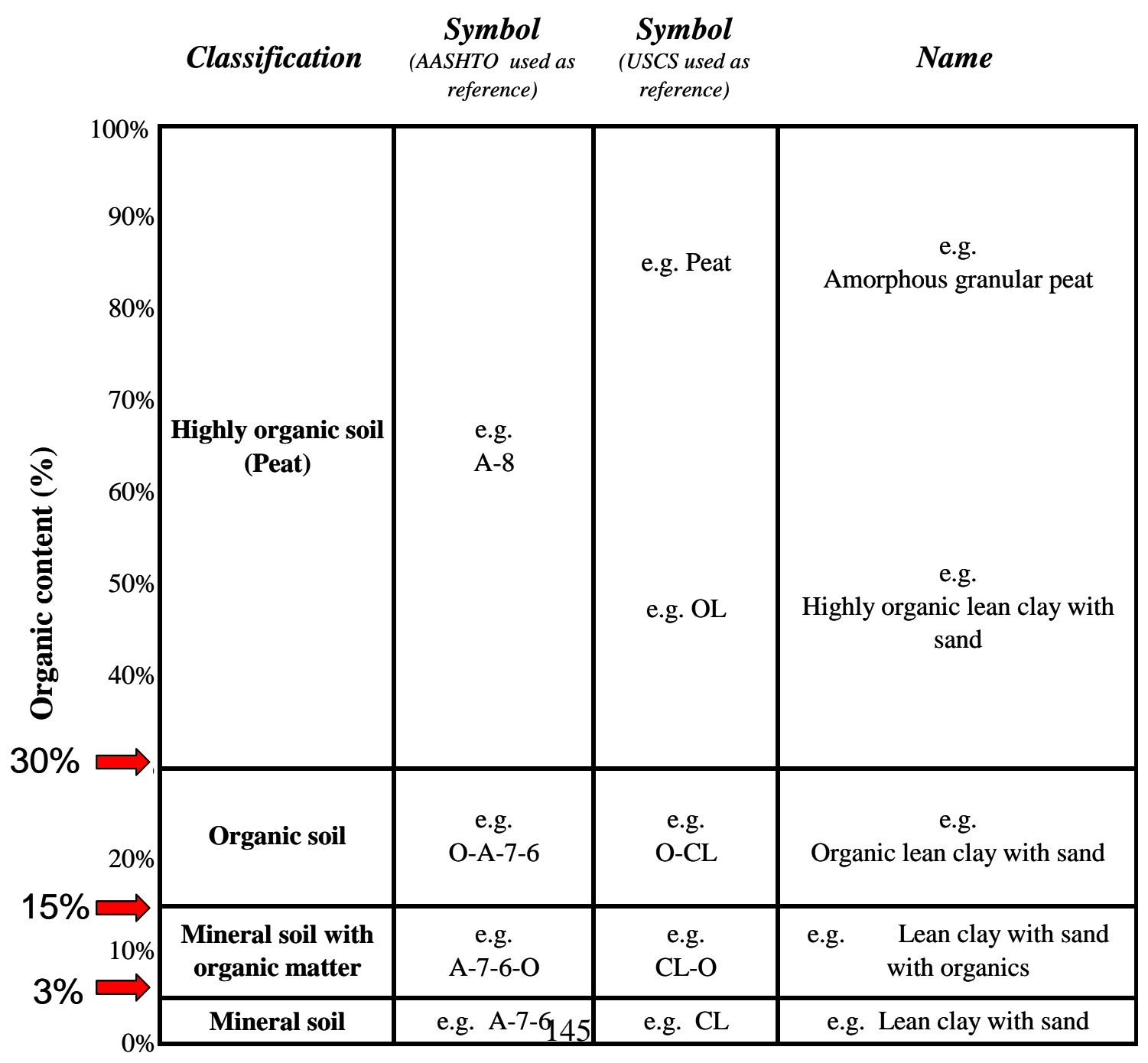


TABLE 6.2- Criteria of organic soil classification by INDOT (section 903.05)

\begin{tabular}{lc}
\hline Classification & LOI Percentage \\
\hline With Trace Organic Matter & 1 to 6 \\
With Little Organic Matter & 7 to 12 \\
With Some Organic Matter & 13 to 18 \\
Organic Soil (A-8) & $19-30$ \\
Peat (A-8) & More than 30 \\
\hline
\end{tabular}

TABLE 6.3- Summary of some engineering classification systems

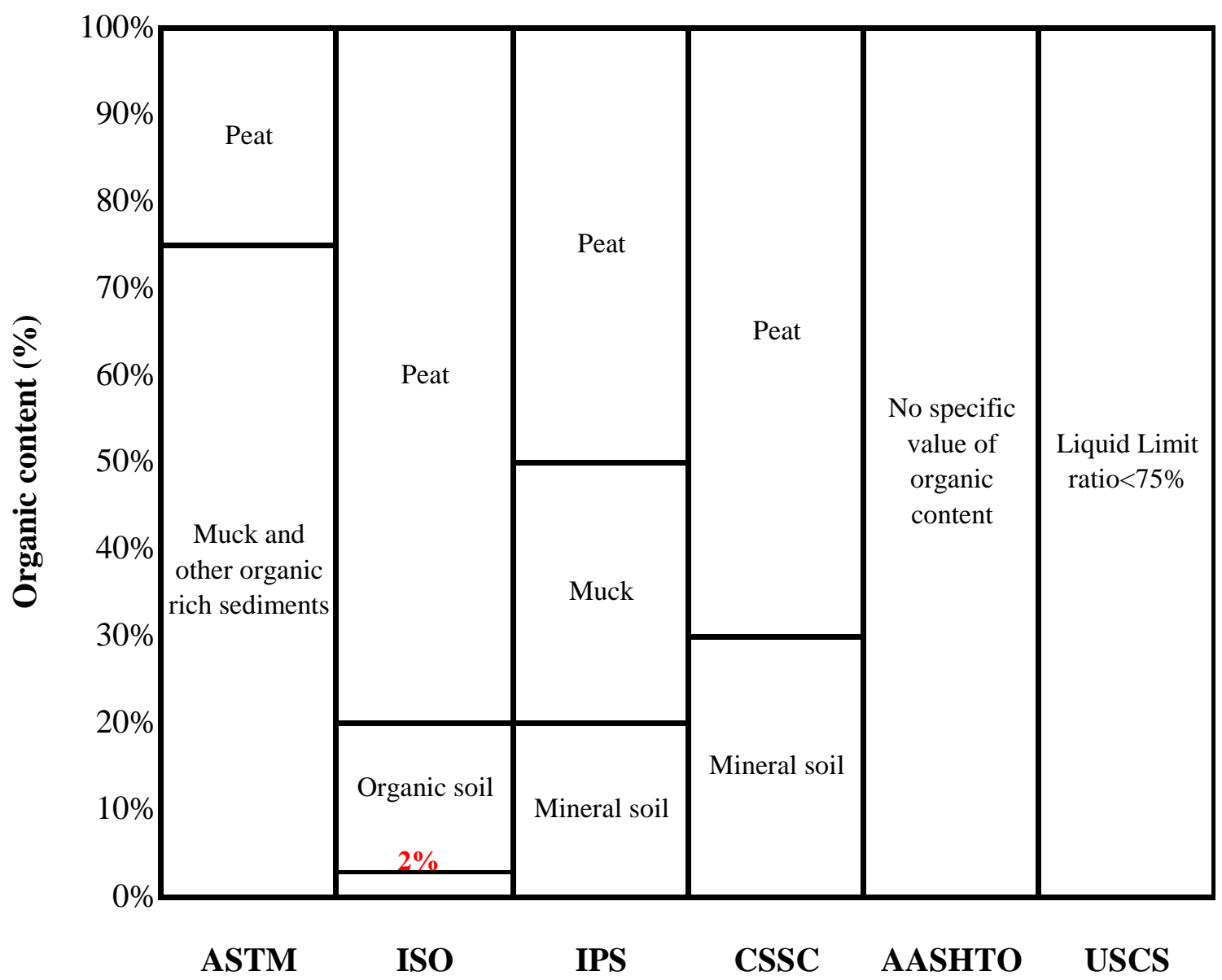

ASTM: American Standard for Testing Materials.

ISO: International Organization of Standardization

IPS: International Peat Society

CSSC: Canada Soil Survey Committee

AASHTO: American Association of State Highway and Transportation Officials

USCS: Unified Soil Classification System 146 


\subsection{Screening Approach}

As indicated in Table 6.1, the proposed classification of soils as mineral soils, minerals soils with organic matter, organic soils and highly organic soils is based on the true organic content of the soil. It has also been emphasized in this report that for low values of the organic content $(\sim<10 \%)$ the LOI test which is the most routine means for measuring organic content can often lead to erroneous measurements that greatly overestimate it. This suggests that this method is not satisfactory for distinguishing between mineral soils and mineral soils with organic matter, and an alternative approach is required.

Figure 6.1 presents the recommended test procedure for classifying soils based on organic content in form of flow chart. The LOI test is used first to provide a first assessment of the organic content. Organic matter is usually adsorbed to fine particles. Thus, in order to risk underestimating the LOI due to the presence of large particles it is recommended that the soil used for the LOI be sieved through the No.10 sieve (2 mm). Figure 6.1 shows that based on the outcome of the LOI test it is possible to classify the soils in one of the four categories with the only uncertainty remaining in the case in which the LOI falls in the $3-15 \%$ range. In this case, in fact, the LOI may or may not overestimate the soil's true organic content and thus an alternative screening approach based on the use of the colorimetric test and/or the liquid limit test is proposed. 


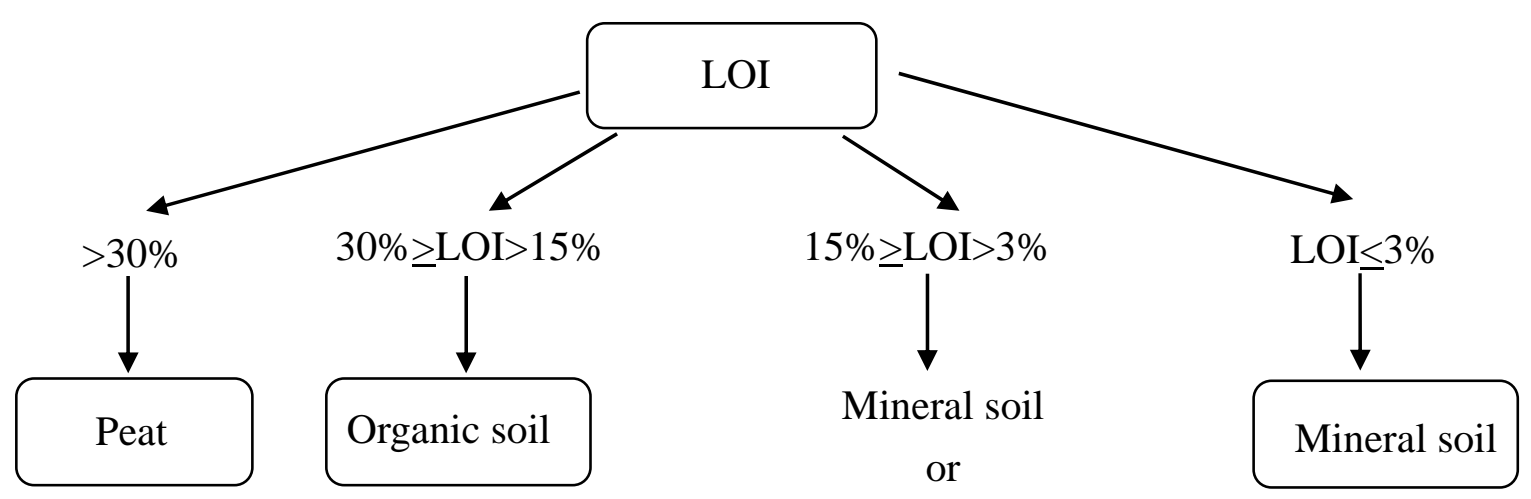

Mineral soil with organic matter

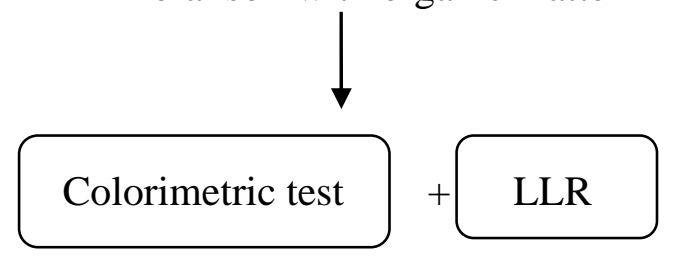

FIG 6.1- Flow chart for the classification of organic soils

The screening approach is summarized in Figure 6.2.

In this approach, for coarse-grained soil with fine fraction (i.e. passing \#200 sieve) less than $12 \%$ (e.g. an A-3 soil), the colorimetric test is performed. If the color is lighter or equal to the organic plate No.3, the soil is classified as a mineral soil, i.e. it is concluded that the LOI test overestimates the true organic content of the soil. Reliance on the results of the colorimetric test is based on the sensitivity of this test to the presence of organic matter, as discussed in Chapter 5.

For coarse-grained soil with fine fraction more than $12 \%$ (also A-2), the colorimetric test is also conducted first. If the color is lighter or equal than the organic plate No.3, the same conclusion as above is drawn, i.e. the soil is classified as a mineral soil. If not, the Liquid Limit ratio is measured. Based on Figure 5.10, if the Liquid Limit ratio is $\geq 0.93$, it is concluded that the organic content is less than $3 \%$ (i.e. it was overestimated by the LOI test) and the soil is classified as mineral soil. Otherwise 
(LLratio <0.93), the soil is classified as a mineral soil with organic matter.

For fine-grained soil (e.g. A-4, A-5, A-6, A-7), the same procedures used for coarse-grained soil with fine fraction more than $12 \%$ are applied.

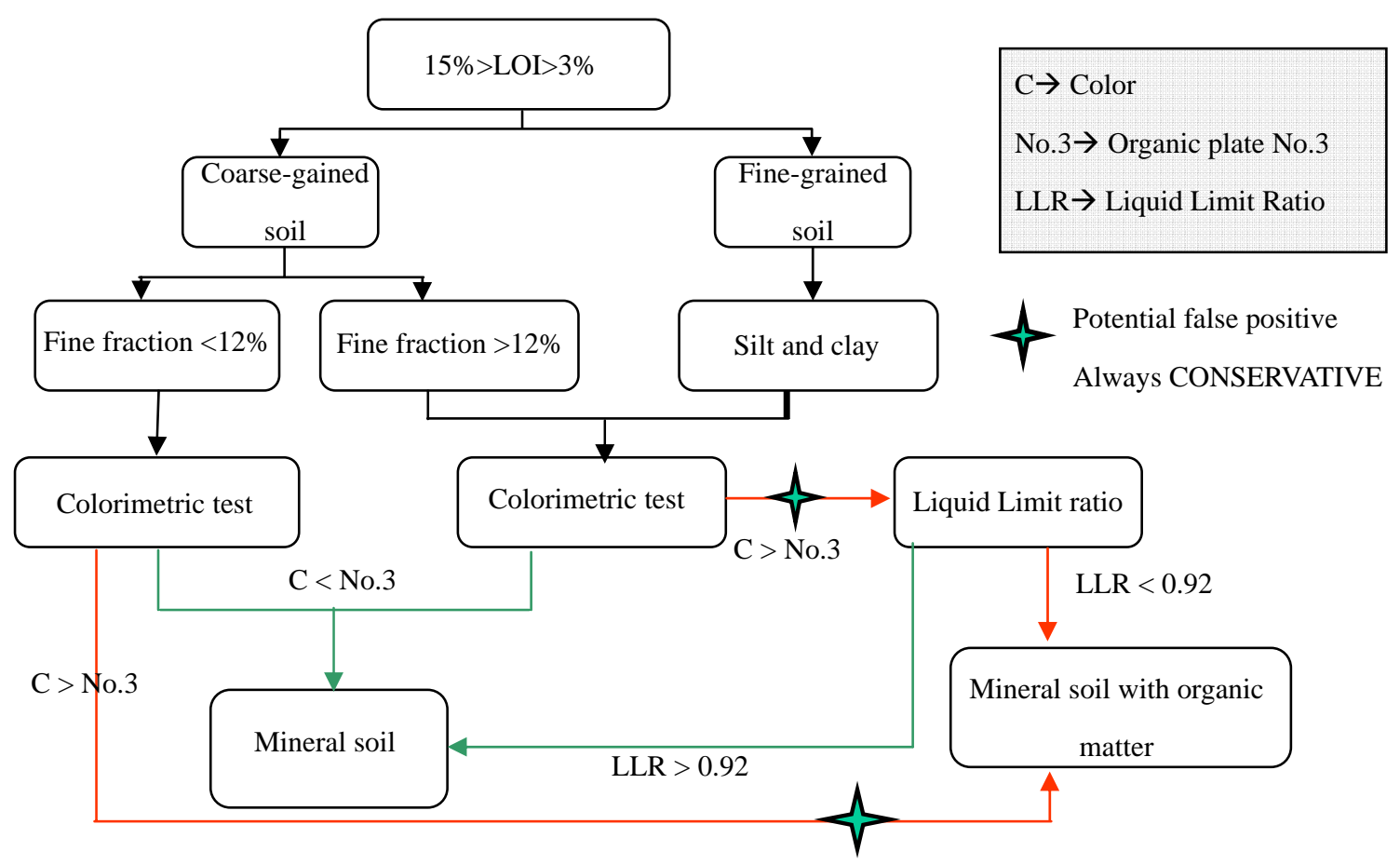

FIG 6.2- Screening approach for the classification of soils with organic content on the border between mineral soil and mineral soils with organic matter

The purpose of employing Liquid Limit Ratio to "re-screen" soils after the colorimetric test shows a color darker than No. 3 is that it has been found (see Chapter 5) that this test can produce false positive results (see "star" symbol in Figure 6.1) in the presence of common impurity such as iron oxide. The liquid limit ratio provides a means to correct for these false positive results. Figure 6.1 suggests that in principle it is possible that such false positives occur also in coarse grained soils (despite the fact that no such 
occurrences were observed in this research). In this case, measurement of the liquid limit ratio would not be an option and thus it is possible that such a soil would be classified more conservatively as a mineral soil with organic matter instead of as a mineral soil. For these soils, there remains the option to perform a measurement of the true organic content through a technique such as the LECO analysis (see Chapter 5).

Examples of the use of the proposed classification to 11 different soils are presented in Appendix A.

In addition to the above described approach for classifying soils in the 4 categories outlined in Section 6.2, a method was also developed to establish whether a particular soil can be considered acceptable or not based on existing criteria which limit the organic content of a soil used in a specific application (typically to a value less than 2-7\%, depending on the State and the application). This method, which is based on the same tests used for soil classification, is summarized in Figure 6.3. It is intended to be applied to soils which are not obviously organic.

As shown in Figure 6.3 the colorimetric test is once again used to perform a first screening. Given its sensitivity to the presence of organic matter, the test allows immediate acceptance of all soils for which the color of the supernatant fluid is lighter or equal to the organic plate No.3. As discussed earlier in this report, the colorimetric test may yield false positives, i.e. the fact that the supernatant liquid is darker than the organic plate No.3 does not necessarily mean that the soil contains organic matter. Figure 6.3 suggests that in this case it be established whether the fines content of the soil exceeds $5 \%$. If this is not the case (i.e. fines $<5 \%$ ), it is suggested that the soil can be accepted without further evaluation. This recommendation is based on the assumption that the 
organic matter will be primarily present in the fines, and that, unless the fines are obviously organic (evidence of this would be their color), only a limited fraction of the $5 \%$ (maximum) of the fines would actually be formed by organic matter. This would put the total organic content below typical organic content threshold values used in practice.

If the $\%$ of fines, instead, exceeds 5\%, the method summarized in Figure 6.3 proposes that an assessment of the organic content of these fines be made using either the LOI test or the curve of liquid limit ratio versus true organic content (Figure 5.9). An estimate of the organic content of the soil in its entirety would be then obtained by multiplying this value times the \% of fines. Depending on whether this value exceeded or remained below the threshold used for a given application the soil would then be rejected or accepted.

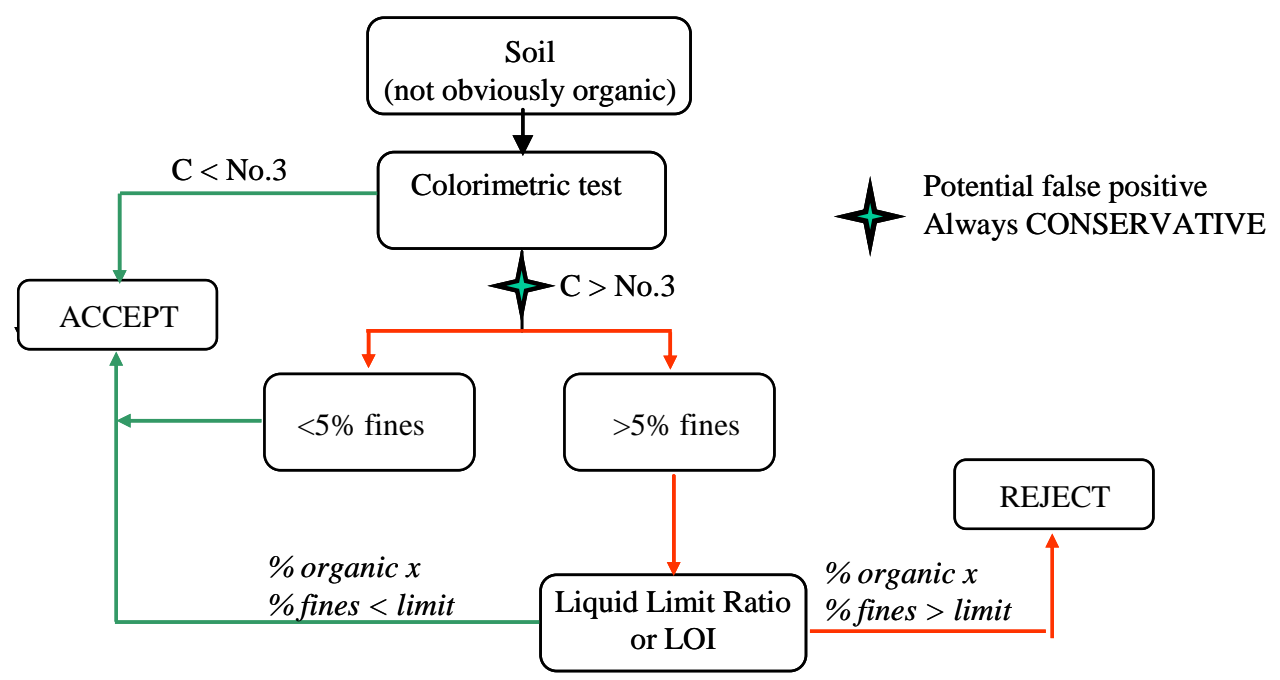

FIG 6.3- Approach for establishing whether a soil may be accepted in an application for which there is a maximum threshold organic content 


\subsection{Summary}

The proposed classification system and approach for screening soils provide more information about the organic soil and increase the precision of classification. The proposed approach does not require equipment that would not be typically available in a geotechnical soil classification laboratory. Additionally, it is time-effective: the colorimetric test usually provides an answer within the first 3 hours, while Atterberg limit tests can be conducted in 2-3 days including the time for mellowing and oven-drying. For civil engineering practice, this approach is economic and can be widely used. 


\section{CHAPTER 7}

\section{Conclusions and Recommendations}

\subsection{Conclusions}

This section is a summary of the most important conclusions reached with this research. It is divided into five sub-sections. The first three summarize the most significant observations derived from the literature review work and address: the classification of organics, the effects of organic matter on the geotechnical properties of soils, and the methods of determining organic matter. The last summarize the key conclusions of the experimental work and the proposed classification, respectively.

\subsubsection{Classification of organics}

Soil organic matter is a complex mixture of organic compounds. It includes plant, animal, and microbial residues, fresh and at all stages of decomposition, and relatively resistant soil humus. Living organic matter and non-living organic matter are two major categories of soil organic matter. Non-living organic matter is usually divided into humic and non-humic substances. Soil organic matter is usually used as a synonym of humic substances. Strictly, soil organic matter includes only those organic materials that accompany soil particles which are smaller than $2 \mathrm{~mm}$.

There is no general accepted classification for organic soils. Instead there exist numerous classification systems developed in different fields including agronomy, botany and engineering which for the most part apply to soils containing significant amounts of organic matter.

Agricultural classification systems are based on the genus of the soil, from which basic properties of the soil can be inferred. Botanical classification systems focus 
primarily on peat type soils which are formed primarily by organic matter. The primary division of these soils is based on the structural form (granular versus fibrous) and on their description based on floristic terms.

There is a number of engineering classification systems used around the world. The most widely used are the USCS system (documented in ASTM D2487) and the AASHTO system. Both utilize particle size analysis and/or Atterberg limits for distinguishing for classifying coarse and fine grained soils. In the AASHTO system a specific group (A-8) is used to identify highly organic soils based exclusively on visual inspection. In the USCS system soils are termed organic if the liquid limit decreases by more than $25 \%$ after oven drying, while the identification of peats relies on visual inspection. A separate standard (ASTM D4427) addresses the classification of peats (intended for peat producers) defined as materials with loss on ignition (LOI) greater than 75\%. Neither the ASTM nor the AASHTO systems address classification of soils containing small amounts of organic matter.

Other engineering classification systems do, instead, provide a means to classify such soils, primarily based on the percentage of organic matter. This is the case, for example, of the ISO system which distinguishes between low organic (2-6\%), medium organic (6-20\%) and high organic ( $>20 \%)$ soils. Similarly, the classification system currently used by INDOT identifies five classes or organic soils from soils with traces of organic matter (organic content $=1-7 \%$ ) all the way to peats $(>30 \%)$.

\subsubsection{Effects of organic matter on geotechnical properties of soils}

The geotechnical properties of organic soils depend on the following factors: (1) organic content; (2) type of organic matter; and (3) degree of decomposition of the 
organic matter. In particular these factors determine the structure of the soil with the void ratio and the water content increasing with increasing organic content and decreasing degree of decomposition.

In general, high Atterberg limits, high cation exchange capacity, and acidity are associated with high organic content, whereas specific gravity, bulk density, plasticity index, and efficiency of compaction decrease with increasing organic content. Associated with the high void ratios typical of organic soils are high values of the permeability, the compressibility and the creep coefficient, with secondary compression playing a critical role when constructing on these soils. The strength of soils is also reduced with the presence of organic matter; however, a fibrous structure, if present, may lead to significantly increase the strength (as reflected by very high friction angles cited for some fibrous peats) and some tensile strength is expected.

Less data are available on the effects of small percentages of organic matter on the properties of soils. Atterberg limits and specific gravity measurements indicate, however, that organic matter percentages as small as $5 \%$ significantly impact the structure and nature of mineral soils.

\subsubsection{Methods for determination of organic content}

Methods for the determination of organic matter can be divided into two categories: direct methods and indirect methods. Direct methods include the loss on ignition method and the hydrogen peroxide $\left(\mathrm{H}_{2} \mathrm{O}_{2}\right)$ digestion method. Indirect methods include dry/wet combustion and dichromate oxidation. The loss on ignition method is the most common method in civil engineering practice; however, there are potential errors associated with its use as the loss of structural water present in some clay minerals (e.g. 
gypsum), the de-hydroxylation of some aluminosilicates and the decomposition of inorganic carbonates can also contribute to the weight loss measured after heating to $440^{\circ} \mathrm{C}$, leading to overestimate the organic content. The error becomes especially significant when the organic content of soil is low $(\sim<15 \%)$. For these soils a more accurate quantification of the organic matter content must be based on chemical analysis, which, however, requires more sophisticated equipment and procedures, which are not commonly used in geotechnical engineering.

In addition to the direct and indirect methods listed above, there are additional methods that can testify to the presence of organic matter without quantifying its amount. One of such methods is the colorimetric test which is used to detect the presence of organic impurities in fine aggregates used to manufacture concrete. The test is based on mixing the soil with a $\mathrm{NaOH}$ solution and observing the color of the supernatant solution after 24 hours. In correspondence to a specific color of the supernatant (darker than glass color standard organic plate No. 3), the soil is considered to contain organic matter. The test is very easy, economic, requires limited time (the change in color usually occurs within 2 hours), and is sensitive to small amounts of organic matter. Another approach, already utilized in geotechnical engineering, for establishing whether a soil can be termed organic is based on the comparison of the liquid limit before and after oven-drying the soil at $110^{\circ} \mathrm{C}$. For example, this USCS system terms a soil organic if the Liquid limit

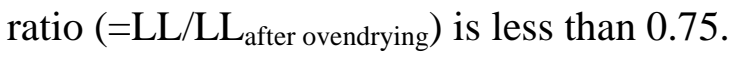

\subsubsection{Experimental work}

The experimental work conducted for this research employed three types of soils: natural soils primarily from the state of Indiana; clay minerals; and soils prepared in the 
laboratory with known amounts of organic matter by mixing three different mineral parent soils and one organic source material. The testing program included: LOI tests, colorimetric tests, Atterberg limits, and dry combustion test for the identification of the presence of organics and/or the determination of the organic content. Additionally thermal analysis and XRD analysis were employed to study the thermal behavior and the mineralogy of a few of the soils tested. The following are the main findings derived from this work:

(1) For soils with organic matter less than $15 \%$ the LOI test can lead to significantly overestimate the organic content.

(2) The overestimation of the organic content by the LOI method is associated with the loss of structural water, the de-hydroxylation of select clay minerals, and the decomposition of inorganic carbonates. For example, it was shown in this research that, as a result of de-hydroxylation, in the case of an inorganic clay such as Kaolinite, the LOI can exceed $10 \%$.

(3) Experiments conducted on soils with organic content varying between 0 and $40 \%$ indicate a continuous decrease of the liquid limit ratio with increasing organic content. Especially for low values of the organic content, the liquid limit ratio is very sensitive to the presence of organic matter, suggesting that this parameter may be used as an indirect means of quantifying organic matter. Based on the tests performed, a liquid limit ratio of 0.75 (the value used in the USCS to identify a soil as organic) corresponds to an organic content of about $15-18 \%$. The LLratio corresponding to a $3 \%$ organic content (the maximum value allowed by INDOT in subgrade soils and backfill) is 0.93 .

(4) The colorimetric test is very sensitive to the presence of organic matter, especially 
in the case of coarse-grained soils. This suggests that the test can be employed as a means to verify the results of the LOI test.

(5) While in the experimental program the colorimetric test never failed to detect the presence of 3\% (and in many cases much lower) organic matter, false positives were observed to occur in a few fine grained soils containing iron oxides.

\subsubsection{Proposed classification}

Based on the research conducted for this project, an approach for the classification of soils in terms of the organic content is proposed. This classification is based on observations form the experimental work as well as on a review of the pertinent literature and a critical evaluation of currently existing classification systems. The proposed system classifies soils into four groups based on organic content: mineral soils (O.C. $\leq 3 \%)$; mineral soils with organic matter $(3 \%<$ O.C. $\leq 15 \%)$; organic soils $(15 \%<$ O.C. $\leq 30 \%)$; and highly organic soils (peat) (O.C. > 30\%).

Recommendations are also provided for the methods to be used for assessing the organic content. While in principle a method such as dry combustion would provide the most accurate estimates of the organic content of a soil, it is assumed that the use of such a technique may not be viable in geotechnical engineering practice. Thus it is suggested that the LOI test be employed to perform a first screening of any soil. No further testing is required if the $\mathrm{LOI}$ is either $\leq 3 \%$ or greater than $15 \%$, i.e. in these cases the $\mathrm{LOI}$ is considered to provide a sufficiently accurate estimate of the true organic content of the soil, which can thus be classified in one of the categories listed above with no further testing. For LOI values in the $3-15 \%$ range, this test is instead not considered reliable. An approach based on the colorimetric test and the liquid limit ratio is proposed to further 
screen such soils and ascertain whether they should be classified as "mineral soils" or as “mineral soils with organic matter”.

Recommendations are also provided for the use of symbols and names to be used in referencing soils containing organic matter. The symbol and naming schemes are intended to be consistent with either the AASHTO or the USCS system.

\subsection{Recommendations}

This research has focused on reviewing the literature on several topics relevant to the engineering classification of organic soils, in particular the characteristics of soil organic matter, currently existing classification systems, and methods for the determination of organic content. Additionally experimental work involving a battery of tests on both natural soils, clay minerals and laboratory manufactured organic soils has been conducted. This work has led to the proposal of a new and improved system for the classification of soils containing organic matter, as well as of the experimental methods required for classifying the soils.

The scope of the work has been ultimately limited by time and resource availability, and there are undoubtedly issues that would require further consideration. The recommendations for future studies can be summarized as follows:

(1) In this research the relationship developed between liquid limit ratio and organic content was based on data for 11 natural soils and 3 types of artificial organic soils. In order to gain greater confidence in this relationship, based on which the critical LLratio of 0.93 used in the classification system was determined, it is recommended that additional tests for a broader spectrum of natural soils with a variety of organic contents be developed. For these same soils chemical analysis 
should be employed as a means of verifying the relationship between LLratio and true organic content.

(2) This research utilizes a value of the LLratio equal to 0.93 as a means to detect the presence of organic matter, leading to classify a soil as "mineral soil with organic matter”. It is, however, recognized that the lack of repeatability in the outcome of the test may also lead to a value of the LLratio of 0.93 or smaller. Thus future studies should focus on developing a statistics based approach which, for example, requires that multiple determinations of the LLratio be performed and that a certain percentage fall below 0.93 .

(3) The colorimetric test is a very useful and economical method to identify organic matter; however, the occurrence of potential false positive results limits its application. In this study it was found that iron oxides are responsible for false positives. Future research should further investigate this issue and identify other possible sources of false positive result.

(4) Always with regards to the colorimetric test, there is an opportunity to further investigate and understand the processes occurring as a result of the exposure to the extracting solution, by testing a broader variety of soils containing different types of organic matter and performing chemical analyses on the supernatant solution.

(5) As discussed in Chapter 1, the research presented in this report was motivated by difficulties in classifying soils containing small amounts of organic matter, and in screening soils to verify whether the organic content fell below the $3 \%$ threshold required by INDOT. As a result, the work performed focused primarily on soils at the low end of the organic content (0-15\%). Additional work is recommended 
to improve the classification of soils with organic content exceeding $30 \%$.

(6) In addition to classifying soils based on organic matter content, the existing INDOT specifications also classify soils based on the content of marl. Given the different nature of marl compared to organic soils, the results of this work cannot be extrapolated to marls. Further research would be required to evaluate the classification system and the testing methods used for marly soils. 


\section{LIST OF REFERENCES}

AASHTO Standard M-145, Standard Specification for Classification of Soils and Soil-Aggregate Mixtures for Highway Construction Purposes.

AASHTO Standard T267, 2004, Standard Method of Test for Determination of Organic Content in Soils by Loss on Ignition.

Abdallah, I. Husein Malkawi, S. Alawneh Ahmed, and T. Abu-Safaqah Osama, 1999, "Effects of Organic Matter on the Physical and the Physicochemical Properties of an Illitic Soil,” Applied Clay Science, Vol. 14, pp.257-278.

Abu-Zreig, M.M., Al-Akhras, N.M., and Attom, M.F., 2001, "Influence of Heat Treatment on the Behavior of Clayey Soils," Applied Clay Science, Vol. 20, pp.129-135.

Allison, L.E.,1965, "Organic Carbon", in C.A. Blace et al. (Ed.) Method of Soil Analysis Part 2, Agron. Monogr. 9, ASA, Madison, WI.

Amaryan, L.S., 1993, Soft Soils Properties and Testing Methods, Rotterdam:Balkema, $180 \mathrm{p}$.

ASTM Standard C-40, 2004, Standard Test Methods for Organic Impurities in Fine Aggregates for Concrete, Vol. 04.02.

ASTM Standard D 2487, 2000, Standard Practice for Classification of Soils for Engineering Purposes (Unified Soil Classification System), Vol. 04.08.

ASTM Standard D 2974, 2000, Standard Test Methods for Moisture, Ash, and Organic Matter of Peat and Other Organic Soils, Vol. 04.08.

ASTM Standard D 4318, 2005, Standard Test Methods for Liquid Limit, Plastic Limit, and Plasticity Index of Soils, Vol. 04.08.

ASTM Standard E 794, 2006, Standard Test Methods for Melting and Crystallization Temperature by Thermal Analysis, Vol. 14.02 . 
ASTM Standard E 1131, 2003, Standard Test Methods for Compositional Analysis by Thermogravimetry, Vol. 14.02.

Avery, B.W. (1980) Soil Classification for England and Wales (Higher Categories). Soil Survey Technical Monograph No. 14. Harpenden.

Ball, D.F., 1964, "Loss on Ignition as an Estimate of Organic Matter and Organic Carbon in Noncalcareous Soils," Journal of Soil Science, 15, pp. 84-92.

Baran, B., Ertiirk, T., Sarikaya, Y., and Alemdaroglu, T., 2001, "Workability Test Method for Metals Applied to Examine a Workability Measure (Plastis Limit) for clays," Applied Clay Science, Vol. 20, pp.53-63.

Basama, A.A., Ai-Homoud, A.S., and Al-Tabari, E.Y., 1994, "Effects of Methods of Drying on the Engineering Behavior of Clays," Applied Clay Science, Vol. 9, pp.151-164.

Ben-Dor, E., and A. Bain, 1989,'”Determination of Organic Matter Content in Arid-Zone Soils Using a Simple Loss on Ignition Method," Communication Soil Science Plant Analysis, 20, pp. 1675-1695.

Berry, P.L., and T.J. Poskitt, 1972, “Consolidation of Peat,” Geotechnique, Vol.22, No.1, pp. 27-52.

Bish, D.L., and Duffy, Cl., 1990," Thermogravimetric Analysis of Minerals," In J.W. Stucki, D.L. Bish, and F.A. Mumpton, Eds., Thermal Analysis in Clay Science, p. 96-157, Clay Minerals Society Workshop Lectures, Boulder, Colorado.

Booth, J.S., and Dahl, A.G., 1985, “A Note on the Relationship between Organic Matter and Some Geotechnical Properties of a Marine Sediment," Marine Geotechnology, Vol.6 (3), pp. 281-297.

Chau, P.P. 1999, "Definition of muck." M.S.Thesis, Mississippi State University, Department of Civil Engineering, Mississippi State, MS.

Christensen, B. T., and Malmros, P. A., 1982, "Loss-on-Ignition and Carbon Content in a 
Beech Forest Soil-Profile," Holarctic Ecology, 5(4), 376-380.

Cline, M.G., 1949, "Basic principles of soil classification,” Soil Science, 2, pp. 81-91.

David, M.B., 1988,'Use of Loss-on-Ignition to Assess Soil Organic Carbon in Forest Soils," Communication Soil Science Plant Analysis, 19, pp. 1593-1599.

Davies, B.E., 1974,'Loss on Ignition as an Estimate of Soil Organic Matter," Soil Science Society American Proc., 38, pp. 150-151.

Donkin, M.J., 1991, "Loss-on-Ignition as an Estimation of Soil Organic Carbon in A-Horizon Forestry Soils," Communication Soil Science Plant Analysis, 22, pp. 233-241.

Eswaran H. 2002, Soil Classification: A Global Desk Reference, CRC Press.

Feustel, I. C. and Byers, H. G., 1930, "The Physical and Chemical Characteristics of Certain American Peat Profile,” U.S. Dept. Navy, Bureau of Chem. and Soils Tech. Bull 214, Washington, D.C.

Geiman, C.M., and Filz, G.M., 2005, "Stabilization of Soft Clay Subgrades in Virginia: Phase II Laboratory Study," Virginia Department of Transportation, Report No. VTRC05-CR16.

Goldin, A., 1987, "Reassessing the Use of Loss-on-Ignition for Estimating Organic Matter Content in Noncalcareous Soils," Communication Soil Science Plant Analysis, 18, pp. 1111-1116.

Goryachkin, S.V., Tonkonogov, V.D., Gerasiova, M.I., Lebedeva, I.I., Shishov, L.L., Targulian, V.O. 2003, "Chapter 15: Changing Concepts of Soil and Soil Classification in Russia," In Eswaran, H. (Ed.) Soil Classification: A Global Desk Reference, CRC Press.

Greve M.H. and H.B. Madsen, 1999, Soil Mapping in Denmark, European Soil BureauReport No.6. 
Hayes, M.H.B., and R.S. Swift, 1978, "The Chemistry of Soil Organic Colloid,” In D.J. Greenland and M.H.B. Hayes (Ed.), the Chemistry of Soil Constitutes, Wiley-Intersci, New York.

Hewitt, A.E. 2003, “Chapter 13 - New Zealand Soil Classification - Purposes and Principles," In Eswaran, H. (Ed.) Soil Classification: A Global Desk Reference, CRC Press.

Howard, P. J. A., 1966, "The Carbon-Organic Matter Factor in Various Soil Types," Oikos, 15, pp. 229-236.

Howard, P. J. A., and Howard, D. M., 1990, "Use of Organic-Carbon and Loss-on-Ignition to Estimate Soil Organic-Matter in Different Soil Types and Horizons," Biology and Fertility of Soils, 9(4), 306-310.

Hwang, J.H., Aaron Humphrey, Antonio Bobet, Maria Caterina Santagata, 2005. "Stabilization and Improvement of Organic Soils", FHWA/IN/JTRP-2004/38, Report of Joint Transportation Research Program, Indiana Department of Transportation and Purdue University, $270 \mathrm{p}$.

Hwang, J.H., 2006, "1-D Consolidation Behavior of a Cement Treated Highly Organic Soil," PhD Thesis, School of Civil Engineering, Purdue University, West Lafayette, IN, $434 \mathrm{p}$.

Isbell, R., 2002, “The Australian Soil Classification”, CSIRO Publishing, Available on line at http://www.clw.csiro.au/aclep/asc_re_on_line/soilkey.htm

ISO 14688 Part 1 Geotechnical Investigation and Testing - Identification and Classification of Soil - Identification and description. 2002.

ISO 14688 Part 2 Geotechnical Investigation and Testing - Identification and Classification of Soil - Principles for a classification. 2004.

Jarrett, P.M. (Ed.), 1982, Testing of Peats and Organic Soils: A Symposium Sponsored by ASTM Committee D-18 on Soil and Rock, Toronto, Canada, 23 June 1982. 
Kang, Y.I., 2006, “Stress-Strain-Strength Properties of In-Situ Deep Mixed Clays.” PhD Thesis in Progress, Purdue University, West Lafayette, IN.

Kogel-Knabner, I., 1997, "13C and 15N NMR Spectroscopy as A Tool in Soil Organic Matter Studies," Geoderma, 80(3-4), 243-270.

Landva, A.O. and P.E. Pheeney, 1980, "Peat Fabric and Structure," Canadian Geotechnical Journal, pp. 416-435.

Landva, A.O., Korpijaakko, E.O., Pheeney, P.E., 1983, "Geotechnical Classification of Peats and Organic Soils," Testing of Peats and Organic soils, ASTM STP 820, P.M. Jarret, Ed., American Society for Testing and Materials, 1983, pp 37-51.

Lea, N.D. and C.O. Brawner, 1959, "Foundation and Pavement Design for Highway on Peat," Proc. Fortieth Convention, Can. Good Roads Association, Ottawa, pp. 406-424.

Leifeld, J., Franko, U., and Schulz, E., 2006, “Thermal Stability of Soil Organic Matter Responds to Long-Term Fertilization Practices," Biogeosciences Discussion, 3, pp. 309-320.

Lied, D.R., 1993, Handbook of Chemistry and Physics, CRC Press, Ann Arbor, MI.

Loeppert, R.H. and Suarez, D.L., 1996, "Carbonate and Gypsum," Methods of Soil Analysis Part 3: Chemical Methods, Soil Science Society of America, pp. 437-456.

Lombardi, K.C., Guimaraes, J.L., Mangrich, A.S., Mattoso, N., Abbate, M., Schreiner, W.H., and Wypych, F., 2002, "Structural and Morphological Characterization of the PP-0559 Kaolinite from the Brazilian Amazon Region”, Journal of Brazilian Chemical Society, Vol. 13(2), pp. 270-275.

Lowther, J.R., P.J. Smethurst, J.C. Carlyle, and E.K.S. Nambiar, 1990, "Method for Determining Organic Carbon in Podzolic Sands," Communication Soil Science Plant Analysis, 21, pp. 457-470. 
MacFarlane, I.C. (Ed.), 1969, Muskeg Engineering Handbook, University of Toronto Press.

Mebius, L.J., 1960, "A Rapid Method for the Determination of Organic Carbon in Soil," Anal. Chim. Acta, 22, pp120-121.

Mesri, G, and Godlewski, P.M., 1977, “Time and Stress-compressibility Interrelationship," Journal of Geotechnical Engineering, ASCE Vol. 103, No.5, pp.417-430.

Meris, G., T.D. Stark, and Chen C.S., 1994, "Discussion of $\mathrm{C} \alpha / \mathrm{Cc}$ Concept Applied to Compression of Peat", Journal of Geotechnical Engineering, ASCE Vol. 120, No.4, pp.764-767.

Mesri, G, T.D. Stark, M.A. Ailouni, and C.S. Chen, 1997, "Secondary Compression of Peat with or without Surcharge," Journal of Geotechnical and Geoenvironmental Engineering, Vol. 123, No. 5, pp.411-421.

Moran, Proctor, Mueser, and Rutledge, 1958, Study of Deep Soil Stablization by Vertical Sand Drains, US Dept. Navy, Bureau of Yards and Docks, Rept. No. y88812, Washington, DC, $231 \mathrm{p}$.

Myslinska E., 2003, "Classification of Organic Soil for Engineering Geology," Geological Quarterly, 2003, vol. 47(1), pp 39-42.

Nelson, D.W. and Sommers, L.E., 1996, “Total Carbon, Organic Carbon, and Organic Matter," Methods of Soil Analysis Part 3. Chemical Methods Soil Science Society of America, pp. 961-1010.

Oades, J.M. 1989. "An Introduction to Organic Matter in Mineral Soils," In Minerals in Soil Environments, J.B.Dixon and S.B.Weed, Eds., Soil Science Society of America, Madison, pp.89-160.

Radforth, N.W. 1969. “Classification of Muskeg.” In Muskeg Engineering Handbook. Ed. Ivan C. MacFarlane. Toronto, University of Toronto Press, 31-39. 
Radforth N.M., and Brawner C. O., 1996, Muskeg and the Northern Environment in Canada, University of Toronto Press, Toronto, Ontario, Canada.

Ranney, R.W., 1969, “An Organic Caron-Organic Matter Conversation Equation for Pennsylvania Surface Soils," Soil Science Society American Proc., 33, pp. 809-811.

Rather, J.B., 1917, “An Accurate Loss on Ignition Method for Determination of Organic Matter in Soils," Arkansan Agric. Expt. Stn. Bull. No.140.

Schnitzer, M., and S.U. Khan, 1972, Humic Substances in the Environment, Marcel Dekker Inc, New York.

Schulte, E.E., C. Kaufman, and J.B. Peter, 1991, "The Influence of Sample Size and Heating Time on Soil Weight Loss on Ignition," Communication Soil Science Plant Analysis, 22, pp. 159-168.

Schulten, H.R., Schnitzer, M. 1995. "Three-Dimensional Models for Humic Acids and Soil Organic Matter," Naturwissenschaften 82(11), pp. 487-498.

Soil Classification Working Group. 1998. The Canadian System of Soil Classification. Agric. and Agri-Food Can. Publ. 1646 (Revised) 187 pp. NRC Research Press, Ottawa. Available on line at: http://www.pedosphere.com/resources/CSSC3rd/

Soils of Russia: Correlated with the Revised Legend of the FAO Soil Map of the world and World Reference Base for Soil Resources, June 2000, International Institute for Applied Systems Analysis obtained from www.iiasa.ac.at

Soil Science Society of American, 1979, Glossary of Soil Science Terms, Rev. Ed., SSSA, Madison, WI.

United States Department of Agriculture, 1999. Soil Taxonomy Text, Natural Resources Conservation Service, http://soils.usda.gov/technical/classification/taxonomy

Spain, A.V., M.E. Probert, R.F. Isbell, and R.D. John, 1982, "Loss-on-Ignition and the Carbon Content of Australian Soils," Australia Journal Soil Research, 20, pp. 147-152. 
Sparks, D.L., 2003, Environmental Soil Chemistry $2^{\text {nd }}$ Ed., Academic Press, Amsterdam, The Netherlands.

Stevenson, F.J. (1994). Humus Chemistry: Genesis, Composition, Reactions $2^{\text {nd }}$ Ed., John Wiley \& Sons, Inc., New York, NY.

Storer, D.A., 1984, “A Simple High Sample Volume Ashing Procedure for Determining of Soil Organic Matter," Communication Soil Science Plant Analysis, 15, pp. 759-772.

Swift, R.G., 1996, “Organic Matter Characterization,” Methods of Soil Analysis Part 3. Chemical Methods” Soil Science Society of America, pp. 1011-1069.

Tan, K.H., 2005, Soil Sampling, Preparation, and Analysis, Boca Raton, FL: Taylor \& Francis/CRC Press, 2005.

Taxonomy of Soils and Landscapes, Canadian System of Soil Classification, $3^{\text {rd }}$ Edition, Agriculture and Agri. Food Canada obtained from URL: http://sis.agr.gc.ca/cansis/taxa/cssc3/index.html

Terzaghi, K., R.B. Peck, and G. Meris, 1996, Soil Mechanics in Engineering Practice, $3^{\text {rd }}$ Edition, John Wiley \&Sons, Inc.

Velde, B., 1992, Introduction to Clay Minerals: Chemistry, Origins, Uses and Environmental Significance, Chapman \& Hill.

Walkley, A., 1947, “A Critical Examination of A Rapid Method for Determining Organic Carbon in Soils: Effect of Variations in Digestion Conditions and of Inorganic Soil Constituents," Soil Science, 63, pp 251-263.

Walkley, A., and Black, I.R., 1934, "An Examination of the Degtjareff Method for Determining Soil Organic Matter and A Proposed Modification of the Chromic Acid Titration Method," Soil Science, 37, pp 29-38.

Weber, W.J., 1972, Physic-Chemical Processes for Water Quality Control, WileyIntersciences, New York. 
Wolski, W. 1996, Embankments on organic soils. J. Hartlén and W. Wolski, Eds. Elsevier. Amsterdam-Lausanne-New York-Oxford- Shannon-Tokyo.

\section{Zhang, 2002, Personal Communication}

www.soilsworldwide.net/index.php/United_Kingdom_soil_classification_system Soil classification system of England and Wales. 


\section{APPENDIX A \\ Classification Examples}

\section{A.1 Introduction}

This appendix contains examples of the classification of soils containing organic matter based on the system and testing procedures proposed in Chapter 6.

As discussed in Chapter 6, the proposed classification relies on the following three properties: loss on ignition (LOI), response to colorimetric test, liquid limit ratio (where applicable) to classify into one of the following four groups:

- mineral soil,

- mineral soil with organic matter,

- organic soil,

- highly organic soil (peat).

Group symbols and group names are also proposed. If the soil is classified as a mineral soil, the symbol used to denote is the one corresponding to either the USCS or AASHTO classification (based on particle size and Atterberg limits). If the soil is classified as a mineral soil with organic matter or as an organic soil, the letter " $\mathrm{O}$ " is used as a modifier of either the USCS or AASHTO symbol, which would be otherwise used to denote the soil. In one case (mineral soil with organic matter) the "O” follows the USCS or AASHTO symbol (e.g. A-2-O or ML-O). In the other case (organic soil) the "O" precedes the USCS or AASHTO symbol (e.g. O-A-2 or O-ML), reflecting the fact that the organic matter starts to play a dominant role.

As discussed in Chapter 6, if the soil is classified as a highly organic soil there are a few different options for selecting the symbol and the name. 
In addition to using a symbol, a name can also be used to denote each soil as done in the USCS system. The criteria for assigning names to soils were discussed in Chapter 6.

In this appendix the classification is applied to 11 natural soils employed in the experimental program.

For ease of reference for each of these soils Table A-1 summarizes the following: liquid limit, plastic limit, plasticity index, loss on ignition, result of colorimetric test, true organic content (based on organic and inorganic carbon determination). This last parameter alone would allow classification of the soils in one of the four groups listed above. Given that in practice such a test would not be routinely conducted, the proposed classification methods do not rely on it. The data on true organic content data are, however, reported in Table A-1 as a means to verify the proposed method. 
TABLE A-1

\begin{tabular}{|c|c|c|c|c|c|c|c|c|}
\hline & Soil name & $\mathbf{L L}$ & PI & PI & LOI & $\begin{array}{c}\text { Liquid Limit } \\
\text { Ratio } \\
\end{array}$ & $\begin{array}{c}\text { Colorimetric } \\
\text { Test }\end{array}$ & $\begin{array}{c}\text { True } \\
\text { Organic } \\
\text { Content } \\
\end{array}$ \\
\hline & & $\%$ & $\%$ & $\%$ & $\%$ & - & Color No. & $\%$ \\
\hline \multirow{11}{*}{ 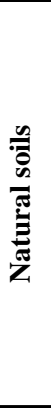 } & Soil 1 & 49.0 & 27.2 & 21.8 & 3.72 & 0.96 & 1 & 0.36 \\
\hline & Soil 2 & 36.9 & 28.0 & 8.9 & 4.50 & 0.94 & 3 & 1.71 \\
\hline & Soil 3 & 31.2 & 23.6 & 7.6 & 3.63 & 0.98 & 3 & 2.76 \\
\hline & Soil 4 & 46.7 & 35.0 & 11.7 & 5.13 & 0.88 & 3 & 2.45 \\
\hline & Soil 5 & 32.1 & 20.1 & 12.0 & 1.80 & 0.98 & $1+$ & 1.01 \\
\hline & Soil 6 & $\mathrm{n} / \mathrm{a}$ & $\mathrm{n} / \mathrm{a}$ & $\mathrm{n} / \mathrm{a}$ & 0.00 & $\mathrm{n} / \mathrm{a}$ & $<1$ & 0.00 \\
\hline & Soil 7 & 47.7 & 38.6 & 9.1 & 9.72 & 0.68 & 5 & 12.45 \\
\hline & Soil 8 & 41.7 & 33.8 & 7.9 & 4.40 & 0.85 & 4 & 4.76 \\
\hline & Soil $9^{(1)}$ & 34.0 & 25.3 & 8.7 & 4.30 & 1.00 & 4 & 1.73 \\
\hline & Soil 10 & 55.8 & 26.7 & 29.1 & 2.85 & 0.99 & $1+$ & 1.01 \\
\hline & Soil 11 & 151.1 & 123.0 & 28.1 & 43.98 & 0.58 & $\mathrm{n} / \mathrm{a}$ & 40.34 \\
\hline
\end{tabular}

(1) while this ASTM clay is commericlaized as a CL, the limites performed lead to classify it as a ML 


\section{SOIL 1}

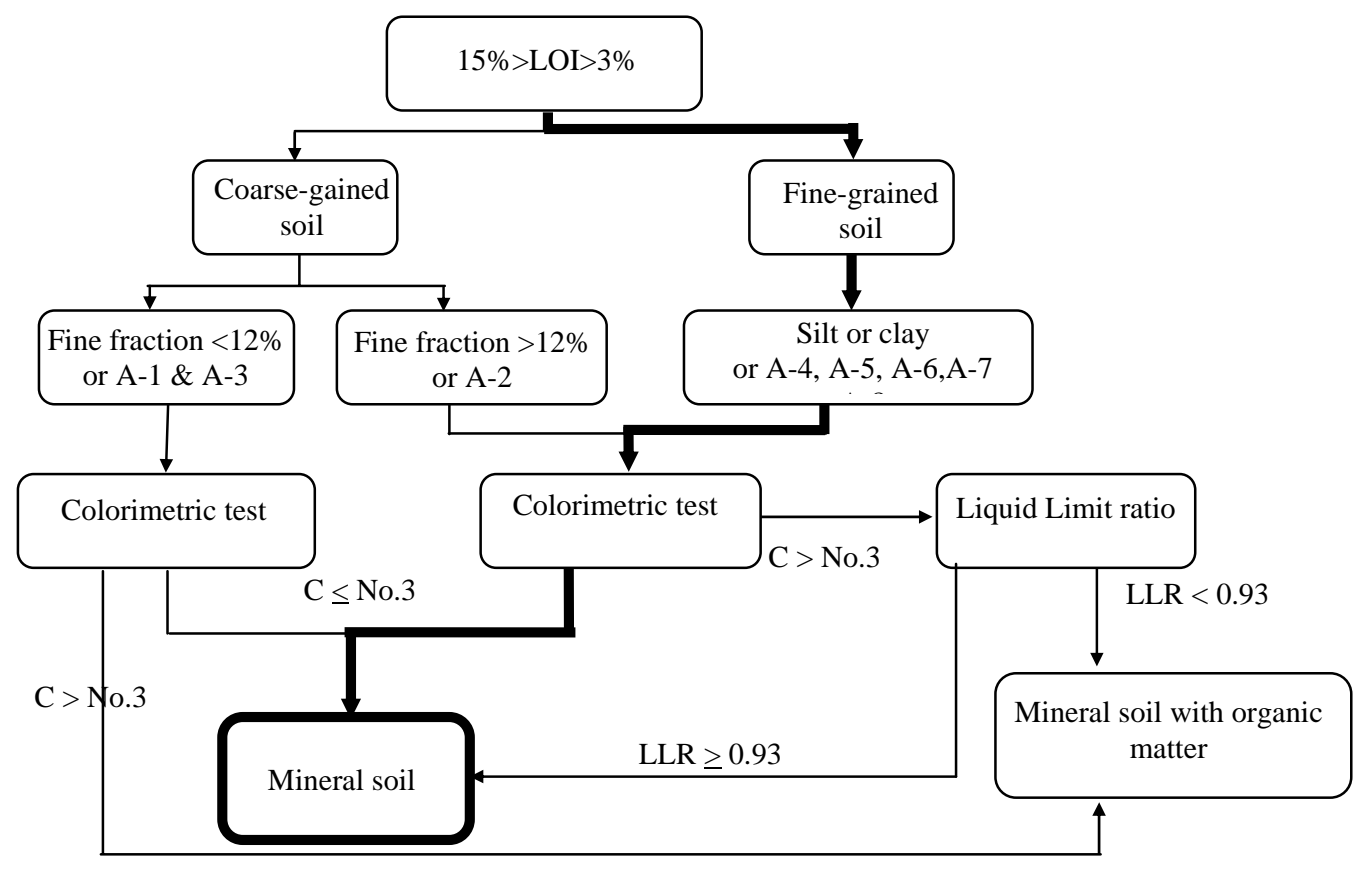

Classification: Mineral soil (consistent with true organic content $<3 \%$ )

Symbol (in accordance with AASHTO): $\underline{\text { A-7-6 }}$

Symbol (in accordance with USCS): $\underline{\mathrm{CL}}$

Name (in accordance with USCS): Lean clay 


\section{SOIL 2}

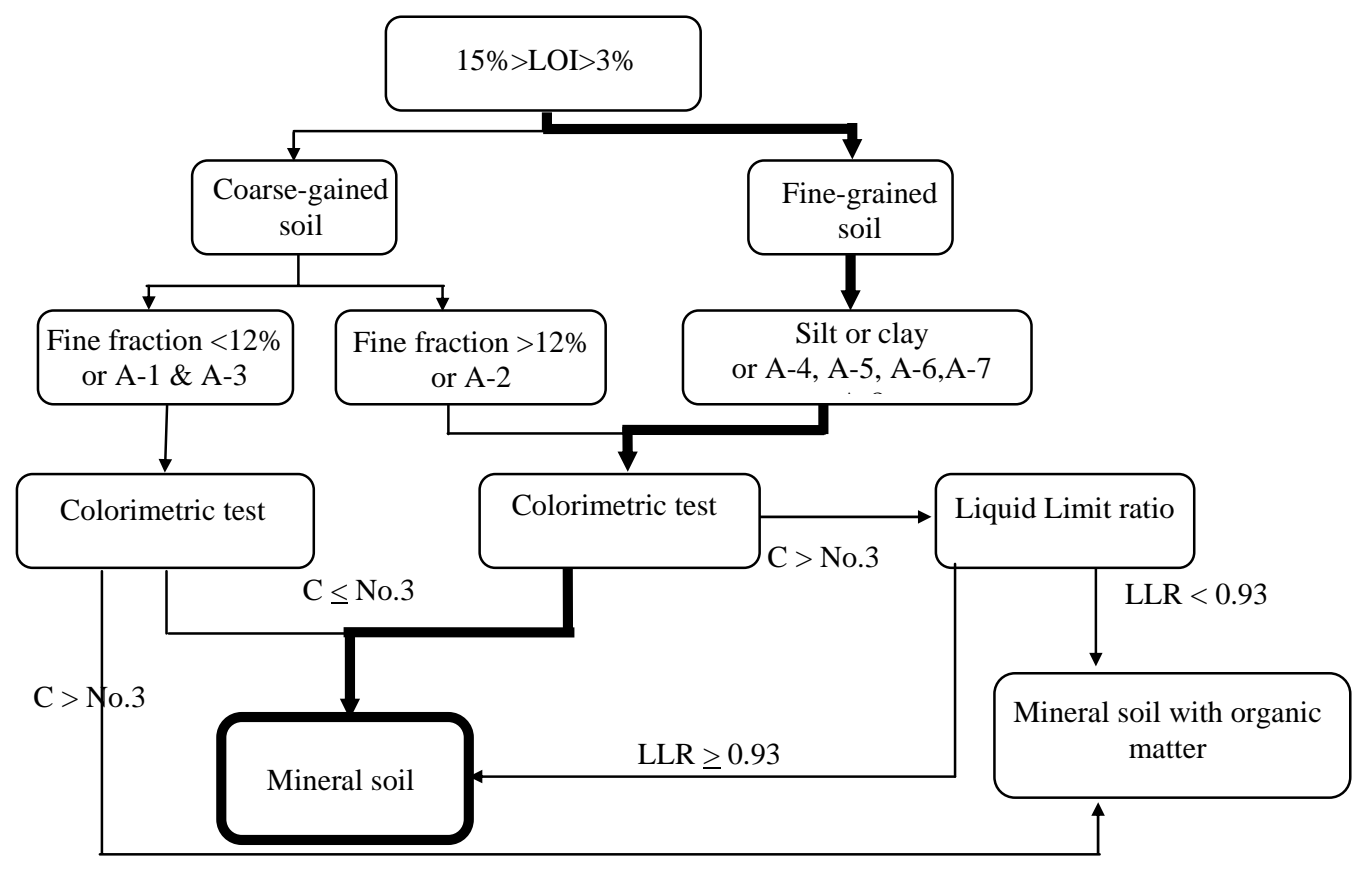

Classification: Mineral soil (consistent with true organic content $<3 \%$ )

Symbol (in accordance with AASHTO): $\underline{\mathrm{A}-4}$

Symbol (in accordance with USCS): $\underline{\mathrm{ML}}$

Name (in accordance with USCS): $\underline{\text { Silt }}$ 


\section{SOIL 3}

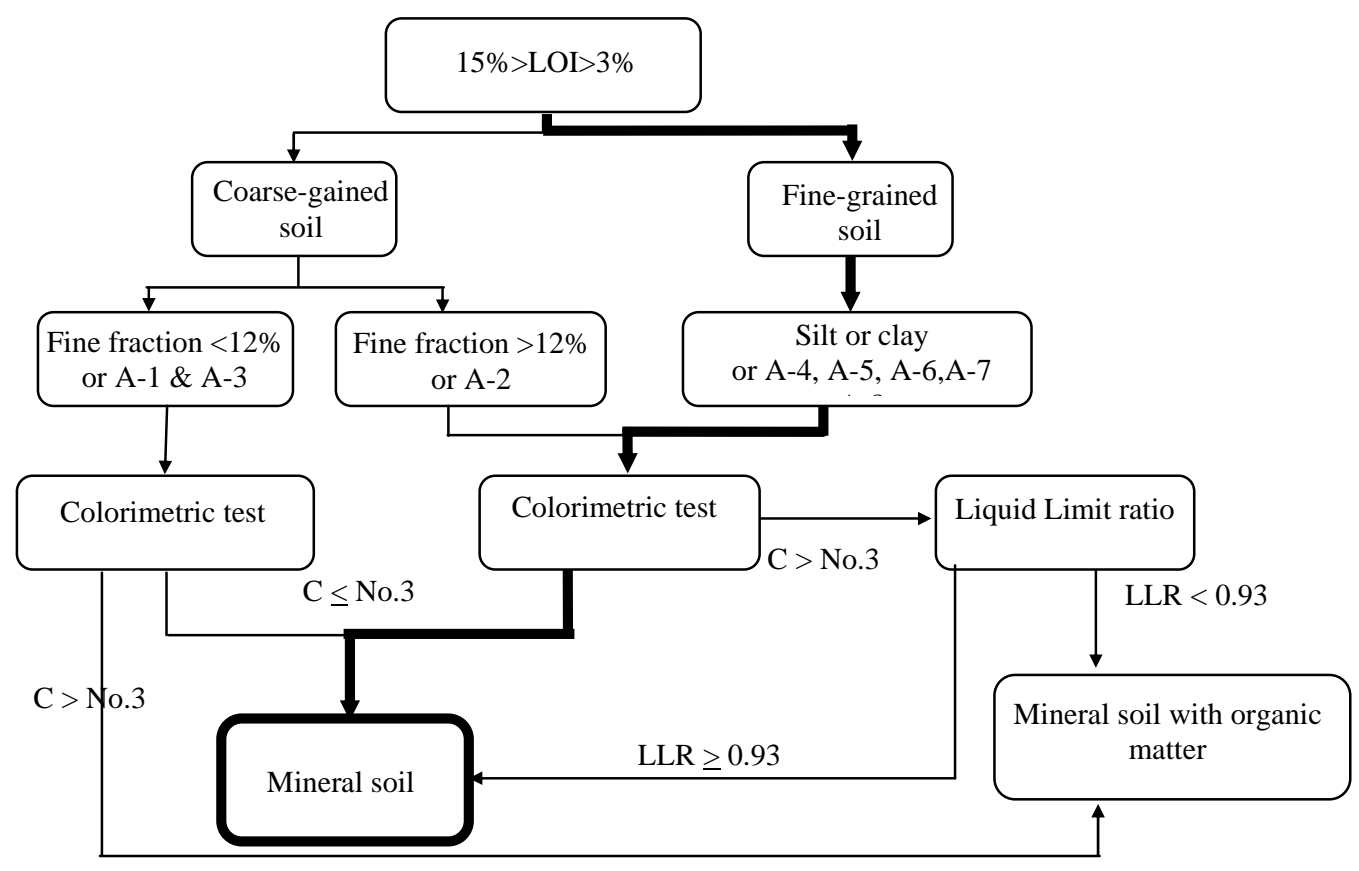

Classification: Mineral soil (consistent with true organic content $<3 \%$ )

Symbol (in accordance with AASHTO): $\underline{\mathrm{A}-4}$

Symbol (in accordance with USCS): $\underline{\mathrm{ML}}$

Name (in accordance with USCS): $\underline{\text { Silt }}$ 


\section{SOIL 4}

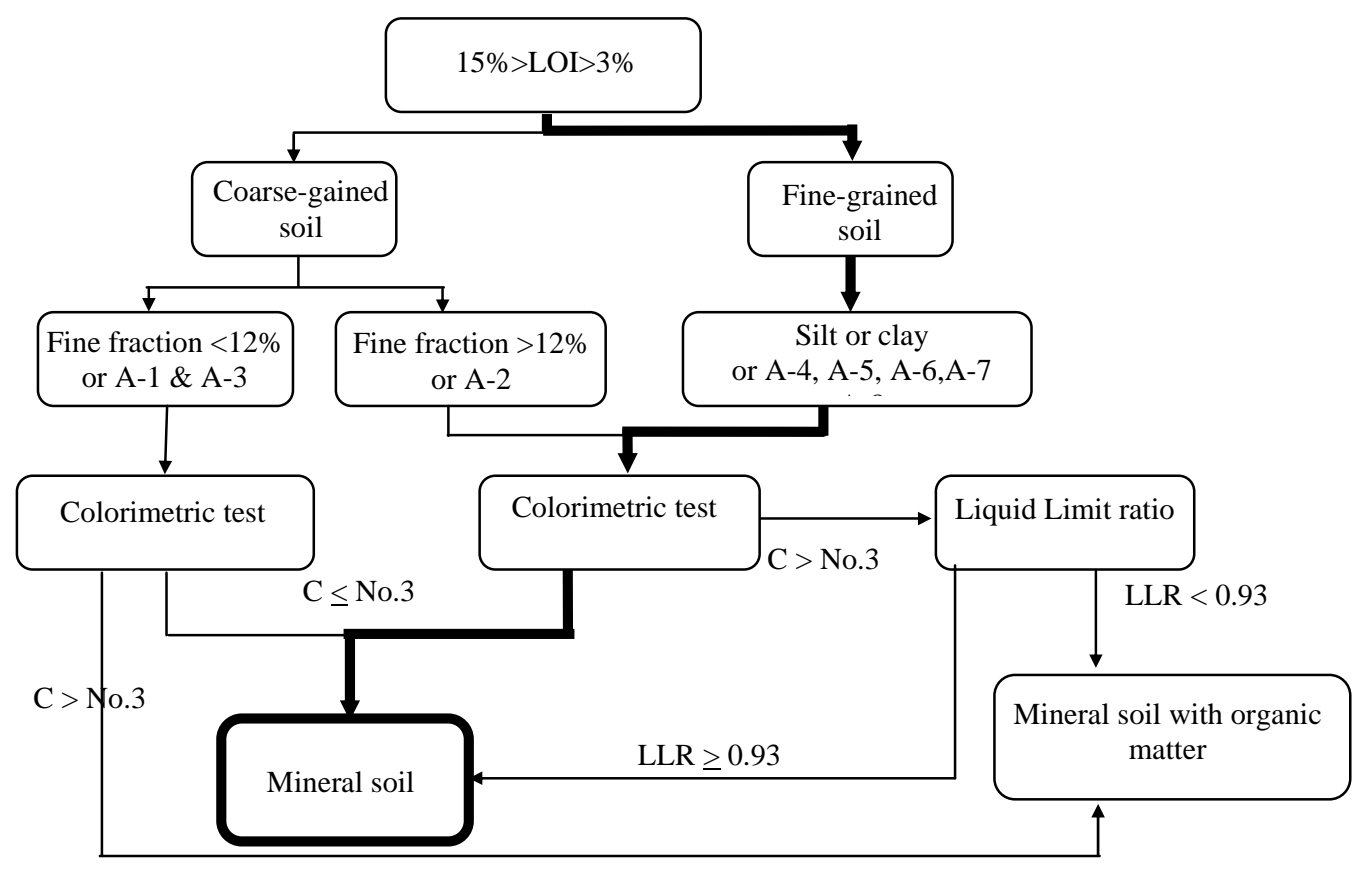

Classification: Mineral soil (consistent with true organic content $<3 \%$ )

Symbol (in accordance with AASHTO): $\underline{\text { A-7-5 }}$

Symbol (in accordance with USCS): $\underline{\mathrm{ML}}$

Name (in accordance with USCS): $\underline{\text { Silt }}$ 


\section{SOIL 5}

$\mathrm{LOI}<3 \%$

Classification: Mineral soil

Symbol (in accordance with AASHTO): $\underline{\text { A-6 }}$

Symbol (in accordance with USCS): $\underline{\mathrm{CL}}$

Name (in accordance with USCS): Lean clay

\section{SOIL 6}

$\mathrm{LOI}<3 \%$ (This soil is Ottawa sand in silt size)

Classification: Mineral soil

Symbol (in accordance with AASHTO): $\underline{\mathrm{n} / \mathrm{a}}$

Symbol (in accordance with USCS): $\underline{\mathrm{n} / \mathrm{a}}$

Name (in accordance with USCS): $\underline{\mathrm{n} / \mathrm{a}}$ 


\section{SOIL 7}

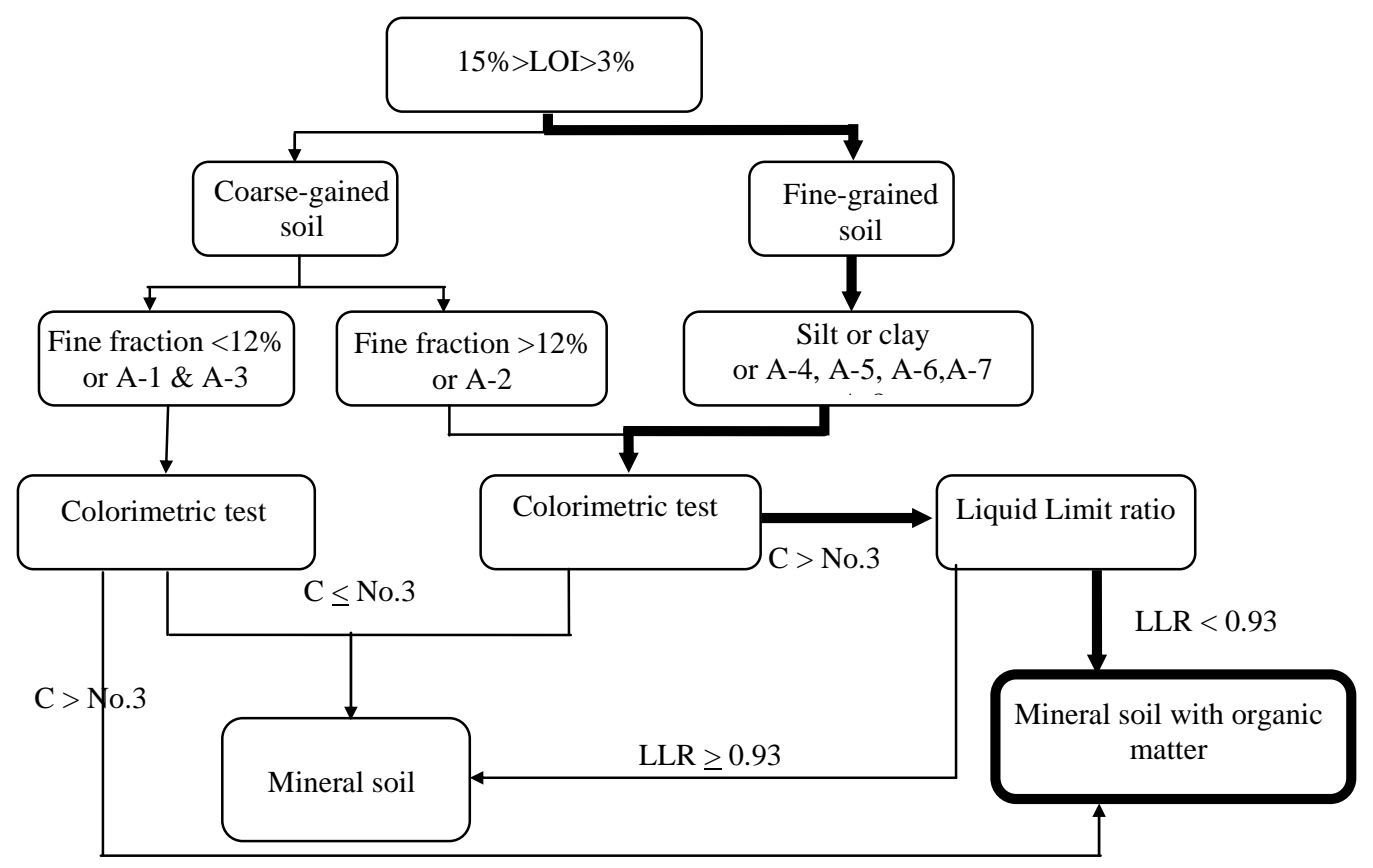

Classification: Mineral soil with organic matter (consistent with true organic content $>3 \%$ and $<15 \%$ )

Symbol (in accordance with AASHTO): $\underline{\text { A-5-O }}$

Symbol (in accordance with USCS): $\underline{\text { ML-O }}$

Name (in accordance with USCS): Silt with organic matter 


\section{SOIL 8}

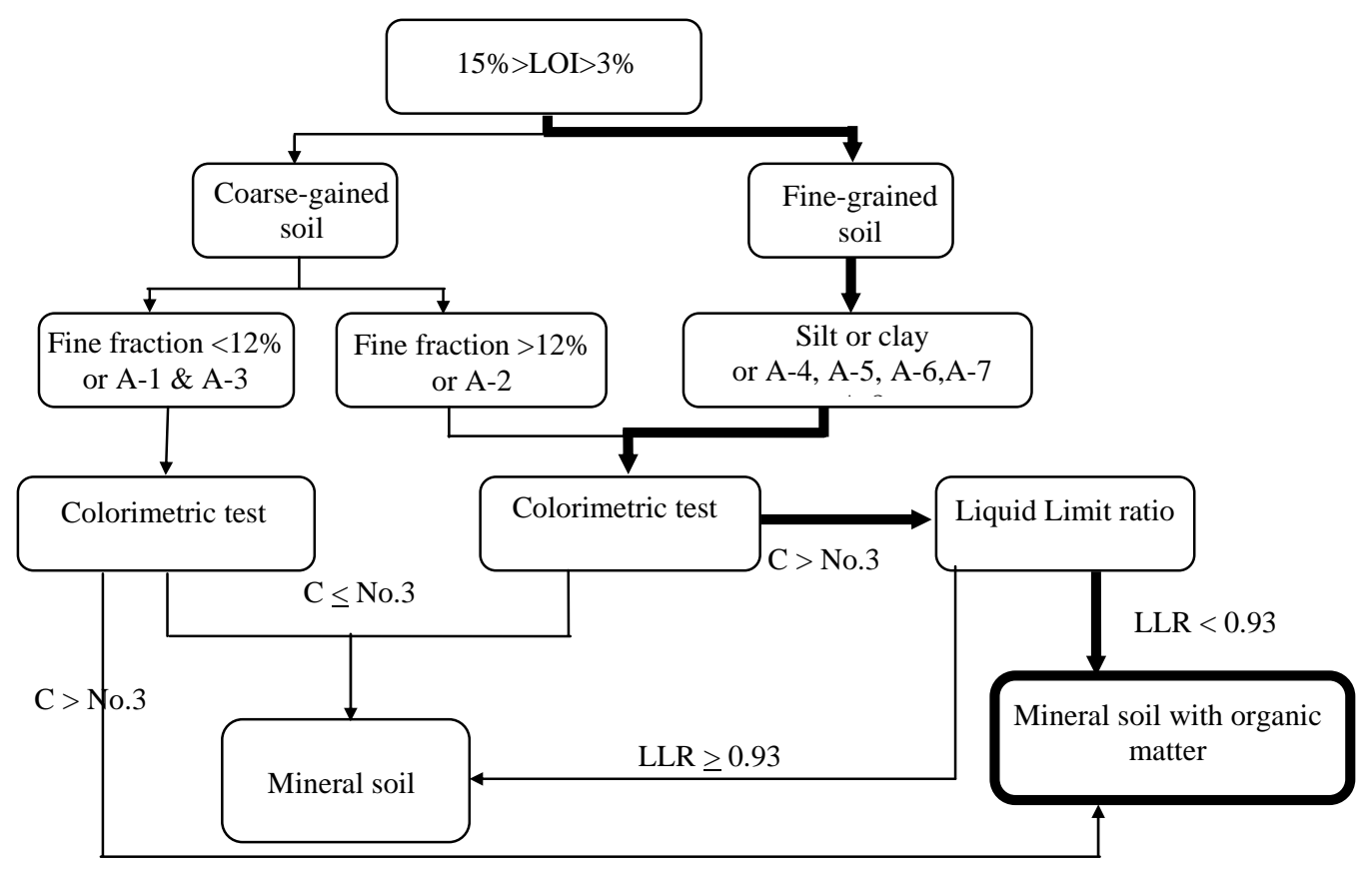

Classification: Mineral soil with organic matter (consistent with true organic content $>3 \%$ and $<15 \%$ )

Symbol (in accordance with AASHTO): $\underline{\text { A-5-O }}$

Symbol (in accordance with USCS): $\underline{\text { ML-O }}$

Name (in accordance with USCS): Silt with organic matter 


\section{SOIL 9}

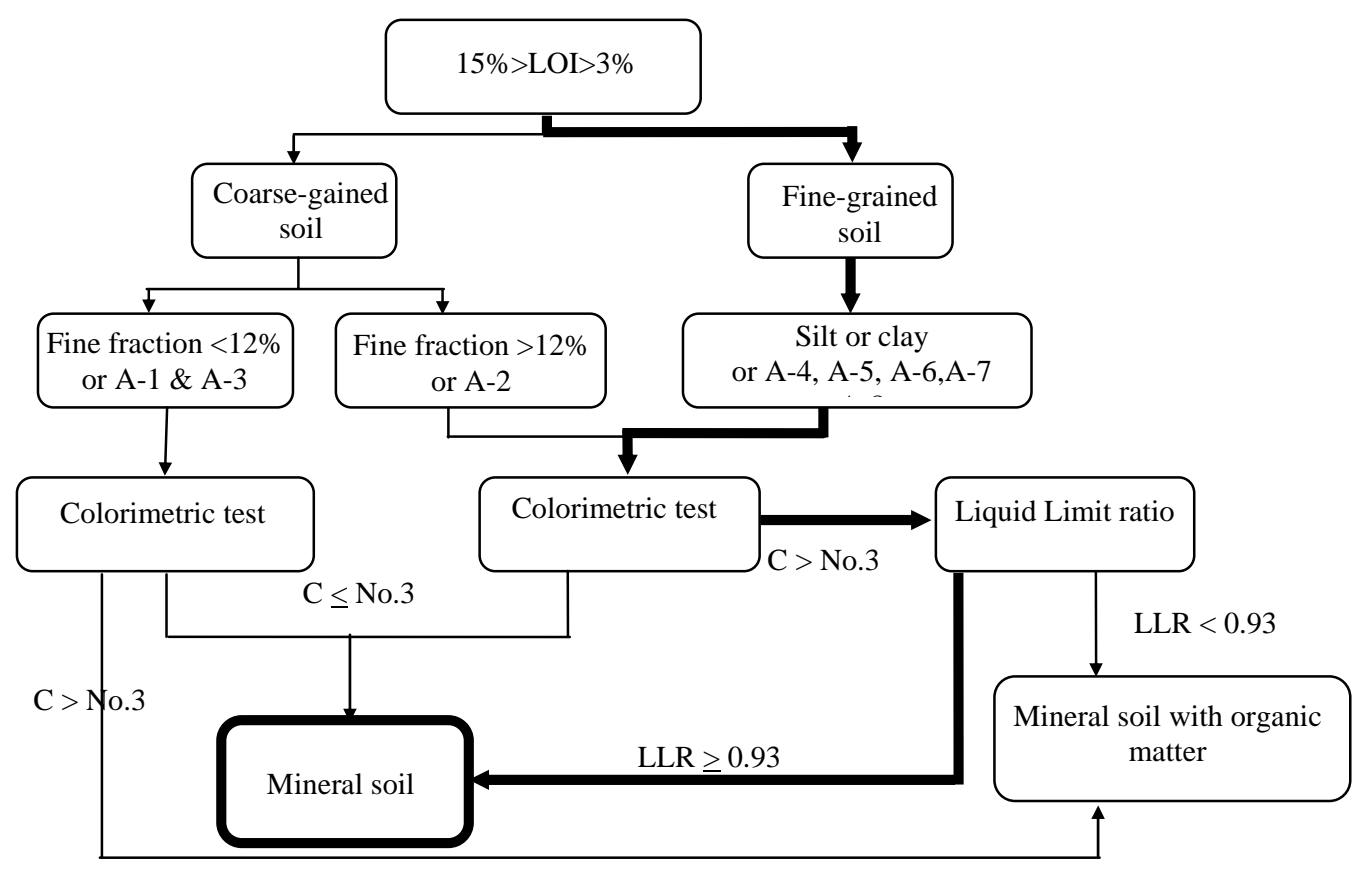

Classification: Mineral soil x

Symbol (in accordance with AASHTO): $\underline{\mathrm{A}-4}$

Symbol (in accordance with USCS): $\underline{\text { ML }}$

Name (in accordance with USCS): $\underline{\text { Silt }}$ 


\section{$\underline{\text { SOIL } 10}$}

Classification: Mineral soil (consistent with true organic content $<3 \%$ )

Symbol (in accordance with AASHTO): $\underline{\text { A-7-6 }}$

Symbol (in accordance with USCS): $\underline{\mathrm{CH}}$

Name (in accordance with USCS): Fat clay 


\section{SOIL 11}

LOI $>30 \%$

Classification: Highly organic soil

Symbol (in accordance with AASHTO): $\underline{\mathrm{A}-8}$

Symbol (in accordance with USCS): $\underline{\text { Peat }}$

Name (in accordance with USCS): $\underline{\text { Peat }}$ 